AUSTRALIAN INSTITUTE OF MARINE SCIENCE MONOGRAPH SERIES

Volume 2

\title{
A REVIEW OF \\ THE PHYSICAL OCEANOGRAPHY \\ OF THE \\ GREAT BARRIER REEF \\ AND \\ WESTERN CORAL SEA
}

by

G. L. Pickard

with

J. R. Donguy

C. Henin

F. Rougerie 



\title{
A REVIEW OF THE PHYSICAL OCEANOGRAPHY OF THE GREAT BARRIER REEF AND WESTERN CORAL SEA
}

\author{
G. L. Pickard \\ Instutute of Oceanograply: \\ Lniversity of l3ritish Columbia \\ Vancouter, Cinnada \\ with \\ J. R. Donguy \\ C. Henin \\ F. Rougeric \\ Section deccanographic \\ O.R.S.T.O.M., Centre de Noumea \\ New Caledonia
}


Australian Instifue of Marme Seience

Promate Matil liag No. 3. M.S.().

Jomnstle, (0)d tro

\section{ISBN 0612026351}

Commonwealth of Austratia 1977

Printed by The Dominion Press, Joseph Strect, Nth. Blackburn, Victoria. 


\section{Contents}

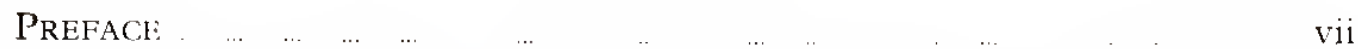

ACKNOWLEDGMHNTS

PART 1-THE GREAT 13ARRIER REEF

G. L. Pickard

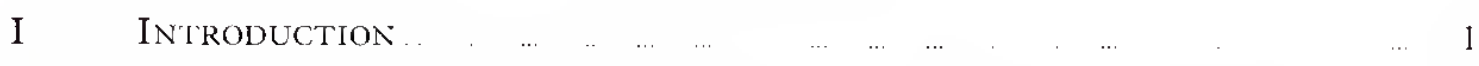

II TOPOGRAPHY

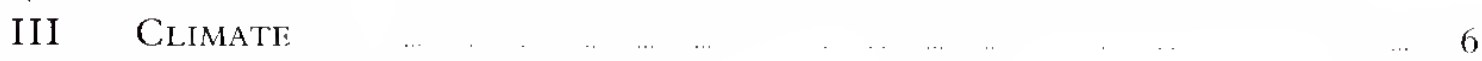

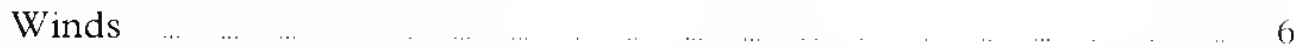

$\begin{array}{lllllllllllllllllllllll}\text { Cyclones } & \ldots & \ldots & \ldots & \ldots & \ldots & \ldots & \ldots & \ldots & \ldots & \ldots & \ldots & \ldots & & \ldots & \ldots & \ldots & \ldots & & 6\end{array}$

$\begin{array}{llllllllllllllllll}\text { Air temperature } & \ldots & \ldots & \ldots & \ldots & \ldots & \ldots & \ldots & \ldots & \ldots & \ldots & \ldots & \ldots & \ldots & \ldots & \ldots & & 8\end{array}$

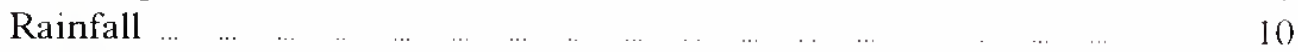

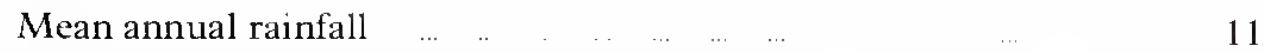

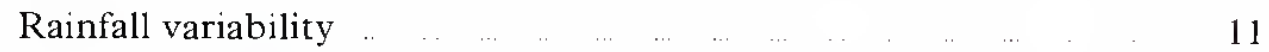

$\begin{array}{llllllll}\text { Comparison of rainfall on land and on islands } & \ldots & \ldots & \ldots & \ldots & \ldots & 12\end{array}$

River runoff $\begin{array}{lllllllllllllllllllll} & \ldots & \ldots & \ldots & \ldots & \ldots & \ldots & \ldots & \ldots & \ldots & \ldots & \ldots & \ldots & \ldots & \ldots & \ldots & \ldots & \ldots & 13\end{array}$

\begin{tabular}{llllllllllllllll} 
Cloud and humidity & $\ldots$ & $\ldots$ & $\ldots$ & $\ldots$ & $\ldots$ & $\ldots$ & $\ldots$ & $\ldots$ & $\ldots$ & $\ldots$ & $\ldots$ & $\ldots$ & $\ldots$ & $\ldots$ & \\
\hline
\end{tabular}

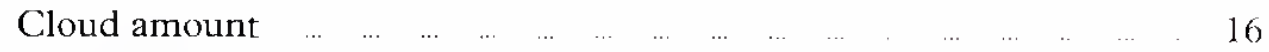

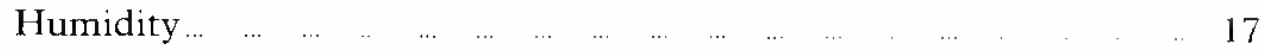

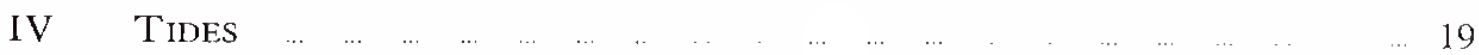

$\begin{array}{lllllllllllllllllllll}\text { Tide levels } & \ldots & \ldots & \ldots & \ldots & \ldots & \ldots & \ldots & \ldots & \ldots & \ldots & \ldots & \ldots & \ldots & \ldots & \ldots & \ldots & \ldots & \ldots & 19\end{array}$

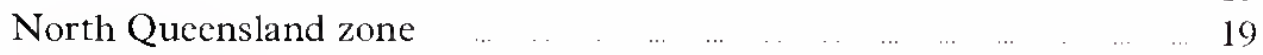

$\begin{array}{lllllllllllllllllll}\text { Mackay zone ... } & \ldots & \ldots & \ldots & \ldots & \ldots & \ldots & \ldots & \ldots & \ldots & \ldots & \ldots & \ldots & \ldots & \ldots & \ldots & & & 21\end{array}$

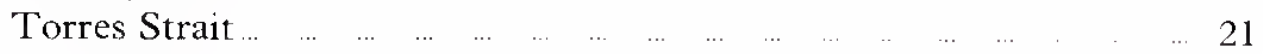

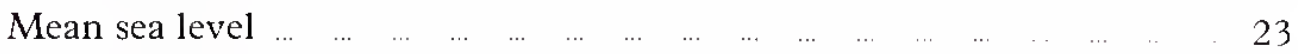

$\begin{array}{lllllllllllllllllll}\text { Annual cycle } \ldots & \ldots & \ldots & \ldots & \ldots & \ldots & \ldots & \ldots & \ldots & \ldots & \ldots & \ldots & \ldots & \ldots & \ldots & \ldots & \ldots & 23\end{array}$

Mean sea level and latitude $\quad \begin{array}{llllllllllllll} & \ldots & \ldots & \ldots & \ldots & \ldots & \ldots & \ldots & \ldots & \ldots & \ldots & \ldots & \ldots & 23\end{array}$

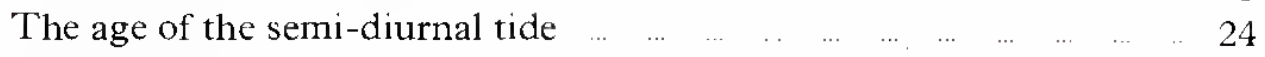

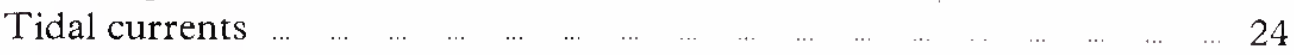

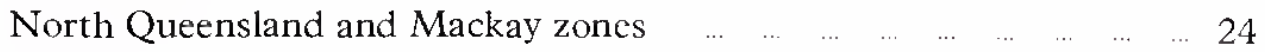

$\begin{array}{llllllllllllllllllll}\text { Torres Strait } & \ldots & \ldots . & \ldots & \ldots & \ldots & \ldots & \ldots & \ldots & \ldots & \ldots & \ldots & \ldots & \ldots & \ldots & \ldots & \ldots & 24\end{array}$

$\begin{array}{lllllllllllllll}\text { V Water Properties in the Lagoon } & \ldots & \ldots & \ldots & \ldots & \ldots & \ldots & \ldots & \ldots & \ldots & \ldots & \ldots & \ldots & 25\end{array}$

$\begin{array}{llllllllllllllllllll}\text { Temperature } & \ldots & \ldots & \ldots & \ldots & \ldots & \ldots & \ldots & \ldots & \ldots & \ldots & \ldots & \ldots & \ldots & \ldots & \ldots & \ldots & \ldots & \ldots & 25\end{array}$

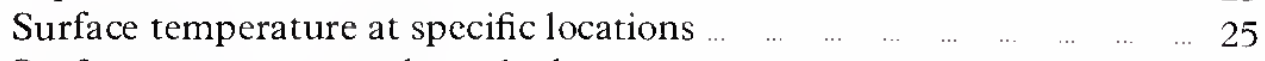

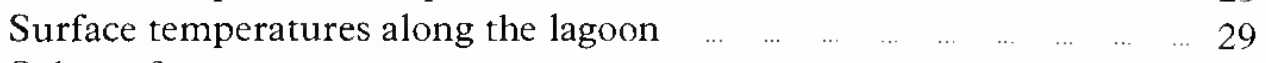

$\begin{array}{lllllllllllllllll}\text { Sub-surface temperatures } & \ldots & \ldots & \ldots & \ldots & \ldots & \ldots & \ldots & \ldots & \ldots & \ldots & \ldots & \ldots & \ldots & 31\end{array}$ 
Salinity

Surface salinity at a specific location ... $\quad \ldots \quad 32$

Surface salinity along the lagoon $\ldots 33$

Surface salinity gradients across the lagoon $\quad \ldots \quad 34$

Sub-surface salinities $\ldots \ldots \ldots . . .35$

Dissolved oxygen . . . . . . . . . . . 36

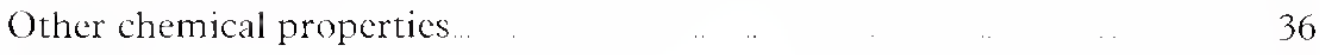

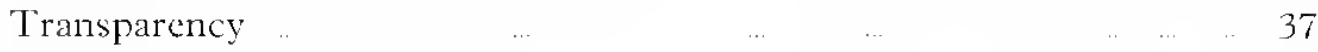

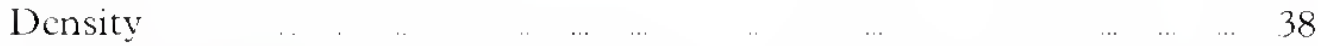

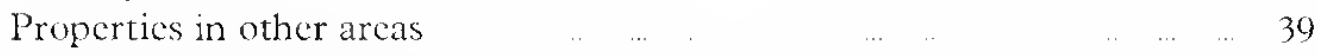

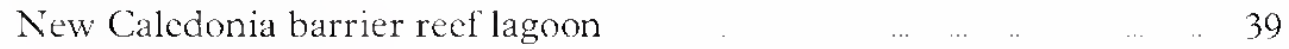

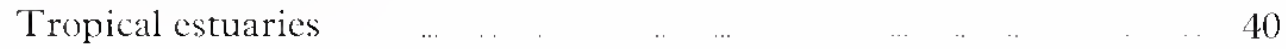

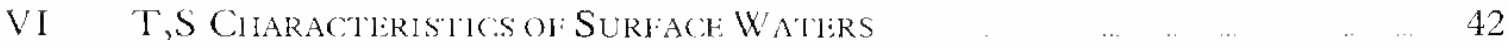

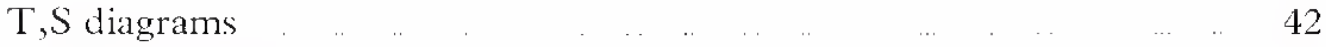

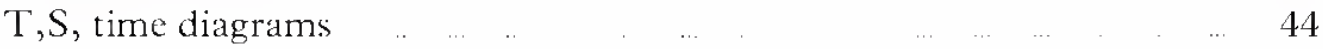

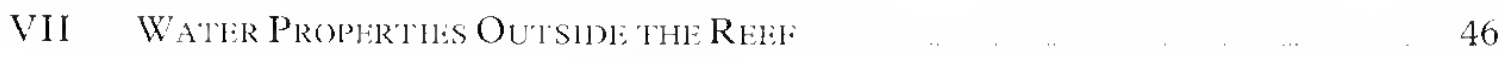

Individual properties outside the Reef _..... . . . 46

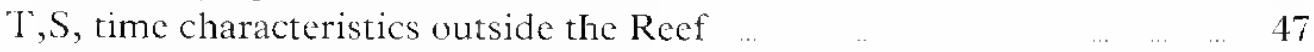

Temperature and salinity variations across the lagoon--
Further remarks

VIII CURRENTS

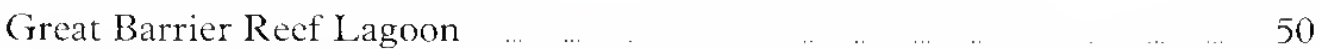

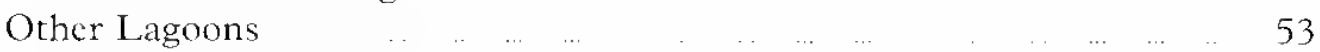

Bikini and Rongelap Atolls (Marshall Is., approx. $11.5 \mathrm{~N}$,

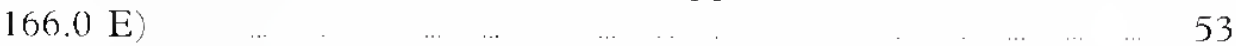

Ouotoa Atoll (Gilbert Is., 1.8 S, 175.5 E) _. _ _ _ . . . . . . . . . 56

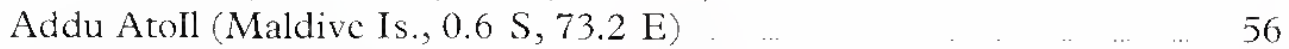

Rangiroa Atoll (Tuamotu Is., $15.0 \mathrm{~S}, 147.5 \mathrm{~W}$ ) . _ . . . ...... $\quad 56$

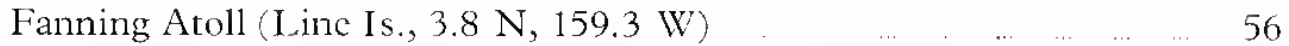

The barrier reef lagoon off Nouméa (New Caledonia, 22.3 S,

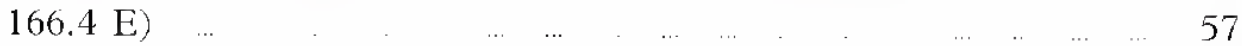

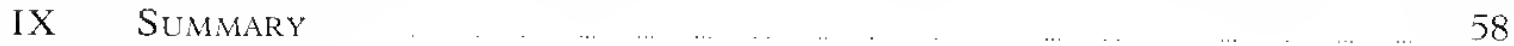


PART 2-THE WESTERN CORAL SEA

\author{
G. L. Pickard \\ with \\ F. R. Donguy, C. Henin E F. Rougerie
}

II TOPOGRAPHY

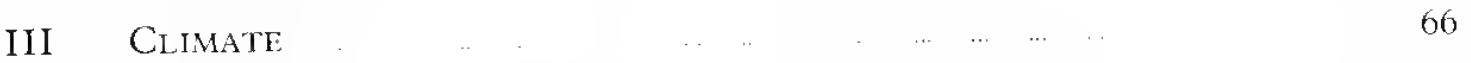

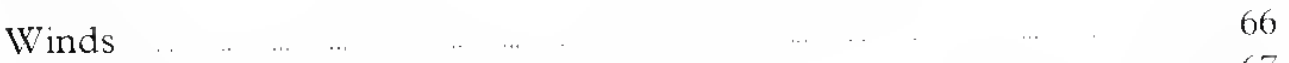

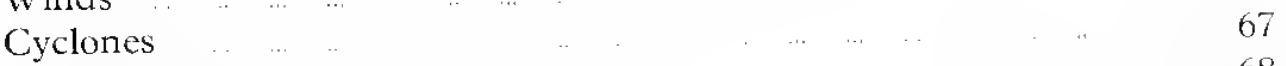

Air temperature $\quad \begin{array}{lllllllllllll} & \ldots & \ldots & \ldots & & \ldots & \ldots & & \ldots & \ldots & 68\end{array}$

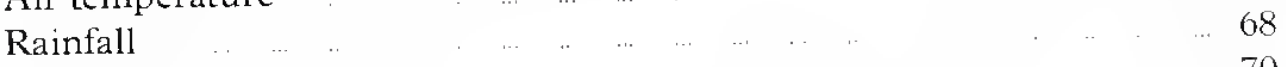

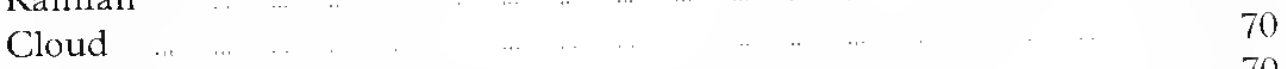

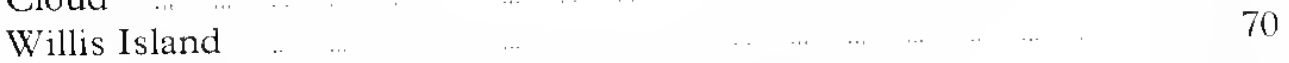

IV Water Masses, Propertils and Dledced Flow Paths _....

Introduction-salient characteristics $\quad 72$

Surface water characteristics $\quad 75$

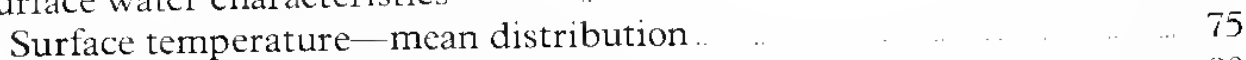

Surface salinity - mean distribution

Mean seasonal variations of surface temperature and salinity by areas 83

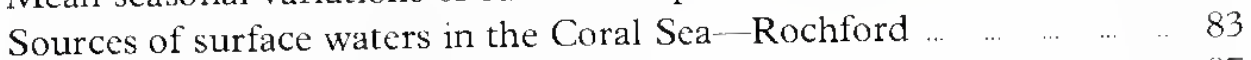

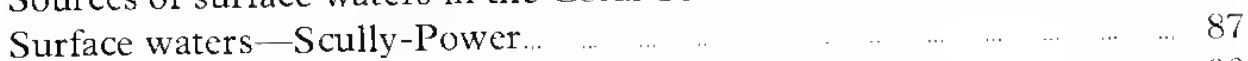

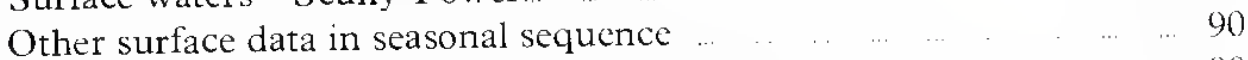

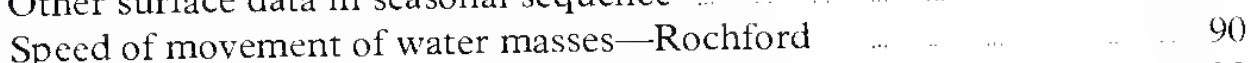

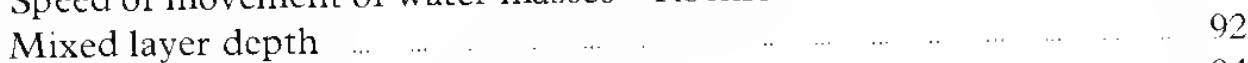

Subsurface water masses and flow patterns $\quad \begin{array}{lllllllll} & \ldots & \ldots & \ldots & \ldots & \ldots & \ldots & \ldots & 94\end{array}$

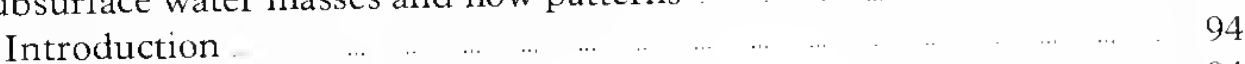

Isentropic analysis-Rochford ..

\begin{tabular}{lllllllllllll} 
The $27.2 \sigma_{\mathrm{t}}$ surface & $\ldots$ & $\ldots$ & $\ldots$ & $\ldots$ & $\ldots$ & $\ldots$ & $\ldots$ & $\ldots$ & $\ldots$ & & $\ldots$ & 94 \\
\hline
\end{tabular}

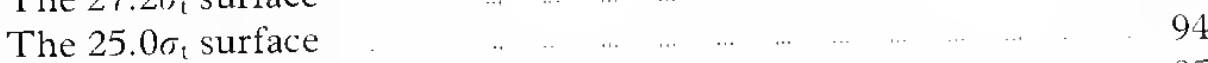

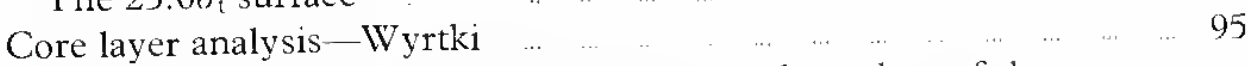

Continuity of water masses along the western boundary of the
Tasman and Coral Seas-Rochford
Tas

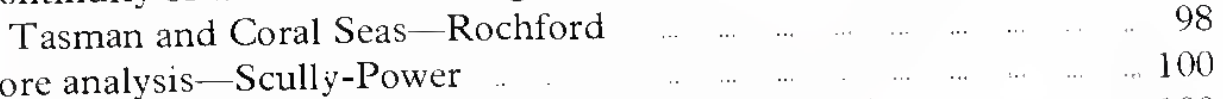

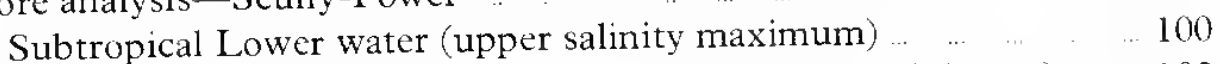

Antarctic Intermediate water (intermediate salinity minimum) . . 103

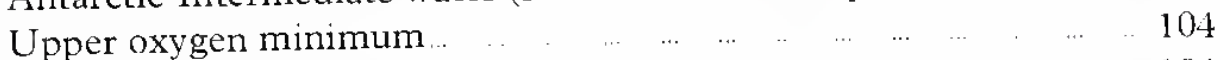

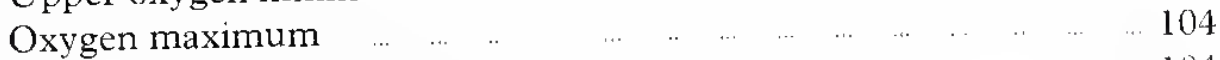

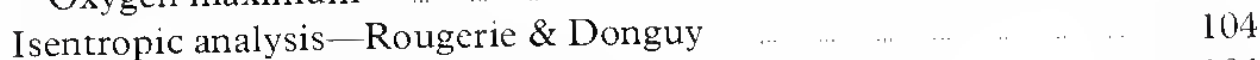

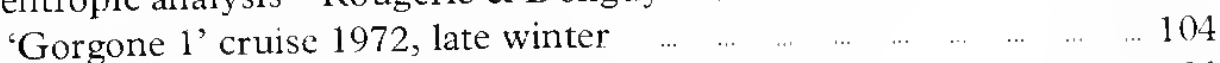

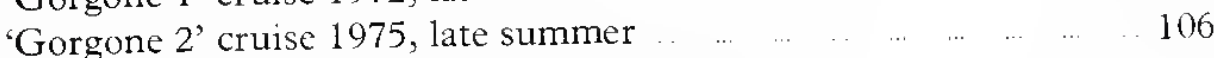

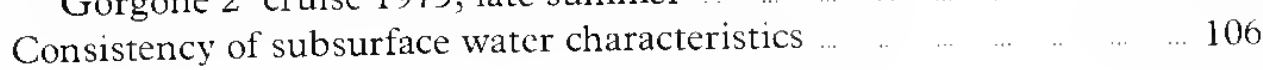


Introduction 109

Surface circulation $\quad 109$

Wyrtki, 1960, 1962b-Current atlas and geostrophic circulation $\quad 109$

Rotschi, 1958-61--Earlier O.R.S.T.O.M. cruises $\quad 112$

Takahashi, 1959, 1960-Eddy in Coral Sea _ ... .. ... . 112

Donguy, Oudot \& Rougerie, 1970-Review of 1956-68 northern Coral Sea data

Rougeric \& Donguy, 1975-'Gorgone 1' 1972 cruise, northern Coral Sea

Donguy \& Henin, 1975b-Review of flow at 158 and $163 \mathrm{E} \ldots \ldots \quad . \quad 114$

Scully-Power et al., 1969, 1973a, b-Western Coral Sea _.. ... 114

Subsurface circulation.. ... ...

Hamon, 1958-Inflow to the northern Coral Sea from the east $\quad 116$

Wyrtki, 1962b-Geostrophic circulation in the Coral Sea

Rotschi, 1958-61-O.R.S.T.O.M. earlicr cruises, volume transports

1)onguy, Oudot \& Rougerie, 1970-Review of 1956-68 northern Coral Sea data

Rougerie \& Donguy, 1975-'Gorgone 1' 1972, late winter.

Rougcrie \& Donguy (unpubl.) - 'Gorgone 2' 1975, late summer

Scully-Power ot al., 1969, 1973a, b, c-Geostrophic circulation

May-July 1968 and volume transport budgets, Western Coral Sea 119

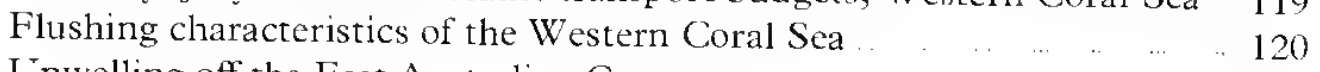

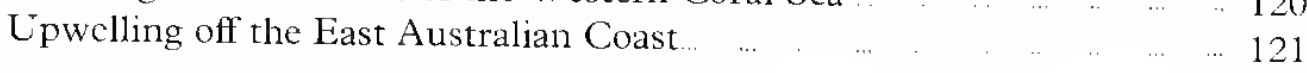

V1 SUMMARY

Water masses

Introduction

Surface waters

$\begin{array}{lllllllllllllll}\text { Characteristic diagrams } & \ldots & \ldots & \ldots & \ldots & \ldots & \ldots & \ldots & \ldots & \ldots & \ldots & \ldots & \ldots & \ldots & \ldots \\ \end{array}$

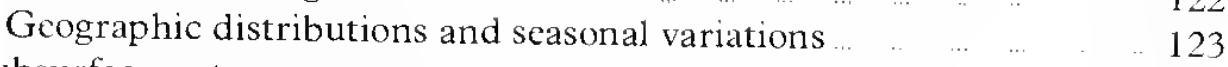

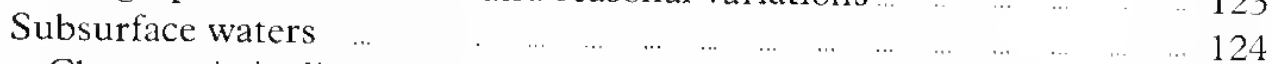

\begin{tabular}{lllllllllllllll} 
Characteristic diagrams & $\ldots$ & $\ldots$ & $\ldots$ & $\ldots$ & $\ldots$ & $\ldots$ & $\ldots$ & $\ldots$ & $\ldots$ & $\ldots$ & $\ldots$ & $\ldots$ & $\ldots$ & $\ldots$ \\
\hline
\end{tabular}

$\begin{array}{lllllllllllll}\text { Geographic distribution } \ldots \ldots & \ldots & \ldots & \ldots & \ldots & \ldots & \ldots & \ldots & \ldots & \ldots & \ldots & \ldots & 126\end{array}$

$\begin{array}{lllllllllllllllllll}\text { 'Coral Sea water' } & \ldots & \ldots & \ldots & \ldots & \ldots & \ldots & \ldots & \ldots & \ldots & \ldots & \ldots & \ldots & \ldots & \ldots & \ldots & 126\end{array}$

\begin{tabular}{lllllllllllllllllllll} 
Circulation & $\ldots$ & $\ldots$ & $\ldots$ & $\ldots$ & $\ldots$ & $\ldots$ & $\ldots$ & $\ldots$ & $\ldots$ & $\ldots$ & $\ldots$ & $\ldots$ & $\ldots$ & $\ldots$ & $\ldots$ & $\ldots$ & $\ldots$ & $\ldots$ & 126 \\
& & & & & & & & & & & & & & & & & & & & \\
\hline
\end{tabular}

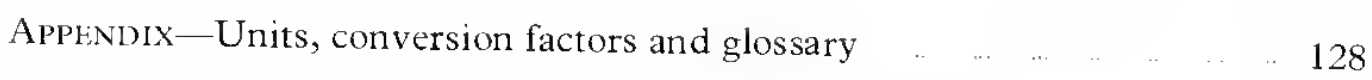

$\begin{array}{lllllllllllllllllllll}\text { REFERENCES } & \ldots & \ldots & \ldots & \ldots & \ldots & \ldots & \ldots & \ldots & \ldots & \ldots & \ldots & \ldots & \ldots & \ldots & \ldots & \ldots & \ldots & \ldots & 130\end{array}$ 


\section{Preface}

The object of this study is to review what is known of the physical oceanography of the waters of the Great Barrier Reef and Western Coral Sca. Because the two regions are sharply different topographically (the first being a reef-studded strip of shallow coastal water, generally well mixed vertically, while the second is chiefly 1000 to $5000 \mathrm{~m}$ deep with marked water structure in the vertical), they can best be treated separately with references to their interactions where appropriate (or, more exactly, where known). In neither case is the available information sufficient for a full description.

In the presentations for both areas, the topography is described briefly and available climatic information is summarised as background. Then descriptions are given in turn of the surface distributions of water properties, the subsurface characteristics and their distributions, and the circulation, referring to the sources of information in each case. Finally, a short summary is presented.

For Part 1 on the Great Barrier Reef lagoon, information is limited, and some suggestions are offered for possible future investigations of the physical oceanography of this region. In this connection, it should be noted that there are very few data on the physical oceanography of any barrier reef lagoons to which one can refer for guidance. An opportunity is available here for pioneering work. (A project for the study of the New Caledonia barrier reef lagoon is already under way.)

For Part 2 on the Western Coral Sea, there is more information; here the salient papers are reviewed specifically, and then an attempt is made to summarise the present state of knowledge of the region. For some readers, the summary may be sufficient for their needs, while it is hoped that the revicw as a whole will form a useful introduction to this region for physical oceanographers prior to study of the original papers for a fuller understanding of the development of the knowledge and of the limited extent of the data available at present,

Much of the review is a presentation of the analyses of previous workers, although the mode of presentation of results is sometimes different from theirs. However, some of the material in this review is derived from new analyses of existing data. If the original author is not quoted it may be assumed that the results presented are novel in this review.

A common bibliography is attached. Most of the items are referred to in the text but some, such as data records used by some of the authors, have been included for completeness though not specifically quoted in this text.

G. L. Pickard

June 1976 


\section{Acknowledgments}

Having acquired an interest in the water circulation patterns in recf and lagoon areas during many visits to Pacific islands, the senior author was pleased to accept Dr M. Gilmartin's suggestion that he review existing knowledge of the physical oceanography of the Great Barrier Reef and adjacent Coral Sea as background for further studies of this arca. He is grateful to Dr Gilmartin, as Dircctor, for making available to him facilities to work at the Australian Institute of Marine Science; to Dr K. R. Allen and Messrs B. V. Hamon, D. J. Rochford, and R. J. Edwards of the CSIRO Division of Fisheries and Occanography, Cronulla, and to P. D. Scully-Power of the Royal Australian Naval Research Laboratory, Sydney, for assistance in locating and evaluating information; to many members of the Section d'Océanographic, O.R.S.T'O.M. Centre de Nouméa, for suggestions and assistance related to both parts of this review; to Mr J. Ngai for his cxccllent drafting of the figures; and to his collaborators in Part 2.

He wishes to thank the Director-General of O.R.S.T.O.M. and M. Lcgand, Director of the Centre de Nouméa, for permission to use the facilities of the centre at Nouméa and for other courtesies during his stay. He is particularly grateful to M. Henri Rotschi, until recently head of the Section d'Océanographie, who first roused his interest in the southwest Pacific and fostered it during two previous visits to Noumca including participation in two major cruises in the western equatorial Pacific in N.O. Coriolis.

Permission to reproduce figures as indicated in the legends is gratefully acknowledged. 


\section{PART 1}

The Great Barrier Reef

by

G. L. Pickard 


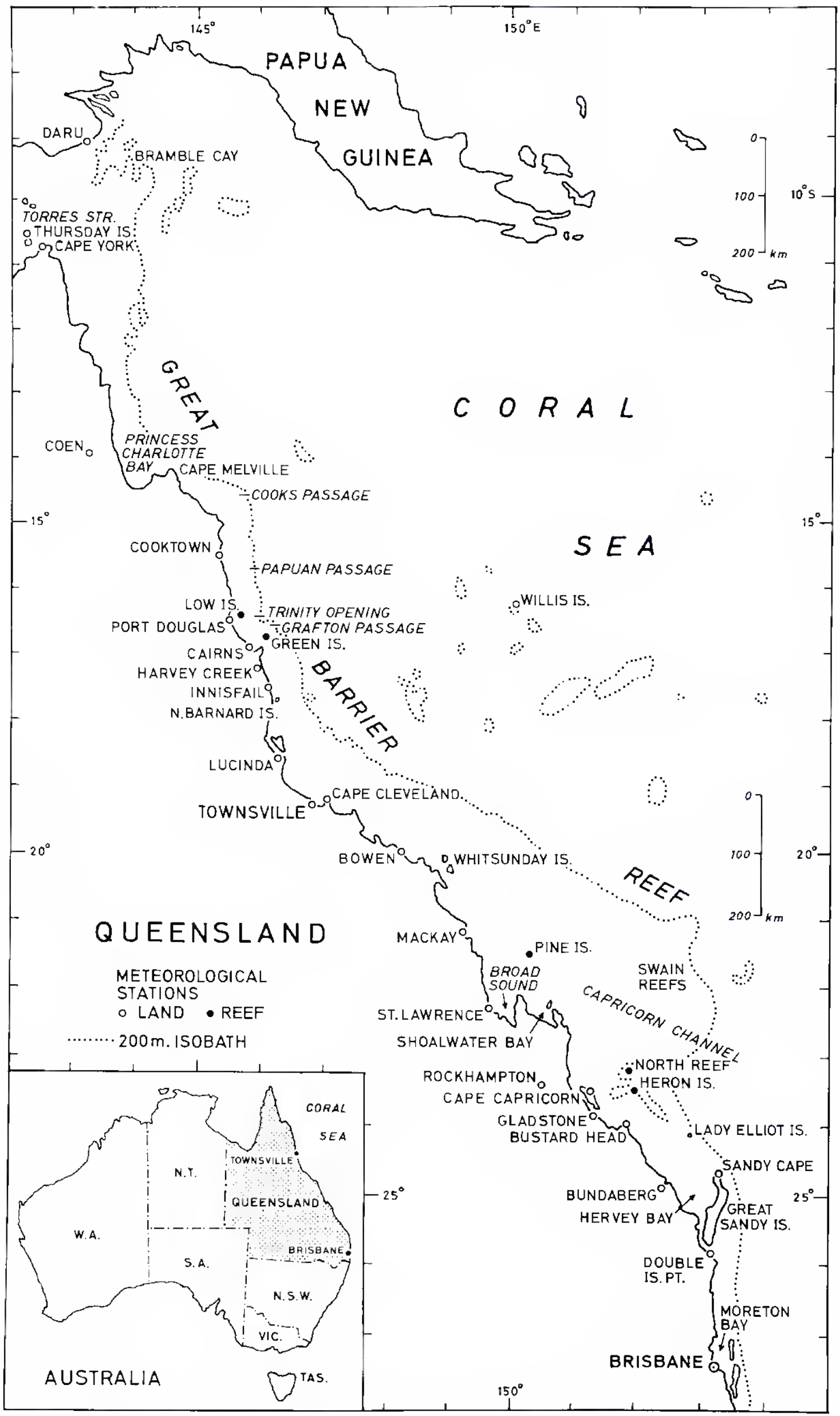

Fig. 1 Australian Great Barrier Reef region. 


\section{I \\ Introduction}

The Great Barrier Reef off Queensland, Australia, extends more than $2000 \mathrm{~km}$ from about 9.1 S, just south of Papua New Guinea, to about 24 S (Fig. 1). Although a considerable number of biological investigations have been carried out in the region, relatively few studies have been made of the physical oceanography (water properties, currents, etc.). The main ones are those on water properties by $\operatorname{Orr}(1933$ a,b) and Moorhouse (1933) (both at Low Isles during the Great Barrier Reef Expedition) and by Brandon (1973), and on the tides by Easton (1970). The Australia Pilot, Vol. IV (British Admiralty, 1962) gives some information on currents and the annual Australian National Tide Tables (e.g. 1976) on tides and tidal currents. Maxwell (1968) has described the geographical, geological and other features at length. There is also information on water properties and climate in Weather on the Australia Station (RAAF, 1942), Sea areas around Australia (Roy. Neth. Met. Inst., 1949), and the Monthly Oceanographic Charts, Tasman and Coral Seas (CSIRO, 1974).

The present paper will review current knowledge of the physical oceanography of the Great Barrier Reef region for the use of marine scientists working in the area, and will suggest directions for future study. 


\section{II \\ Topography}

The Grear Barricr Reef is an asscmbly of coral reefs and lagoons off the cast coast of Qucensland. The coral reefs are found as far north as Bramble Cay at about $9.1 \mathrm{~S}$, close to the coast of Papua New Guinea; this cay will be taken as the northern limit of the Barrier Reef region for physical oceanographic consideration. A southern limit of $25 \mathrm{~S}$ is arbitrarily selected; this latitude is in the vicinity of a marked feature of the coast, Great Sandy Is., and is just south of the southernmost coral reefs. The western boundary is taken as $142 \mathrm{E}$ in Torres Strait and the Queensland coast to the south. The eastern boundary is taken as the position of the $100 \mathrm{~m}$ depth contour just outside the outer reefs, a depth greater than those found between the shore and the outer reefs, and close to the drop-off to the continental slope. The seaward limit will not be adhered to too rigidly and, in the south, the Capricorn Channcl will be included west of a line from outside the Swain Reefs to Sandy Cape.

For this review, the term "Great) Barrier Rect" will be used to refer to the region as a whole from west to east boundaries, The term 'outer reef' will be uscd for the main boundary structure on the eastern side, and the term 'lagoon' to the main body of decper water between the land and the outer reef. The word 'reef' alone will be used to refer to individual features of the coral structures of the region; thesc may enclose their local (shallow) 'lagoons'. Howcver, attention will be devoted chicfly to the main lagoon rather than to the local lagoons.

Despite its name the Great Barrier Reef is not continuous and ccrtainly does not present an impermeable barrier to the passage of water. 1ig. 2 shows schematically the general character of the outer reef. 'The linear distance scale is taken along the castern face of the outer reef, and the intersections with parallels of latitude are indicated; the lattcr scale is non-linear because of the changes in the orientation of the reef face. The northern $40^{\prime \prime}$ " of the reef, from 9.5 to $16.5 \mathrm{~S}$, is one of the more continuous stretches, with reefs coming close to the surface for about $90^{\prime \prime}$ " of the distance. Then from 16.5 to $20 \mathrm{~S}$ shallow rcefs occupy only about $10^{\prime \prime}$ " of the distance along the recf. There is a short stretch of dense reef from 20 to $21 \mathrm{~S}$, followed by the Swain Reefs to about $22.5 \mathrm{~S}$, in which the reefs are scattered but the east-west width is greater than elsewhere. The Capricorn Channel is open to the south and provides a wide and deep entrance to the southern end of the lagoon. The southern $60^{\prime \prime}$ " of the outer reef length is thus only about 20 " "occupied by actual coral rects. The above figures are approximate but do indicate that the lagoon waters inside the outer recf are by no means isolated from the Coral Sea outside. In addition, it should be noted that in the more continuous stretches of reef, water from the sea may enter not only through the gaps between the coral reefs ('passages' etc.) but also over the reefs as swells break on them.

The Reef as a whole extends roughly in a NW-SE direction, with an outer reef length of about $2300 \mathrm{~km}$; thc width from shore to outer rcef varies from $23 \mathrm{~km}$ at $14 \mathrm{~S}$ to $260 \mathrm{~km}$ at $22.5 \mathrm{~S}$ and averages $100 \mathrm{~km}$. The area between land and outcr reef is about $230000 \mathrm{~km}^{2}$.

A more significant dimension oceanographically is the depth of water, An estimate of the distribution of depth in $20 \mathrm{~m}$ intervals has been made from Maxwell's (1968) Figs. $16 \mathrm{~A}-\mathrm{E}$. The areas between $0-10,10-20 \mathrm{fm}$ etc. were estimated by $\frac{1}{4}$ degree square unit for each of Maxwell's five regions and are shown in Fig. $3 \mathrm{~A}$ as percentages of the area in that 


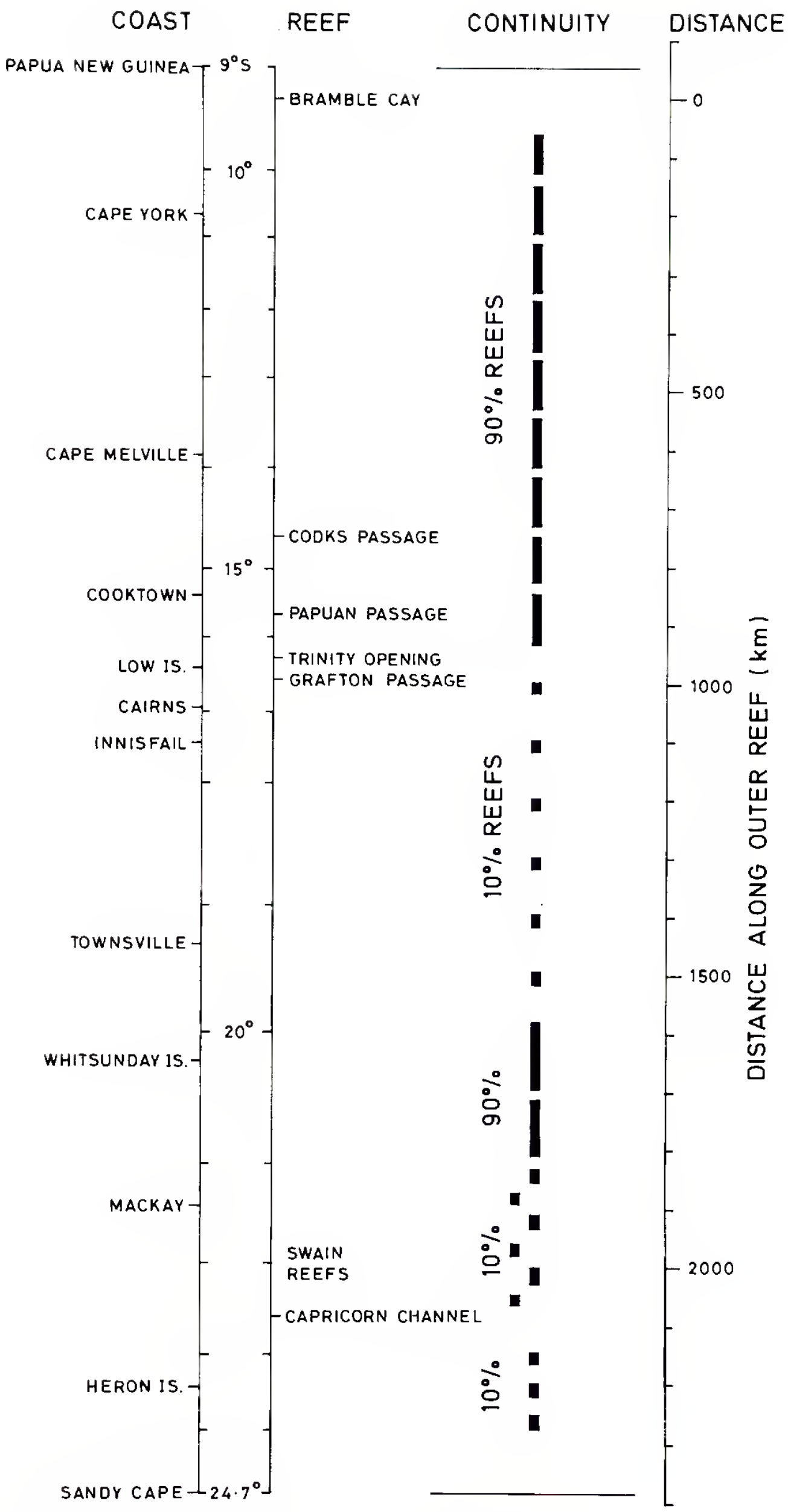

Fig. 2 Schematic representation of outer reef continuity, Great Barrier Recf. 
region (shore to $50 \mathrm{fm}$ ). There is also a component of uncertain depth in most regions because of the incompleteness of the hydrographic surveys. In Fig. $3 \mathrm{~B}$ are presented the areas within the depth zones for the Reef area as a whole. From this graph the values for zones $0-20 \mathrm{~m}, 20-40 \mathrm{~m}$ etc. were interpolated (extrapolated for the $100 \mathrm{~m}$ value) and are presented in Table 1. From this it is estimated that the mean depth of the surveyed area of the lagoon is about $35 \mathrm{~m}$, and depths over $60 \mathrm{~m}$ are uncommon. The unsurveyed areas are probably mostly in the shallow end of the depth range. It should also be noted that aerial photographs are available for about $80^{\prime \prime}$ " of the Reef region (some sources are given at the end of the References).

Fig. 3 (A) 1)epth distribution in Great Barrier Reef lagoon by 10 fathom intervals in each of Maxwell's 1968) regions, expressed as percentage of area of each region,

(B) Hypsometric curve for Great Barrier Reef lagoon, derived from diagram A above.
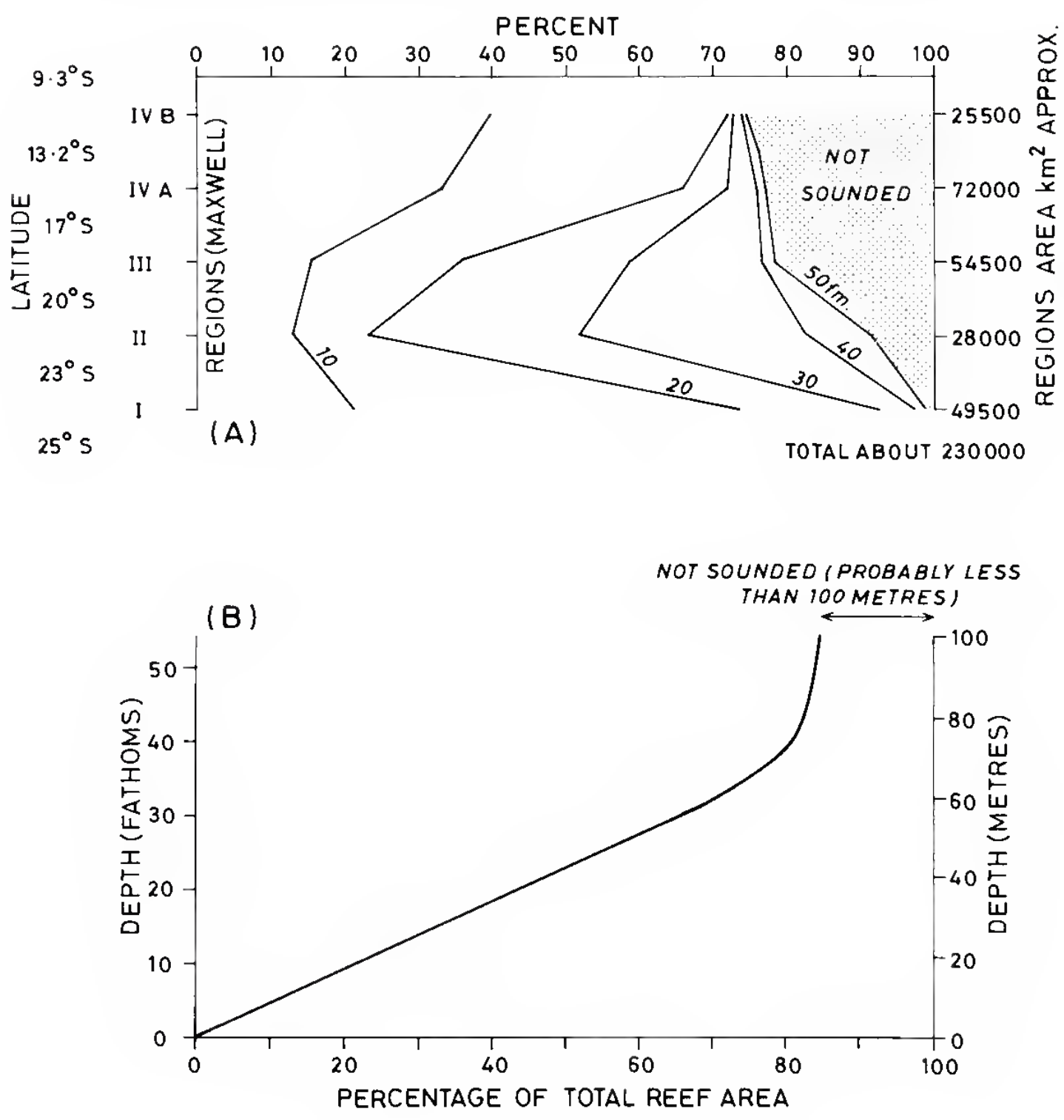
Table I. Percentage of Great Barrier Reef area in various depth zones

Not

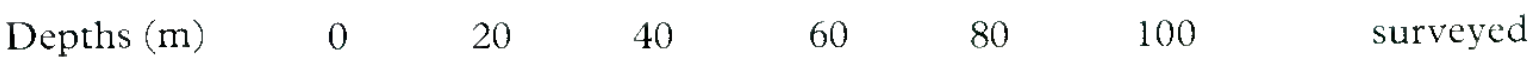

Areas $(0)$

$23 \quad 25.5$

22.5

11.5

2.5

15

Mean depth $35 \mathrm{~m}$; total area about $230000 \mathrm{~km}^{2}$ 


\section{III \\ Climate}

Information on some aspects of the climate particularly relevant to the physical occanography of the Barrier Recf has been extracted from Weather on the Australia Station (RAAF, 1942), the Australia Pilot (1962), Sea areas around Australia (Roy, Neth. Met. Inst., 1949) ctc., and are summarised in this section. One important factor is that most of the regular observing stations are on land; in this regard, two points must he noted. First, the local topography is likely to affect the meteorological factors, particularly wind direction and rainfall. Second, the degree to which land station measurements can be applied to the neighbouring sea areas, particularly at distances as great as $250 \mathrm{~km}$, is always uncertain. However, there are some island stations which afford an opportunity to evaluate this factor to some extent.

\section{WINDS}

South of $15 \mathrm{~S}$, the SE trade winds prevail and the wind direction is generally from between east and south. North of $15 \mathrm{~S}$ the NW monsoon invades the region. In the north, the NW winds start in December, develop through January and February and dic out in March to be replaced by SE winds. Their effect is felt as far south as 15 to $16 \mathrm{~S}$ in lessened degrec. Increased rainfall is associated with this wind direction.

The most common wind directions and typical speeds are shown in Fig. 4 for a selection of stations near the Reef. Willis Is. is included in this and other climate tables, although it is $460 \mathrm{~km}$ east of the reef, because it is the only continuous long-period reporting station representative of open sea conditions with little topographic interference (the island is only about $8 \mathrm{~m}$ above sea level). The above information is taken from $W$ eather on the Australia Station (RAAF, 1942), in which the frequency of occurrence of winds is given for eight directions (and calm) on a monthly mean basis. The specd is given as a single monthly mean value for $0900 \mathrm{hr}$ and $1500 \mathrm{hr}$. The monthly sheets of the General Air Circulation in Sea areas around Australia (Roy. Neth. Met. Inst., 1949) show only a single arrow in each 1 square to represent the general direction and speed; this information agrees well with that in Fig. 4. The effect of the NW monsoon is chiefly to decrease stability and to introduce westerly to northerly components of wind to 15 to $16 \mathrm{~S}$. South of this latitude, an easterly component of wind prevails from August to January or February, with southerly winds prevailing for the rest of the year. A feature in the Cairns-Townsville area (17 -19 S) particularly, and to some extent for other southern areas, is for the wind to back by 45 to 90 (from SE toward NE) between 0900 and $1500 \mathrm{hr}$ during much of the year.

\section{CYCLONES}

On the average, two cyclones per year affect the Queensland coast, the associated heavy rainfall in short periods of time probably being the most important factor oceanographically. Cyclones originate in the Intertropical Convergence Zone between 8 and $18 \mathrm{~S}$ in the northern Coral Sea and are most common (about $76^{\prime \prime}{ }_{11}$ ) in January to March, with 
another $18^{\prime \prime}$ occurring in December or April. They initially move to the west. Those north of about $12 \mathrm{~S}$ tend to continue west across the Cape York peninsula, while the more southerly ones tend to curve SE and parallel the coast. On the average there are the same number of lesser disturbances each year, $80^{\prime \prime}$ " of which occur between January to July inclusive.

Fig. 4 Preponderant wind directions in the Great Barrier Reef region. W'ind blows tow ard the dot, number: represent the mean wind speed ( $\mathrm{m}$ s) for 0900 and 1500 hrs (Daru 0900 hr only). For stations from Daru to $\mathbb{W}$ illis Island the two wind vectors indicate two predominant directions during the month (associated with the NW monsoon), while from Cairns to Sandy Cape the two vectors indicate that the wind backs from the $0900 \mathrm{hr}$ observation (the more clockwise vector) to the $1500 \mathrm{hr}$ observation. Circles indicate $10^{\prime \prime}$, or more calms in the month.

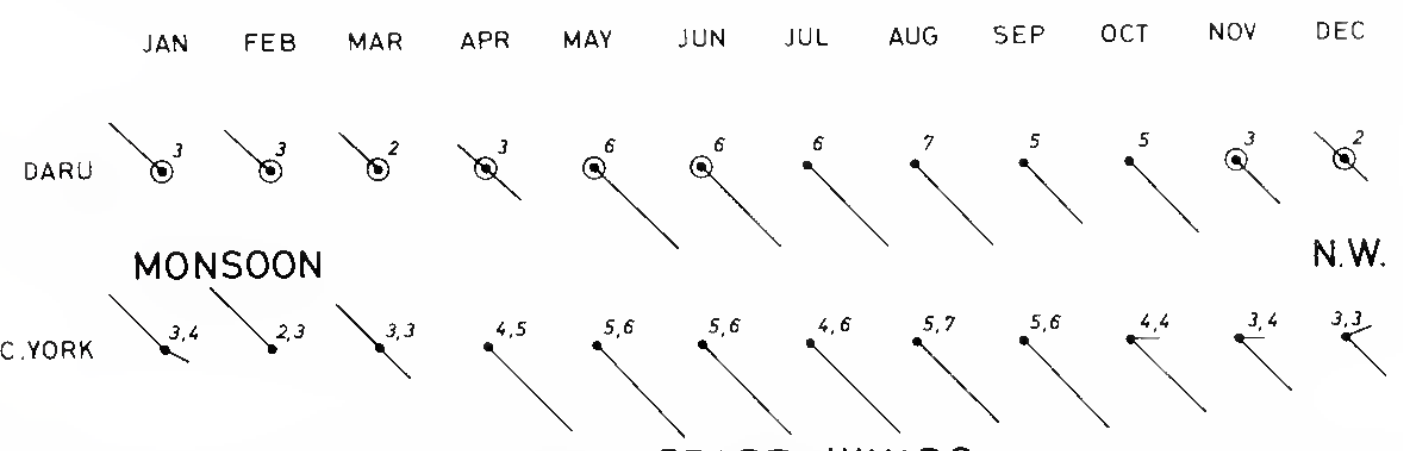

S. E. TRADE WINDS

COOKTOWN

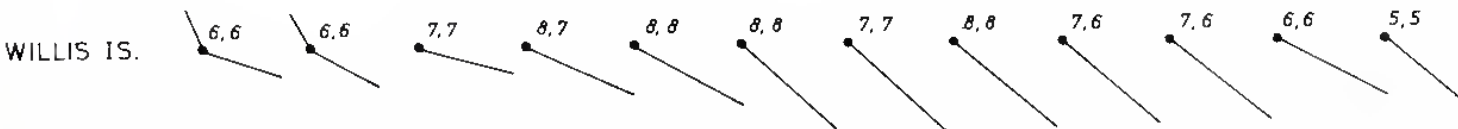

CAIRNS

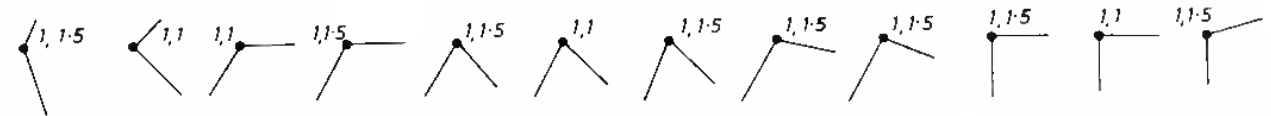

TOWNSVILLE
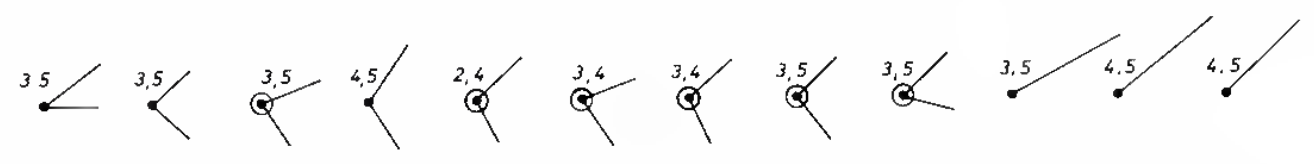

MACKAY
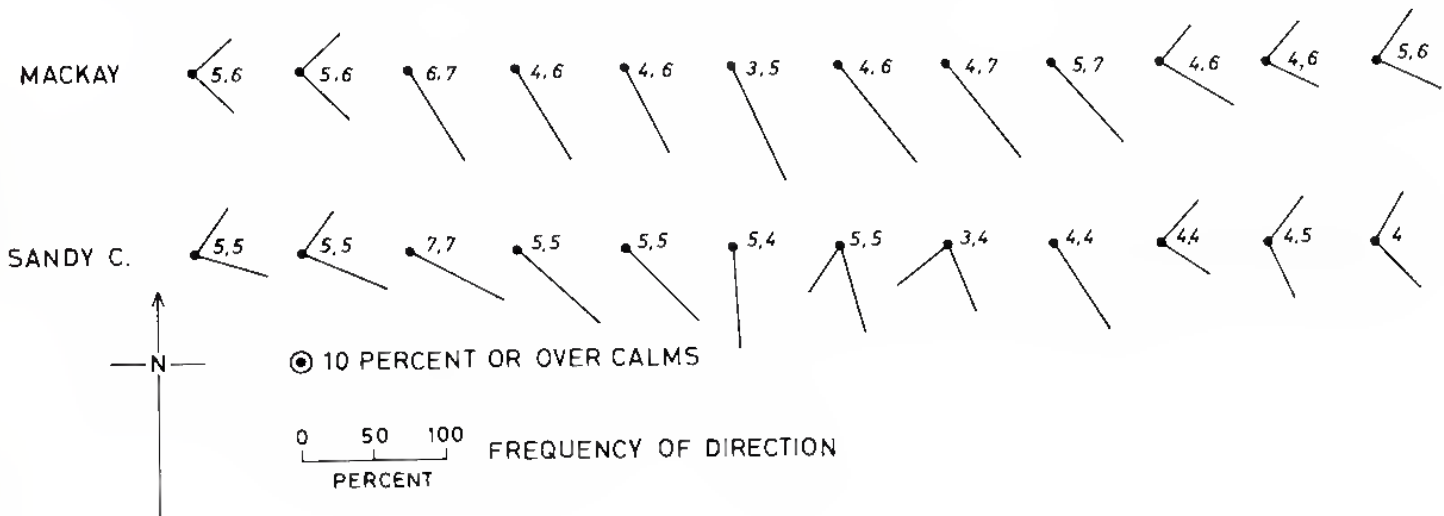

○ 10 PERCENT OR OVER CALMS<smiles>CC(C)C(C)(C)C</smiles><smiles>CCC</smiles>

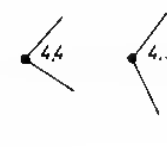

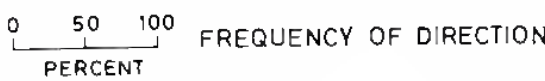




\section{AIR TEMPERATURE}

The air temperature cycles for monthly mean maximum and minimum temperatures show a maximum in December or January and a minimum in August. Curves for selected stations at the north (Cape York) and the south (Sandy Cape) are shown in Fig. 5. The curves for 'lownsville and Cape Cleveland are shown partly to represent an intermediate latitude and partly to show how much difference there may be between neighbouring stations. These two are only $20 \mathrm{~km}$ apart and at the same latitude. It is concluded that for any heat budget studies, it would be essential to use actual observations for the locality being investigated.

Sea areas around Australia (Roy. Neth. Met. Inst., 1949) has monthly charts of mean air tempcrature averaged by 1 squares with whole number isotherms interpolated on the plots. For the Barrier Reef region temperature time curves for $11 \mathrm{~S}, 19 \mathrm{~S}$ and $25 \mathrm{~S}$ have been compared with the maximum and minimum plots of Fig. 5. The Dutch data values fall half way between the maximum and minimum values for Cape York (10.7 S), lownsville (19.2 S) and Sandy Cape (24.7 S) (within $\pm 0.5 \mathrm{C}$ ), except that the Dutch values fall about $1.5 \mathrm{C}$ lower near the minimum.

Fig. 5 Scasonal variation of air temperature for selected typical stations along the Great Barrier Reef coast. (A) Monthly mean maximum, (B) Monthly moan minimum. Cape York-10.7 S, Cape Cleveland19.2 S, Townsville-19.2 S, Sandy Cape-24.7 S.
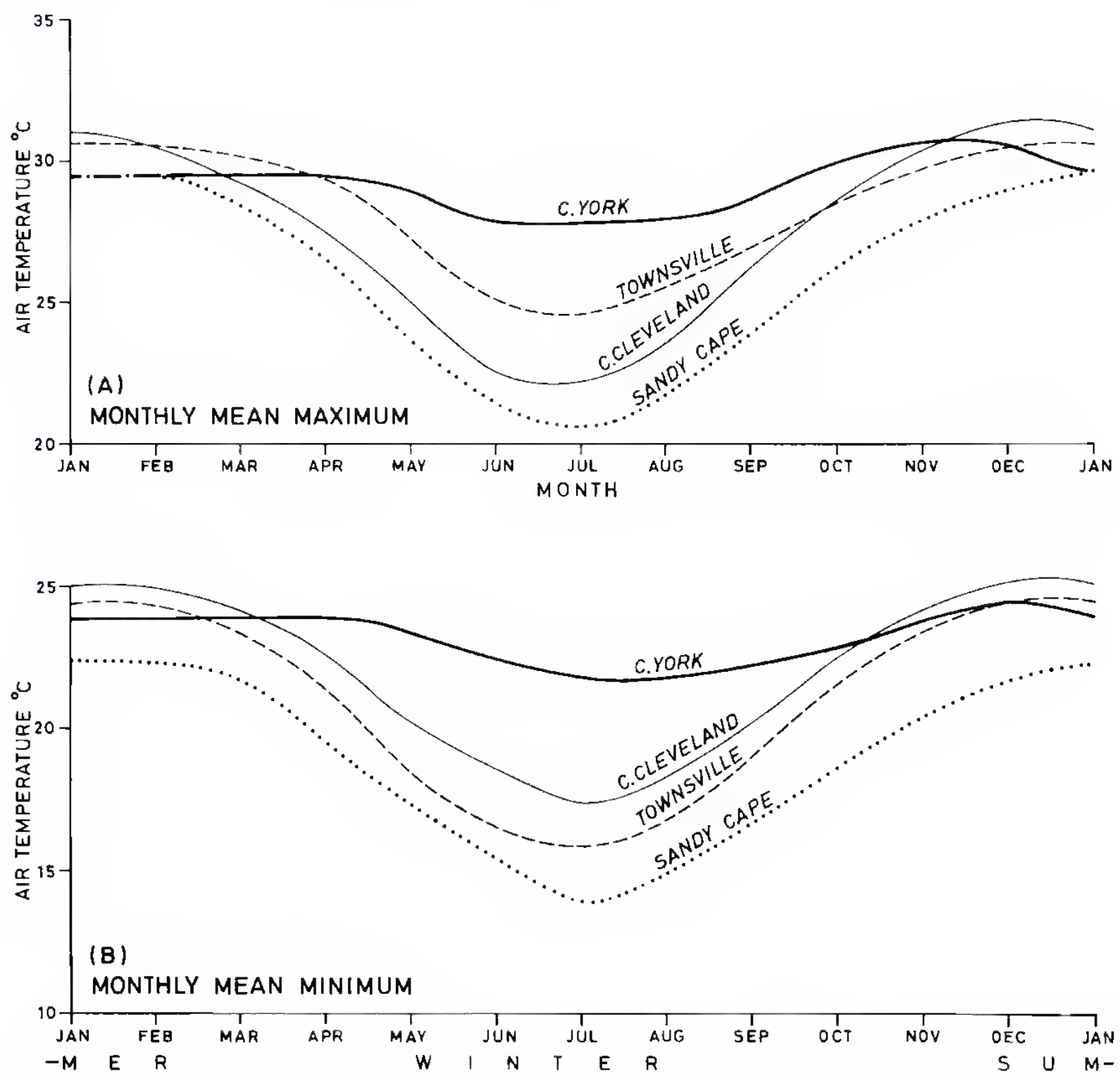
An indication of the geographical scatter of mean air temperatures is given in Fig. 6 in which the monthly means of daily maximum and minimum temperatures (RAAF, 1942) and the monthly mean temperatures, are plotted against latitude. Mean lines have been visually drawn through the points, with reduced weight being given to stations more than $10 \mathrm{~km}$ inland from the coast and to Willis Is. offshore. It will be seen that the maximum is substantially constant from 9 to $20 \mathrm{~S}$ and then decreases southward, while the minimum decreases steadily to the south. The annual mean air temperatures derived from the Dutch data above lie about $0.4 \mathrm{C}$ higher than those in Fig. 5.

Fig. 6 Minimum and maximum values of monthly mean air temperatures, and annual mean air temperature, for stations along the Great Barrier Reef coast. Means are of at least 20 years ubservations to 1939 except for Daru $(16)$, C. Cleveland $(8) .()=$ more than $10 \mathrm{~km}$ inland, [ ] = Willis Is., about $460 \mathrm{~km}$ east of outer reef.

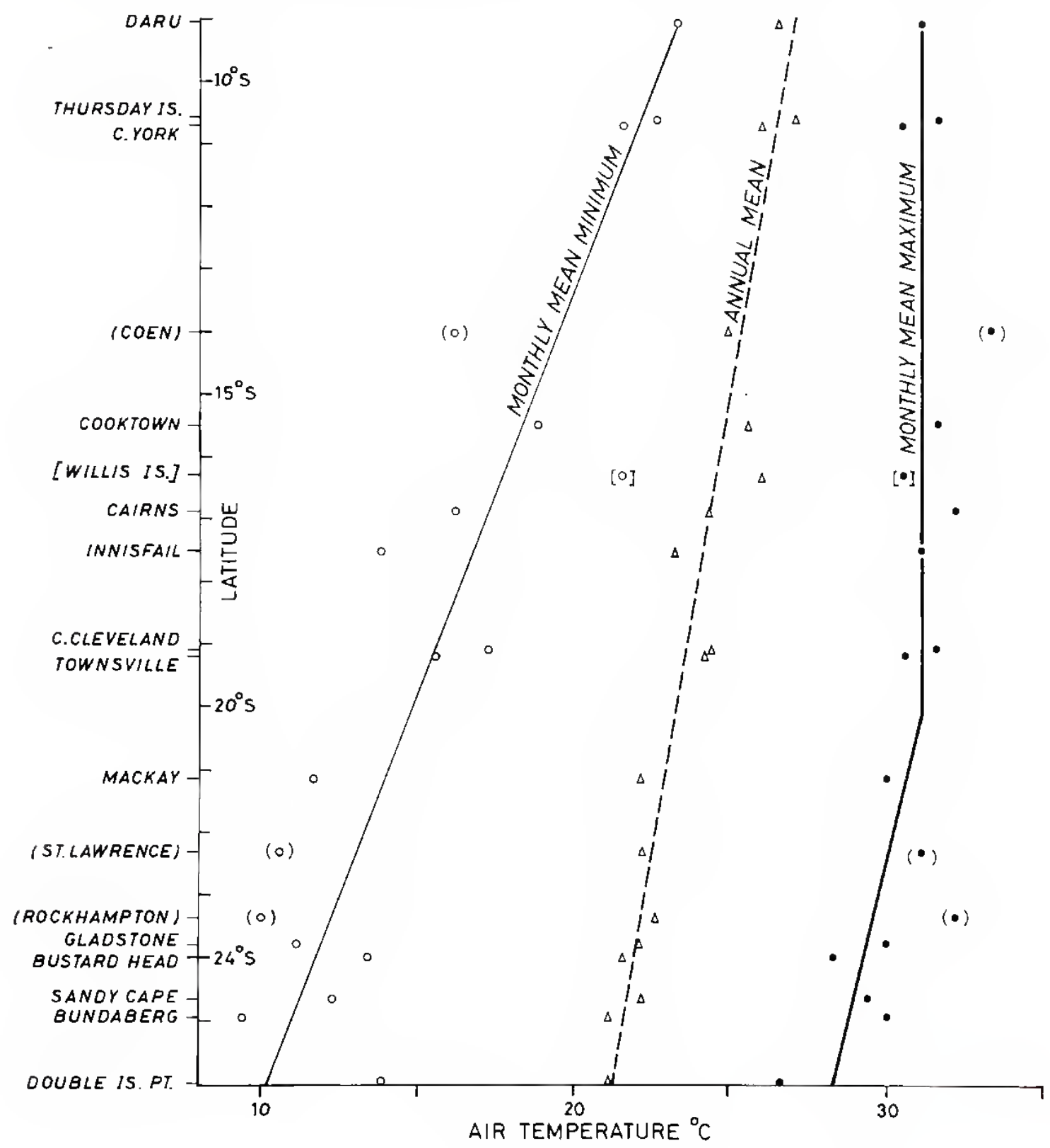




\section{RAINIAILI.}

In coastal scas particularly, labliall and river rumoll are imporlant liactors in their elfect on

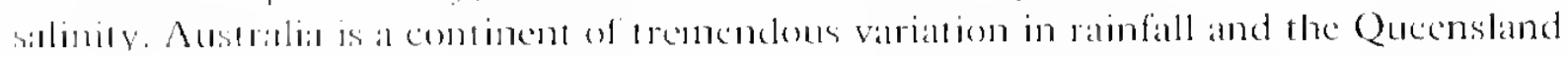
coast is lle weltest part ol the country. 'This point is often overemphasised an the mean anmual rainfall along the coast is mot high by world standards (about $1500 \mathrm{~mm}$, the same as Vancouvere, one of the drier parts of the British (columbia coast). What mal be more important occanographically (and socially ceonomically) are the very large variations in spiec and time ol the ramball. As this section al the review is incended primatrily for

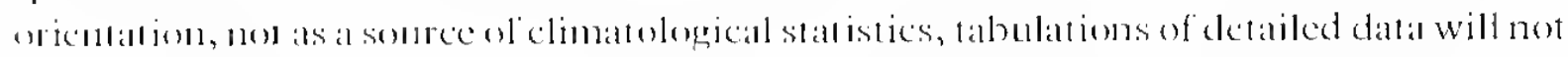

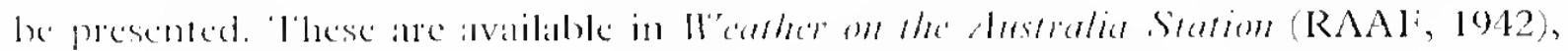

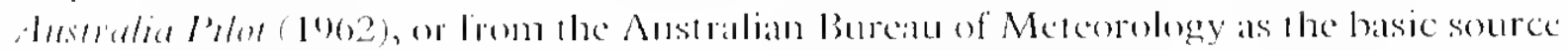

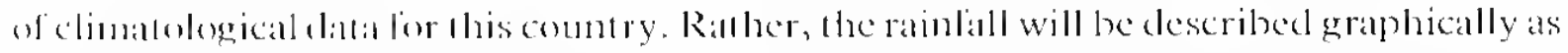

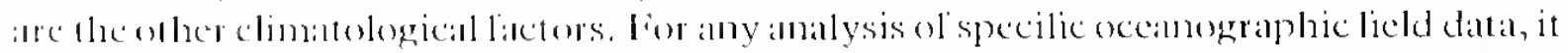
will be mandatery onse actual weather inlomation, rather lhan climatological averages, becaluse of the latge varialions wilh lime (day 10 day or year to year) which are characteristic of this coast. 1)ata liom standardobserving stations maly beavilable, but in

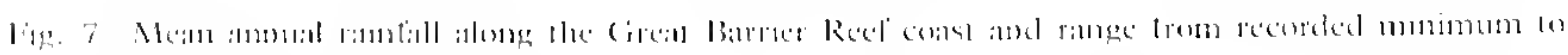

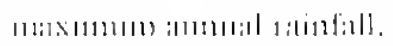

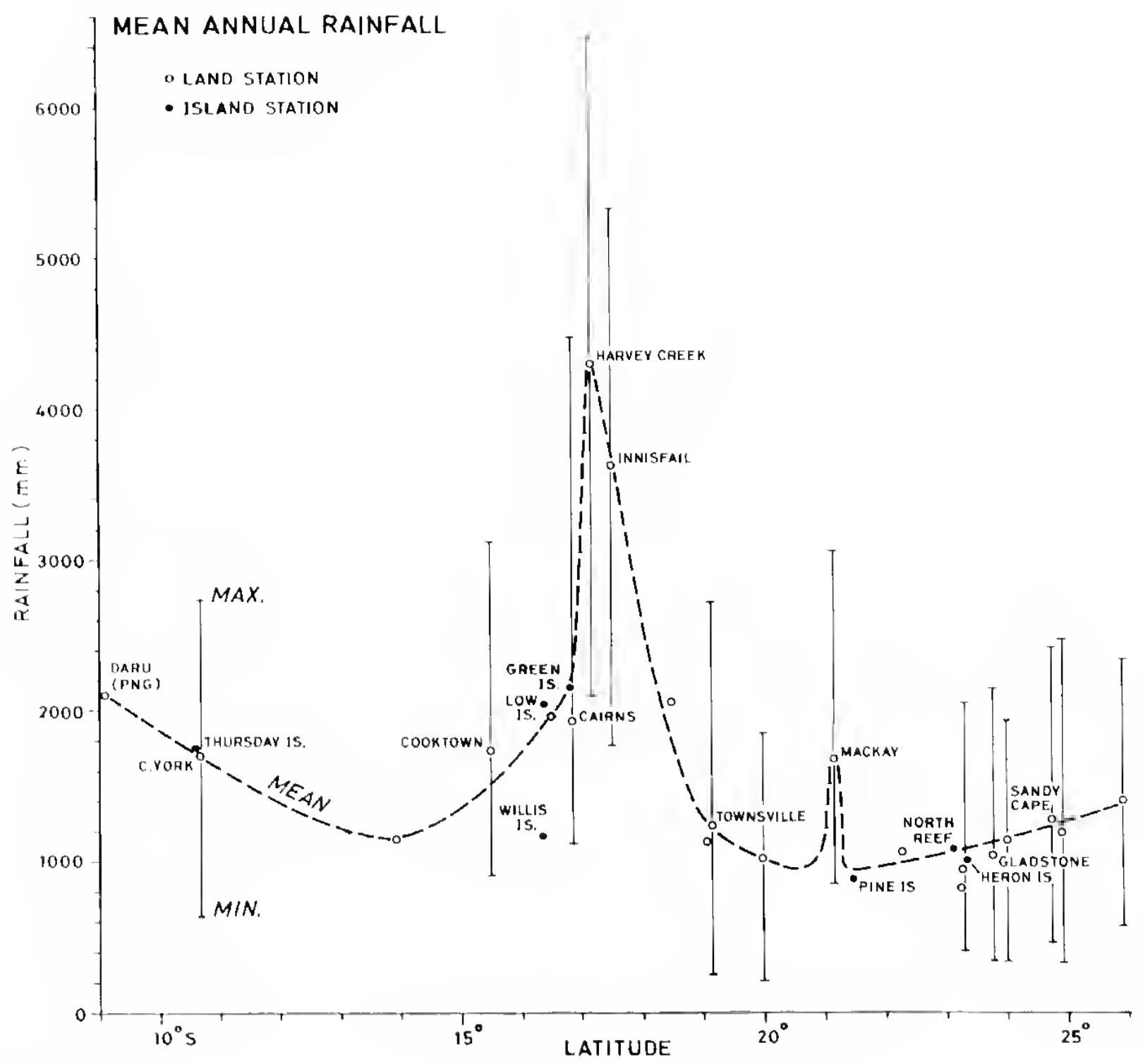


view of the significant spatial variations it may be necessary in some cases to schedule weather recording for the area of oceanographic study,

Rainfall values have been rounded off to the nearest ten millimetres as the precision implied in the published figures to the nearest millimetre seems inappropriate when year to year variations may be measured in metres (e.g. Fig. 7).

\section{Mean annual rainfall}

Fig. 7 shows the long-term mean annual rainfall as a function of latitude, with a few names added for convenience and the land and island stations distinguished (Sources: RAAF, 1942; Brandon, 1973). It will be seen that the mean anmual precipitation is between about 1000 and $2000 \mathrm{~mm}$ except for the notorious but restricted zone near Innisfail $(17.5 \mathrm{~S})$. Also it is noted that the island stations lie on the same curve as the land stations (except for Willis Is. far offshore). This point will be discussed later.

\section{Rainfall variability}

Fig. 7 also has bars indicating the range between recorded minimum and maximum annual rainfalls (Source: RAAF, 1942). This figure shows one aspect of the variability of rainfall on this coast, that the variation is often greater than the mean. A plot (not shown) of the differences between recorded maximum and minimum against long-term mean annual values shows a roughly linear relationship from 1000 to $4000 \mathrm{~mm} \mathrm{yr}$. A few values are:

$\begin{array}{lllll}\text { Long-term mean annual rainfall (mm) } & 1000 & 2000 & 3000 & 4000 \\ \text { Difference, recorded max.-min. (mm) } & 1700 & 2500 & 3300 & 4100\end{array}$

This table gives an indication of the long-term variability, although it must be noted that the differences are from records of 50 to 72 years duration and such large variations need not be expected very frequently.

In records of maxima and minima for individual months, the variability is even greater than that shown by the annual maxima and minima. A few examples from tabulations in Weather on the Australia Station (RAAF, 1942) will suffice to indicate the tremendous ranges of rainfall to be expected. For Innisfail $(17.5 \mathrm{~S})$, January rainfalls from 30 to $1580 \mathrm{~mm}$ (mean $510 \mathrm{~mm}$ ) and August falls from 0 to $450 \mathrm{~mm}$ (mean $130 \mathrm{~mm}$ ) have been recorded; for Bowen (20 S), the January range is 5 to $1180 \mathrm{~mm}$ and for April 0 to $640 \mathrm{~mm}$. Ranges such as these are typical, not rare.

On a still smaller time scale of days, the variability of rainfall can be very large, particularly during the wet season when the heavicst falls are associated with cyclonic systems moving through the region. Practically every coastal station south of $15 \mathrm{~S}$ has received at least one fall excecding $250 \mathrm{~mm}$ in 24 hours (RAAF, 1942). The recorded 24hour maximum rainfall values in the climatological tables (RAAF, 1942), when plotted against mean monthly values on a scatter diagram (not shown), can be summarised as follows:

\begin{tabular}{|c|c|c|c|}
\hline \multirow{3}{*}{-} & & Monthly average $\left(\mathrm{R}_{M}\right)$ & 24-hr maxima \\
\hline & Dry season & up to $150 \mathrm{~mm}$ & 0.8 to 5 times $R_{M}$ \\
\hline & Wet season & 100 to $650 \mathrm{~mm}$ & 0.5 to 2 times $\mathrm{R}_{M}$ \\
\hline
\end{tabular}


Although the dry season 24-hour maximum factor may be larger (up to 5 times), it is the wet season 24-hour maxima which are likely to be more significant oceanographically because of their greater volume.

$\Lambda$ generalised picture of the seasonal variations of rainfall during the year is presented in liig. 8. Mean monthly rainfall valucs for each station were normaliscd by dividing by the mean annual rainfall for that station. Curves drawn of normalised rainfall against month show the well-known features of (a) distinct wet and dry scasons and (b) more marked distinction between the seasons in the north and centrc areas than in the south. Mean curves were presented for these threc zones in order to avoid the confusing appearance of a large number of eurves (for all the stations) on one diagram. (Note that there are only three stations, widely spaced at $10.6,10.7$ and $14.0 \mathrm{~S}$, for the north zone.) Because Fig. 8 is a simplification from the original diagram, which shows considerable scatter about these mean curves, it should not be uscd to scale off values for individual stations (from their mean rainfall values) except for very approximate values. Tables of climatic records should be used for this purpose, c.g. RAAF (1942), Australia Pilot (1962), Brandon (1973) for immediate reference, or the Bureau of Metcorology as the hasic source, especially for recent data. However, Fig. 8 does show the two basic features of the rainfall distribution noted above. The concentration of rainfall (about $70^{\prime \prime}$ "of the annual amount) in the January to March period for the north and centre zoncs is well shown.

Note that Innisfail, in the centre maximum rainfall zone, does not fall clearly on any of the curves (it is shown by the symbol ' $I$ ' on the diagram). It has an extended wet season similar to the south zone but falls between the centre and south zones in the dry season. This is attributed ( $\mathrm{RAAl}, 1942$ ) to orographic showers occurring in the nominal dry scason.

\section{Comparison of rainfall on land and on islands}

Earlier it was noted in reference to Fig. 7 that the rainfall statistics for the islands of the Reef were not much different from those on the land stations nearby. Brandon (1973) examined this aspect by comparing the rainfall at islands and land stations for the same group of ycars (the data in Fig. 7 are for different numbers of years for the different stations). The ratios which he ohtained were, for the same years for cach comparison but not the identical years for all:
(a) Low Is./Port Douglas
$=1.02$
(b) Green Is. Cairns
$=1.09$
(c) Pinc Is./Mackay
(d) Pine Is./Rockhampton
(c) Heron Is. C. Capricorn*
$=0.51$
$=1.09$
$=1.60$

*Eight years only

'T'o these are added, before discussion:

(f) Pine Is. St Lawrence

(g) Heron Is. C. Capricorn ${ }^{* * *}$

$=0.83$

(h) Heron Is. Gladstone

$=1.23$

$=0.98$

(i) Hcron Is. Bustard Hd

$=0.84$

Note: the latter are not for the same groups of years in each case. 
For Heron Is, Brandon concluded from the ratio 1.60 (c) that rainfall at the island was significantly higher than at the neighbouring coast station. He did not point out that the rainfall at C. Capricorn for the 8 years for which Heron Is. data are available was substantially below its long term average $(600 \mathrm{~mm}$ against $810 \mathrm{~mm})$ and that use of this latter figure would yield the lower ratio of 1.23 as in $(\mathrm{g})$ above. Also, the ratios for Heron Is. rainfall to two other stations at the same distance as C. Capricorn are (h) 0.98 and (i) 0.84. Brandon regarded the Pine Is. Rockhampton ratio of 1.09 (d) as more significant than that to Mackay of 0.51 (c), which station is nearer but in a local high rainfall area. Note the Pine Is./St Lawrence ratio of 0.83 (f), St Lawrence being nearer than Rockhampton and the same distance as Mackay.

Overall, the evidence above suggests that the rainfall over the Reef area is probably not very different $\left( \pm 15_{0}^{\circ}\right)$ from that on land in the vicinity (same latitude), and that for climatological calculations the mean rainfall curve of Fig. 7 could be used for the lagoon. However, it would be desirable to have more data for the Reef area itself to verify this opinion, particularly from positions further from land, and it is not expected that the very high coastal rainfall near $17 \mathrm{~S}$, related to orographic effects, extends very far across thic lagoon. (Ref. Chapter X, Reef Climate.)

\section{RIVER RUNOFF}

Rainfall on the lagoon is not the sole cause of reduced salinity; river runoff from precipitation on land is also a factor in coastal areas. Previous descriptions of salinity distributions in the Barrier Reef lagoon have attributed reduced salinity in part to river runoff, but curiously only one paper (Endean et al., 1956a) has given any values for river

Fig. 8 Seasonal variation of rainfall along Great Barrier Reef coast, expressed as fraction of mean annual value:

North zone: 10.5 to $15 \mathrm{~S}$, mean annual rainfall $1750 \mathrm{~mm}$, Jan. - Mar. $=70$, of annual; Centre zone: 15.5 to $21.2 \mathrm{~S}$, mean annual rainfall $2000 \mathrm{~mm}$, Jan. - Mar. $=70^{\prime \prime}$ " of annual;

South zone: 21.5 to $25 \mathrm{~S}$, mean annual rainfall $1000 \mathrm{~mm}$, Jan. - Mar. $=45^{\prime \prime}$ " of annual.

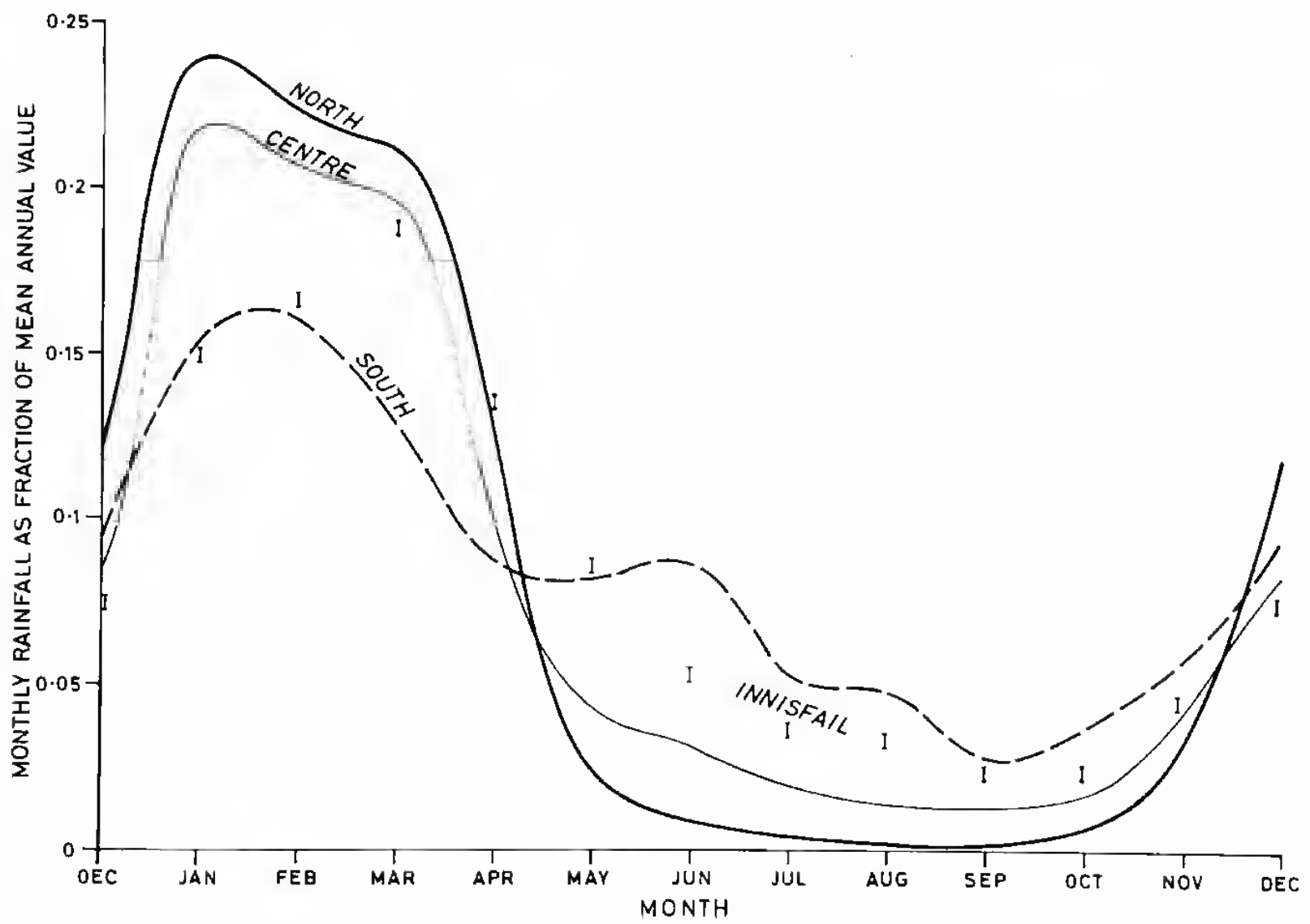


runotl and no one has presented any quantitative comparison of river runoff and rainfall clicets. I'herefore an attempt was made to evaluate the relationship between these two fiaclors.

Only limited information on river runofi is available, the two prime sources being Strum (Ganging Information, Australia, December 1969(Aust. Water Res. Council, 1971), abbreviated to S.G.l. hereafter, and 'Surface IWater Resources' in the Atlas of Australian Revontes (Aust. 1)ept. of Nat. Det., 1967), hereafter S.W.R. S.G.I. lists all river basins with their catchment areas and, in some cases, annual discharge figures. The North-east Coast Division is the one related to the Great Barrier Recf. Runoff information is available for about $318000 \mathrm{~km}^{2}$, i.e. about $76^{\prime \prime}$ " of the total drainage area of $417000 \mathrm{~km}^{2}$ from Cape York to $25.5 \mathrm{~S}$. Unfortunately, much of the catchment area for which runoff is measured is in low rainfall areas inland (less than $50 \mathrm{~mm} \mathrm{yr}$ ) which do not contribute much to the total runoff. Many of the short rivers in the high rainfall regions near the coast are not metered at all. In fact, only one-third of the estimated annual rainfall of $8,3 \times 10^{20} \mathrm{~m}^{3}$ (S.W.R. Commentary Text) is actually measured.

II'hen calculating river runoff from rainfall data in a catchment area which is not generally saturated with movisture, it is neessary to allow for water which is retained in the soil and for that which is lost by evaporation (the actual river runoff is as low as $10^{\prime \prime}$ of atainfall in much of Australia including the inland arcas of Queensland). It should therefore be noted that rainfall maps, such as Fig. 2 in Brandon (1973) or Fig. 53 in Maxwell (1968) can be misleading as far as river runoff is concerned. Because of increased losses inland, the runotf decreases much more rapidly than does rainfall as one proceeds inland from the coast. As an example, in the same distance inland at $18 \mathrm{~S}$ the rainfall decreases by a factor of 5 but the runoff by a factor of 60 .

Iortunately, S.W.R. gives isopleths of runoff per unit area supcrimposed on the Arainage basins; the runoff from each basin was estimated by numerical integration as suggcsted in the S.W.R. Commentary. For the basins for which the measured runoff is given in S.G.I and for which the gauged area includes most of the catchment area, there Was a reasonable correlation between runoff estimated from the S.IF'.R. chart and the actual galuged values in S.G.I., with the exception of the Burdekin River. For this, the estimatc was only $40^{\prime \prime}$, of the gauged figure, The total runoff for the North-east Drainage Basin was estimated as $80^{\prime \prime}$ of the average annual runoff quoted in the S.W.R. Commentary 'lixt, presumably obtained in a similar manner but with larger size charts. '1 he diserepaney is attributed to the small scale of the published S. IW.R. chart which makes it very cramped in the coastal high runoff area. Also, isopleths for more than $1500 \mathrm{~mm}$ yr rainfall are not given in the published chart (because of crowding). Accordingly, estimates for individual basins were increased by 10080 (with the Burdekin River value increased to the measured value) and presented in Fig. 9A.

As these figures are for annual runoff rolume, they cannot be compared directly with rainfall tigures which represent volume per unit surface area, i.c. depth of water. To provide some idea of the relative importance of river runofi and rain components of fresh water input, the river flow value has been compared with rainfall volume over a selected area of the lagoon. The latter was divided into 1 latitude zones and for each the fresh water volume for the annual mean rainfall (Fig. 7) was calculated for an area from the shore to the outer reef or to $60 \mathrm{~km}$ east from the shore, whichever was the smaller distance. (The narrow part of the lagoon, in the north, has an average width from shore to outer reef of close to $60 \mathrm{~km}$, hence the use of this figure where the actual lagoon is wider.) The river runotf into each of the same 1 latitude zones was determined and plottcd (dashed line) with the rainfall value (full line) in Fig. 9B. On this basis the river runofl is about $50^{\circ 1}{ }^{\prime \prime}$ of the rainfall volume.

Several criticisms may be offered. The difficulty of integrating the published chart has been mentioned, but the errors are not likely to be more than $\pm 25^{\circ}$ "from this source (after normalising to the published total runoff figure). However, the information on 
which the S.W.R. is based is admitted to be very limited and more extensive data would certainly improve the quality of the estimate. For the present, the value of trying to improve the runoff estimates is doubtful because of the extreme variability in time of river runoff.

The variations from year to year are very large. The Burdekin River (19.7 S) has the largest recorded mean annual flow for the coast, $0.97 \times 10^{10} \mathrm{~m}^{3}$, and its minimum and maximum recorded flows are $4^{\prime \prime}$ and $300^{\prime \prime}$ "respectively of this mean value. For the Fitzroy River $(23.6 \mathrm{~S})$ the figures are $5.1 \times 10^{10} \mathrm{~m}^{3}, 3^{\prime \prime}$ "and $560^{\prime \prime}$, respectively. The rivers north of $19 \mathrm{~S}$ generally do not show such extreme ranges of flows (e.g. average $40^{\prime \prime}$ "to $210^{\circ}$ " of mean annual) as those south of that latitude (e.g. avcrage $4^{\prime \prime}{ }^{\prime}$ and $390^{\prime \prime}{ }^{\prime \prime}$ ).

It should be noted that the mean seasonal variation of river flow, from the shorter rivers at least, is very similar to the mean scasonal rainfall pattern. S.W.R. gives figures for the Barron River at about 16.8 S, close to the coast, and for the Nogoa River at $23.6 \mathrm{~S}$, about $110 \mathrm{~km}$ inland. The seasonal variations of runoff from these are very similar to those for rainfall for the centre and south zones respectively (Fig. 8). In shorter time intervals, the coastal river flow follows rainfall within a day or two but the smaller inland component may be delayed.

Fig. 9 (A) Mean annual river runoff volumes estimated from Suface Water Resoluces (Aust. Dept. of Xat. Dev., 1967) and Stream Gauging Information (Aust. Wat. Res. Council, 1971),

(B) Comparison of river runoff volume with rainfall volume on lagoon to rect or to $60 \mathrm{~km}$ from shore, whichever is least.
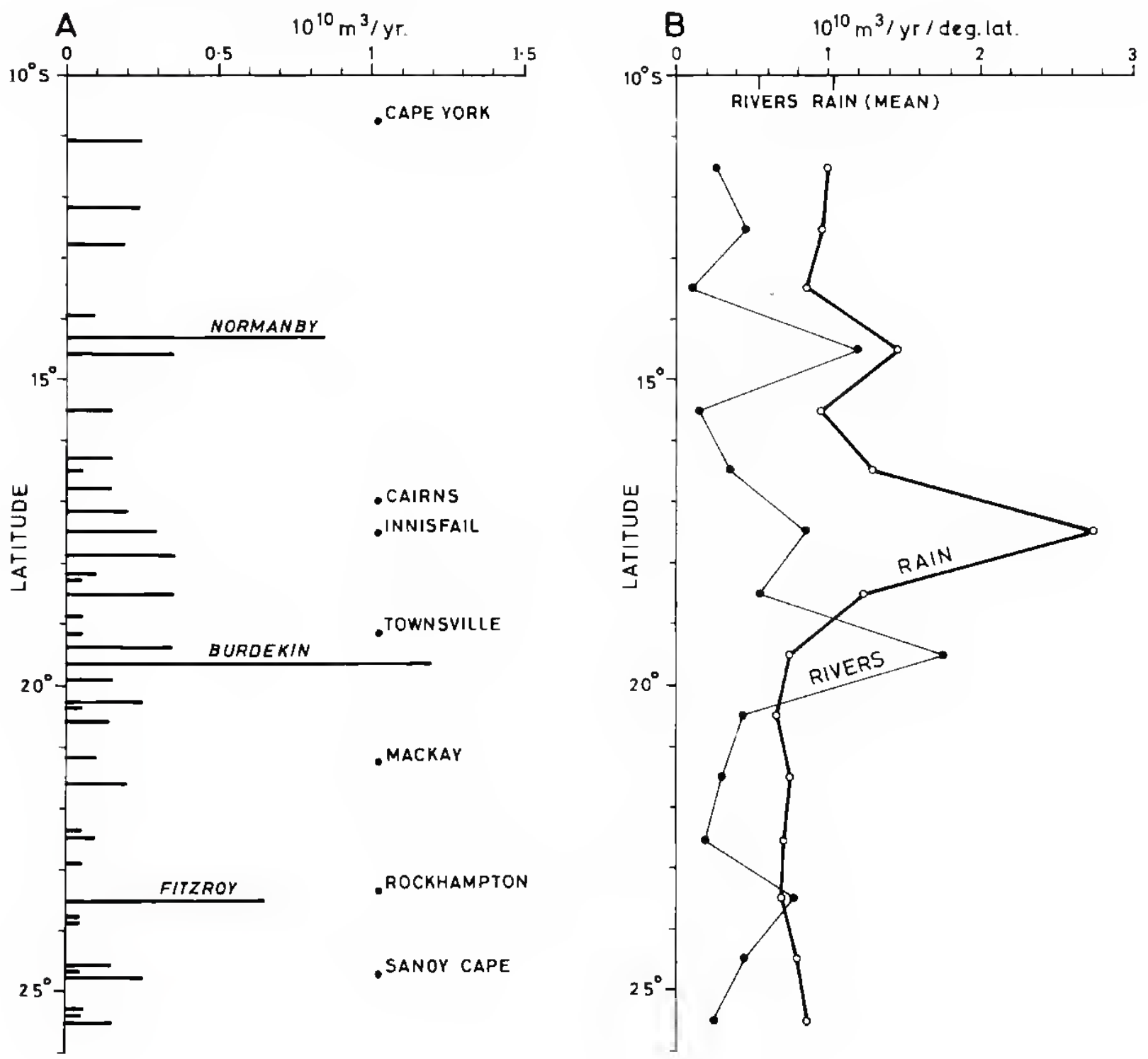
Amether eriticism of the rantall versus runoff comparison ol lig. $9 \mathrm{~B}$ concerns the calculatcd rainlall volume. lor instance, the high rainlall eomponent in the 17 to $18 \mathrm{~S}$ ante ocurs because the local coastal rainfall figure was used; however, the substantial orographice effec here may werstate tle ranfall volume calculated lor the lagoon in this zanc. Secomel, the of $\mathrm{km}$ width of ane for the southern half of the lagoon was chosen rather anbitmaty; if the full widh of the lageon were used, the rainfall component would be increased south of $18 \mathrm{~S}$. 'Third, the tacil assumption in this comparison is that whatever width of zone is chosen, the river and rainfall components are distrihuted cequally and uniformly over it. In liat, this is not likely to be the case for the runoff component beause the rivers are cissent ially point sources at the coastline and their effects will be emphasised neat their mouths. 'This is another reason for not ealculating the rainfall volume over too wide an area ol the lagenn lor comparison. It would be desirable 11) make some mcestsurements ol runofl distribution as a function of time after a heavy discharge. Salinity depeh measurements over an area would be desirable but a lirst order estimate might be made by using the turbidity ol the river water as a visual tracer.

Another way tecompare river runofl with rainfall is to assume the river component to be tunifomly spread over an arcal ol' the lageon as for the ranfall. If this is done, the river waller layer thickness would vary lrom about $15 \mathrm{~cm}$ to $255 \mathrm{~cm}$ (compared with rainfall depths ranging from about 90 ) o over $400 \mathrm{~cm}$ ), lixpressed lais way, it is convenient to note that $100 \mathrm{~cm}$ of w:1ler added to a column of $35 \mathrm{~m}$ depth (mean depth of the lagoon) would decrease the mean salinity by about 1 if mixed uniformly through the column. White rainfall is distributed over an arca, river lunofl is initially concentrated near the river mouths and therefore mily have a greater effect locally in reducing the salinity, A lirequently quoted example is Hedley's (1925a) description ol' the destruction of a coral recl by an exceptionally large river flood.

It is encluded from this discussion that river runofl does introduee a component of fresh water to the lagoon which is quant itatively comparable to the rainfall component. In the main, it will be contributed in phase with the rainlall but, being introduced at specific points along the eoast, it could have greater effect in relucing salinity locally.

\section{(CI.OU1) ANI) HUMIDI'TY}

I'wo other meteorological liators relevant wheat budget studies are cloud amount and the humidity ol the atmosphere above the sea. According to the data available, neither shows much variation.

\section{Cloud amount}

lig. 10A shows that there is a small variation of cloud amount with latitude, the lowest values occurring between aboul 19 and $24 \mathrm{~S}$. There is also some scasonal variation (Fig. $11 \mathrm{~A}$ ) with rather more cloud during the summer wet season than during the winter. The lower mean cloud amount in the south appears to be a result ol' less cloud all year round as is seen when curves a and b are compared in Fig. 11A, although the range of scatter of points about each line is 1 to 1.5 oktas (cighths) or rather more than the separation of the lines. The mean amount of eloud, 4.5 oktas of sky covered in the north in the monsoon season, seems to be low but it should be noted that for the three stations from 10 to $14 \mathrm{~S}$ the values are for 0900 hr observation only, which does not take account of any build-up during the day, Most of the others are for the mean ol 0900 and 1500 hr observations. The summary in the Australia Pilot (1962) of reports from ships at sea shows much the same cloud conditions as described above.

The above remarks apply to all cloud observed lrom the stations. 


\section{Humidity}

The relative humidity (Fig. 10B) shows a slight decrease southward, with lower values in the afternoon than in the morning, which is usual in coastal regions. The humidity also has slightly lower values in late winter (Fig. 11B) and 10" "lower values through the year (curve d against curve c) for the same southern group of stations which show lower cloud amount (Fig. 11A).

Fig. 10 Variation with latitude along Great Barrier Reef coast of:

(A) Cloud amount ( 1 okta = one-eighth of sky covered),

(B) Relative humidity.

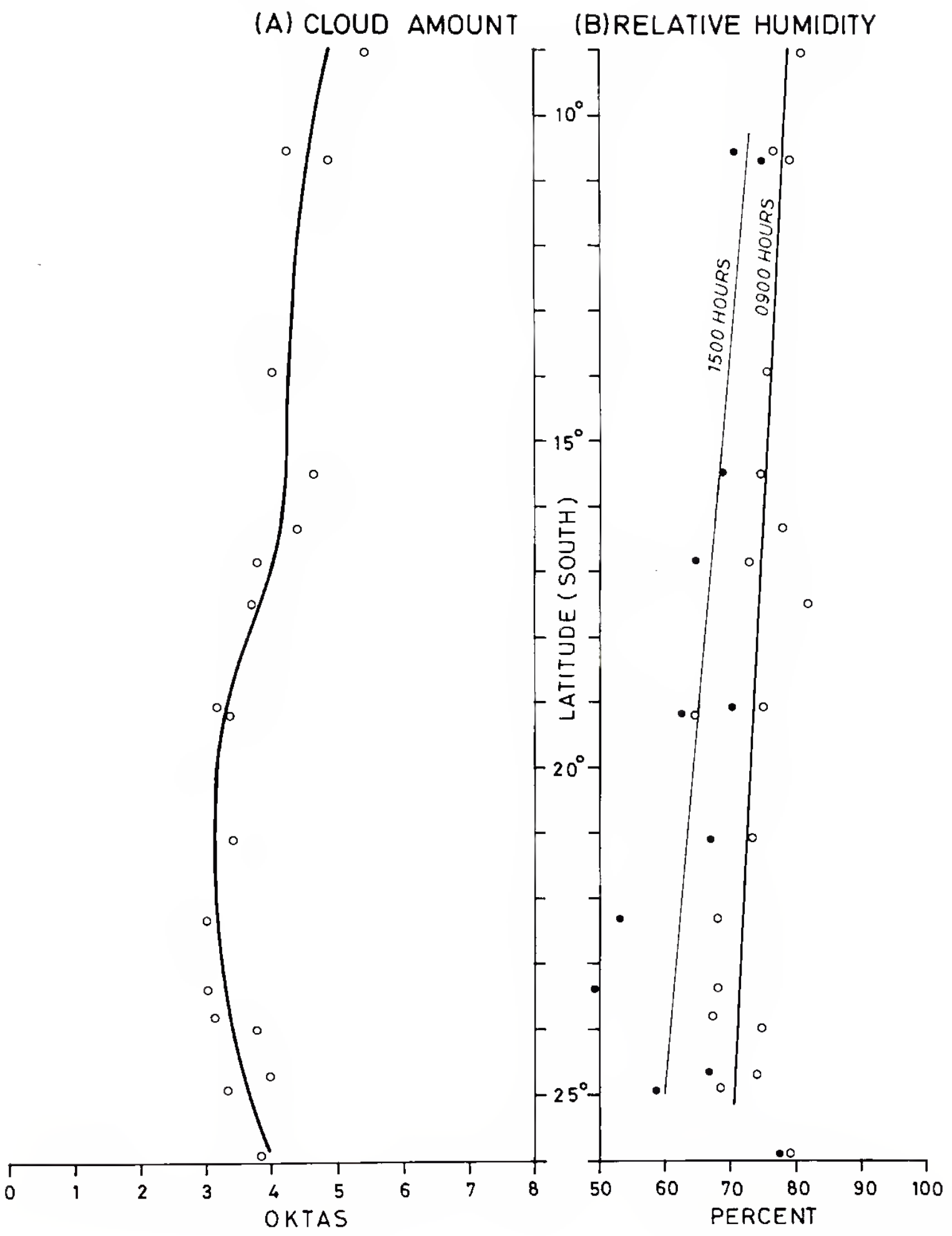


(A) CLOUD AMOUNT

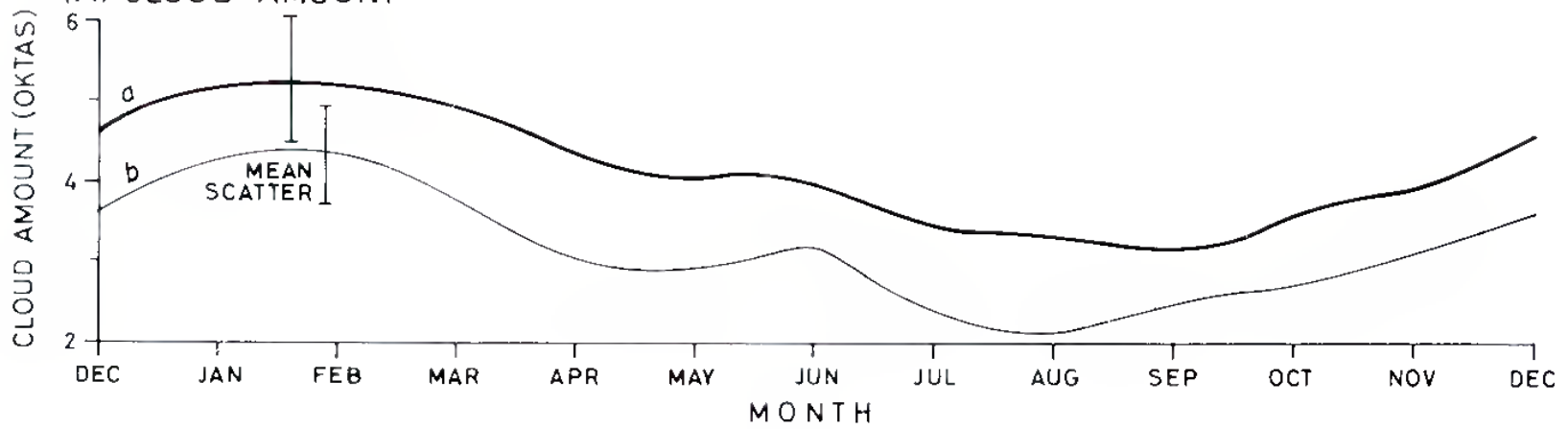

(B) RELATIVE HUMIDITY - 0900 HOURS

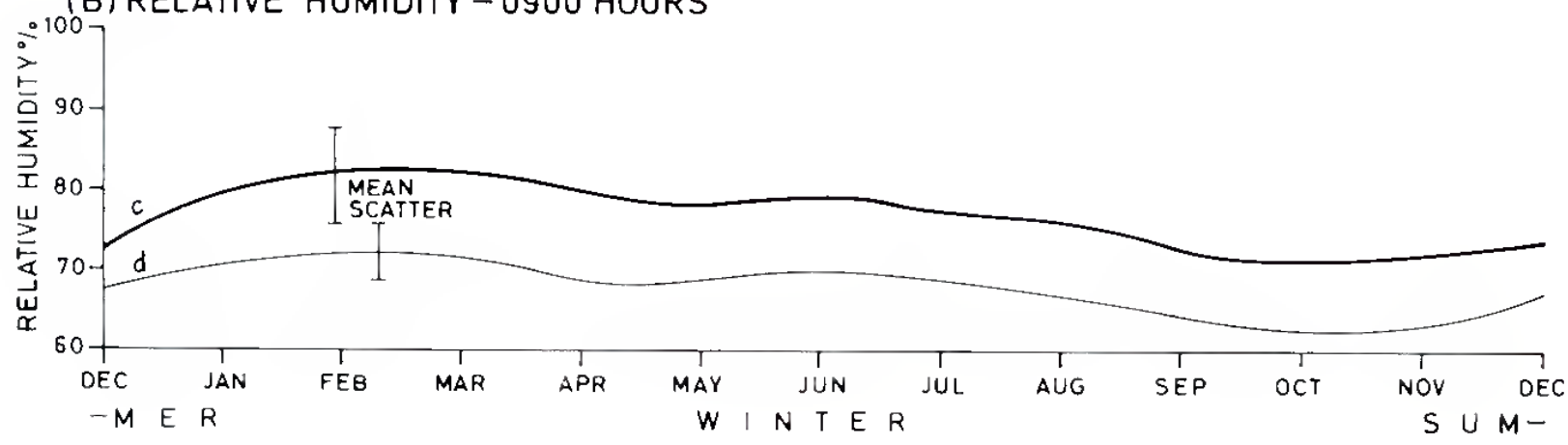

lig. Il Scasonal variation along the Great Barrier Recf coast of:

(A) Cloud amount: (a) $10-18 \mathrm{~S}$ plus $24-25 \mathrm{~S}$, (b) $19-23.8 \mathrm{~S}$,

(B) Relative humidity: (c) $1018 \mathrm{~S}$ plus $2425 \mathrm{~S}$, (d) $1923.8 \mathrm{~S}$. 


\section{IV \\ Tides}

Easton (1970) has descrihed the tides of Australia comprehensively and most of this section is based on his work, with references to the Australia Pilot and the Australian National Tide Tables. The Barrier Reef lies in two of Easton's zones, the North Queensland and the Mackay zones.

\section{TIDE LEVELS}

North Queensland zone (Cape York, 10.7 S, to 19.5 S, north of Mackay)

Cairns is taken as the standard port because its records are regarded as very reliable. The-tidal rise and fall is semi-diurnal in character with significant variation from springs to neaps ( 3.3 to $0.3 \mathrm{~m}$ at the equinoxes, March and September); see Fig. 12. There is considerable diurnal inequality, particularly in the height of successive high waters, amounting to over $1 \mathrm{~m}$ at times (Fig. 12). This should be borne in mind if one runs a ship

Fig. 12 Typical tide height records for three stations along the Great Barrier Recf coast (from Maxwell, 1968).

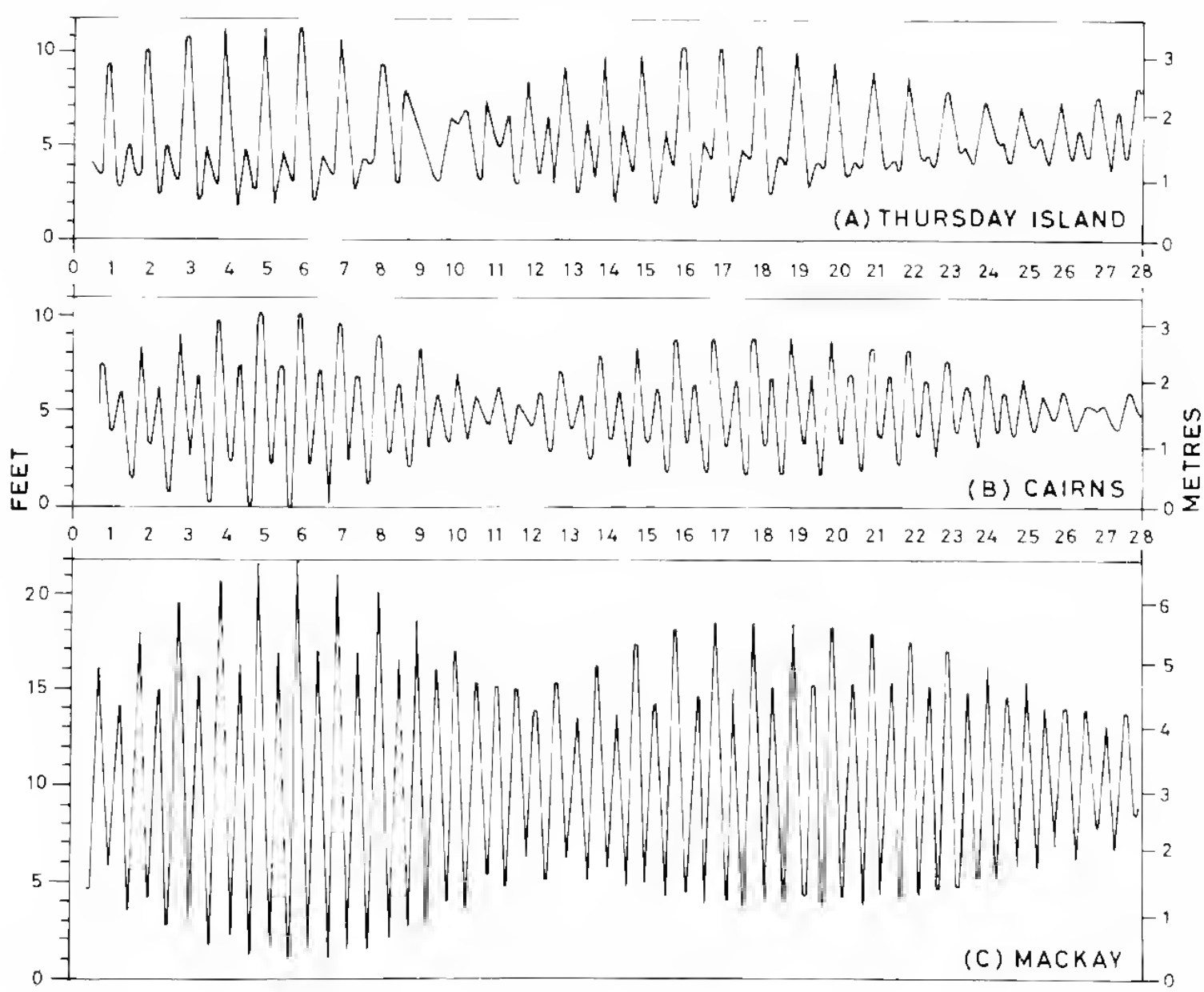


aground. Spring tides oceur 1 or 2 days before full or new moon. At neap tides there are usually one or two days of essentially diurnal tides.

'The tidal wave progresses eastward from the Coral Sea toward the shore and then north-westward north of Cairns, south-eastward south of Cairns (Maxwell, 1968, Fig. 11). lig. 13A shows the time of high water along the shore (full line) relative to that at Cains. 'l he tides oceur earlier on the reef (e.g. 15 min carlier at Green Is. compared to Cairns, 30 km to the west). "l'le dashed line in lig. 13A shows the time of high water at the outer reef, estimated from Maxwell's co-tidal chart (1968, liig. 41).

lïg. 1313, from Maxwell's co-range charl (1968, Fig. 42) shows that the tidal range increases somewhat north of (airns at the coast (full line) and at the reef (dashed line). Because of the very limited amount of tidal data other than at the shore stations, the reef values for phase and range must be regarded as only approximate.

lig. 14A from liaston (1970) shows the percentage frequency of occurrence of hourly lide heights (full line) and of low and high tide levels (dashed lines) at Cairns. 'The full line shows the frequency along the ordinate, in terms of the tide level at hourly intervals, for which the sea level is at or above the corresponding height on the abscissa, e.g. the hourly

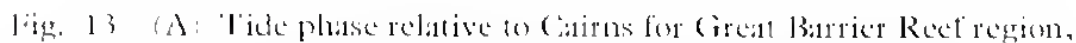

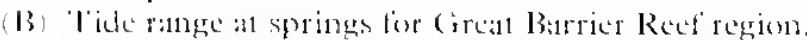

trull line shores, distod line outer recti.)

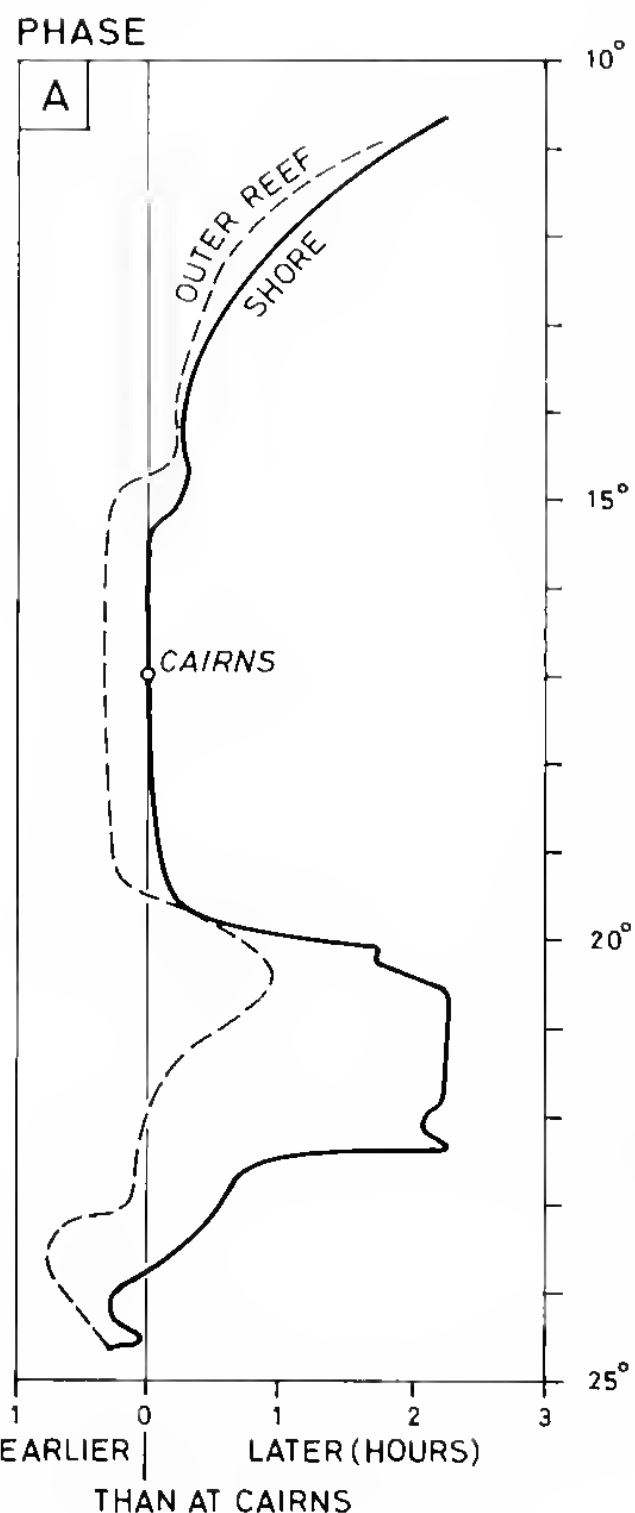

RANGE

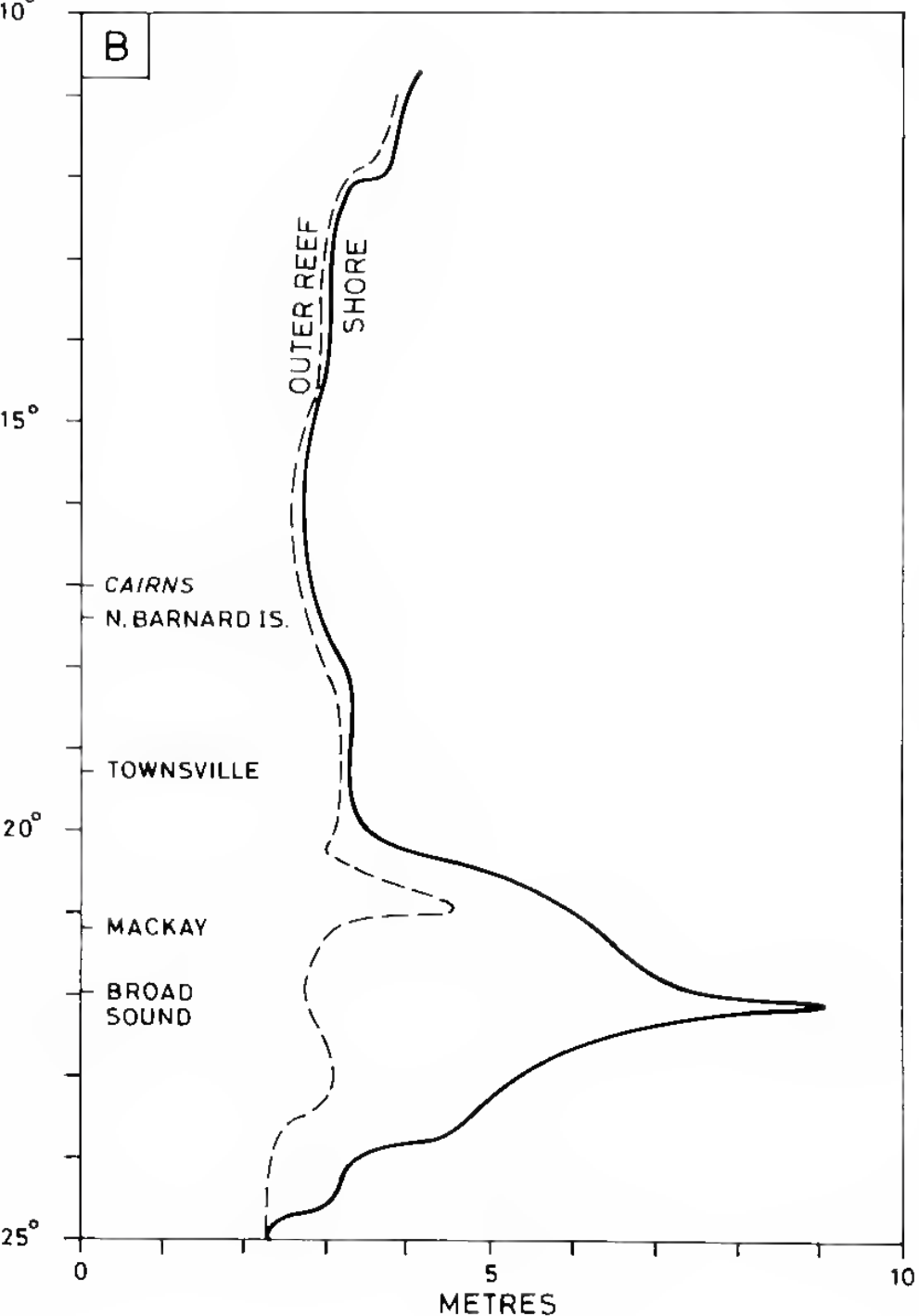


sea level is at $1.0 \mathrm{~m}$ (above datum) or higher for about $76^{\prime \prime}$ "of the time, at $1.5 \mathrm{~m}$ or higher for $43^{\prime \prime}$ " of the time, at $2.0 \mathrm{~m}$ or higher for $16^{\prime \prime}$, of the time, etc. 'The high tide line show's that the high water level oceurs at $1.0 \mathrm{~m}$ or higher on almost 100 " "of occasions, at $2.0 \mathrm{~m}$ or higher on $55^{\prime \prime}$ " of occasions, at $2.5 \mathrm{~m}$ or higher on $15^{\prime \prime}$ "of occasions, etc. The low tide curve shows that low water level is at $0.5 \mathrm{~m}$ or higher on $72^{\prime \prime}$ "of occasions, at $1.0 \mathrm{~m}$ or higher on 22 " of occasions, and at $1.5 \mathrm{~m}$ or higher almost never. This information may be uscful in estimating recf exposures in shallow waters. A minor point to note is that a few (of the lower) high tides occur below mcan sea level, because of the pronounced diurnal inequality of the high tides.

\section{Mackay zone labout 19.5 to $25 \mathrm{~S}$,}

The salient characteristic here is a very large tidal range, with maximal values in Broad Sound (22 S) south of Mackay (21.2 S).

The tides are semi-diurnal with marked inequality of the high tides (up to $1.8 \mathrm{~m}$ at the solstices) but little or none in the low tides (Fig. 12C). Eastonstated 'categorically' that the higher tides oceur during the night in winter and the day in summer. As the spring tide range is greater at the equinoxcs than at the solstices $(6.4 \mathrm{~m}$ compared to $5.8 \mathrm{~m}$ ) and the mean sea level is lowest in September, the lowest water levels occur in September-October and afford the maximum exposure of corals.

The spring tide reaches a maximum of over $9 \mathrm{~m}$ in Broad Sound (Fig. 13B).

Fig. 14B, from Easton, shows the percentage frequency of occurrence of hourly tide heights and of low and high tide levels for Mackay.

Fig. 13A shows that the delay in the tide, relative to that at Cairns, reaches a maximum of about 2.25 hours between 20.5 and $22.5 \mathrm{~S}$ and then decreases, while Fig. 13B shows the marked increase of tidal range to a maximum in Broad Sound and then a decrease to the south. At the outer reef the delay is less or negative (leading the tide at Cairns) and the amplitude is much less than at the shore.

Easton attributed these features (delay and increase in range at the shore) to the offshore break in the Barrier Reef and the presence of Broad Sound". As the outer reef directly offshore from Mackay is one of the more continuous stretches of the whole outer reef, presumably the 'break' to which he refers is the deep Capricorn Channel opening SE of Mackay. Other than this he attempts no explanation of the tidal features. Presumably the topography is the main cause, i.c. the existence of a basin to be filled (Broad Sound and Shoalwater Bay) together with the reduction in depth in the approaches, as in other estuaries. However, there are other regions on this coast which have similar topography, e.g. Princess Charlotte Bay (14 S) and Hervey Bay (25 S), which do not exhibit such extreme tidal features. Possibly the deep Capricorn Channel opening is the critical feature. Hervey Bay is open to the Coral Sea with no reefs but does not have as deep a channel as Capricorn Channel, while Princess Charlotte Bay has extensive inner reefs and a fairly continuous outer reef between it and the Coral Sea. (The Australia Pilot (1962) does mention radial flood and cbb flows near Princess Charlotte Bay, similar to those for Broad Sound to be described below, but less noticeable.) An alternative possibility is that the extensivc shoals of the Swain Reefs area slow the tidal wave and give rise to refraction and consequent focusing to Broad Sound.

\section{Torres Strait}

Technically this may not be a part of the Barricr Reef, but it is in the northern extremity of the region under review and, because of the unusual nature of its tides and currents, it warrants a bricf description, based on Easton (1970) and the Altstralian National Tide Tables (1976).

The Strait lics between the Barricr Reef on the cast with predominantly semi-diurnal tides, and the Gulf of Carpentaria on the west with chiefly diurnal tides. The largest semidiumal components in the east occur 2 days before full moon, whereas in the west they 

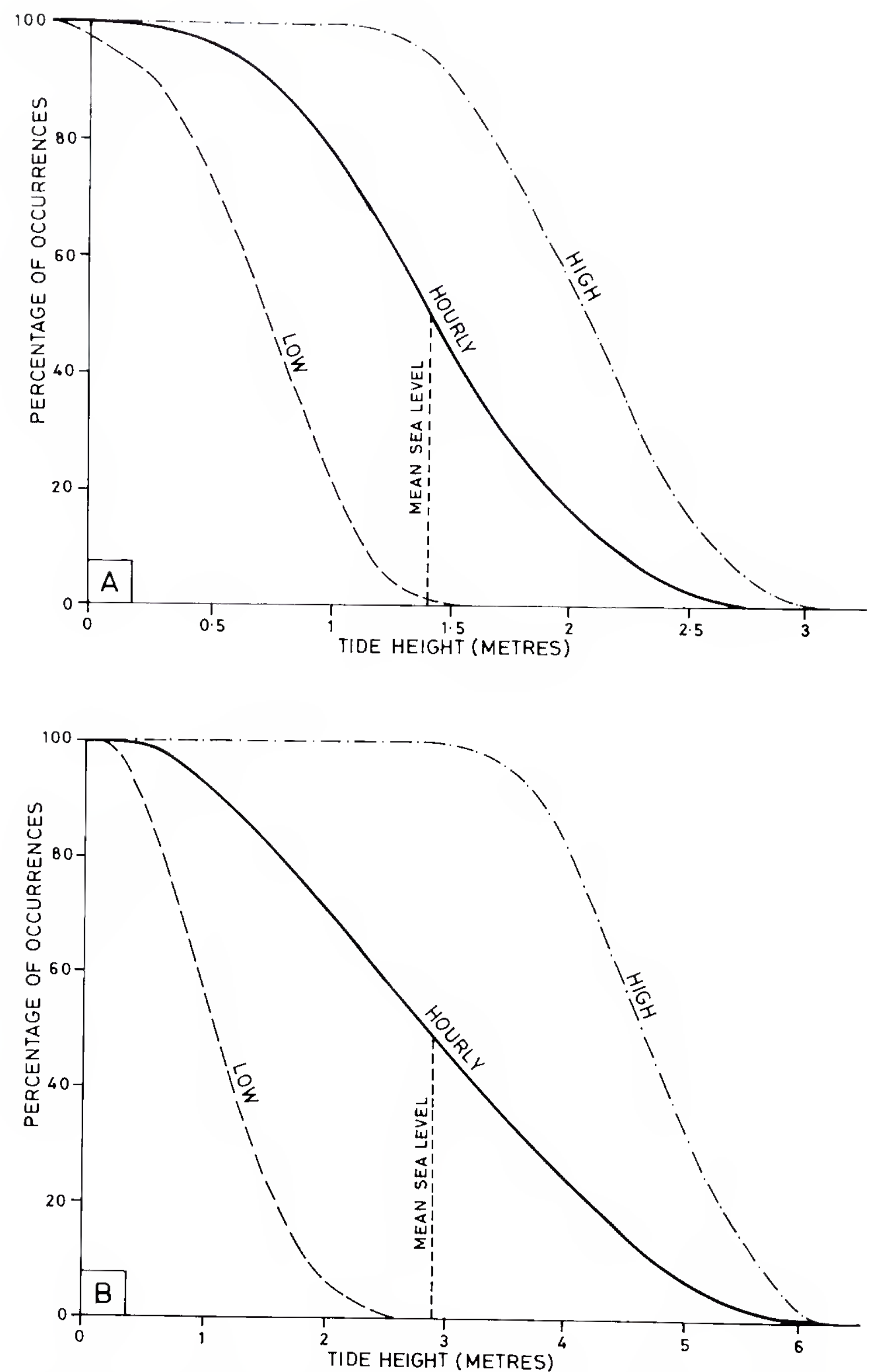
liig. L.t Amnual distributions ol recorded hourly tide heights and predicted high and low tides from
liaston, 1973): (A Cairns, (B) Mackay. 
occur 2 days after full moon; in the Strait they occur from 7 days before to 7 days after full moon. 'Thus it can be spring tides at one end of the Strait anct neaps at the other, and neap tides can occur at full moon. The diurnal tide is the same through the Strait. 'The character of the rise and fall is indicated in Fig. 12A. The information on tides is available for the southern quarter only of the gap between Australia (Cape York) and Papua New Guinea, as the northern part is shallow and not much used.

\section{MEAN SEA 1.EVEL}

\section{Annual eyele}

The monthly mean sea level (m.s.1.) shows an annual cycle, and three sets of measurements have been published. Values for selected locations are presented in Table 2. On the north-east coast of Australia, monthly mean values for Cairns, Townsville and Gladstone in the lnternational Geophysieal Year, July 1957 December 1958, showed a sharp peak in the autumn and a flatter minimum in spring (Hamon $\mathbb{E}$ Stacey, 1960). Easton's (1970) data for 1966-68 show less difference between highest and lowest m.s.l, The Australian National Tide Tables (1976) point out that monthly m.s.1. may vary by $0.07 \mathrm{~m}$ from year to year and that it can stand $\pm 0.3 \mathrm{~m}$ relative to the average for as long as a month.

It may be concluded that relative to the annual mean sea level, the monthly mean is likely to be about $0.15 \mathrm{~m}$ high in March April and $0.1 \mathrm{~m}$ low in September-Octoher.

In the North Queensland zone, Easton (1970) stated that the mean sea level is not related directly to the wind, in contrast to the Mackay zone where the mean sea level is attained under the influence of a $5 \mathrm{~m}$ s southeasterly wind, which is typical for most of the year (Fig. 4). He presented interesting examples (his Fig. 5.8.9) showing the response of mean sea level to wind changes. In particular, an increase of SE wind from the $5 \mathrm{~ms}$ normal to about $15 \mathrm{~m} / \mathrm{s}$ resulted in an immediate increase in mean sea level of $0.3 \mathrm{~m}$.

\section{Mean sea level and latitude}

Hamon \& Grieg (1972) drew attention to the fact that mean sea level apparently rises relative to geodetic levelling by $1.7 \mathrm{~m}$ from $30 \mathrm{~S}$ to $11 \mathrm{~S}$ along the east coast. This change is opposite in direction to that in North America and Europe where sea level falls

Table 2. Monthly mean sea level relative to annual mean sea level

\section{Location}

Highest

Variation in mean scalevel (m)

$\begin{array}{llllll}\text { Cairns } & 17 \mathrm{~S} & \text { April }+0.23 & \text { Oct.-Nov. } & -0.09 & 0.32 \\ \text { Townsville } & 19 \mathrm{~S} & \text { April }+0.27 & \text { Oct.Nov. } & -0.10 & 0.37 \\ \text { Gladstone } & 24 \mathrm{~S} & \text { April }+0.26 & \text { Oct. } & -0.10 & 0.36\end{array}$

Easton (1970):

$\begin{array}{llllll}\text { Cairns } & 17 \mathrm{~S} & \text { March }+0.13 & \text { Scpt. } & -0.10 & 0.23 \\ \text { Townsville } & 19 \mathrm{~S} & \text { March }+0.13 & \text { Sept. } & -0.11 & 0.24 \\ \text { Mackay } & 22 \mathrm{~S} & \text { March }+0.14 & \text { Sept. } & -0.14 & 0.28\end{array}$

Australian National Tide Tables (1976):

\begin{tabular}{|c|c|c|c|c|c|}
\hline Cairns & $17 \mathrm{~S}$ & Feb.-Apr. +0.12 & Sept. & -0.12 & 0.24 \\
\hline & & & & & \\
\hline Mackay & $19-22 \mathrm{~S}$ & Mar.-Apr. +0.12 & Aug.-Oct. & -0.10 & 0.22 \\
\hline
\end{tabular}




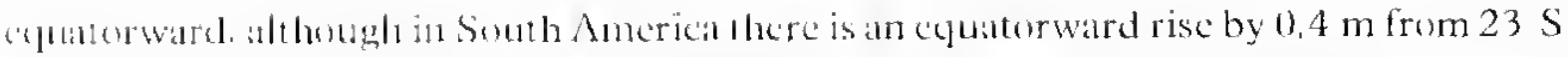
to . S. 'I'he rise oll Australia was not explained by the change in sea water density, and no

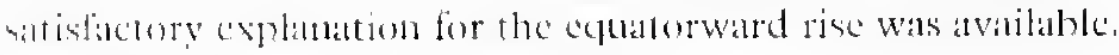

Ihe and of the semi-diurnal tide

This is the time intervis between the time ol new or lull moon and the time of the local spring lick. W' (19673b) has pointed out that the area Irom North Queensland to the Simmealu lstands is one of the few regions in the world where the age is negative, i.e. the spring ticke occurs before new or full mom (by 13 hours at lownille). Webb (1973a) strggested that this is due to a resonance in the Coral Sea with a period of about 1.97 evelesiday from ticlal dalla for Cairns).

\section{TIIDAL, C:URRIIN'I'S}

\section{North Quecusland and Mackay zones}

liaston (1970) stated, without qualilication, that in the North Queenstand \%one the flowd is lo the north and the chb to the sonth. However, the Australia Pilon (1962) states that the flexel is generstly to the north or north-west when north of North Barnard Is. (17.7 S) and to the south when south of that point. Exceptions are in the vicinity of Princess ( Chatlote bay $(14 S)$ and Broad Sound $(22 S)$. The latter description (in the P'lat) would appear wo be the more likely in view of the relative phases of the tide along the costst (Jig. 13A). In the vicinity of the outer reef, the directions mat be modified by the thows through the pisses which are into the lagoon (W or SW) on the flood and out (E or Nli) on the ebb. Speeds are greater in the narrow passes than in the wider ones, with villues up $601.5 \mathrm{~m}$ s during springs.

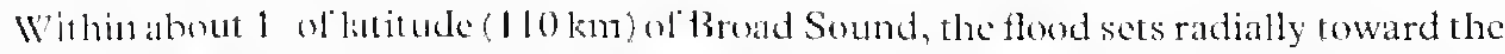
Sound and Sluatwater Bay and the ebh radially away. A similar pattern is observed over a smaller area around l'rincess (Charlote Bay (Amstratia Plot, 1962). In the vieinity of the Capricorn (iroup of islands and reels 23 to 26 S) the charts and Pilot note that the flood direction is 10 lle west, It is not clest how much of the llow to Broad Sound comes by this route and how much through the elear opening of Capricorn Channel $(22.5 \mathrm{~S})$ or through the Swain Recl's (2) to $22 \mathrm{~S}$ ).

the thal streams are gencrally semi-diurnal in charneter, flood and ebh being approximately opposite in clirection. North ol :about $21 \mathrm{~S}$, the diurnal inequality becomes mirked with the stronger streams (flood or ebh) some 50 " greater than the average, and the weaket streams $50 "$ "less than averige, Away from constrictions to the flow, the speed is about $0.5 \mathrm{~ms}$ in the sonthern hall of the lagoon and $0.25 \mathrm{~m} / \mathrm{s}$ in the north. Speeds of up 16) $2 \mathrm{~m}$ s are lound between islands and in the entrances to cosisinl inlets.

It shomkl be noted thit when the Sla 'tades are elfective, the current dae to these wincls in the open areas is stated to be greater than the tidal currents, and a continuing northerly drilt of the watter maly be expected with a tidal perturbation in speed. 'This minter is diseussed lurther is Section VIII, In the north, between about $1 \mathrm{I}$ and $15 \mathrm{~S}$, the NW' monsen wind drilt (in a southerly direction) may be greater than the tidal flood to the north, but the highter winds of the monson season generally result in the tidal current heing more important then than during the SE trades season.

\section{lorres Strit}

Altwough the ridal rise and fall has a marked diurnal character, the tidal currents are predominanty semi-diumal and equal in either direetion with maximum values up to $3.8 \mathrm{~m}$ s Anstraliam Natiomal Tide' Tuble's, 1976, Hammond Rock). There are considerable variatioms in speed in diflerent locations and further observations are being made ( $B, V$. Hatnon, personal communication). 


\section{V \\ Water Properties in the Lagoon}

The chief water properties used by physical oceanographers and for which there are some measurements for the Barrier Reef lagoon are temperature and salinity (independently as tracers and together for the calculation of density), dissolved oxygen and water transparency. There are some measurements of other chemical characteristics phosphate, nitrate, ete.). As the water column in the lagoon is generally well mixed, the surface values for the first three properties $\left(T, S\right.$ and $\mathrm{O}_{2}$ ) give a good idea of the overall distribution and will be deseribed first; comments on the vertical distributions will follow. Variations in the vertical are chiefly in salinity, associated with rainfall and river runoff, and oceur mainly near the coast.

\section{T'EMPERATURE}

\section{Surface temperature at specific locations}

Orr (1933a) deseribed the data obtained at a 'fixed' station in the main lagoon channel $5.5 \mathrm{~km}$ east of Low Isles (station at $16.35 \mathrm{~S}, 145.6 \mathrm{E}$ ) in $32 \mathrm{~m}$ of water. This station will be referred to hereafter as 'Low' Is.' Temperature (and other properties to be described later) was routinely measured at six depths from $0.5 \mathrm{~m}$ ('surface' value) to $28 \mathrm{~m}$, on 47 occasions at approximately weekly intervals for a year from 30 July 1938. The surface water temperatures are plotted in Fig. 15A from Orr's data. The minimum value was $21.5 \mathrm{C}$ in mid-August and the maximum $29.9 \mathrm{C}$ in Mid-February. Short term fluctuations were generally larger ( $c a .1 \mathrm{C}$ ) in summer than in winter. During the warming period from September to December, the water temperature was generally about $2 \mathrm{C}$ less than the daily mean air temperature. During the summer maximum the two were about the same, and during the cooling period the water was about $1 \mathrm{C}$ warmer than the mean air temperature. According to Orr, the wet and dry bulb thermometer readings indicated 'a certain amount of evaporation all the year but the differenee in vapour pressure between sea and air showed no seasonal variation.' He gave no calculation of the volume of water evaporated or of the heat loss.

Moorhouse (1933) presented data and a graph of the temperature taken at 0900 and $1500 \mathrm{hr}$ daily for almost a year at the surface and at $1 \mathrm{~m}$ depth at the Anchorage on the north side of Low Is., but he did not present any analysis of the data. Day to day variations in temperature at the Anchorage at $0900 \mathrm{hr}$ averaged $0.3 \mathrm{C}$ with a maximum of $1.5 \mathrm{C}$, while at $1730 \mathrm{hr}$ the average variation was $0.5 \mathrm{C}$ with a maximum of $4.2 \mathrm{C}$. Diurnally, the $1730 \mathrm{hr}$ temperature averaged about $1 \mathrm{C}$ higher than the $0900 \mathrm{hr}$ value, with a maximum of $4.5 \mathrm{C}$ higher. The larger differences both diurnally and from day to day usually occurred when the winds were light.

The Anchorage temperatures at $0900 \mathrm{hr}$ were close to the Low Is. station values, being on the average $0.2 \mathrm{C}$ lower, while the $1730 \mathrm{hr}$ values at the Anchorage were generally higher by about $1 \mathrm{C}$ on the average and up to $3.5 \mathrm{C}$.

Endean et al. (1956b) gave temperatures for August 1952 to August 1954 obtained from the Marine Branch, Commonwealth Department of Shipping and Transport, for 


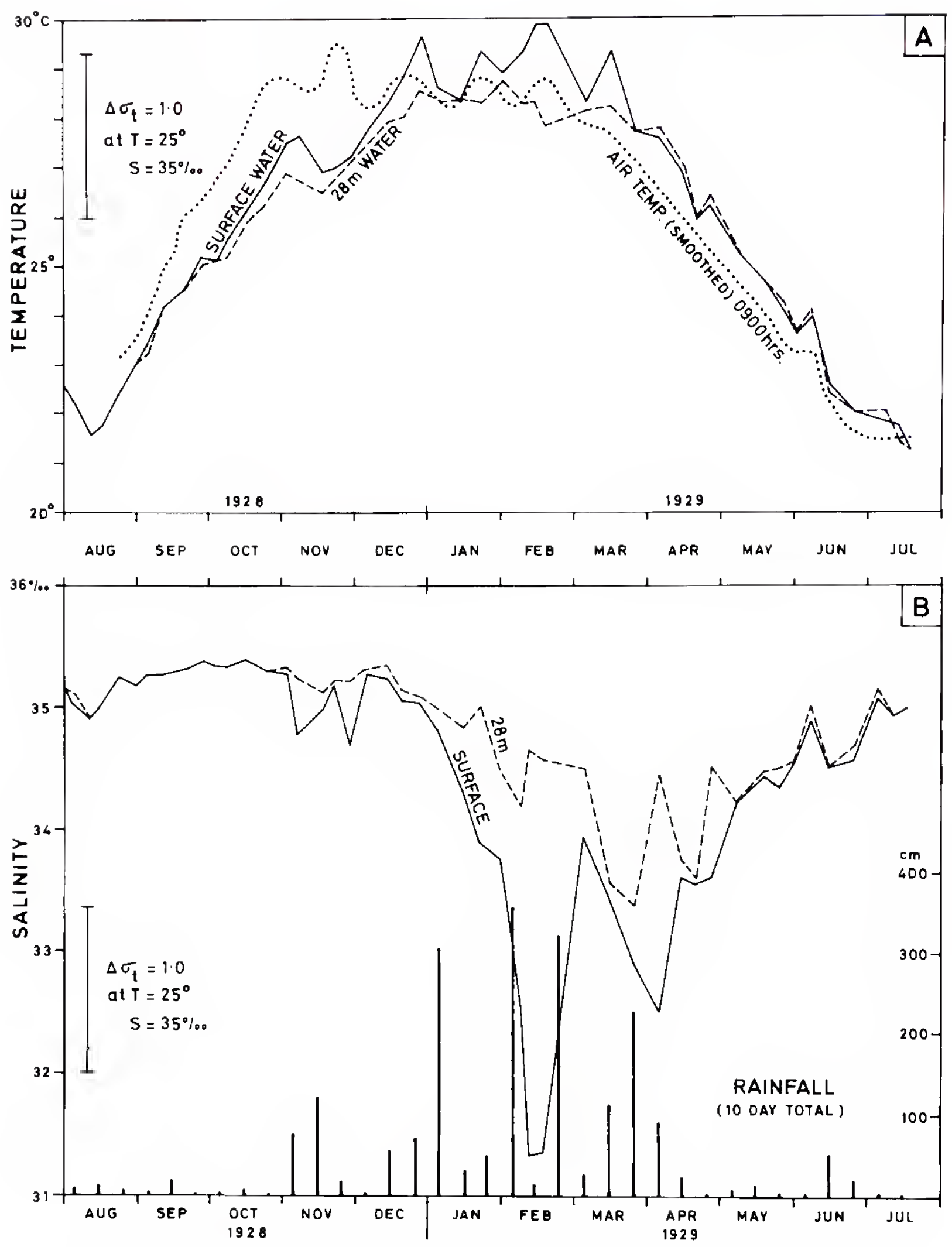

Fig. 15 At Low Is. station, Great Barrier Reef (16.4 S, 145.6 E), one year's records (data from Orr, 1933a) of:

(A) Water temperature: full line $=$ surface, dashed line $=28 \mathrm{~m}$ depth, dotted line $=$ smoothed air tempcrature,

(B) Salinity: full line $=$ surface, dashed line $=28 \mathrm{~m}$ depth; and rainfall by 10 -day periods. 
four islands. Unfortunately only the monthly fange of values from 15 or more observations per month) was given and not the mean value. If one takes the mean of the range bars shown, the Low Is. values for $1952-54$ average $1.0 \mathrm{C}$. lower $2.5 \mathrm{C}$ maximum! than Orr's values, while the annual range of the moans is $6.4 \mathrm{C}$ against Orr's $8.0 \mathrm{C}$. Although the location and procedure for obtaining the Marjne Branch values were not stated, the differences suggest that year to year variations may be expected.

In February, at stations 130 to $180 \mathrm{~km}$ north of Low Is., the temperatures were within $0.5 \mathrm{C}$ of those at Low 1s., while in Papuan Pass (16.8 S) and in Cook's Passage $(14.5 \mathrm{~S}$. the temperature was slightly lower than at Low Is. Between August and November at a station in Trinity Opening (east of Low Is.) the water was IC warmer than at Luw Is. At these times, then, temperature did not change much over about 2 of latitude $(220 \mathrm{~km}$ ) along the lagoon in this region. Orr briefly summarised temperature measurements (presumably surface values) made by the Commonwealth Navigation and I.ighthouse Scrvice at positions along the lagoon northward from $25 \mathrm{~S}$ for several ycars and quoted a maximum recorded temperature of $28.9 \mathrm{C}$, the same as the maximum at Low 1s., and a minimum of $17.8 \mathrm{C}$ at the south. He also noted that the maximum range of temperature during one month from south to north was $7 C$ and the minimum range was less than IC. (this must have been during the summer; see Fig. 17). Orr gave no further data from this source.

Kenny (1974) measured the sea temperature in the top $25 \mathrm{~cm}$ of $\mathrm{Hatcr}$, and the air temperature above the water on some occasions, at the seaward end of the Townsville Harbour eastern breakwater $(19.25 \mathrm{~S}, 146.83 \mathrm{E})$ at irregular intervals and varying times of day during 1961-62, 1966-67, 1968-69 and at weekly intervals at 1400 hr EST during 1970-71, making a total of 212 observations. Fig. 16 (upper curve) presents Kenny's overall mean values by month (joined by a curve) and the ranges of values observed in each of the years (vertical bars). (The individual values were not tabulated in Kenny's paper.) The mean values show a minimum of $21.8 \mathrm{C}$ in July and a maximum of $31.2 \mathrm{C}$ in January (compared with $21.5 \mathrm{C}$ and $29.9 \mathrm{C}$ in a single year at Low Is. The individual tempcrature readings were plotted but not identified by year; the montly ranges of temperature for the four years vary from $2.0 \mathrm{C}$ to $4.4 \mathrm{C}$, which is not negligible compared to the annual range of means of $9.4 \mathrm{C}$. Kenny pointed out that the range of values in one year may lie completely outside that for another year for the same month, c.g. March and April.

Kenny stated that water temperature $\left(\mathrm{T}_{w}\right.$ ) was linearly related to air temperature $\left(\mathrm{T}_{\mathrm{H}}\right)$ at $1 \mathrm{~m}$ above the water surface (in the $1970-71$ series) by the relation: $T_{w}=0.83 \mathrm{~T}_{4} \mid 3.31$.

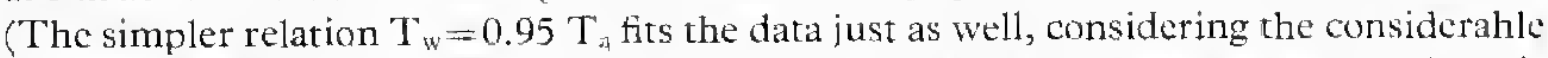
scatter in the $T_{w}, T_{a}$ correlation plot.) Both formulae give a sea temperature less than air temperature (over the range of values recorded) all year round, although Kenny did not remark on this. This result contrasts with Orr's (1933a) note that water temperature was less than air temperature during the spring warming season, the same during the period of maximum temperatures, and greater during the cooling season (sec Fig. 15 A). Possibly Kenny's result of constantly cooler water than air is an artifact arising from the fact that in deriving the water air tempcrature relation he lumped together all his 1970-71 data (inis Fig. 3), not attempting to distinguish seasons. However, more than $90^{\prime \prime}$ "of the points on his Fig. 3 plot of $T_{w}$ versus $T_{a}$ show the water temperature lower than the air temperature which does suggest predominantly cooler water than air (as his data points were taken at uniform intervals of time).

Hedley $(1925 \mathrm{c})$ presented a series of daily $(0900 \mathrm{hr})$ measurements of temperature of a bucket sample drawn from $1.8 \mathrm{~m}$ depth below the surface at the Pile Lighthouse $(27.3 \mathrm{~S}$, 153.2 E) in Moreton Bay for a year from 1 June 1924. Although this location is a little 
south ol the present area under review, it is included here because of the paucity of data for lae Reef area, and becallse it is one of only 1 wo series of daily observations available. The monthly means and ranges of values are presented in ligh. 16 (hower curve). The cycle is secn 10 be similar to that at $\mathrm{I}$. ow Is. and Townsville, although the maximum at Townsville occurs a month earlier than at the other two locations. 'The monthly ranges at Townsville (0.5C: 10 4.9) : over four years) and Moreton Bay (1.3C: to 4C: ) are greater than at Low 1.s. (0.60 $102(;)$. In the Moreton Bay series the change between sucessive days averages 0.5C: will $85^{\prime \prime}$ " of changes being 1.16 , or kess and the maximum being $2.2 C$.

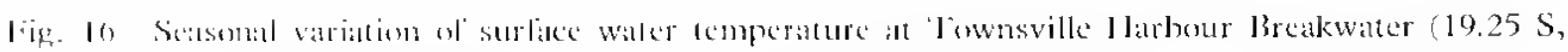

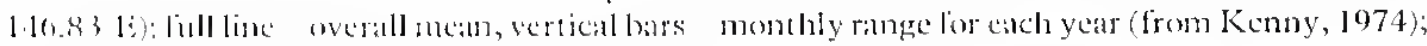

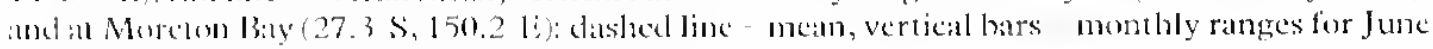
192.1 to Maly 19.25 (lirm Itedley, 1925b).

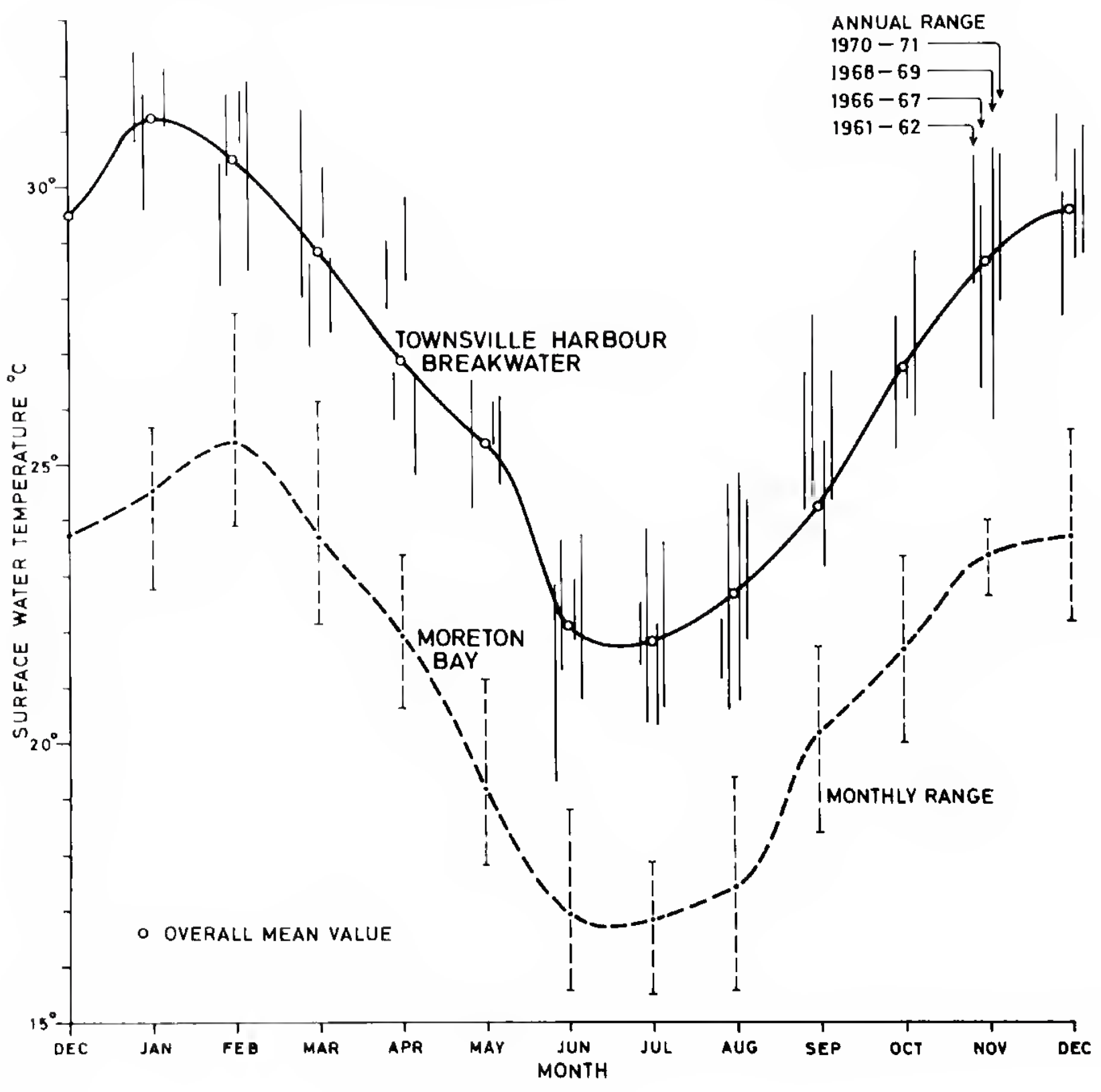




\section{Surface temperatures along the lagoon}

Aurosseau (1938) transcribed some records of surface water temperature and specific gravity made by Capt. Ogura en routc between Nagasaki and Sydney and return. Values in the Barrier Reef lagoon are prescnted in 'lable 3. 'These temperatures are similar to those given by Brandon, discussed below (sec Fig. 17).

Table 3. Surface water temperature, air temperature, and specific gravity in the Barrier Reef Lagoon. (Data from Aurosseau, 1938)

\begin{tabular}{|c|c|c|c|c|c|c|}
\hline \multirow{2}{*}{$\begin{array}{l}\text { Tine } \\
\text { thr }\end{array}$} & \multirow{2}{*}{$\begin{array}{c}\text { Date } \\
\text { (1928) }\end{array}$} & \multirow[b]{2}{*}{ Lat. } & \multicolumn{3}{|c|}{ Temperature $/ \mathrm{C}$} & \multirow{2}{*}{$\begin{array}{c}\text { Sp. Gr } \\
154\end{array}$} \\
\hline & & & Water & & dir & \\
\hline 1751 & $28 \mathrm{July}$ & $9.6 \mathrm{~S}$ & 25.0 & \multirow{2}{*}{$\Delta \mathrm{T}=3.8$} & 24.6 & 1.0253 \\
\hline 0630 & 3 Aug. & $24.1 \mathrm{~S}$ & 21.2 & & 17.1 & 1.0264 \\
\hline 0636 & 30 Aug. & $9.7 \mathrm{~S}$ & 25.0 & \multirow{2}{*}{$\Delta T=3.4$} & 25.0 & 1.0259 \\
\hline 0600 & 25 Aug. & $24.6 \mathrm{~S}$ & 21.6 & & 21.4 & 1.0264 \\
\hline
\end{tabular}

Brandon (1973) wrote a review of some of the water properties of the Great Barrier Reef province, using (a) his own observations (temperature mcasured with bathythermograph and rcversing thermometers) collected during four cruises between September 1967 and August 1968, (b) those of Orr (1933a) and Moorhouse (1933), and (c) data from the CSIRO Division of Fisheries and Oceanography, described in his text as unpublished, and not referenced in his bibliography. (These data are probably from the CSIRO data bank from which the ir 'Oceanographic Charts, Tasman and Coral Scas' were prepared-present reference CSIRO, 1974.) Brandon generally did not distinguish the data sources in his review and unfortunately gave inadcquate information to judge the statistical significance of his mean values and ranges. (Sec note at end of Chapter X.)

Brandon (1973, Fig. 3) presented graphs of mcan temperature against latitude by 1 intervals for January to Novcmber (December being omitted because of inadcquate data although Dccember values were referred to in his text). These graphs arc mostly very irregular and lines for individual months cross over each other apparently at random. $\mathrm{He}$ gave no indication of numbers of observations but it is difficult to believe that the long term average values would be as irregular as those in his plots. He summarised the surface temperature extremes as:

\begin{tabular}{cccc} 
Temperature & North & Contre & South \\
\cline { 1 - 1 } $\begin{array}{c}\text { Maximum } \\
\text { Minimum }\end{array}$ & $\begin{array}{c}\text { January } \\
\text { June-July }\end{array}$ & $\begin{array}{c}\text { January } \\
\text { to }\end{array}$ & $\begin{array}{c}\text { February } \\
\text { July-August }\end{array}$ \\
\hline
\end{tabular}

These observations agree with the maxima shown in Fig. 16, but the Moreton Bay minimum in the extremc south is earlier than Brandon suggested.

To show the seasonal cycle and the latitude variation, Brandon's (Fig. 3) temperaturc values were averaged by month for zones 10.5 to $14.5 \mathrm{~S}, 15.5$ to $19.5 \mathrm{~S}$, and 20.5 to $24.5 \mathrm{~S}$ in an endeavour to smooth the data; temperature/time plots are presented in Fig. 17. Even with this averaging there is still considcrable scatter remaining, particularly in the January to May period.

Sea areas around Australia (Roy. Neth. Met. Inst., 1949) has monthly charts for sea surface temperature averaged by 1 squares with whole number isotherms drawn on the plots. For the Barrier Reef region, temperature/time plots drawn from thesc data show variations similar to those in Fig. 17, but the absolute values average about $0.7 \mathrm{C}$ lower 
than those in Fig. 17. There are much larger numbers of values ( 30 to 150 " per 1 square) than Brandon can have had, but despite this there is considerable scatter $( \pm 0.5 \mathrm{C})$ in some areas of the l)utch data and the positioning of the isotherms in the charts is by no means unequivocal. In addition, the original data will have been taken with a variety of instruments, probably not calibrated frequently, so the scatter is not unexpected. Thus, Brandon's data and the Dutch data are probably reasonably consistent.

The Marine Branch values quoted by Endean et al. (1956b) for August 1952 to August 1954 compare with Fig. 17 as follows:

\section{Station}

Booby Is. $10.7 \mathrm{~S}$

Low Is. $\quad 16.6 \mathrm{~S}$

Trent Is. $20.5 \mathrm{~S}$

Pine Is. $21.5 \mathrm{~S}$

\section{Marine Branch ralues azerage:}

0.1C lower Jan.-June than Fig. 17, NORTH; 1.0C higher July-Dec. than Fig. 17, NORTH,

$1.0 \mathrm{C}$ lower for the year with minimum difference in winter and maximum of $2.5 \mathrm{C}$ lower in Oct.,

Less than $0.1 \mathrm{C}$ difference from Fig. 17, SOUTH.

The range of temperature between annual maximum and minimum, irrespective of month, for each degree of latitude from Brandon's Fig. 3 is shown in Fig. 18. Also included are the annual ranges for Low Is. (Orr, 1933a), Townsville (Kenny, 1974) and Moreton Bay (Hedley, 1925c). The first and last are close to the mean of Brandon's data but the Townsville value is considerably higher. Kenny (1974) attributed the larger Townsville range (than at Low Is.) to the 'more oceanic locality' of the Low Is., and also noted that the range between extreme temperatures at Townsville (12.4C) compared more nearly with the extreme range at the Low Is. Anchorage $(12.7 \mathrm{C})$. However, the latter range is between the lowest $0900 \mathrm{hr}$ reading for the year at the Anchorage and a

Fig. 17 Scasonal variation of surface water temperatures along the Great Barrier Recf, inshore stations (data from Brandon, 1973). North zone-10.5 to $14.5 \mathrm{~S}$, Centre zone-14.6 10 19.5 S, South zone-20.5 to $24.5 \mathrm{~S}$.

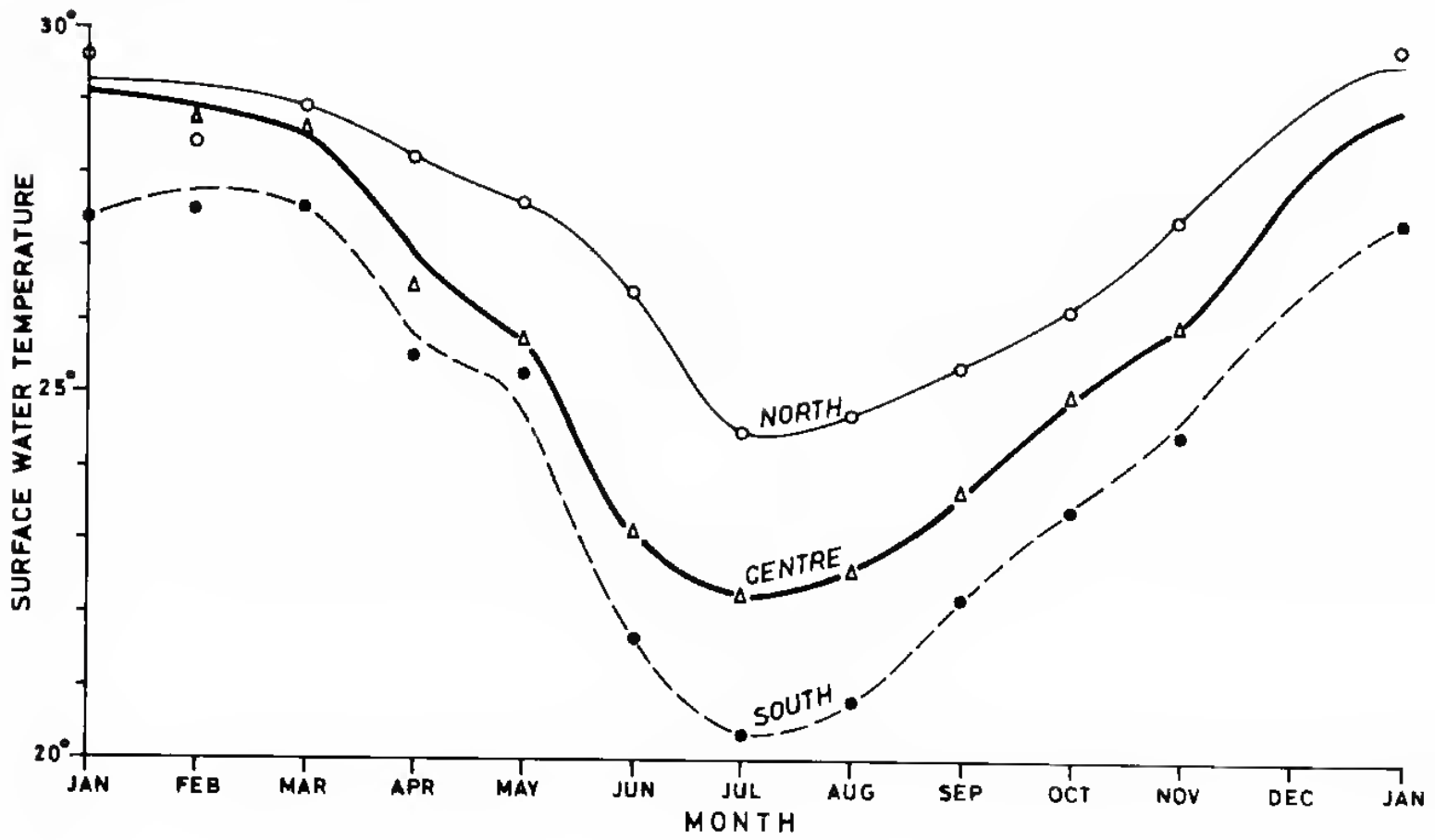


pronounced peak in $1730 \mathrm{hr}$ readings which are generally higher than at $0900 \mathrm{hr}$. A morc realistic figure for the Anchorage would be 10.0C for the $0900 \mathrm{hr}$ range. Therefore the higher than average range for Townsville may be attributable to the location being very close inshore where surface water property ranges are often greater than those offshore due to the presence of river runoff giving a more stable surface layer.

It may be noted that the fairly detailed Low Is. records (Orr, 1933a) showed the highest water temperature in December through March but there were four subsidiary maxima during that period, while the daily Low 1s. Anchorage data (Moorhouse, 1933) showed a series of subsidiary maxima and minima of about 25 days perjod during December through March. The warming and cooling periods were less irregular. The fluctuation in surface water temperature in the north in summer might be due to more frequent periods of light winds during the NW monsoon, allowing greater surface layer heating than in the south where mixing induced by the SE trade winds may be expected throughout the year. Brandon (1973) commented on two periods of lower temperatures between 14 and $15 \mathrm{~S}$ and remarked (p. 198) that "This area of the shelf is unique in another respect as it contains the large, shallow Princess Charlotte Bay indentation of the coast.' It is not clear why Princess Charlotte Bay was considered topographically unique as there are other similar areas along the coast, such as Halifax Bay (19 S) and Broad Sound ( $22 \mathrm{~S}$ ), He continued, "It is felt that the water temperatures here are a combination of shelf conditions, wind and weather. This ared is somewhat more independent than other shelf areas immediately north or south in that a larger number of factors can influence the water column here,' The statement is grammatically faulty and very vague, and its meaning is not clear.

\section{Sub-surface temperatures}

At the Low Is. station (Orr, 1933a) the difference between the surface and the $28 \mathrm{~m}$ depth values was generally small, $38^{\prime \prime}$ of the differences being less than $0.1 \mathrm{C}, 60^{\prime \prime}$ less than $0.2 \mathrm{C}$ and only $15^{\prime \prime}$ "were greater than $0.5 \mathrm{C}$. As may be seen in Fig, 15, the large values occurred during the summer when the surface layer had a low salinity and the upper part of the water column was more stable than usual. The surface water was generally warmer than the $28 \mathrm{~m}$ water during spring and summer. For $28^{\prime \prime}$ "of the stations, the surface water was cooler during the autumn when the water was losing heat, but the water column was stable or neutral within the probable accuracy of measurement.

Fig. 18 Annual range of surface water temperature versus latitude for Great Barrier Reef. Full line and circles $=$ mean for inshore stations (from Brandon, 1973), dashed line $=$ Coral Sea (from Roy, Neth. Met. Inst., 1949), dots = zone averages outside reef (data from CSIRO, 1974).

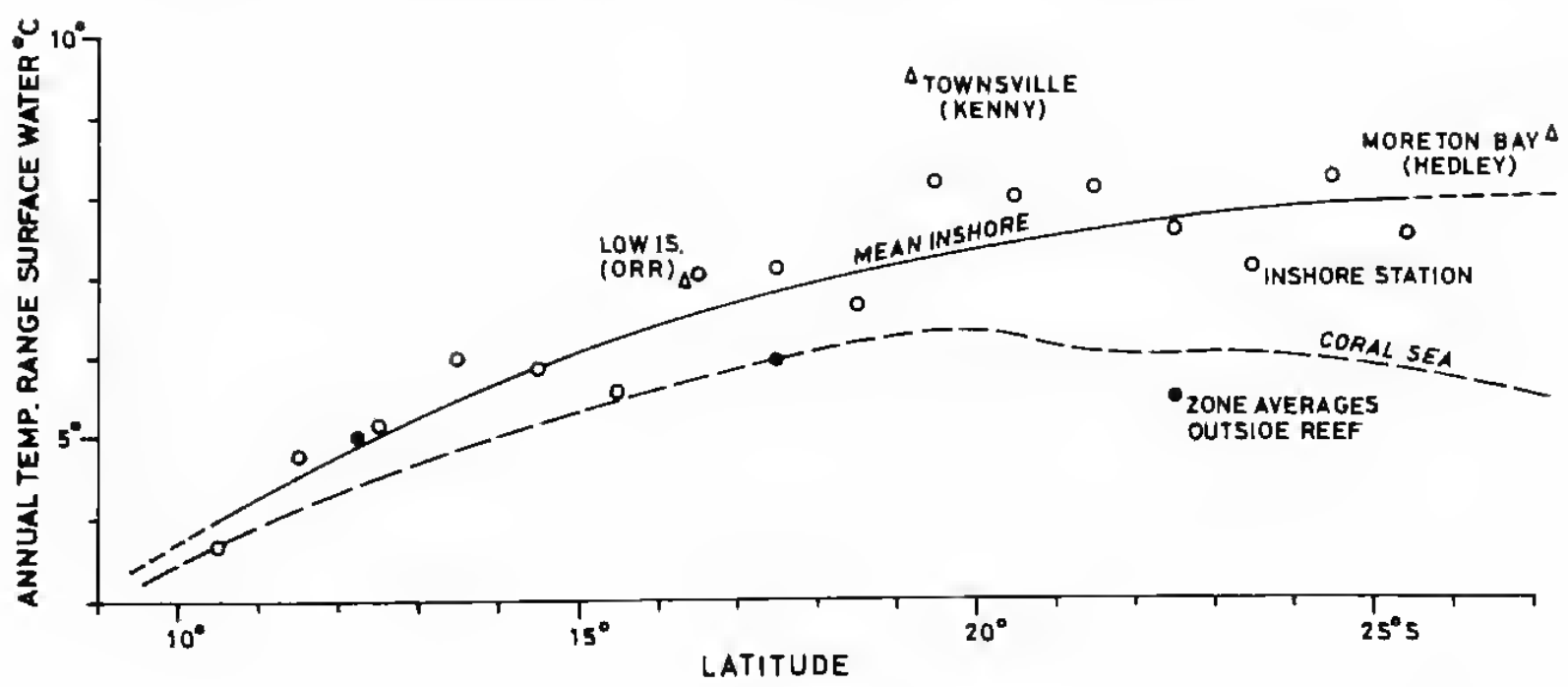


Brandon (1973) described the vertical temperature distribution for the lagoon, although only qualitatively, essentially as summarised above for Low Is. Hc also stated that in the Capricorn Channel, vertical temperature variation is only $\mathrm{I}$ to $2 \mathrm{C}$ on the average' but did not say over what depth range nor which way the temperature ehanged with depth. (This channel has depths to $120 \mathrm{~m}$ close to the recf line and increases to over $400 \mathrm{~m}$ just outside.) Brandon also stated that his bathythermograph measurements over the slelf revealed essentially isothermal water with a few tenths of a Celsius degree warming in the upper few metres, but he did not state which depth range bathythermograph he was using (standard depth ranges are to 60,135 or $270 \mathrm{~m}$ ).

\section{SALINITY}

Surface salinity at a specific location

The annual cycle of values for 1928-29 at Low Is. is shown in Fig. 15B from Orr's (1933a) data. Orr commented that the maximum values $(35.40$ at the surface and 35.47 at $15 \mathrm{~m}$ in October) are "a little lower than would be expected for this latitude' but he did not say on what he based his cxpectation. He attributed the low values to "the proximity of the coast and the considerable land drainage' without giving any data for the latter, although he did quote a few rainfall figures for the coast. He attributed the variations in salinity chicfly to reduction by rainfall, with subsequent return to higher values due 'to wind mixing more saline water upward.' He did not mention the possibility of increase duc to evaporation, having previously noted that the "difference between the vapour pressure of water and air show's no importanı seasonal variation.' Orr was probably in error in dismissing evaporation as unimportant because the rate of loss of water vapour (and henec increase in salinity as well as loss of heat) is also a function of wind speed, increase of which increases the eddy diffusive transport from the sea surface. In the Low Is. area the winds are steadiest and strongest in the dry season (e.g. Fig. 4, Cooktown) and evaporation could be a significant factor. (Brandon did suggcst evaporation as being a significant factor as will be mentioned later.)

Orr noted the minimum surface salinity of 31.3 , remarked that lower values might have occurred in the intervals between occupations of the station, and warned that minimum values must be expected to fluctuate considerably from year to year. $\mathrm{He}$ commented that on 28 February the Daintree River $(17 \mathrm{~km}$ NW of Low Is.) was in flood and its turbid water was visible at Low Is. This river is in a moderately high runoff area but no figure for its flow is given in the Australian Water Resources Council's Stream Galging Information (1971). (My estimate, $0.15 \times 10^{116} \mathrm{~m}^{3} / \mathrm{yr}$, is a litrlc less than the coastal average of $0.2 \times 10^{36} \mathrm{~m}^{3} / \mathrm{yr}$ ). Orr also remarked on the rapid increase in salinity after the reduction due to rainfall, e.g. in late February and in mid-April.

The vertical dashed bars in Fig. 15B show the 10-day accumulated rainfall from Orr's daily values, as an indication of the relationship between precipitation and surface salinity decrease, e.g. a short term effect in November and a longer term and more marked salinity decrease in January to March, presumably associated with the incrcased rainfall. If these events are directly correlated, the response of salinity is rapid, within a few days at most. However, the heavy rainfall in the last week of February is associated with a sharp rise of salinity, which is difficult to understand. One possibility is that some rainfalls are very localised and this, combined with currents, may move a lowered salinity patch of water into an area where observations were being made but which did not itself receive much rain. Alternatively, a lowercd salinity patch after rainfall might be moved away from the site before the next observation was made. 


\section{Surface salinity along the Iagoon}

Brandon (1973, Figs 4, 5 and 6) presented graphs of monthly mean and of maximum and minimum values of surface salinity for restricted latitude bands from 11 to $12 \mathrm{~S}, 16$ to $17 \mathrm{~S}$ and 22 to $23 \mathrm{~S}$. The average values are presented here in a single figure (o) facilitate comparison (Fig. 19) and smoothed curves are drawn through them. "The maximum and minimum value curves presented by Brandon are onitted from Iig. 19 to avoid confusion. Because the number of observations on which they are based is not given, their significance is uncertain but the range between maximum and minimum values, varying from about $0.06:$ to $3.0^{\circ}$, is very wide. The greatest range, for April in the centre zone, is almost as large as the mean annual range for that region 3.7 ).

It is seen that the minimum value occurs in the first part of the year (Fehruary to May) for all zones, with the maximum in the last third. The lowest values occur in the centre zone (in association with the coastal rainlall maximum, Fig. 7), and this minimum dissipates more rapidly than that in the north zone. The difference in behaviour between the north and centre zones is puzzling because the distribution in time of the rainfall is the same in these two zones (Fig. 8) and the centre zone has rather more rain on the average. One possibility is that Brandon's figures were based on limited data and the difference in behaviour in Fig. 19 is associated with the variable nature, in both time and space, of the rainfall in this region. On the other hand, it is seen that the Low ls. data, for a different period, compare well with Brandon's centre zone curve (apart from the April value). Another possible explanation is that Brandon's centre zone curve is for 16 to $17 \mathrm{~S}$ only, and he did state that this salinity time curve is the "most extreme for the centre zone", although the highest rainfalls occur between 17 and $18 \mathrm{~S}$. Brandon himself attributed "the great annual range of salinity ... not only to the high rainfall and runoff (no values given) during the monsoon scason but also to craporation which can create localised zones of high-salinity water.' 'This latter statement is surprising because the great range in the centre zone is due chiefly to the very low wet season value, not to a high dry season salinity, i.e. to evaporation. In fact, the centre zone has the lowest maximum salinity of the three. Brandon attributed the high winter salinities in the north to evaporation but produced neither quantitative nor qualitative evidence to support this, although he did make meteorological measurements including wind speed and wet and dry bulb air temperatures. It is agreed that cvaporation is likely to be significant during the dry months but it would have been more convincing to have given some actual estimates from the meteorological data.

Figs. 11 and 4 together do support the thesis that evaporation is likely to be significant in the spring and early summer (September to November) because the relative humidity decreases during this period, while the winds are steadiest and relatively strong at this time. Evaporation is usually calculated from a rclation of the form:

$$
\begin{aligned}
\text { Evap. }\left(\mathrm{gm} / \mathrm{cm}^{2}, \mathrm{sec}\right)= & \text { Constant } \mathrm{x} \text { wind speed } \mathrm{x} \text { (Vap. press. at water surface-Vap. } \\
& \text { press. in air at } 10 \mathrm{~m} \text { height) }
\end{aligned}
$$

and rough calculations suggest that the potential for evaporation in October-November is 1.5 to 2.5 times that for January-February for the north zone, 1.3 times in the centre zone and 1.1 times in the south zone.

Wyrtki (1961b) made some estimates of evaporation values for the Arafura Sea and Timor Sea, where cvaporation exceeded precipitation from April to November and June to November respectively. He obtained net rates of loss of about $25 \mathrm{~cm}$ /month from the water column. This rate in a column of depth $30 \mathrm{~m}$ would give rise to an increase in salinity of about 0.25 ; per month or about 0.75 ; in three months of relatively low humidity. This is about the same as the amount noted in the north zone in the second half of the year (Fig. 19). Thesc rough calculations support the suggestions that evaporation is a significant factor in increasing the salinity in the dry season in the lagoon. 
The small annual change in salinity in the south (22 to $23 \mathrm{~S}$ near Capricorn Channel) was attributed by Brandon to the area being relatively open to mixing with the Coral Sea waters (ignoring the fact that the Coral Sea waters have an annual salinity cycle) and to the predominance of the SE Trades throughout the year (presumably to their mixing effect). He could also have aclded that the south zone rainfall is more uniformly distributed through the year than that further north, and the annual amounts are only about one-half of those in the centre and north zones, and the lagoon is much wider here than further north.

Unfortunately, Brandon did not specify where the salinity values used for the above described graphs were obtained in the lagoon. The inferenee is that they were obtained in the ship channel which is generally close to the land (on the average about one-quarter of the distance from shore to outer reef). This point is relevant to the next section.

\section{Surface salinity gradients aeross the lagoon}

The salinity variations shown in Fig. 19 are for locations near the land, and the marked reductions in summer are assumed to be due both to direct rainfall on the sea and to river runoff from the land. Further offshore, in the lagoon, the latter contribution of fresh water will not apply directly. In addition, as the reef is approached, the proximity of the Coral Sea waters may be expected to moderate the seasonal variations (although the Coral Sea waters show significant seasonal variation, described later). In consequence, one may expect that during the wet season the salinity will increase from the shore to the reef, while in the dry season, when the inshore salinities increase, a decrease of salinity from shore to reef may be expected. A few scattered tests of this thesis are available from Orr's (1933a) and Brandon's (1973) data, as presented in Table 4. These observations are reasonably consistent with the thesis but are few.

Fig. 19 Scasonal variation of surface water salinity for one degree wide latitude strips, North zone-1 1 to $12 \mathrm{~S}$, Centre zone-16 to $17 \mathrm{~S}$, Southzone 22 to $23 \mathrm{~S}$ (datalfrom Brandon, 1973), and for Low Is., $16.4 \mathrm{~S}$ (data from Orr, 1933a).

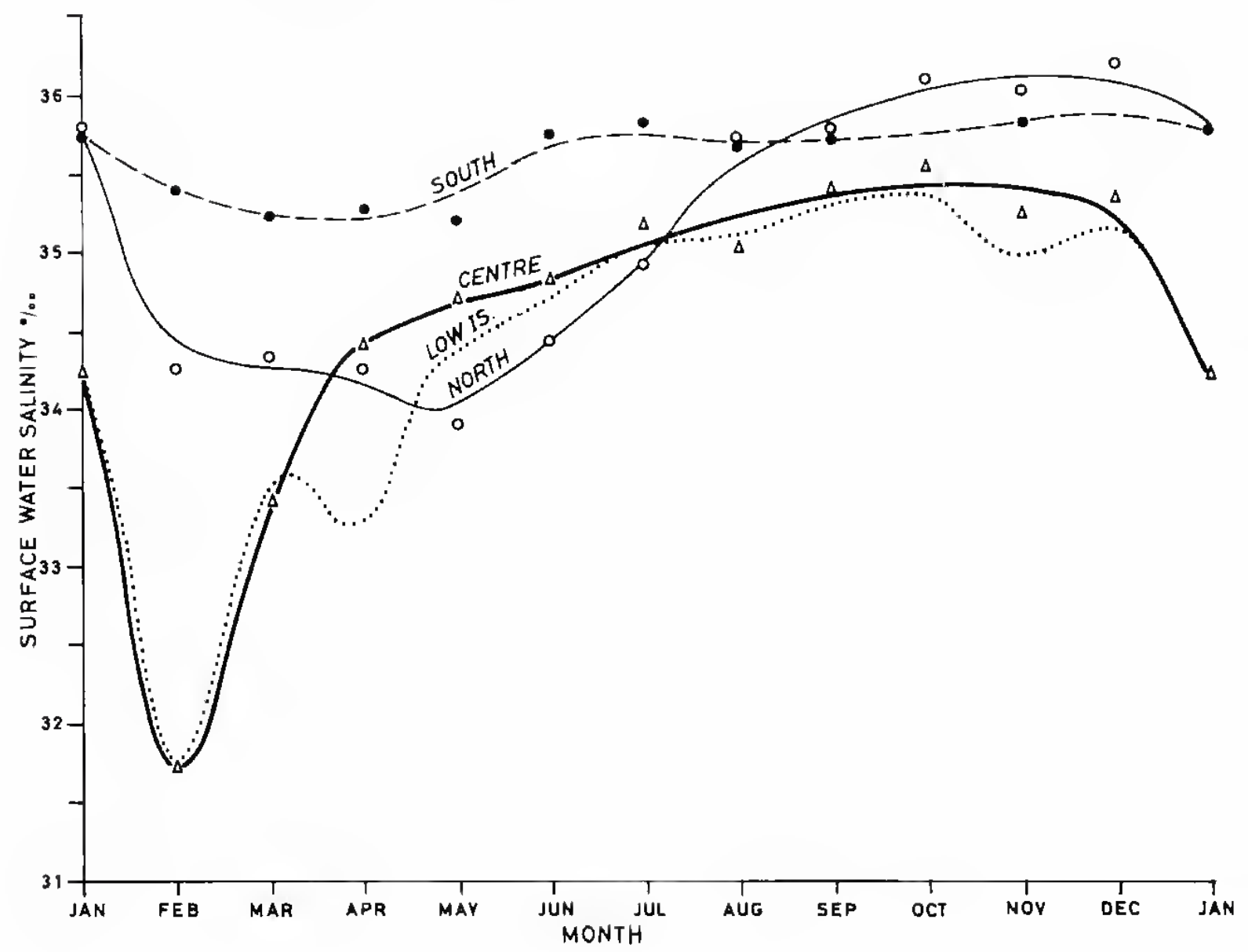


It will be noted later that less consistent results are obtained when the inshore salinitics of Fig. 19 are compared with Coral Sed values near the reef (Fig. 24) and in a short section near Low Is., Orr's (1933a) data show an increase in salinity to seaward in August when one might expect a decrease or isohaline conditions (see the next section).

\section{Sub-surface salinities}

At Low Is. the salinity at $28 \mathrm{~m}$ (decpest measurement) had its seasonal maximum in October and minimum in March (Fig. 15B), following the surface salinity change, and was always equal to or greater than the surface value within the probable precision of measurement (not stated by Orr, 1933a). In winter the difference between surface and deep values was less than 0.2 (average 0.05 ) except for two occasions in November following moderate rain. In summer, January to April, differences ranged from 0.05 to 3.35 (average $0.8:$ ), the two values over 2 being associated with heavy rain (February, Fig. 15B). The greater part of the salinity difference occurred in the top 5 to $10 \mathrm{~m}$.

Orr drew attention to the abrupt increases in decp salinity associated with decreases at the surface on two occasions, 13 February and 5 April. He considered it unlikely that this was due to advection from the south, where the rainfall is also generally heavy, but then said that in the south there are many openings in the reef (through which, presumably, more saline water might enter the lagoon). He also referred to tidal currents through Trinity Opening east of Low Is. In other words, he did not really attempt any explanation of the phenomenon. One possibility is that the large input of fresh water may gencrate a temporary estuarine circulation with outflow (to and through reef openings) in the surface laycr and consequent inflow below (c.g. Pickard, 1975, Ch. 8). Some observations on other tropical arcas which appear to be relevant to this phenomenon are described later in the section on Tropical Estuaries. At the same time it may be noted that there were occasions when the deep salinity decreased with decrease of surface salinity, e.g. early November, from mid-December generally to early February, early March. Therefore, although there may be a phenomenon to be explained it would be best to have more substantial data with which to work before spending much time on it.

At stations 120 to $200 \mathrm{~km}$ north of Low Is. at the end of February, deep salinities were within about 0.2 of those at Low Is. at the same time, but surface values were much higher, the range of values in the column being only 0.4 to 0.6 . At Trinity Opening, $40 \mathrm{~km}$ east of Low Js., the salinity in the column was within 0.1 of that at Low $\mathrm{s}$. in August, September and November.

Table 4. Salinity gradients across the lagoon (selected examples). $\mathrm{O}=\mathrm{Orr}$ (1933a); B=Brandon (1973)

\begin{tabular}{|c|c|c|c|c|c|c|}
\hline \multirow[b]{3}{*}{ Zone } & \multirow{3}{*}{$\begin{array}{c}\text { Latinude } \\
(\mathrm{S})\end{array}$} & \multirow{3}{*}{ Month } & \multicolumn{2}{|c|}{ Change } & & \multirow[b]{3}{*}{ Sorrace } \\
\hline & & & Salinity & & \multirow[b]{2}{*}{ Temp. IC) } & \\
\hline & & & 1.1 & Direction & & \\
\hline \multirow[t]{2}{*}{ North } & 14.5 & February & 0.2 & increase to reef & \multirow[t]{2}{*}{ (isothermal) } & $\mathrm{O}$ \\
\hline & 11.7 & Oct. or Nov. & 0.6 to 0.8 & dccrease to reef & & $\mathrm{B}$ \\
\hline \multirow[t]{8}{*}{ Centre } & 15.8 & March & 0.1 & increase to recf & \multirow{5}{*}{$\begin{array}{l}(0.3 \text { decr.) } \\
\text { (isothermal) }\end{array}$} & $\mathrm{O}$ \\
\hline & 14.7 & Mar, or Apr. & 2.0 & increase to reef & & B \\
\hline & 17 & April & 1.1 & increase to recf & & B \\
\hline & $17-18$ & April & 1.9 to 2.9 & increase to reef & & $\mathrm{B}$ \\
\hline & 19 & April & 0.1 & increasc to reef & & $B$ \\
\hline & $14.5-16.5$ & July & \multicolumn{2}{|c|}{ isohaline } & (2.6 incr.) & B \\
\hline & 16.4 & October & 0.15 & decrease to reef & (0.3 incr.) & $\mathrm{O}$ \\
\hline & 16.4 & November & 0.1 & decrease to reef & $(0,4$ decr. $)$ & $\mathrm{O}$ \\
\hline
\end{tabular}


At a group of stations along a line $50 \mathrm{~km}$ long from the mouth of the Daintree River and past $\mathrm{L}$,ow $1 \mathrm{~s}$. to the inside end of 'Trinity Opening in August, the salinity change at all depths was within 0.4 and the temperature change within $1.75 \mathrm{C}$, the highest values being in Trinity Opening for both properties.

Brandon (1973) referred to making Nansen casts (for water samples and temperatures) but he presented no data on vertical profiles of salinity. He stated "The vertical salinity profile on the Queensland shelf is, for the most part, isohaline for the majority of the year. The only exception to this is during the rainy season when the surface salinity may be greatly reduced' and also 'From May to the commencement of the rainy season, salinity differences between the surface and bottom waters on the Northern Queensland shelf probably rarely exced 0.1 . Local variations may occur during this time after a rainfall, but these would be exceptions and of short duration. This is most likely true of the southern shelf also as the SE T'rades remain dominant over the year and are capable of keeping the water column mixed. "The speculative nature of these remarks is surprising if Brandon had data of his own on which he could have based more firm statements. Brandon also reviewed some of Orr's observations and speculated about lagoon salinities north of $14 \mathrm{~S}$ during the wet season.

\section{DISSOLVED OXYGEN}

Orr (1933a) made regular measurements of dissolved oxygen at all depths at Low Is, and found relatively small variations with time or depth, the water generally being undersaturated. His results may be summarised as:

\begin{tabular}{|c|c|c|c|c|}
\hline & $\begin{array}{l}\text { Mean } 0_{2} \text { conc. } \\
\quad(\mathrm{ml} / 1) \\
\end{array}$ & $\begin{array}{c}90^{\prime} \text { "of values } \\
\text { between: }\end{array}$ & $\begin{array}{l}\text { Mean sat. } \\
\text { (") }\end{array}$ & $\begin{array}{l}90 " \text { "of values } \\
\text { between: }\end{array}$ \\
\hline Surface & 4.6 & 4.3 to 4.9 & 95 & 92 to 99 \\
\hline $28 \mathrm{~m}$ & $4.5 \overline{5}$ & 4.1 to 4.8 & 93 & 88 to 97 \\
\hline
\end{tabular}

Slightly lower values were observed at all depths from January to April than at other times, but the seasonal variation was small. Orr considered that there was a significant oxygen demand by the particulate material and as this was continually mixed through the column, the demand showed little or no variation with depth most of the time. Only in calm periods was there a possible greater reduction of oxygen content in the deeper water than in the upper waters. Orr remarked on the large diurnal changes in oxygen content which occur in the shallow waters of the reef flats but considered that the volume of water involved was too small for the lagoon waters to be significantly affected away from the immediate vicinity of the reef.

Kinsey \& Kinsey (1967) measured oxygen content over and near Heron Is, reef and showed that while large changes, particularly between day and night, occurred over the reef $(7.5$ to $1.5 \mathrm{ml}, 1)$ the changes at $2 \mathrm{~m}$ depth only $100 \mathrm{~m}$ outside the reef showed a range of only 4.66 to $4.92 \mathrm{ml} \cdot 1$ (95 to $102^{\prime \prime}$ " saturation). The value $15 \mathrm{~km} \mathrm{SE}$ of Heron Is. and $5 \mathrm{~km}$ from the nearest reef was $4.76 \mathrm{mll}\left\langle 97^{\prime \prime}\right.$ " saturation), very similar to the Low Is.
values.

Brandon (1973) reported no measurements of dissolved oxygen.

\section{OTHER GHEMICAL PROPER'TIES}

Orr (1933a) reported that dissolved phosphate showed 'no seasonal character' although his data table showed variations from 0 to $8 \mu \mathrm{gm} / \mathrm{l}$. Most of the values were between 3 and $5 \mu \mathrm{gm} / 1$ with an average of $4 \mu \mathrm{gm} / 1$ with no significant difference through the water column, and no systematic seasonal variation. 
A few measurements were made of silicate, giving values between 40 and $110 \mu \mathrm{gm} 1$. A very few measurements were made of nitrate but these were regarded as uncertain because of long storage.

Orr's (1933a) measurements of hydrogen ion concentration gave $\mathrm{pH}$ values of $8.26 \pm 0.01$. Brandon (1973) stated that he made $\mathrm{pH}$ measurements during September-November 1967 but as no significant variations or correlations with other data were found the measurements were discontinued.

\section{TRANSPARENCY}

Orr (1933a) made a secchi disc measurement at each Low Is. station and at the other stations in the lagoon and outside the reef. The Low Is. values ranged from 3.5 to $25 \mathrm{~m}$, averaging $12 \mathrm{~m}$, with no seasonal variation perceptible but apparently a correlation in which low secchi disc depths were associated with high wind speeds and lasted for a few days after such a wind.

From Orr's data it can be shown that the secchi disc depth $(S)$ in metres is related to the wind speed (W) during the previous 24 hours approximately by:
(a) W in knots: for $\mathrm{W}=0$ to $8 \mathrm{kts}$,
$S=27-2 W$,
for $W=8$ to $15 \mathrm{kts}$,
$\mathrm{S}=19-\mathrm{W}$,
(b) W in $\mathrm{m} / \mathrm{s}$ : for $\mathrm{W}=0$ to $4.5 \mathrm{~m} / \mathrm{s}$,
$\mathrm{S}=27-4 \mathrm{~W}$,
for $\mathrm{W}=5$ to $9 \mathrm{~m} / \mathrm{s}, \quad \mathrm{S}=19-2 \mathrm{~W}$.

The standard deviation of the original points about these mean lines was about $\pm 2.5 \mathrm{~m}$.

Hedlcy (1925b) recorded secchi disc depths of 2 and $2.5 \mathrm{~m}$ respectively at the jetties at Townsville and Cairns, while in the lagoon he recorded values of 5 to $33 \mathrm{~m}$.

The reduction in transparency with increase of wind speed was attributed by Orr to stirring up of the fine grey sediment characteristic of inncr passages of the lagoon (clay size fraction about $35^{\prime \prime}{ }_{11}$ ).

Fig. 20 Seasonal variation of water density (as $\sigma_{t}$ ) at $28 \mathrm{~m} \mathrm{depth}$, and difference $\left(\Delta \sigma_{\mathrm{t}}\right.$ ) between $28 \mathrm{~m}$ depth and surface at I.ow Is., $16.4 \mathrm{~S}$ (data from Orr, 1933a),

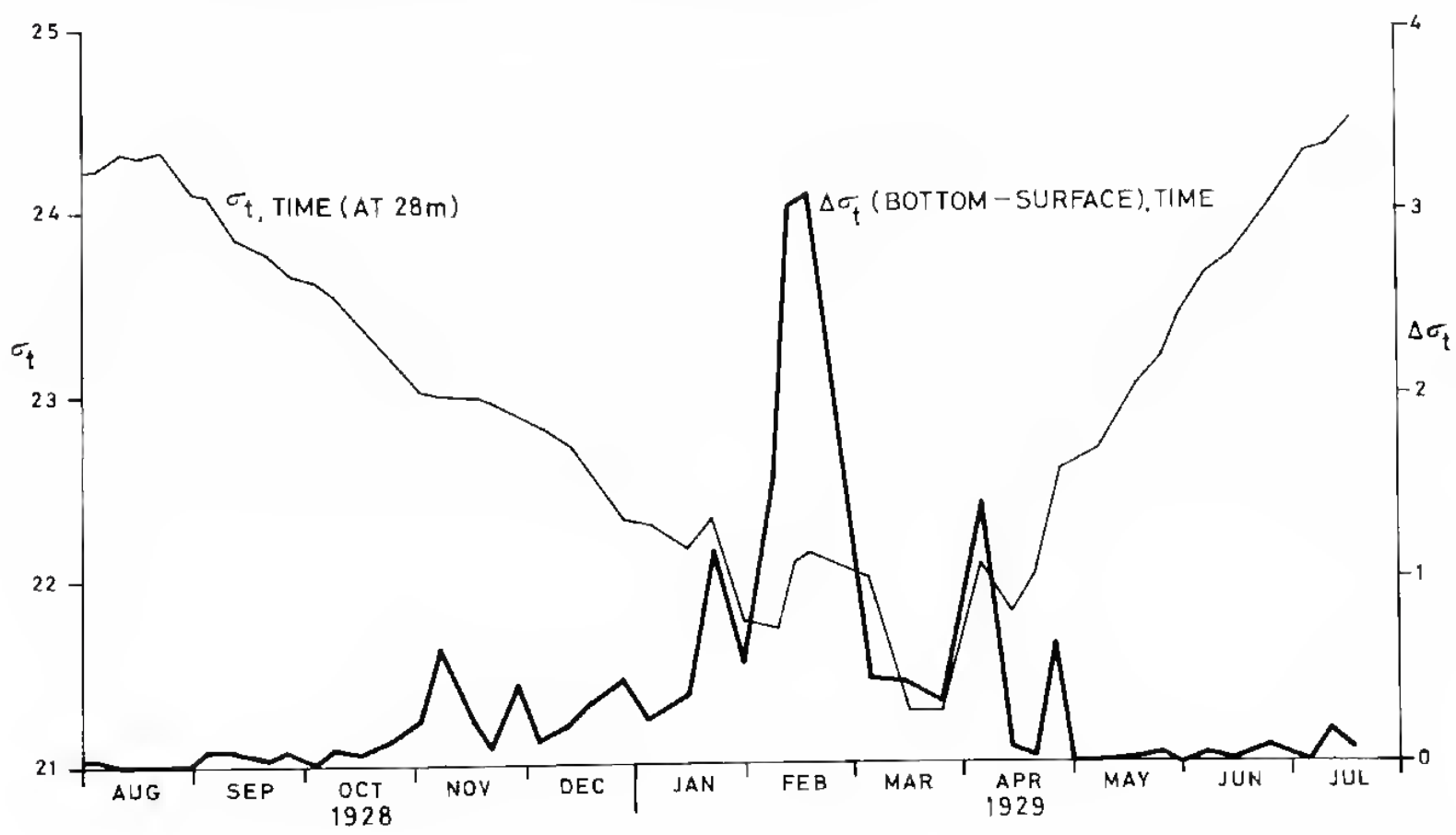


Approaching the outer reefs, in Trinity Opening, secchi disc depths of 11 to $30 \mathrm{~m}$ were recorded, being associated by Orr with the coarser bottom material there. To seaward of the outer reef values from 14 to $40 \mathrm{~m}$ were measured. (I have observed the same correlation between poor visibility in the presence of fine bottom sediments in a lagoon contrasted with good visibility and coarse bottom sediment near or outside the reef in many areas, e.g. Glovers Reef, Tikehau, Majuro and Nomoi. This is the case even when the lagoon is much calmer than the reef area.)

\section{DENSITY}

Orr (1933a) presented a density (as $\sigma_{t}$ ) versus time plot for the Low Is. data. As the surface value curve is very similar to the salinity time plot (Fig. 15B), it has not been reproduced here; however, Fig. 20 presents the $28 \mathrm{~m}$ depth $\sigma_{\mathrm{t}}$ values-versus time as well as the difference $\left(\Delta \sigma_{t}\right)$ between $28 \mathrm{~m}$ and surface values. This graph shows the marked decrease of $\sigma_{\mathrm{t}}$ in summer, while the $\Delta \sigma_{\mathrm{t}}$ curve gives an indication of the gravitational stability of the water $\left(\Delta \sigma_{1}: \Lambda z\right)$. Actually, in the summer most of the change of density $\Delta \sigma_{t}$ took place in the top $10 \mathrm{~m}$ ( $5 \mathrm{~m}$ for the cases where $\Delta \sigma_{1}$ was greater than 1$)$ and so the stability of the upper layer is generally greater than indicated by this curve.

Fig. 21 T, S, time diagram for surface and $28 \mathrm{~m}$ depth at Low Is. station, 16.4 S (data from Or.r, 1933a).

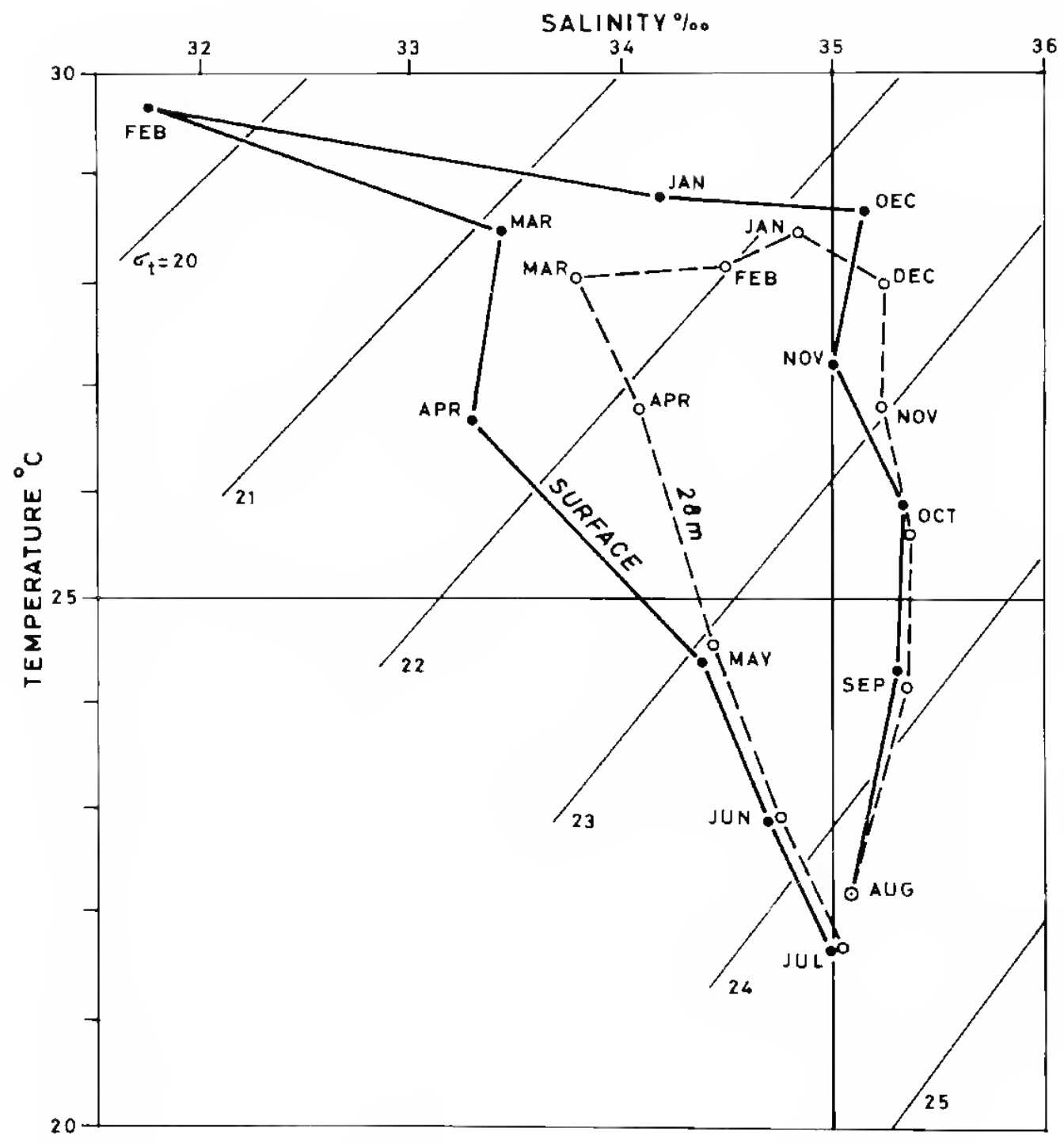


The similarity of the salinity time and the density tine curves led Orr to state that "It is salinity rather than temperature which is the determining factor in the stability of the sea in the Barrier Reef lagoon.' This statement is misleading in that it is only true for one third of the year, the wet season from December to March; at other times, temperature plays a major role in determining density.

This is evident from Fig. 21, in which the monthly average values of temperature and salinity at Low Is. are plotted on a $T, S$ diagram and connected in temporal sequence. Curves for the surface and for $28 \mathrm{~m}$ are presented. At the surface, for December to March the change is mainly of salinity, and the $\sigma_{t}$ change can be attributed to this factor, but for July to December the change is almost isohaline, and the $\sigma_{\text {t }}$ change must be due to change: of temperature. For the period March to July both temperature and salinity play a part. At $28 \mathrm{~m}$, salinity plays an even smaller role than at the surface.

Fig. 21 also shows clearly the uniformity of the water column during the winter dry season because the T, $S$ time curves for all depths lie between the surface and 28 mones which are almost coincident.

\section{PROPERTIES IN O'I'HER AREAS}

\section{New Caledonia barricr reef lagoon $(22 \mathrm{~S}, 166.4 \mathrm{~L})$}

H. Rotschi and Y. Magnier (personal communication of O.R.S.T.O.M., Centre de Noumća, made observations of water properties for a year in 196162 along a section from the Tontouta River in the Baie St Vincent (22 S, 166 E), west coast of New Caledonia, to the barrier reef. The water depths ranged from $6 \mathrm{~m}$ at the inner station to over $200 \mathrm{~m}$ near the recf. 'T'he rainfall in this region is typical of the west coast of New Calcdonia, with a January maximum then falling steadily to Norember (5:1 ratio) betore rising again, the annual average being $1100 \mathrm{~mm}$ (compared to twiec this on the east coast).

The property distributions showed a sequence from salinity stratified water during the wet season, January to April, to a relatively homogeneous water column in the drier season, August to November. At stations near the middle of the Baie St Vincent (Stn 3, depth $21 \mathrm{~m}$ ) and near the recf (Stn 6 , depth $100 \mathrm{~m}$ ) the mean differences in the water column from the surface to $20 \mathrm{~m}$ depth were:

\begin{tabular}{|c|c|c|c|c|c|}
\hline \multirow[b]{2}{*}{ Sfc. to $20 \mathrm{~m}$} & \multirow[b]{2}{*}{ Scason: } & \multicolumn{2}{|c|}{ Stn 3 (shore) } & \multicolumn{2}{|c|}{$\operatorname{Stn} 6(\mathrm{recf})$} \\
\hline & & Wet & Dry & Wet & Dry \\
\hline$\Delta \mathrm{T}(\mathrm{C})$ & & 0.8 & 0.2 & 0.2 & 0.3 \\
\hline$\Delta S(i)$ & & 0.6 & 0.1 & 0.3 & 0.2 \\
\hline$\Delta \mathrm{O}_{2}(\mathrm{ml} \mathrm{l})$ & & 0.1 & 0.1 & 0.3 & 0.1 \\
\hline
\end{tabular}

At the deeper station ( $\operatorname{Stn} 6$ ) the property changes deeper than $20 \mathrm{~m}$ were small compared to those for the upper $20 \mathrm{~m}$.

These results are similar to those found at the Low Is, and neighbouring stations (Orr, 1933a) of the Great Barrier Reef, with a well-mixed water column except during the wet season.

P. Bourret (personal communication) of O.R.S.T.O.M., Centre de Noumća, made available surface temperature and salinity measurements for 10 months in 1966 at Pam in the north of New Calcdonia $(20.3 \mathrm{~S})$ about $6 \mathrm{~km}$ from the mouth of the Diahot River in a region with an annual rainfall of $1500 \mathrm{~mm}$ with a January maximum and October minimum (12:1 ratio). A T,S, time plot of these data was very similar to that for the centre zone of the Great Barrier Reef (Fig. 23) but with a less pronounced Fcbruary salinity minimum. The temperature and salinity ranges for the period February to November were $7 \mathrm{C}^{-}$and 4.5 respectively, with the temperature minimum in July and salinity 
maximum in October November. The larger salinity range at Pam than in the Great Barrier Reef data is attributed to the fact that Pam is closer to the river and in a more restricted waterway than the inshore channel of the Barrier Reef lagoon for which Fig. 23 data were obtained.

The correspondence between these two sets of results for the New Caledonia lagoon and those for the Great Barrier Reef lagoon suggests that neither is a unique region and that there may be many features in common between the various barrier reef lagoons.

\section{Tropical estuaries}

Relative to the speculation that estuarine circulations may develop in the lagoon after heavy rainfall, Yves Magnier, O.R.S.T.O.M., Centre de Nouméa, drew attention to two studies made by himself and Piton in Madagascar (Baie d'Ambaro, two years' observations, Piton \& Magnier, 197l; and Baic d'Ampasindava, one year's observations, Magnicr \& Piton, 1972) which suggest that the estuarine circulation hypothesis is reasonable. These bays are subject to a precipitation and river runoff regime very similar to that of the North Queensland coast, although they do not have any barrier reef outside. Ambaro is an open bay while Ampasindava is narrower.

The runoff into the bays had a maximum of about $500 \mathrm{~m}^{3} \mathrm{~s}$ in February - March falling in exponential fashion to less than $10 \mathrm{~m}^{3} \mathrm{~s}$ in October-November and then rising rapidly. The vertical profiles of water properties were similar to those at Low Is. (Orr, 1933a) with vertical diffcrences as:

\begin{tabular}{lcc}
\hline Difference & \multicolumn{2}{c}{ Scason (Baie d'Ambaro) } \\
Sfc. to $15 \mathrm{~m}$ & Wet (March) & Dry (Sept.) \\
\hline$\Delta \mathrm{T}(\mathrm{C})$ & 1.0 & 0.50 \\
$\Delta \mathrm{S}(\mathrm{T})$ & 10.0 & 0.02 \\
$\Delta \sigma_{\mathrm{t}}$ & 7.5 & 0.15 \\
\hline
\end{tabular}

(Most of wet scason changes were in the upper $5 \mathrm{~m}$ ).

Calculations for an cstuarine circulation suggested outflow speeds in the upper layer of about $4 \mathrm{~km}$ day.

The observations in the Baie d'Ampasindava gave very clear indications of estuarine circulation. In the dry season (e.g. October) the water was isohaline to within 0.1 from top to bottom, and had a uniform dissolved oxygen content of $4.5 \mathrm{ml} \mathrm{l}$ and nitrate-N of less than $0.2 \mu \mathrm{g}$ at 1 . By mid-December, when the runoff had started, there was a salinity difference of 5 between the surface and $20 \mathrm{~m}$ depth, and the oxygen content had decreased to $4 \mathrm{ml} 1$ in the bottom $10 \mathrm{~m}$ ( $40 \mathrm{~m}$ water depth) near the head of the bay. By February (runoff maximum) the bottom watcr oxygen content had fallen to less than $2.2 \mathrm{ml} \mathrm{l}$ and nitrate- $\mathrm{N}$ increased to over $6 \mu \mathrm{g}$ at 1 . These marks of stagnation at the bay head were clear indications of the development of an cstuarine circulation. The surface outflow driven by the river runoff entrained and carried out salt water which was replaced by a subsurface inflow, trapping a pocket of water below the surface at the estuary head (e.g. Pickard, 1961). As the river runoff decreased in April-May and the surface outflow consequently diminished, the subsurface inflow decreased and the stagnant pocket of water at the bay head dissipated, the water column becoming homogencous by July.

Therefore, in the Great Barrier Reef where the runoff charactcristics are similar to those in Madagascar, with a sharp rise in January, the associated development of an estuarine circulation with outflow of the surface layer and inflow developing below may be expected. The formation of a pocket of stagnant water is typical of the conditions at the head of a bay and probably would not oceur in the open lagoon of the Barrier Reef. The real extent of the estuarine eirculation is something which will have to be determined by observation. 
Piton \& Magnier (1971) also described very clcarly, from results at a 50-hour station, the effect of wind in causing mixing. For the first 24 hours, the wind averaged $2 \mathrm{~m} \mathrm{~s}$ and the water ( $12 \mathrm{~m}$ depth) remained distinctly stratified with a salinity difference top to bottom of $1.6 \%$. The tidal amplitude was $3 \mathrm{~m}$ at this time. 'Then, in a period of about 2 hours, the wind rose to $7 \mathrm{~m} / \mathrm{s}$ and within 9 hours the water had become completely isohaline from surface to bottom. The salinity stratification was redeveloping within 6 hours of the wind starting to decrease from $7 \mathrm{~m} / \mathrm{s}$ to $4 \mathrm{~m} / \mathrm{s}$. 


\title{
VI \\ T,S Characteristics of Surface Waters
}

\author{
'I'SIIIACIRAMS'
}

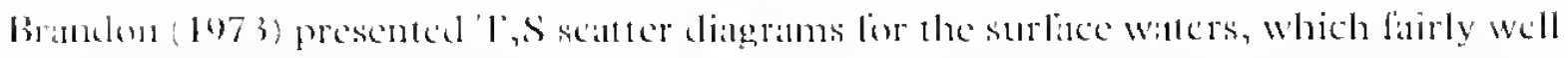

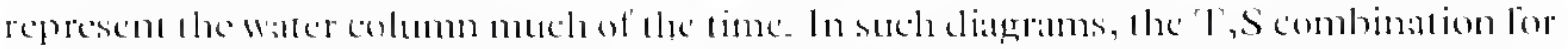

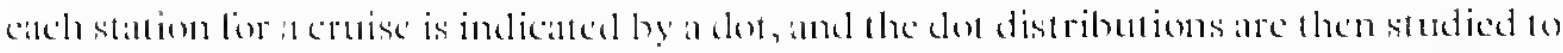
see if they show :my systematic groupings which might assist in describing the distribution in space of enmbinations of "l's propertics. A comparison of such diagrams

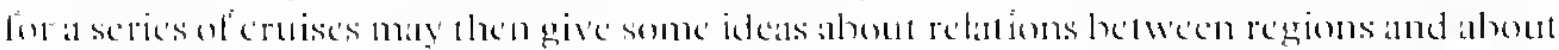
changes with 1 me. Ilowerer, one must remember that at the suthese, temperature and salinity are not conservative properties and it a cruse extends ower a signilicant period of time the seasonst change's ol the properties may distort the distrihution ol points on the di:1grims.

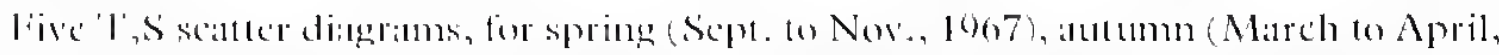

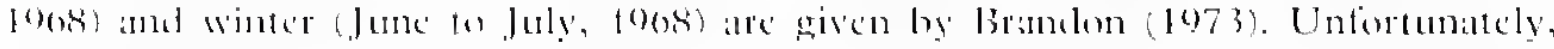

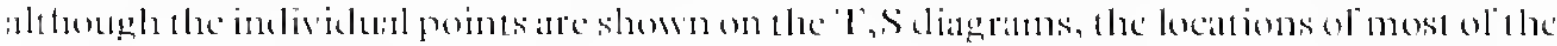
stations ane not given in the paper. (On the diagrams, the geographical locattons are indicated only in very generil terms. Rather than reproducing Brandon's tive scatter diagrams (which use ditlerent scalles), me;n lines have becn drawn through his groups ol

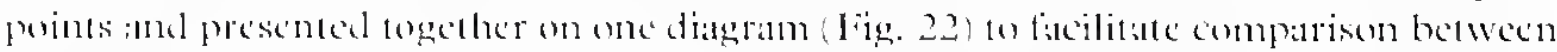

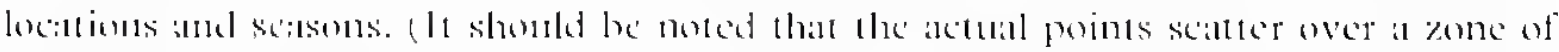

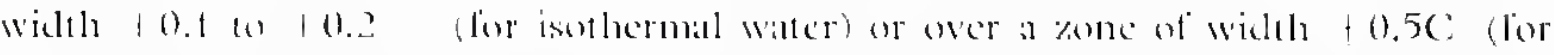

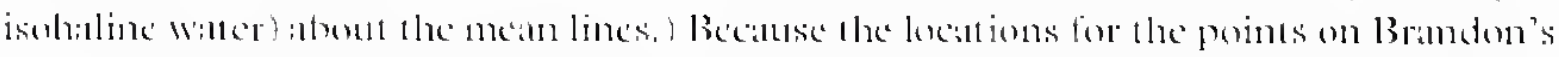

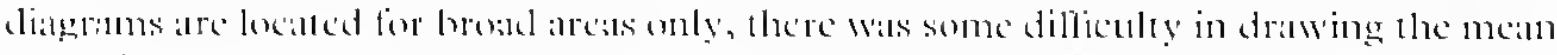

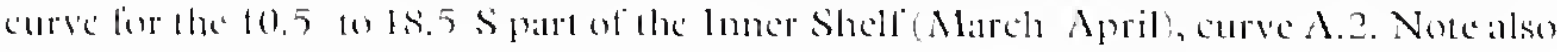

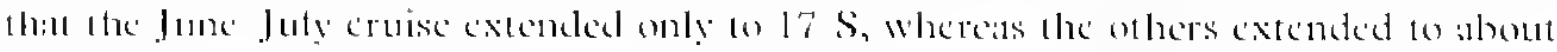
$25 \mathrm{~S}$

Some of the fertures shown by lig. 22 ill:

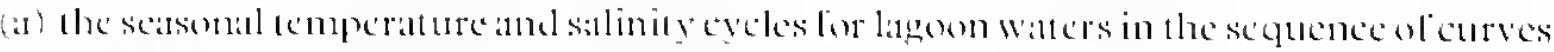
A. I, A.2, A. 3 sece also the next section,

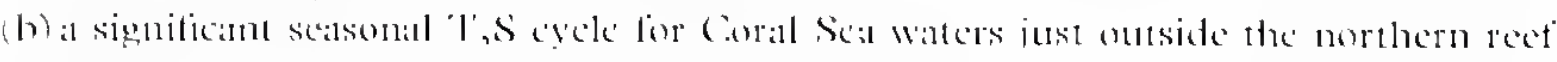
(comeses (.2, (..3),

(6) the large silinity gradient across the shell tor the atumn (A.2 at ahout 16.5 S, B.2, (..2),

(1) the cyele in the 'lorres stratit (1).1, 1).2, 1), 3) inctuding the low salinity (1).2) due to castward transport of low salinity water lrom the Aralura sea snd northern ciall of Corpentarial during lhe Nit' monson.

One notices the gap between curves $A .3$ and C. 3. As the latter represents a transect liom oustide the red to the shore, one would expece the shoreward end of C. 3 (low temperature to approich the 17 s end ol A, 3 which is lor the inner (shoreward) part of the lagoen. Bramblon stated that "l'he 'l's values on the shell south of Cape Grenville (12.0 S) to Princess Charlone Bay (1.1.3 S) are not shown but they reftect the trend of graklually increasing solinities from the low values registered during the monsom season'. 
Possibly the A. 3 curve represented values during June while C. 3 represents later values in July when the salinity on the shelf had increased scasonally.

Another feature of Brandon's T,S scatter plots is an apparent bunching of points geographically. For instance, on his Fig 8 (Sept.-Oct.) there is a gap with no points in the temperature dimension between 18 and $19 \mathrm{~S}$, and in the vicinity of $13.5 \mathrm{~S}$ (latitudes taken from his text description). $1 \mathrm{n}$ his Fig. 11 , there is a gap of $0.6 \mathrm{C}$ and 0.4 at $22 \mathrm{~S}$, of 0.7 between 19 and $18.5 \mathrm{~S}$, and of about $1 \mathrm{C}$ and $\mathrm{l}$ at $14 \mathrm{~S}$. 1 if these gaps in the occurrence of water properties are real, representing step increases in properties over short distances, rather than resulting from spatial gaps in the station distribution, they present an interesting feature to be explained.

Fig. 22 Mean T,S, curves for surface waters of arcas of the Great Barrier Red lagenn, the Coral Sua just outside the reef, and the lorres Strait, for 1967-68 (data from Brandon, 1973):

Inner shelf: A.1 Sept, Oct, A.2-Mar., Apr., A.3 June, July,

Centre shelf: B.1-Nov (10.5 13.5 S), B.2-Mar, Apr. (14.5-17 S),

Coral Sea: C.l omitted (no data), C.2-Mar., Apr, $(1-4.5-16.5$ S), C. 3 July 16.7 S,

Torres Strait: D.1-Oct, D.2-Mar., Apr, D.3-July

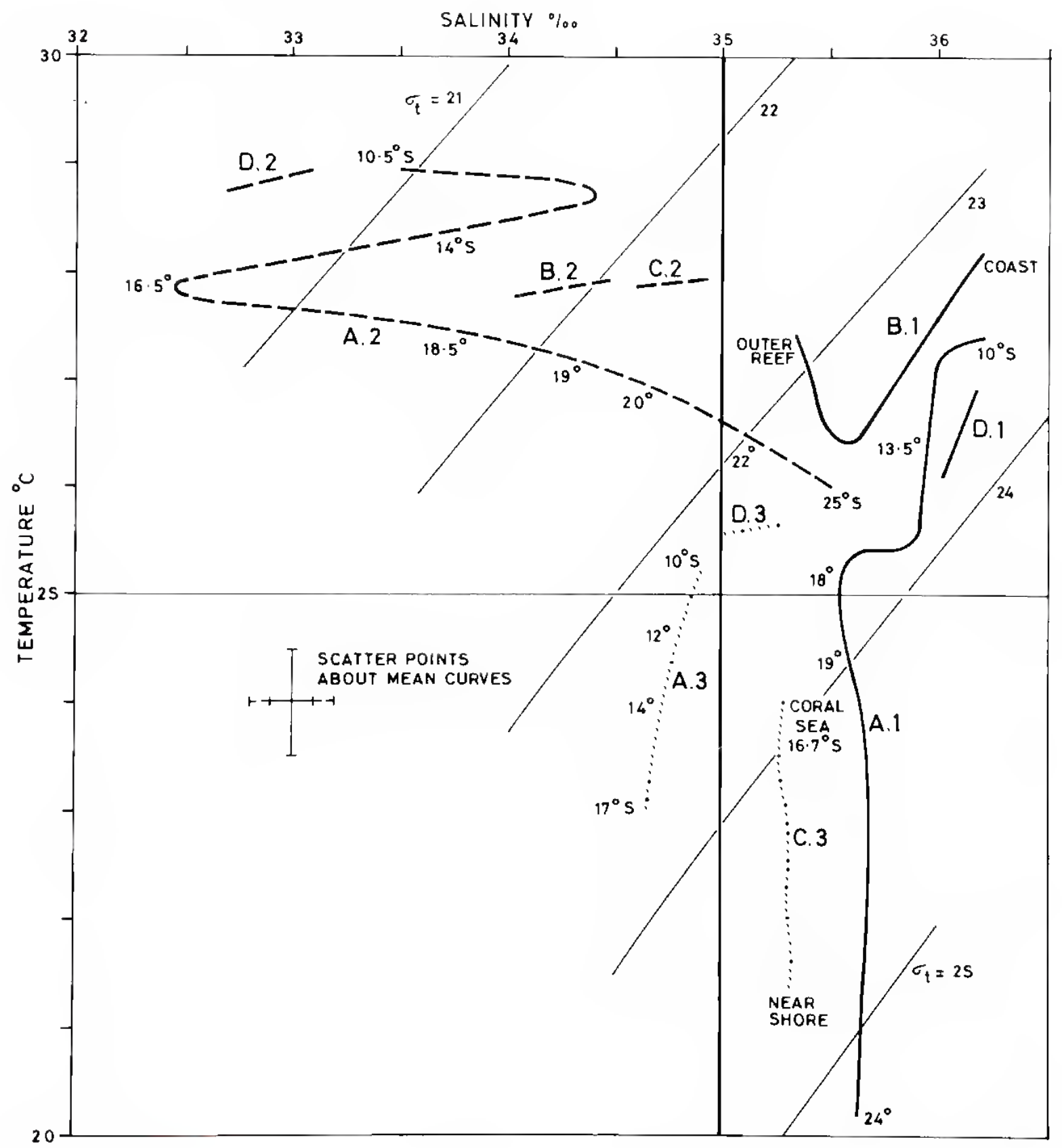


The T,S, time diagram for the Low Is. data (Fig. 21) has already been discussed.

From Brandon's (1973) data via the present Figs. 17 and 19, T,S, time diagrams of monthly mean values are presented in Fig. 23. (Note that these data are not homogeneous in that the monthly temperature data (Fig. 17) are for latitudinally wider zones (4 to 5 degrees) than are the salinity data (Fig. 19, 1 degree wide zones). However, the only effect of this will be to emphasize the reduction in salinity in the wet season for the centre zone.) An indication of the scatter about the monthly points is shown in the diagram $( \pm 0.8 \mathrm{C}$, and +0.2 for north and south zones and \pm 0.4 for centre zones).

Fig. 23 T,S, time diagrams for surface waters of the Great Barrier Reef lagoon, shore side, for zones as:

$\begin{array}{lll} & \text { Temperature } & \text { Salinity } \\ \text { North zone: } & 10.5-14.5 \mathrm{~S}, & 11-12 \mathrm{~S}, \\ \text { Centre zone: } & 14.6-19.5 \mathrm{~S}, & 16-17 \mathrm{~S}, \\ \text { South zone: } & 20.5-24.5 \mathrm{~S}, & 22-23 \mathrm{~S},\end{array}$

(data from Brandon, 1973)

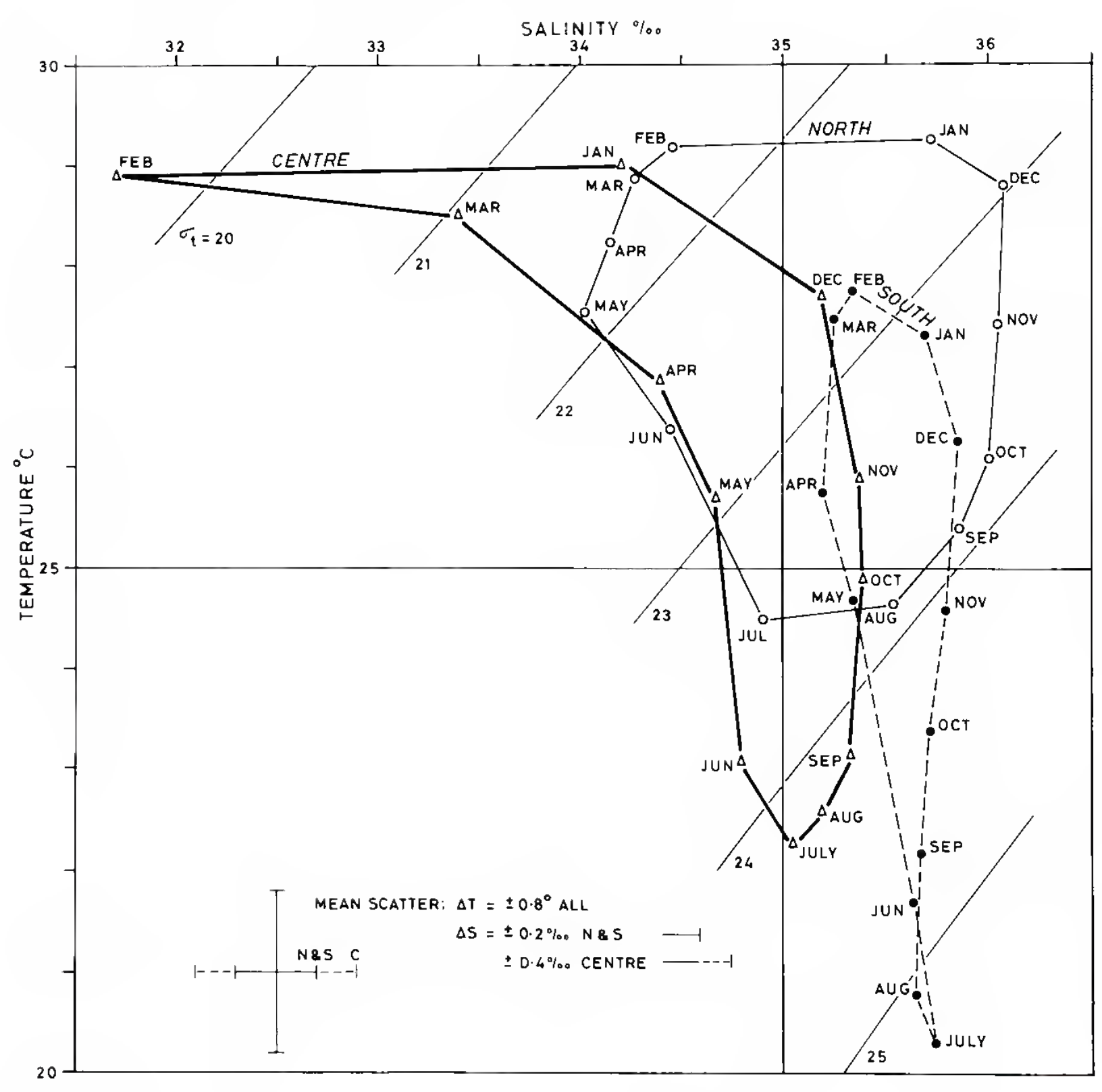


Data from some stations taken from F. V. Degei in August 1965 (CSIRO, 1968a) between 22 and $24 \mathrm{~S}$ fit these curves within the scatter given, being about $0.5 \mathrm{C}$ warmer on the average and 0.2 : more saline.

Fig. 23 reveals very well the cycle of temperature and salinity changes in the lagoon, and the different emphasis in the three zones. The most obvious feature is the greater extent of salinity variations in the north and centre zones than in the south, related to the rainfall cycle. The second feature shown is the greater difference in minimum temperature between the zones than in maximum temperature. The third feature is that, as remarked for Low Is., the annual cycle of density is determined both by temperature and by salinity changes; in fact, in the south zone the temperature plays the major role because the salinity change is quite small compared to that in the other zones. 


\title{
VII \\ Water Properties Outside the Reef
}

\author{
INI)IVIIUUAL, PROPERTIIS OU'TSIDE 'THL RELI'
}

()re (1933a) made a few measurements of water propertics just outside the outer reef line at 'l'rinity opening (16,4 S) east ol' L ow ls., at Papuan Pass $(15.8 \mathrm{~S})$ about $75 \mathrm{~km}$ north of low ls., and at Coxk's P'assage $(14.5 \mathrm{~S})$ about $200 \mathrm{~km}$ north. At Trinity Opening in October and November (dry season) the surface temperature and salinity values were cssentially the same ats an low ls. at the same time. At Papuan l'ass in March (end of the wet seasom) the temperature was the same and the salinity greater than at Low 1 s by 1.2 , and at Cook's Passage in lebruary (wet season) the temperature was 1.60 . higher and the salinity 1.7 higher. 'lhe oxygen content was essentially the same at Low Is. and butside the rect in all three calses.

Below the surface all propertices were much the same as at the surlace to 50 to $100 \mathrm{~m}$ depth (wind mixed layer). Below this a thermocline extended to the maximum depth sampled to 10 (Cat 600$) \mathrm{m}$ ). There was a salinty maximum of about 35.7 at $100.200 \mathrm{~m}$ ancl an atssociated oxygen minimum of about $3.5 \mathrm{ml}$ l. Orr regarded the salinity maximum as unexpected but it was, ol course, characteristic of the Pacific Subtropical Lower water of wide distribution in the south-west P'acilie (see Part 2 Western Coral Sea).

As the depth of the wind-mixed layer outside the red (up to $100 \mathrm{~m}$ ) is greater than that (l) most of the lagroon (lig. 313), it is the properties ol only this layer which are significant in exchanges between the seal and lageon. Alse, because the layer is well-mixed, the surface values lor the sea outside provide most ol the information needed when considering the selfects ol the outer sea on the lagoon waters.

Brandon (1973) discussed conditions outsicle the Reel but presented no data of his own, relying on other accounts and particularly on three sections into the Coral Sea made from the Umiaka Mart in December 1967 (no reference given) starting at $13,16.5$ and $18.5 \mathrm{~S}$. Ile was particularly conerned about Orr's (1933a) and Maxwell's (1968) suggestions on the possibility and signilicance of upwelling outside the Reef. He conclued that there was some evidenee in the Umiraka Marm data lor limited upwelling, pussibly from between 50 and $100 \mathrm{~m}$ depth. I do not think that the data show this; and Branclon himself, carlier in his paper, had acepted Wyrtki's (1900) suggestion of downwelling against the Reel. (1t should be noted that Brandon's technique (1973, section V.B) lor calculating geostrophic currents in the upper layers is not acceptable dynamically, nor is his subsequent treatment ol these currents as absolute currents.)

A feiture of the Lminaka Marm datia as presented by Brandon, but upon which he did not comment, was the almost complete absence ol an upper mixed layer. The temperature decreased almost linearly from the surlace to $250 \mathrm{~m}$ at all three lines of stations (from about 28 to 17 -20 ()). Silinity data were not shown but density decreased steadily from the surface to $250 \mathrm{~m}$ with a slightly smaller rate of decrease in the upper $30 \mathrm{~m}$. This lack of a marked mixed layer is unexpected in this region and when the SE trades are still blowing (1)ectmber). 
From the 1966-74 Monthly Oceanographic Charts, Tasman and Coral Seas (CS1RO, 1974), Coral Sea surfaee temperature and salinity values just outside the reef have been estimated for the three zones: north (10 to $14.5 \mathrm{~S})$, centre $(15$ to $19.5 \mathrm{~S})$ and south (20) to $25 \mathrm{~S}$ ). The data in the charts are averaged by 1 squares for each month. Because of the limited number of observations in most months in the north-western Coral Sea, interpolated (and sometimes extrapolated) isotherms and isohalines had to be used in most cases. The procedure was to estimate the range of values for eath month $(1966-74)$ for each zone, rejeet the highest and lowest months, and take the mean of the remainder and also estimate a range $( \pm)$ which included all or most of the remaining values, rounding off to the nearest $0.5 \mathrm{C}$ or 0,1 . The mean values for the three zones are presented in $\mathrm{T}, \mathrm{S}$, time plots in Fig, 24 (the centre zone plot is displaced to the left to reduce crowding). It should be noted that data are missing or inadequate to make estimates of temperature or salinity values outside the Reef for $32^{\prime \prime}$ "of months for the north zone, 26" "for the centre and 6" "for the south. In many cases, particularly in the north, the number of actual values for the water properties was small and the interpolated values cannot be considered very reliable,

A conspicuous feature is that the north zone shows the lowest salinities, rather than the centre zone as is the case for the lagoon waters. This is probably due to the seasonal eastward flow through Torres Strait of low salinity Arafura Sea water under the influence of the NW monsoon (Rochford, 1959), together with a possible reduction of salinity due to river runoff from Papua New Guinea (Scully-Power, 1973a).

Fig. 24 'T,S, time diagrams for Coral Sea just outside Great Barrier Rede mean of' $1966-74$ with indication of scatter about mean data from CSIRO Atlas, 1971).

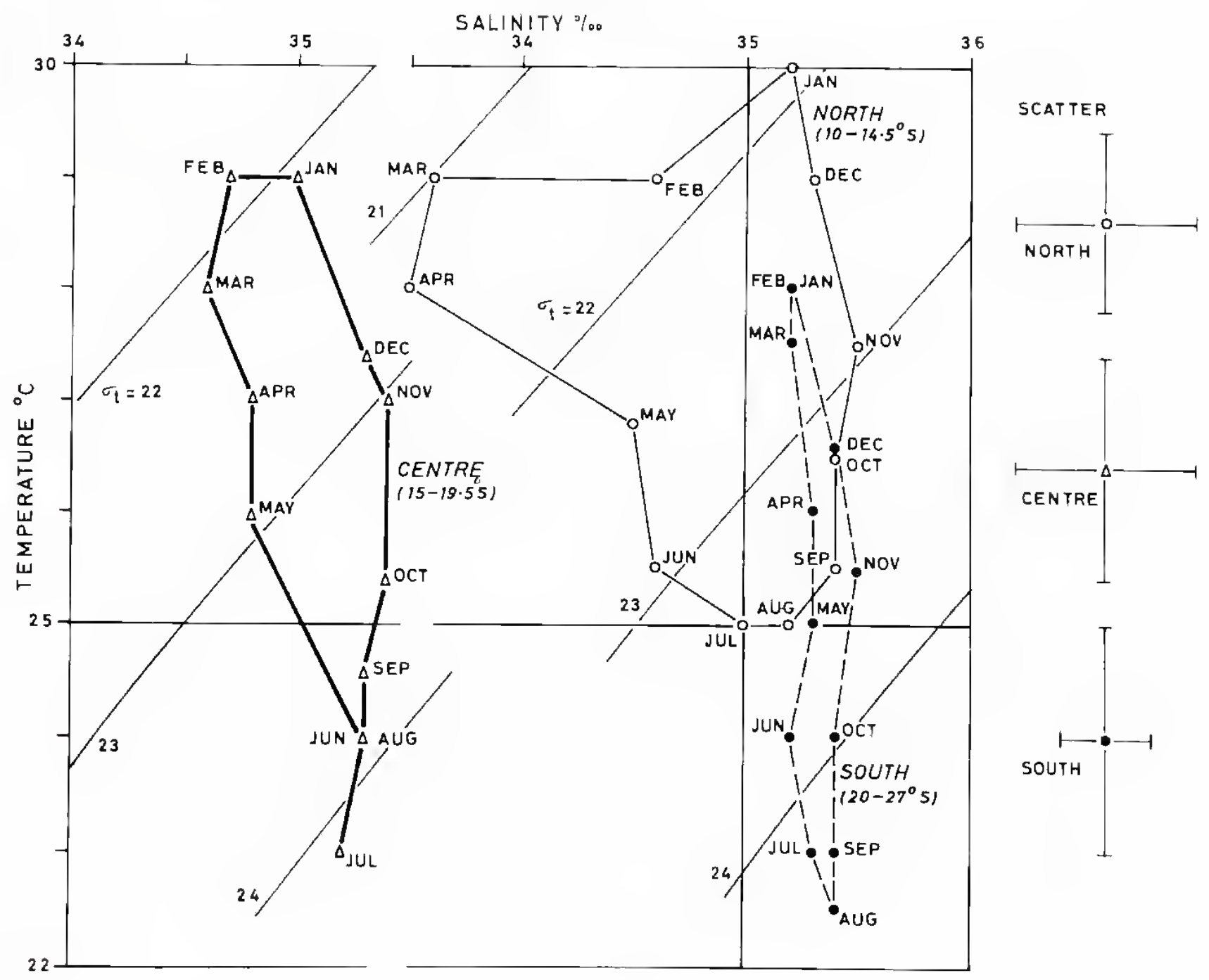




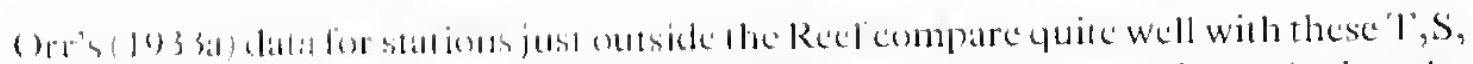

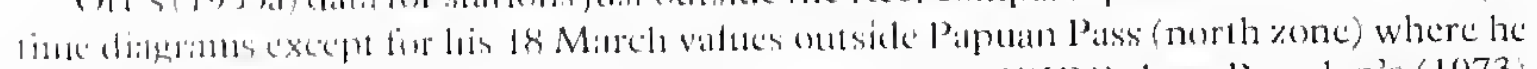

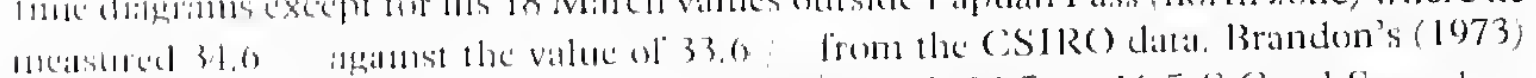

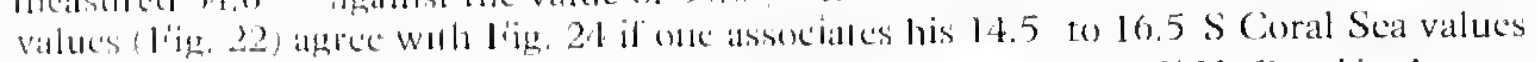

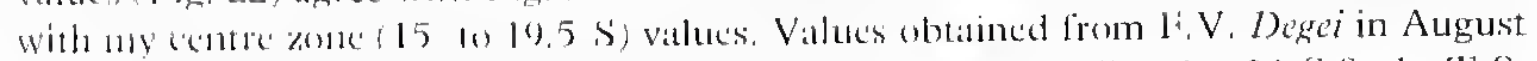

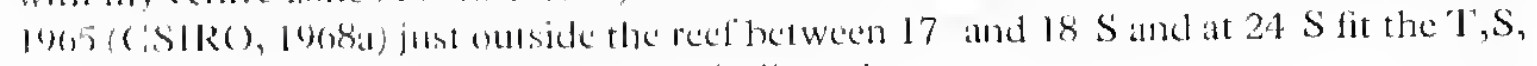

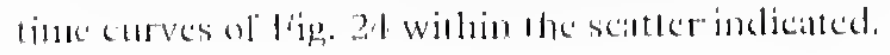

\section{'IIMI'IRAIURI: ANI) SALINITY VARIA'IIONS ACROSS 'IHEL LAGOON- I'UR'IIILR RI:MARKS}

'l'ke difference in lemperat ture and salinity between inshore lagoon watcers and Coral Sea

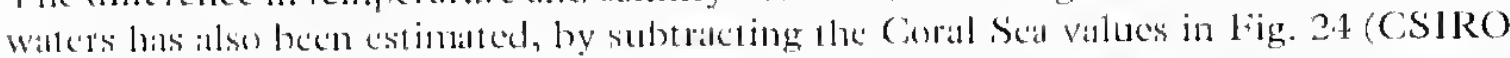

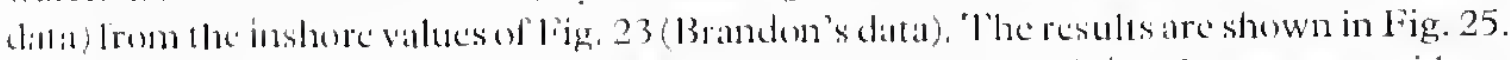

Some of ale expected feitures of the shore un Comal Scat salinity changes are evident, c.g. in tle dry seasom the salinity cleceasess seaward in the north (and possibly in the south)

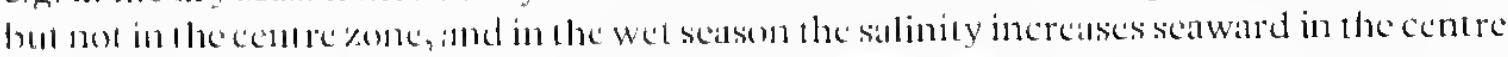
\%onc. An unexpected fuature in the norlh is a decreane in salinity to scaward in the late wet

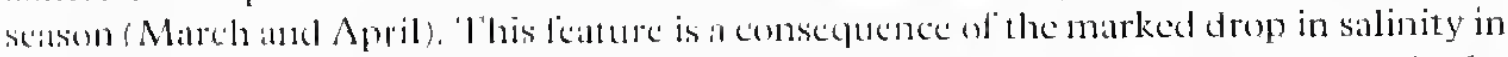

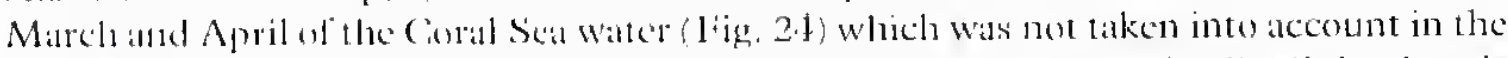

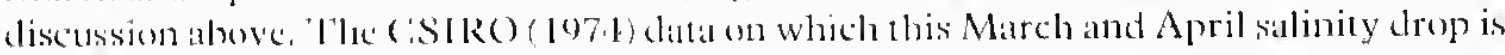
hased ane very scattered for this region and, in the absence of directevidence, the features

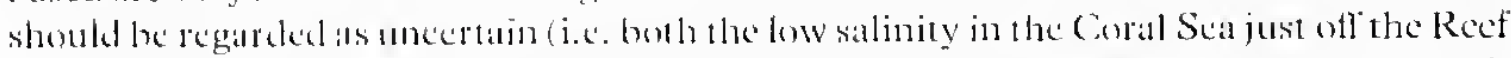

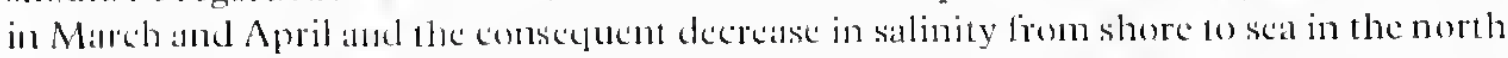

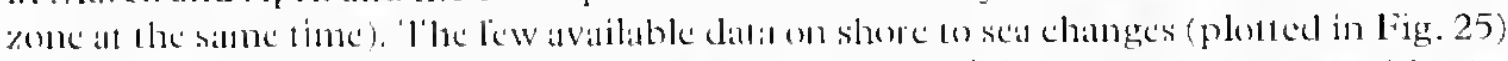
show rough therement although the large values for salinity increase to seaward in the centreyone, wet scisson (Branden's ditti), weeur later than the curve suggests. 'The smaller saldinity diflerences in the south \%one ane 10 be expected from the smaller and less comecent rated randall there than in the norla and centre.

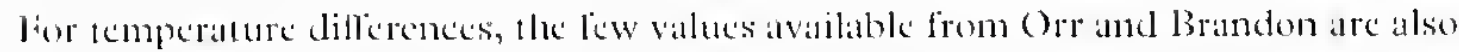
plofled on lige. 25. Aganin Brandon's value in July in the centre zone is much higher than the curve values, hut Ore's centre zone values are smaller and ctose to the curve exeept for November. 'l'he remaining conspicuous leat ture is the marked temperature rise to seaward in the winter in the south zone.

Having derived these curve's and discussed their leatures and Orr's and Brandon's datta, a note of callt ion is in order. lowking at the two tigures (23 and 24) from which lig. 25 was derived, one notes the information on scatter about the points (about $10.8 \mathrm{C}$ and $\pm 0,1$. . I'hese seatter magniludes are indicaled on lijg. 25 and suggess that possibly the only leatures which alle statistically signiticant are the salinity increase to seaward in the ecntre zone in summer and the temperature increase to scaward in the south zone in winter, lf property gradients lrom shore to sea turn out to be important, it will be necessary to verily or redetermine the ligg. 25 inlormation by direct measurement along transects. 'l'he best way to carry out such measurements would probably be to use continuously recording instruments mounted below the surlace in order to avoid the error's introduced by shore term valtations (sce lig. 15 for cxamples of variations associated with weekly sampling or the graph of daily temperature readings presented by Moorhousc, 1933 .

In his Ph.1). Hexis, Branden (1970) included the oceanographic data obtained during his three cruises in Ciape . Hortom and copics of Umitaku Marn data as follows:

\section{liandion}

(1) Cruise (iBR-1)131 67: $17 \mathrm{Sep}$. If $\mathrm{Nov}, 1907$ from 27.0 S $1010.5 \mathrm{~S}$ and return to $15.0 \mathrm{~S}$, surtace samples and verticial prodiles. 
(2) Cruise GBR-DB2 68: 17 Mar.-17 Apr. 1968 from 10.6 S to 27.0 S, surface samples only.

(3) Cruise GBR-DB3/68: 15 June-29 July 1968 from $16.8 \mathrm{~S}$ to $10.5 \mathrm{~S}$ and return to $17.2 \mathrm{~S}$, surface samples and vertical profiles.

\section{Umitaka Maru}

(4) Stations UM6715-6730, 6-12 Dec. 1967 in the Western Coral Sea from $12.0 \mathrm{~S}$ to $18.5 \mathrm{~S}$, surface to $1000 \mathrm{~m}$ or deeper.

Brandon did not present tables of his data obtained on transverse sections across the lagoon from the yacht C-Gem (Brandon, 1970, p. 11).

It would probably be profitable to review Brandon's data in detail.

Fig. 25 Scasonal variations of salinity and temperature differences across Great Barrier Reef lagooninshore value minus Coral Sea value. Full line $-\Delta S$ from Figs. 23, 24; Dashed line $-\Delta T$ from same Figs., Points - triangles $\Delta S$, dots $\Delta T$ (from data of Oır, 1933a, and Brandon, 1973).
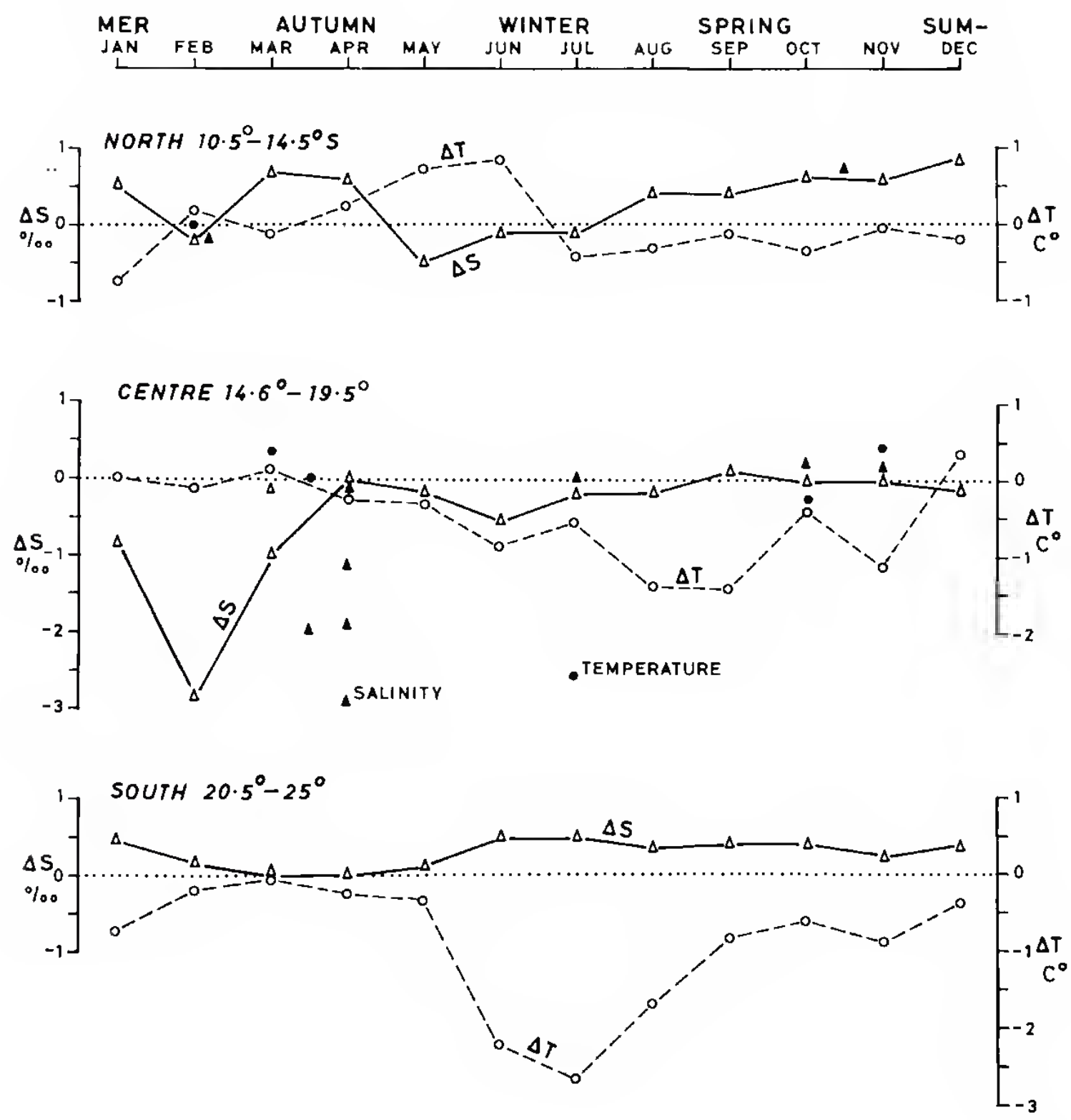

ESTIMATED SCATTER:

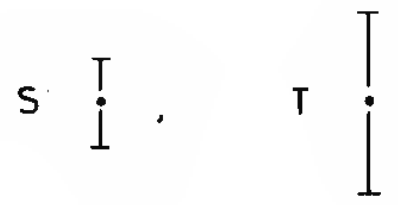




\section{VIII}

\section{Currents}

\section{GREAT BARRIER REEF LAGOON}

The main sources of information on currents are the Australia Pilot $(1962,1973)$ and Sea areas aromend Alstralia (Roy. Neth. Met. 1nst., 1949), both of which base their statements on ship's estimates from their navigation records. In addition, Woodhead (1970) made some drift float measurements in the Capricorn Channel area,

According to the Pilot, the total current is a combination of that due to the wind and that due to the tide. Except in narrow passages, the wind driven current is stated to be the major component. Over most of the lagoon this is due to the SE trade winds and is therefore to the north or north-west, setting fairly along the main channels with a speed of 0.25 to $0.6 \mathrm{~m} 5$ but somewhat less south of $20 \mathrm{~S}$. The reversing tidal currents are superimposed on the wind-driven current. In the open lagoon, this means that there will be a general north or north-west set varying in speed semi-diurnally with the tide. In narrow passages the tidal currents may be stronger and the total current may change direction four times in each 25 hours. In the north zone, the current due to the NW' monsoon wind is less strong than that due to the tides, generally resulting in irregular currents in this zone in December to March with, perhaps, a southerly tendency less than $0.4 \mathrm{~ms}$.

There are a number of remarks in the Pilot about currents in various places along the lagoon, and it is suggested that anyone interested in a specific locality should refer to that publication for any data which may be available. Such information however, comes from an unspecified number of observations irregularly spaced in time and can, at best, be regarded as only an indication of possible water movements.

In Torres Strait, the tidal currents are strong and variable. 'There is considered to be a net set (mean flow) to the west from March to November but an eastward set during the NW monsoon in January and possibly also in December and February, according to the Pilot. Hamon (CSIRO, 1958) states that there is a net flow to the cast between December and March and to the west between May and October, the annual mean transport being zero. The maximum net transport is $0.9 \times 10^{6} \mathrm{~m}^{3} \mathrm{~s}$ in February. (The U.S. Navy Pilot Charts (U.S.N.O.O., 1955) show a westward flow through Torres Strait even in December to February but this must be an error.)

Sea areas around Australia (Roy, Neth. Met. Inst, 1949) presents information on currents in the Reef area in two forms: (a) monthly charts of mean current vectors in one degree squares and (b) current roses for two locations in the lagoon. The data were obtained from ships' logs from several countries and for different periods between 1880 and 1939.

As Wyrtki (1960) has pointed out, vector avcrages give too small values for the mean speed and no information at all on variability. In addition, the number of observations in the Barrier Reef lagoon area 1 squares varies from 1 to 23 per month. South of 19 S there are usually 5 or more observations for each square but north of that there are often none or only 1 or 2 observations. All months in the first set of charts above, with five or more current observations in the lagoon, were reviewed. With that criterion there is no information from 10 to $15 \mathrm{~S}$. From 15 to $20 \mathrm{~S}$ there is a net flow to the north for most of 
the year, with southward How in October to December. South of $20 \mathrm{~S}$ there is a net flow south, which is contradictory to the information in the lilot, although the mean speed is only about $10 \mathrm{~km}$ per day $(0.1 \mathrm{~m} \mathrm{~s})$. Probably only limited weight should be given to this source of information for scientific use. Its main value is presumably to alert masters of vessels to regions where significant currents have been observed in the past (and therefore might be in the future).

The second presentation is limited to two locations for the lagoon, at $19 \mathrm{~S}$, NE of Townsville, and at $23.5 \mathrm{~S}$, NE of Rockhampton. For these positions, current roses are given with frequency of occurrence and speed for 16 directions for each month. Most directions are represented for most months but the predominant ones are:

\begin{tabular}{|c|c|c|c|c|c|c|}
\hline \multirow[b]{2}{*}{ Position } & & \multirow{2}{*}{$\begin{array}{l}\text { Av. obs. } \\
\text { per month }\end{array}$} & \multicolumn{3}{|c|}{ Dircction sector of flow } & \multirow[b]{2}{*}{ Av.. speed } \\
\hline & & & Calm & $\mathrm{W}^{\prime}$ to $\mathrm{N}$ & E to $\mathrm{S}$ & \\
\hline $19 \mathrm{~S}$ & $147.5 \mathrm{E}$ & 49 & $16^{\prime \prime \prime}$ & 33 & $322^{\prime \prime}$ & $0.4 \mathrm{~ms}$ \\
\hline $22.5 \mathrm{~S}$ & $150.1 \mathrm{E}$ & 52 & $10^{11}$ & $23^{11}$ & $39^{\prime \prime}$ & $0.4 \mathrm{~ms}$ \\
\hline
\end{tabular}

At $19 \mathrm{~S}$, the $\mathrm{W}$ to $\mathrm{N}$ direction of flow is favoured for the first half of the calendar year and the $\mathrm{S}$ to E direction for the second half; at $22.5 \mathrm{~S}$ the E to $\mathrm{S}$ direction is favoured all year. It is hard to reconcile this information with the Pilot's prefcrence for a predominant $\mathrm{N}$ or NW set, but equally hard to ignore it. The E to $\mathrm{S}$ tendency at the $22.5 \mathrm{~S}$ location is consistent with Woodhead's results, to be described next.

Woodhead (1970) made some measurements of water movements in the Swain Reefs to Great Sandy Is. region (22 to 24 S) by means of surface drifters consisting of a $22 \mathrm{~cm}$ dameter polypropylene plate with a $1 \mathrm{~m}$ long rod perpendicular to it and ballasted to float with most of the rod submerged. The drifters were dropped in bundles of a dozen from an aircraft. To determine "the extent to which the surface drifters were affected by wind driven movements of the surface layers' Woodhead compared the deduced drift directions for drifters released near Heron Is. with the wind at that station. During the period of the experiment, the directions towards which the wind was blowing were in the quadrant from NW to SW while the drifters were found in a quadrant from W to $S$. Woodhead concluded from this that 'the prevailing winds had not had predominant effects on the movements of the drifters.' In this conclusion, Woodhead ignored the fact that a wind-driven current would tend to be directed somewhat to the left of the wind, i.e. morc toward the direction in which the drifters moved, than in the actual wind direction. He also used only the $0900 \mathrm{hr}$ wind at Heron Is. whereas at that time of the year the winds tend to back in the afternoon, their direction then tending towards the $W$ to $S$ quadrant, near to the observed drifter motion. In other words, it is probable that the drifter movements werc not really independent of the local wind, nor is it probable that they should bc (c.g. see von Arx's (1948) comment quoted below, and results under "T he barrier recf lagoon off Noumća, New Caledonia'.)

Driftcrs were released at 5 to 7 stations each on four lines oriented at about 060 true starting close to the mainland as shown in Fig.26. Lines 2, 3 and 4 were laid on 18 September 1966 and line 1 on 3 October. About 25" of the drifters were recovered, mostly on the central Queensland coast between 23.5 and $26 \mathrm{~S}$, but some from as far as southern N.S.W.

As usual, only the release and rccovery points were known, while the time from releasc to recovery was an upper limit to the drift time, so that any calculated drift speed was a lower limit. Woodhead gives only two specds - to Jervis Bay (35 S) at $0.39 \mathrm{~m} / \mathrm{s}$ (32 km/day) and to ' 450 miles of NSW coastline' with a mean speed of $0.3 \mathrm{~m}$ 's $(25 \mathrm{~km} /$ day $)$. Most of these travels would be in the East Australian Current. 


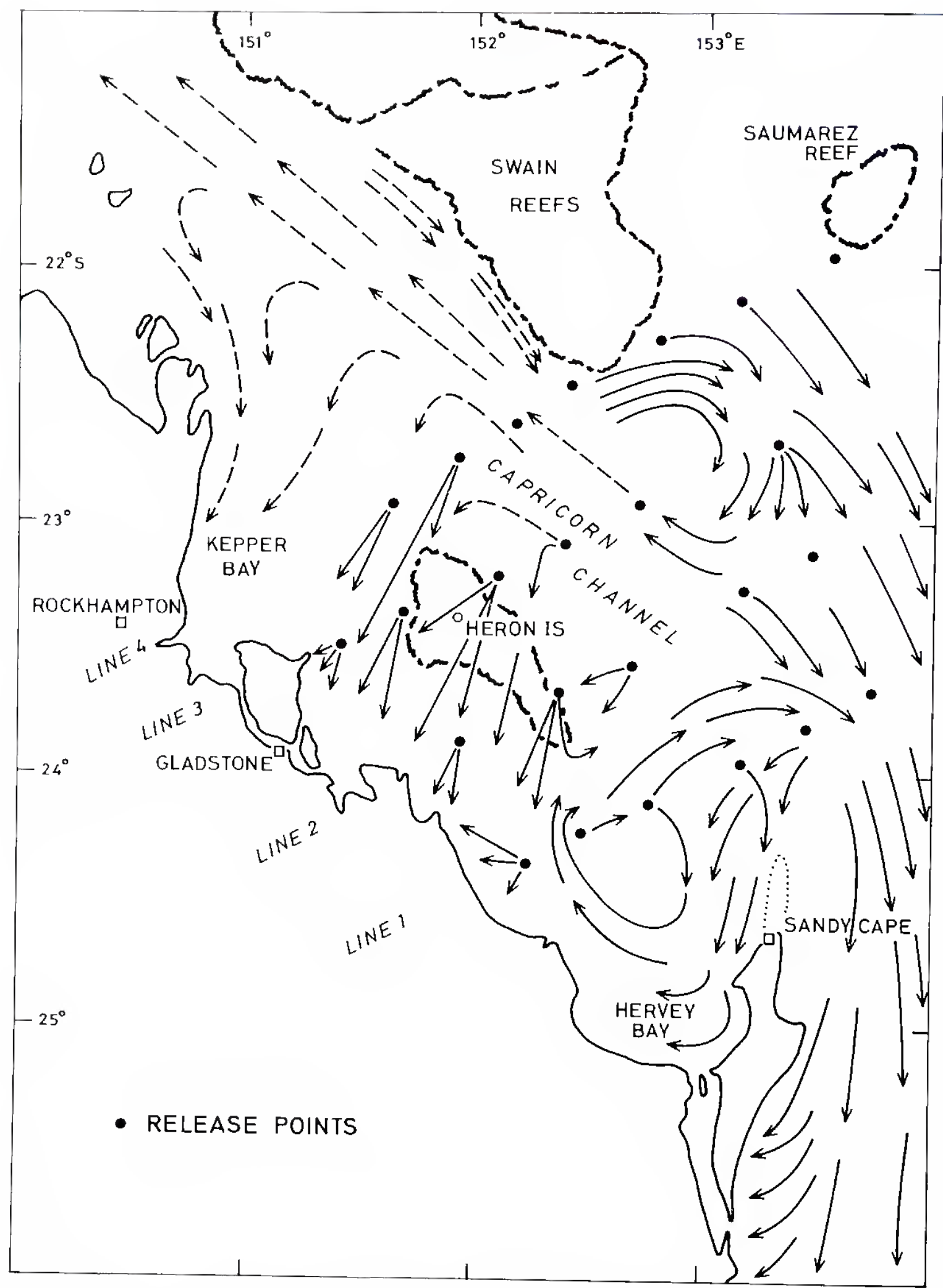

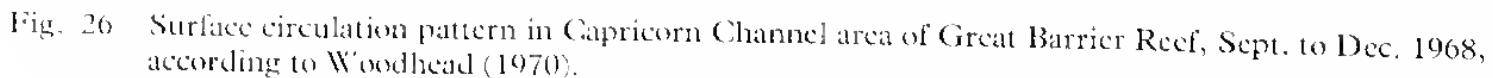


Many of the lines drawn from release to recovery points crossed, for all lines of releases and particularly from lines 1 and 3. This made the interpretation difficult. Fig. 26 (redrawn from Woodhcad's Iig.8) shows W'oodhead's interpretation of the circulation, assuming a steady state over the period of $3 \frac{1}{3}$ months to the end of 1966.

Referring to Fig.26, the north-westward flow up the Capricorn Channel was deduced from three drifters from lines 3 and 4 together with the lack of any recoveries to the south of the stations from which these came. This is somewhat negative evidence, although a NW flow under the influence of the SE trades is to be expected (by the Pilot at least). Woodhead assumed that all of the NW flow could not continue un the lagoon and that some of it must return in his postulated SE flow immediately south of the Swain Reefs. It is not ccrtain that this countercurrent is necessary-water could equally well flow out over the outer reef or through it. "The clockwise circulation in Hervey Bay (25 S) is attributed to the trade winds which "would also help maintain such an eddy within the Bay." Woodhead does not point out that lateral shear across the wind system would be necessary to generate the vorticity associated with such a circulation. One of the features which is difficult to accept for a steady state circulation is the apparent crossing of flow directions north of Sandy Cape (at about $24 \mathrm{~S}$ ).

The 22.5 S current rose position in the Sea areas around Australia atlas is in the region of Woodhead's study where there are both NW and S components of flow according to him, so the two are consistent if his results are not from a steady state circulation but from one which changed with time.

It may be noted that Wyrtki (1960) paid little heed to the Barrier Reef as an obstacle to surface water flow. In his monthly charts for the Coral and Tasman Scas he showed current arrows and streamlines passing over the wider part of the Reef between 19 and $23 \mathrm{~S}$ (Swain Reef area) for all months and also stated "to the north of Gt. Sandy Is. . . the Coral Sea water masses which flow over the shelf between the mainland and the Gt Barrier Reef are integrated into the (East Awstralian) current'.

\section{OTHER LAGOONS}

In vicw of the paucity of data on circulation in the Barrier Reef lagoon relevant portions of several papers concerned with other lagoon areas are reviewed.

Bikini and Rongelap Atolls (Marshall 1s., approx. $11.5 \mathrm{~N}, 166.0 \mathrm{E}$.

Von Arx (1948) described a fairly detailed quantitative study of the eirculation in two atolls, Bikini and Rongelap. While there are notable differences between an atoll and the Great Barrier Reef lagoon, particularly the impervious barrier at the leeward side of the latter compared to the leaky barrier of an atoll, there are some similarities so that the information about an atoll may at least give hints for the Barrier Reef. Two statements by Von Arx should be noted initially, first that 'most of the water motion in the lagoon is produced by wind traction at their surfaces' and second that 'the exchange of lagoon water with that of the sea is accomplished in the trade wind season by tides and wave action.'

An atoll basically consists of a shallow lagoon bounded by a recf, usually with passes connecting the sea with the lagoon. The atoll teef consists of a broad annular waterfilled terrace bounded on the seaward side by a bulwark of coral (marginal shelf reef), over and through which water passes, and on the inner side by an island strip interrupted by passes. For Bikini, the terrace water level was about $0.5 \mathrm{~m}$ higher than in the lagoon and about one-third of the daily new water inflow to the lagoon came by this route from the ocean, over the outer reef into the terrace and thence through the passes between the islands. The average speed of flow across the terrace was $0.5 \mathrm{~m} / \mathrm{s}$.

The wind stress over the lagoon (average depth about $50 \mathrm{~m}$ ) gencrated a downwind flowing surface layer current of 5 to $20 \mathrm{~m}$ thickness (average $13 \mathrm{~m}$ during the trade wind 


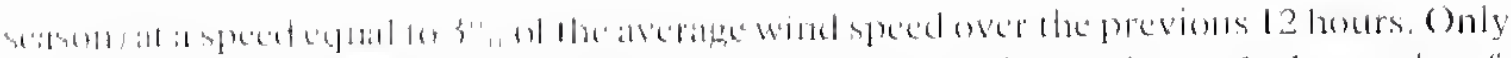

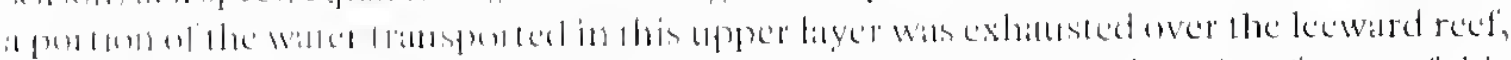

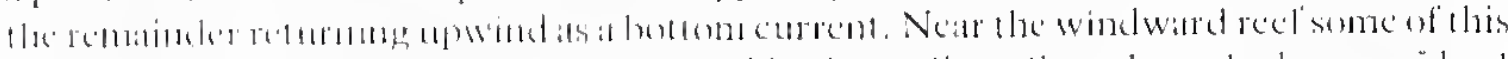

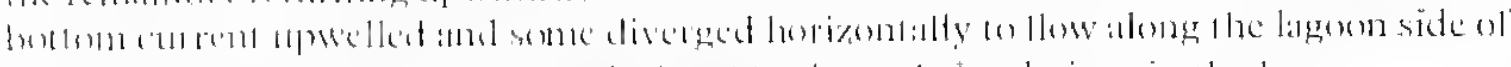

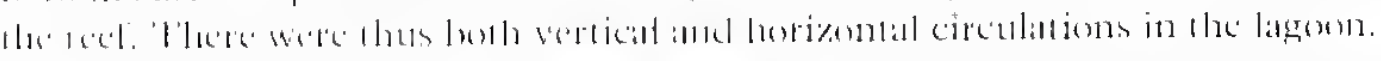

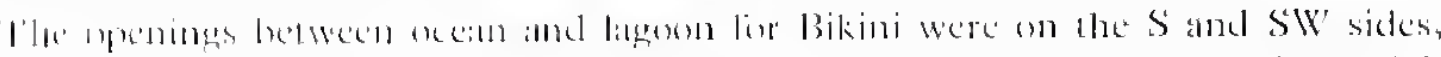

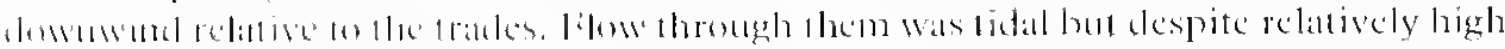

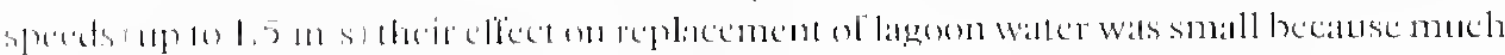

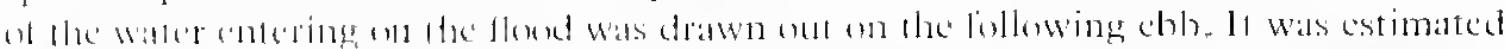

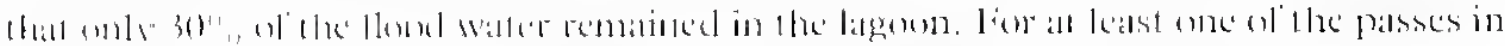

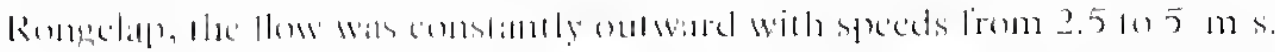

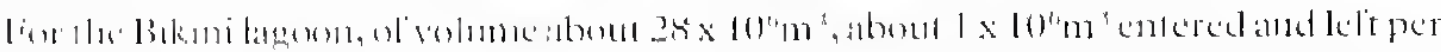

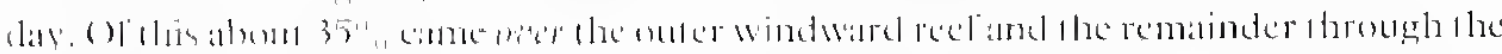

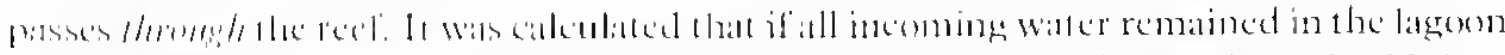

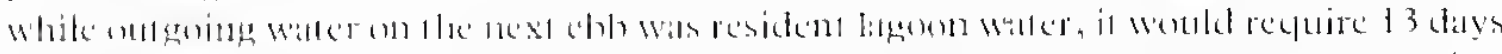

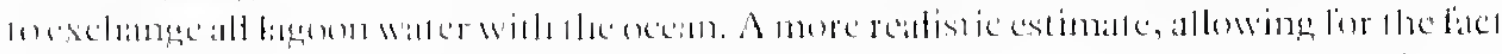

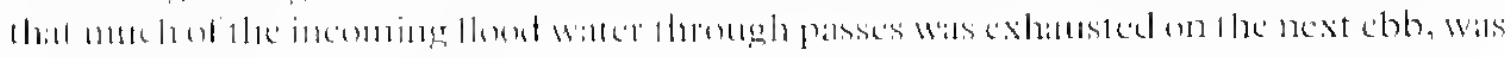

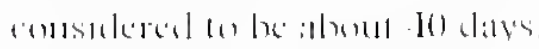

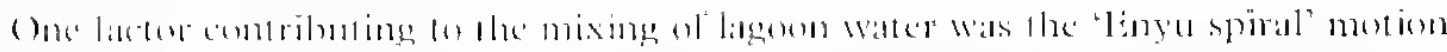

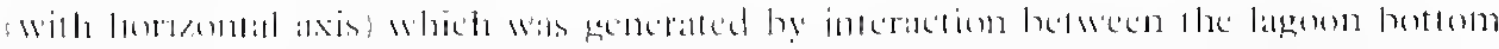

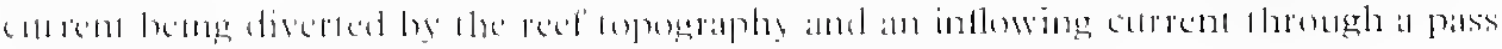

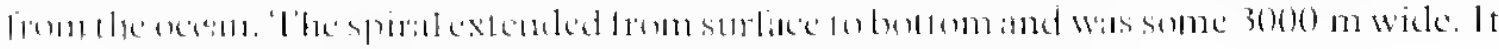

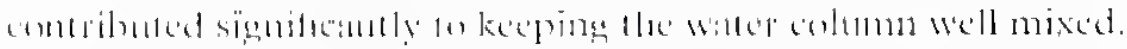

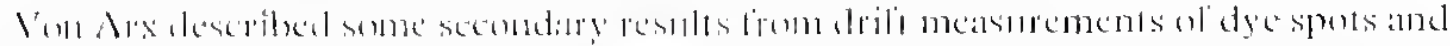

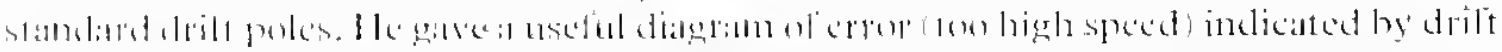

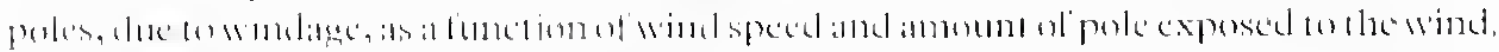

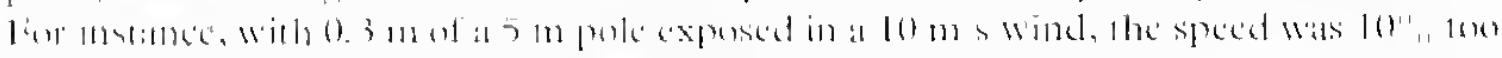

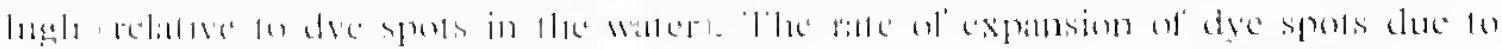

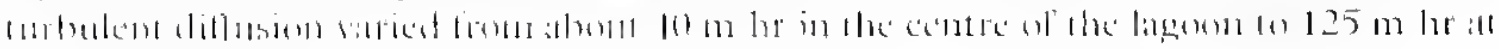
1lu wimlainlal side.

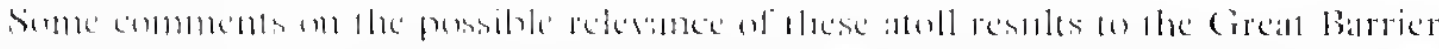

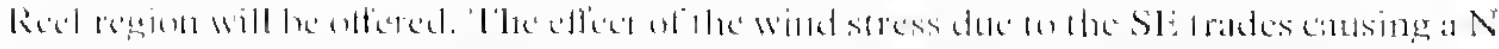

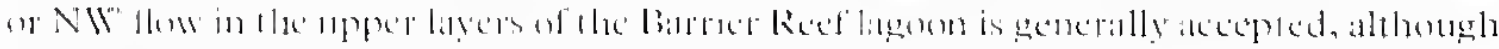

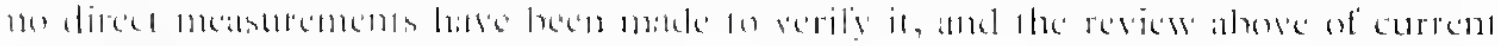

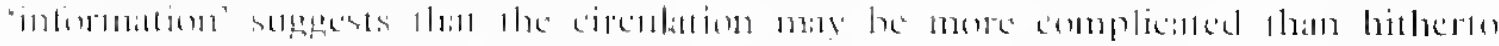
:

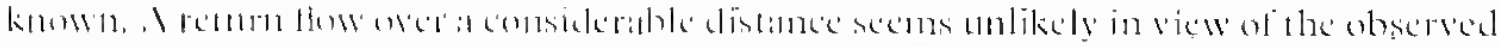

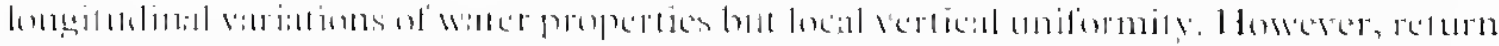

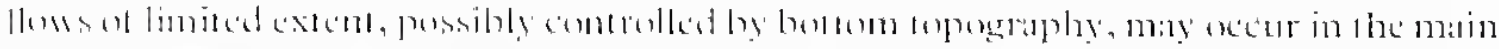

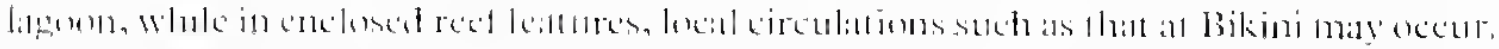

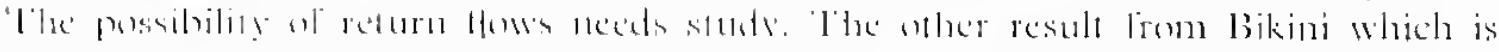

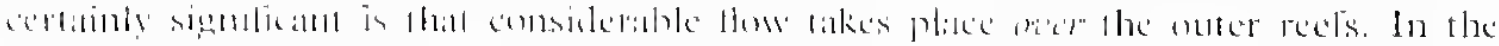

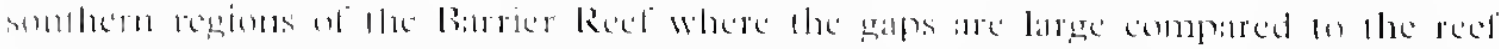

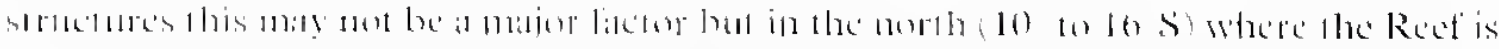

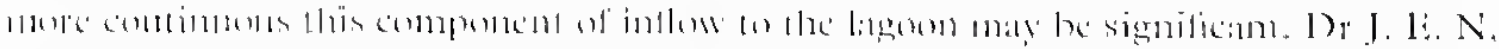

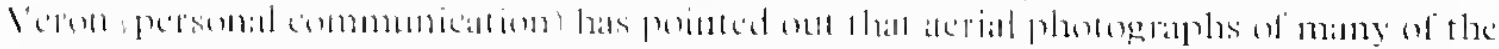

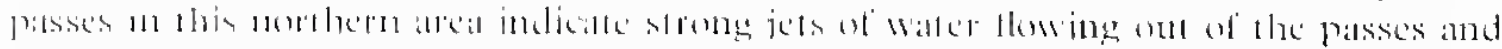

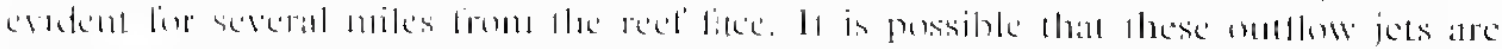

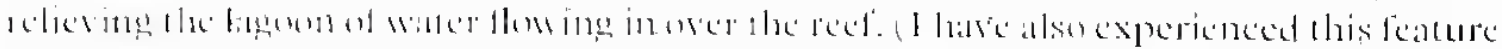

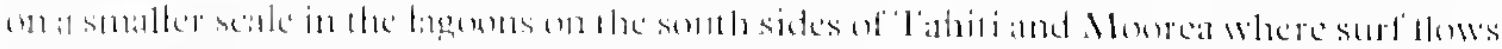

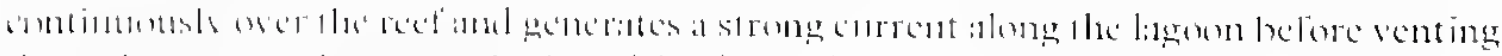

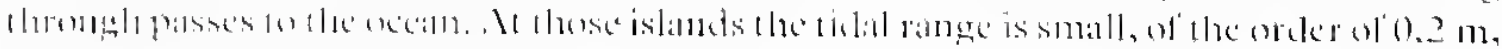

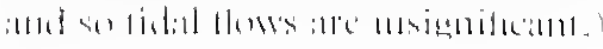




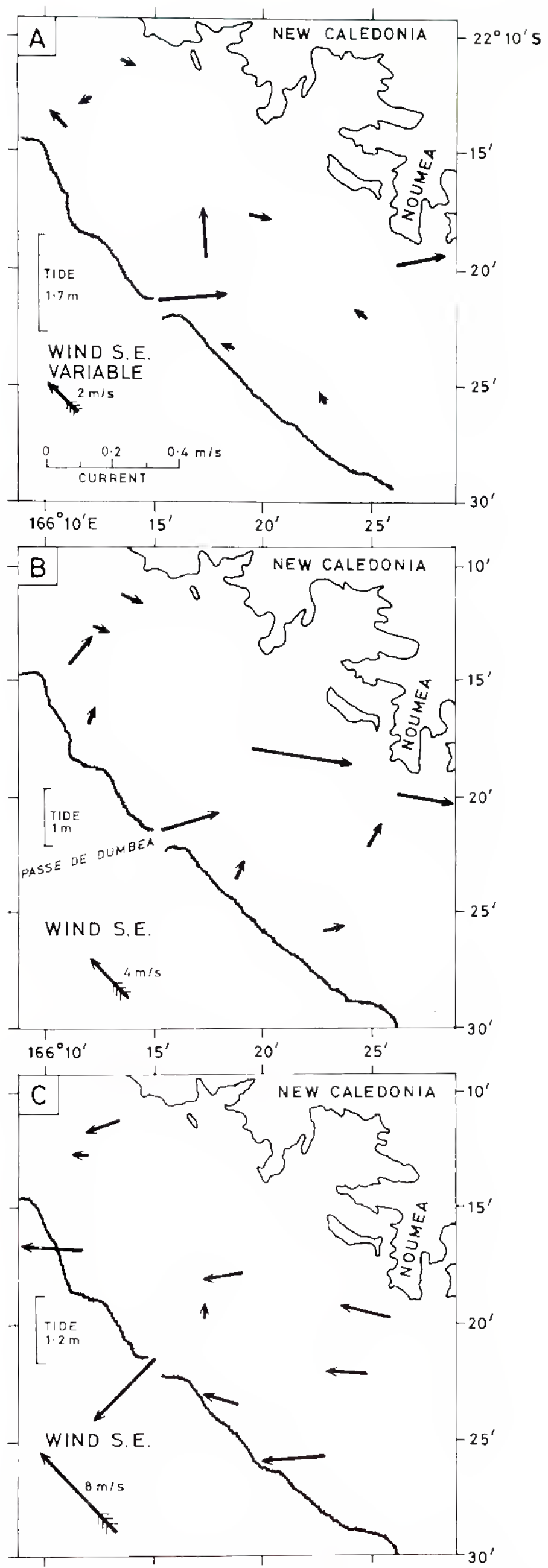

Fig. 27 Mean flow pattorns in New Caledonia bartier recf lagoon off Noumca for three combinations of wind and tide: (A) light wind, spring tide, (B) light wind, neap tide, C) strong SE wind, intermediate tide. 
In the eomplicated structure of the Barrier Reef lagoon, there are likely to be many regions where currens may meet and generate vertical components of motion, after the fishion of the "Enyu spiral" at Bikini, and assist in vertical mixing.

\section{Ouotoa Atoll Gillet Is, $1.8 \mathrm{~S}, 175.5 \mathrm{ES}$}

Cloud 1952$)$ described some observations of water movement on the reef flat and edge on the east (windward) side of Ouotoa Atoll where there are extensive islands blocking flow into the lagoon. During the ebb, dye placed in the water on the reef flat showed a tendeney For seaward flow at the bottom, eventually reaching the surge channels leading to the ocean. No measurements were made during the flood.

\section{Addu Atoll Maldive Is, $0.6 \mathrm{~S}, 73.2 \mathrm{E}$}

According (o) the Ifest Coast of India Pilot (quoted by Stoddart, 1966) there is a reversing tidal current through one of the SE passes but a constant outflow through the neighbouring pass only $4 \mathrm{~km}$ away. "The same situation occurs in the two passes on the north side only $2 \mathrm{~km}$ apart. It was also stated that continual wave action on the reef edge, together with tidal variation, sends a continuous sheet ol water across the reef flats, particularly between islands', and that current measurements with floats and fluorescein dye at higin water gave current speds of 0.5 to $1.0 \mathrm{~m} \mathrm{~s}$ lagoonward.

\section{Rangiroa Atoll Tuunotu Ls, $15.0 \mathrm{~S}, 1+7.5 \mathrm{WF}^{\mathrm{r}}$}

Michel ct al. (1971), in a study of the atoll of Rangiroa, found that while the barrier reef permitted ocean water to enter the lagoon over the reef when the ocean swell from the east broke on the outer edge, especially near high water (tidal amplitude about $1 \mathrm{~m}$ ), very little w'ater passed out over the reef even on the "down-swell" side of the atoll. Apparently all the discharge was through the passes on the north side 240 and $300 \mathrm{~m}$ wide, 14 and $6 \mathrm{~m}$ deep respectively). Current measurements in the deeper of the passes gave values up to $2 \mathrm{~m} \mathrm{~s}$ for both flood and $e b b$, with a rapid change of direction and very brief slack water. (The flood and ebb appear to be of equal speed and duration and therefore it is not clear why it was argued that all the over-the-reef inflow had to go out via the passes, unless the volume of reef inflow was small compared to the tidal component through the passes. Von Arx found the reel intlow about $30^{\prime \prime}$ " of the total.

At times, when a particularly heavy swell broke over the reef, the water level in the lagoon was raised and the flood period was reduced from about 6 hours to as little as 2 hours.

Another significant feature related to the flow through the pass was that the strong currents generated an upwelling of water from below sill depth on both flood and ebb and carried this water into or out of the lagoon. This was evident both from observations of water properties and from direct measurements of currents close to the passes. Although volume flow's were not estimated it was observed that lagoon water properties were always close to those ol the ocean water outside and it was judged that exchange between lagoon and ocean must have been fairly rapid.

\section{lianning Atoll / Linc Is, $3.8 \mathrm{~N}, 159.3 \mathrm{Il}^{\circ}$}

Current and tidal measurements in Fanning Atoll lagoon were described by Gallagher et al. (1971) and showed many interesting (and puzzling) features. Those which relate to the Barricr Reef are (a) that the currents through the passes were tidal and showed a very rapid change from flood to ebb and vice versa, as for Rangiroa; (b) that there was very limited mixing between the clear oceanic tidal water inflow and the very turbid lagoon water, as von Arx found for Bikini; (c) the water going through the main pass formed a sharply defined jet into or out of the lagoon, as has been observed, at least for the outflow, for the Barrier Reef passes. 
The barrier reef lagoon off Noumea / New Caledonia, $22.3 \mathrm{~S}, 166.4 \mathrm{~F}$

The most ambitious current measurement project to date in a barrier reeflagoon was carried out off Noumea on the SW side of New Caledonia between 6 December 1974 and 10 January 1975. This was a joint study by the O.R.S.'1.O.M. Centre de Nouméa, the Horace Lamb Institute of Oceanography, South Australia, and Flinders University, South Australia (Jarrige et al., 1975). Eleven current measurement stations and five tide gauge stations were established in a section of the New Caledonia lagoon, about $28 \mathrm{~km}$ long in a NW-SE direction and $17 \mathrm{~km}$ wide, between the barrier recf and a line along the outlying points of the New Caledonia mainland. (There are several extensive shallow bays on the landward (NE) side of this line. 'l he reef is continuous except for a major pass (Passe de Dumbea) near the centre of the section studied. The mean water depth is about $19 \mathrm{~m}$ and the current meters were set at $5 \mathrm{~m}$ from the bottom in all cases. To the south of the section there are numerous wide openings in the reef; to the north the rect closes the land and the water becomes shallower.

Three periods between 27 December and 7 January when the records were most complete were selected for analysis, with the following results (see Fig. 27 for mean flow patterns, items (iii) below):

(a) light wind, spring tide ( $1.7 \mathrm{~m}$ range):

(i) flood - - general flow to the NW in the lagoon with inflow at the pass:

(ii) ebb - gencral flow to the SE in the lagoon with outflow at the pass;

(iii) mean flow (averaged over a whole number of tidal cycles to eliminate, as far as possible, tidal effects)

- net flow to the NW inside the rect and SE near the land, with net flow in through the pass.

(b) light wind, neap tide ( $1.0 \mathrm{~m}$ range):

(i) flood - currents weaker than in (a) (i) with some indications of NW flow inside the reef area and SE along the land; inflow through the pass,

(ii) ebb - currents weaker than (a)(ii) with some indication of SE How everywhere; inflow through the pass,

(iii) mean - shoreward flow inside the reef and SE flow near the land; net flow in through the pass.

(c) strong SE trades, intermediate tide ( $1.2 \mathrm{~m}$ range):

(i) flood - W or NW flow everywhere and slight inflow through the pass,

(ii) ebb - W or NIW flow everywhere and strong outflow through the pass,

(iii) mean - chiefly $\mathrm{W}$ to $\mathrm{NW}$ flow and outflow through the pass.

The most conspicuous feature was the marked effect of the SE trades (as in (c) (iii)), the strong $\mathrm{W}$ flow becoming established within one day of the wind starting. It is also interesting to note that across the southern part of the region, the mean displacement of a water particle in 24 hours was of about the same magnitude as the dimensions of the region, i.e. the flushing characteristics should be good. It was pointed out in the discussion. of the results that there are indications of significant flow over the reef, especially in light winds and neap tides (case (iii) above), but no estimate was made of the relative magnitude of this component (P. Rual, personal communication). The reasons for the net flow (tidal effect removed) during light wind conditions i.e. (a) (iii) and (b) (iii) above, are not yet understood. It is noted however that for the (a) and (b) cases the wind was not zero, but about $3 \mathrm{~m} / \mathrm{s}$ compared to $8 \mathrm{~m} / \mathrm{s}$ for case $(\mathrm{c})$.

O.R.S.T.O.M., Section d'Océanographie, plans an intensive field program to study the New Caledonia barrier reef lagoon starting in June 1976. 


\section{IX \\ Summary}

'I'he Great Barrier Recf extends for about $2300 \mathrm{~km}$ along the cast coast of Queensland from ahout 9 to $25 \mathrm{~S}$ (Fig. 1) with the outer recfs at 23 to $260 \mathrm{~km}$ from the shore. It hounds a lagoon, very much broken up by reels, having a mean depth of $35 \mathrm{~m}$ and in which cepths over $60 \mathrm{~m}$ are uncommon. The most continuous deep passage is near the shore.

I'he winds are chiefly from the south-east, but the NW' monsoon winds penetrate as far south as $15 \mathrm{~S}$ in 1 )ecember to February (Fig. 4). 'The annual mean air temperature and the range from annual minimum to masimum are, respectively, $27 \mathrm{C}$ and $9 \mathrm{C}$ at $11 \mathrm{~S}$ and 22 C and 190 at $25 \mathrm{~S}$ ( Trigs. $5,6 \%$.

'the muan annual rainfall is about $1500 \mathrm{~mm}$ with a peak of about $4000 \mathrm{~mm}$ at $17 \mathrm{~S}$ ( 1 ig . 7), Year-to-year veriations are large, and very heavy rainfalls in short periods of time are characeristic of the January to March period when tropical depressions and eyclones oceur. About $70^{\prime \prime}$ " of the annual rainfall oceurs in January to March in the 10 to $20 \mathrm{~S}$ zone hut it is more uniformly distributed south of $20 \mathrm{~S}$. 1nformation on raintall away from the land is scanty and on river runofl is incomplete, but it is estimated that the rivers contributu about one half ats much fresh water as does rainfall directly on the lagoon (Fig. 9). As the river runoff is highly localised at the coast, this component of fresh water ean be expected to be mportant both physically and biologically.

lides have a range of about $3 \mathrm{~m}$ at springs along most of the coast, increasing to 6 to 9 m between 21 and $23 \mathrm{~S}$ (Broad Sound arca, lig. 13). 'They are basically semidiurnal with diurnal inequality increasing to the north unt il they become almost diurnal in Torres Strait (1ig. 12).

'The mean surface water temperature has its maximum in January or February and minimum in July', these values average $29.5 \mathrm{C}$ and $24.5 \mathrm{C}$ in the north third of the lagoon, decreasing to $27.5 \mathrm{C}$ and $20.5 \mathrm{C}$ in the south third (Fig. 17). Temperatures during four years at 'lownswille $(19.3 \mathrm{~S})$ and one and a half years in Moreton Bay (27.3 S) showed ranges of temperature during individual months of up to $4 C$ when the annual range of montlyly mean temperature was about 9C (Fig. 16).

Surface salinity in the north has a flat minimum of 34 from February to May and a maximum of 36 in November Decunber. In the south, the minimum is 35.2 and maxinum 35.8 at the same times. 1 the central third of the lagoon the salinity has a shap minimum of less than 32 in liehruary increasing to a maximum of over 35 in October (Fig. 19).

The scasomal cycle of temperature and salinity is well shown in the T, S, time diagrams (1) Fig. 23.

for most of the year the water column is well mixed vertically; stratification occurs unly an a consequence of the fresh water input of rain and river runoff in January to March w April, and then mainly in the upper $10 \mathrm{~m}$ (Figs. 15, 20, 21). Density changes in the water are determined chicfly by temperature changes from April to December but by sallinity changes from January to March (Figs. 21, 23),

Dismolved oxygen has only small variations at all depths, e.g. for a year at Low 1s. at $28 \mathrm{~m}$ depth, $90{ }^{\prime \prime}$, of the values were between 4.1 and $4.8 \mathrm{ml} 1$ ( 88 to $97^{\prime \prime}$ "saturation).

1t should be noted that only one systematic time-series of oceanographic observations of the water column has been made, by Orr near Low Is. (16.4 S) during the Great Barrier Reef Lispedition 1928-29 (Figs. 15,20,21). The remaining observations are from cruises 
covering parts of the lagoon during periods of a few weeks, or from irregular observations of surface properties at various points along the lagoon.

There is very little information on interaction between the waters of the lagoon and those of the Coral Sea outside. Surface data compiled hy CSIRO indicate that there are significant annual cycles of temperature and salinity outside the Barrier Reef (Fig. 24).

The tidal currents are semi-diurnal in character. North of $17.7 \mathrm{~S}$ the flood is generally to the north or north-west at average speeds of about $0.25 \mathrm{~m} \mathrm{~s}$ in the open waters, while south of $17.7 \mathrm{~S}$ the flood is to the south or south-east averaging $0.5 \mathrm{~m} \mathrm{~s}$. II'thin about $100 \mathrm{~km}$ of Broad Sound $(22 \mathrm{~S})$ the flood and ebb tend to be radially in or out respectively. At spring tides the speed is about 1.5 times the average; at neaps it is about 0.5 times the average. In passes and constrictions, currents of up to $2 \mathrm{~m} \mathrm{~s}$ are experienced.

Information on mean currents is sparse and conflicting. The only actual measurements of any sort appear to be from the drifter study by Woodhead in the south. No records of direct measurements in the water column below the surface have been located. The only sources of information are the Australia Pilot and the Royal Netherlands Meteorological Institute atlas, both for surface currents. These two sets of information were derived from ship's navigation logs.

The Pilot states that the mean current is to the north or northwest along the whole lagoon generally at 0.25 to $0.6 \mathrm{~m} \mathrm{~s}$ but less than this south of $20 \mathrm{~S}$ and north of $15 \mathrm{~S}$ during the NW" monsoon. The Dutch atlas, in its one degree square mean current vector set, has no information from 10 to $15 \mathrm{~S}$; from 15 to $20 \mathrm{~S}$ it shows a southerly set from October to December and northerly from January to September; and from 20 to $25 \mathrm{~S}$, a southerly set of about $0.1 \mathrm{~m} \mathrm{~s}$. In the current rose data set, for $19 \mathrm{~S}$ the rose indicates that $33^{\prime \prime}$ "of recorded sets (predominantly in January to June) are directed between west and north, while 32 " (predominantly in July to December) are between cast and south. The 23 S rose shows 23 " of the currents directed hetween west and north and 39 " between east and south, the latter being distributed over the whole vear. The speed values average about $0.4 \mathrm{~m} \mathrm{~s}$ at both locations.

Woodhead's observations of drifters released at 22 to $24 \mathrm{~S}$ in September-October and recovered during the following three months showed prevailing net flow to the south or south-east, in agreement with the I) utch atlas information for $23 \mathrm{~S}$ (1 ig. 26).

A series of current measurements in the New Caledonia barrier reef lagoon in 1974- 75 showed that while both wind and tide contributed significantly to the circulation, other (undetermined) factors may also have influenced the flow. 



\section{PART 2}

The Western Coral Sea

by

G. L. Pickard

J. R. Donguy

C. Henin

F. Rougerie 


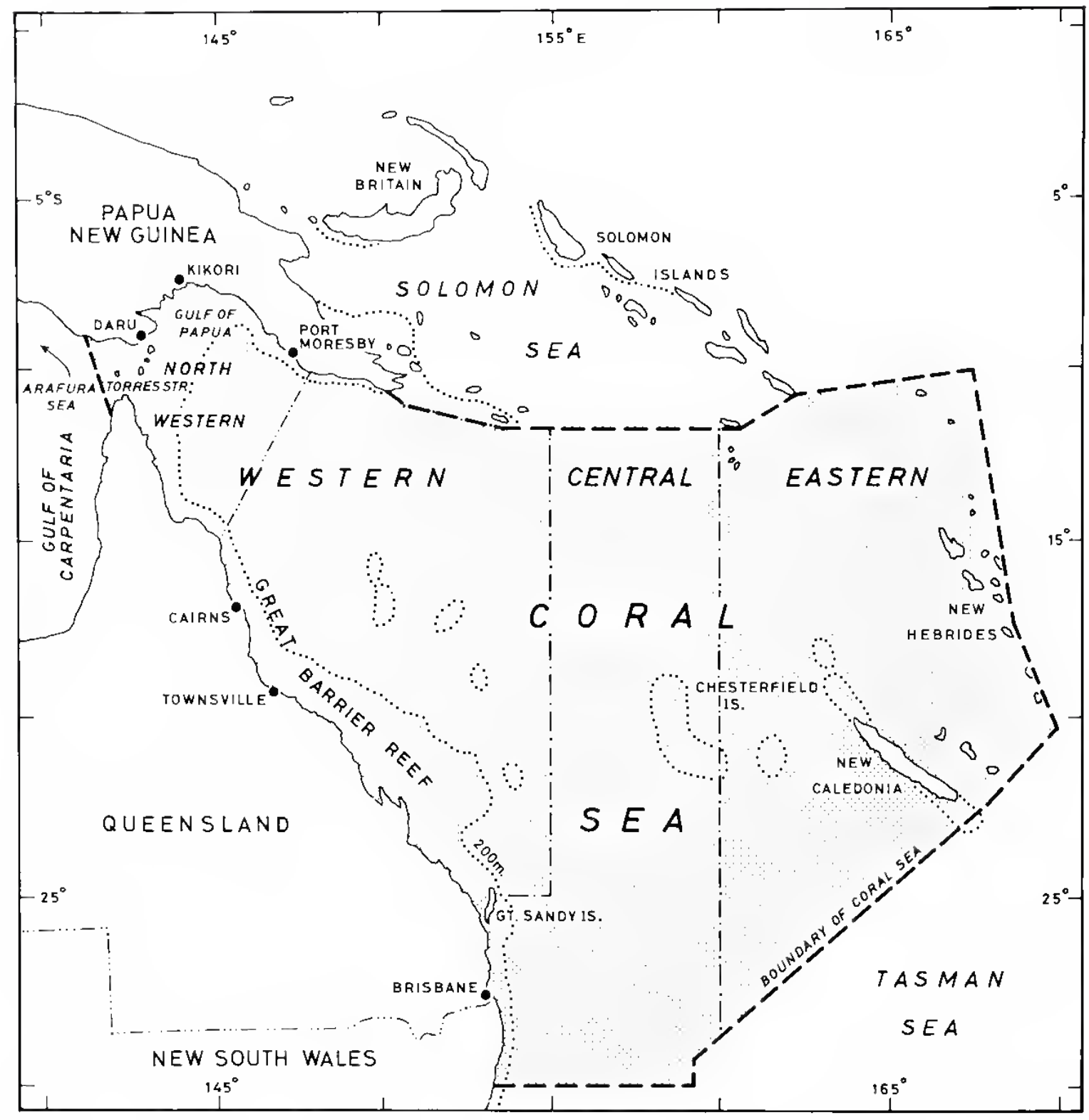

Fig. 28 The Coral Sea, and divisions used in this review. 


\section{I \\ Introduction}

Rotschi \& Lemasson (1967) reviewed in considerable detail the knowledge available on the oceanography of the whole of the Coral and Tasman Seas up to about 1965. The present work is a review up to 1975 of the main features of the physical oceanography of that part of the Coral Sea proximate to the Great Barrier Reef and thus likely to affect the properties of the Barrier Reef lagoon waters.

The formal boundaries of the Coral Sea are set out in Limits of oceans: and seas: (Int. Hydrog. Bureau, 1937) and are shown in Fig. 28. For the present review the limits adopted are the formal boundaries on the west and north (the Australia and Papua New Guinea coasts), the $155 \mathrm{E}$ meridian, and the $25 \mathrm{~S}$ parallel as shown by the dashed line in Fig, 28. This part is referred to as the 'Western Coral Sea', abbreviated to WCS. In addition, 'Ccntral' and 'Eastern' Coral Sea divisions have been established for convenience in reference. The eastern and southern boundaries for the WCS have been chosen arbitrarily and areas outside of them will be considered when necessary to understand the Coral Sea itself.

No water masses are formcd in the Coral Sea and, in fact, the source areas of most of the Coral Sea water masses are at considerable distances, including areas north of the equator, the eastern Pacific and the Antarctic. Most of the flow into the WCS is across $155 \mathrm{E}$, north of $20 \mathrm{~S}$, with a seasonal inflow to the North-west Coral Sea through Torres Strait during the NW monsoon; there is outflow in the north to the Solomon Sea and in the south to the East Australian Current.

This review will be concerned with the upper waters, from the surface to about $1000 \mathrm{~m}$ depth, as this is adequate to cover exchanges with the Barrier Reef lagoon. However, the data available are quite limited both in space and time. It is believed that the main features of the water masses are known but, as is the case in most of the oceans, their variation with time is incompletely understood and there is much to learn yet about the circulation.

The chief papers on the properties and circulation of the watcrs deeper than the Antarctic Intermediate (about $1200 \mathrm{~m}$ ) are those by Rochford (1960c) and Wyrtki (1961', 1962a). These and other papers were well summariscd in the review by Rotschi \& Lemasson (1967) to which reference may be made. Thcre have been no significant deep water studies in the Western Coral Sca since that review.

The sequence will be to describe the topography of the region briefly (the deep bottom topography is of little concern here) and the climate, then to summarise the main descriptions available of the water mass characteristics and infer red flow patterns, and the determinations of the circulation by observation and dynamic methods, and finally to summarise the present knowledge of the region. 


\section{II \\ Topography}

In Fig. 29 are shown the 200 and $2000 \mathrm{~m}$ isobaths in the Western Coral Sea, with the $1000 \mathrm{~m}$ isobath added where the other two are significantly separated (data from Mammarickx ot al., 1974). The main features are the Queensland Plateau off the Great Barrier Reef with depths less than $2000 \mathrm{~m}$ (much of it less than $1000 \mathrm{~m}$ ), the Papuan Plateau in the northwest, and the Coral Sea Basin with depths of more than $4500 \mathrm{~m}$. The shallow area of the Chesterfield Is. is just outside the WCS but with depths of less than 200 $m$ in the vicinity of the main inflow it must have a significant influence on the sub-surface circulation to the WCS.

The connection northward to the Solomon Sea is limited to $200 \mathrm{~m}$ depth between Papua New Guinea and $154 \mathrm{E}$ but has depths to $3800 \mathrm{~m}$ between $156 \mathrm{E}$ and the Solomon Is. To the east between the Solomon Is. and the Chesterfield Is., the sill depth is greater than $3000 \mathrm{~m}$. To the south, the sill depth between the Chesterfield Is. and the Barrier Reef is about $3300 \mathrm{~m}$ but this is in a very narrow gap and the main trough is less than $1500 \mathrm{~m}$ deep. The connection through Torres Strait to the west is less than $20 \mathrm{~m}$ deep.

Typical dimensions for the WCS are given in the Appendix. 


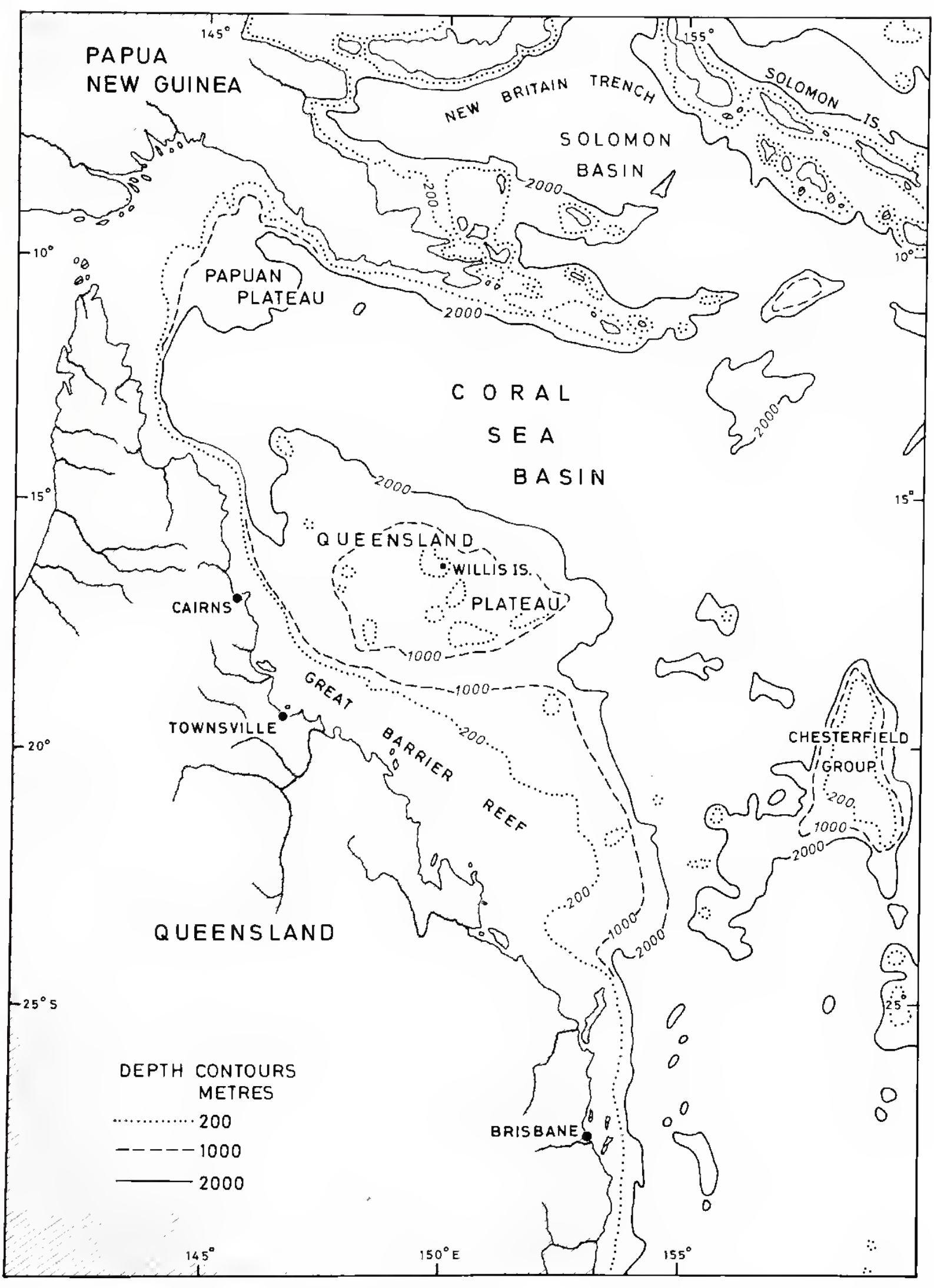

Fig. 29 Bathymetry of the Western Coral Sea, based upon J. Mammerickx et al., South Pacific, Sheet 11, revised 1974. 


\section{III \\ Climate}

\section{IWINISS}

The main wind systems alfecting the Coral Sea are the Sli trade winds for most of the year and the NW monsoon winds in summer. Weather on the Alstralia Station (RAAF, 19:2) presents quarterly charts for the WCS with wind frequency but no speeds. Sea ureas around Alstralia (Roy. Neth. Mut. Inst, 1949) gives wind information in two forms, monthly claarts of the 'Creneral Air Circulation' giving the vector mean wind by 1 squares, and monthly charts with wind roses by 5 squares with frequency and wind speed for 16 directions.

Toprovide a simpler picture of the wind character for this review, the wind rose charts have heen used to prepare four quarterly mean wind rose charts for Iecember-February, March-May, etc. lo simplify the diagrams the 16 directions have been reduced to 8 (NNE combined with NE and attributed to NE, ENli combined with $\mathrm{E}$ and attributed to E, etc.). The results are shown in Fig. 30. In this figure, the wind roses represent the information available for the sea areas within the nominal 5 squares. At the bottom left of the square is shown the percentage frequency of occurrence of calms, and at the top right is the mean wind speed in $\mathrm{m} / \mathrm{s}$ for the prevaliling direction in that square. These diagrams display the main features of the wind systems. During the period from March to November (17ig. 3013, (, 1$)$ ) the SE trake winds predominate over the entire area; in 1)ecember to February ( I ig. 30A) the effect of the NW monsoon is evident to $15 \mathrm{~S}$. It will also be noted ( Fig. 30C) that in winter, as the Sta trades move north the westerlies intrude into the area and give rise to increased westerly components south of $20 \mathrm{~S}$.

The General Air Circulation charts by 1 squares (Roy. Neth. Met. Inst., 1949) emphasise these features where the winds are predominantly from one direction, but are not very helpful where there is much variety in direction because the procedure of vector averaging conceals varicty in direction (as well as tending to give too low a mean wind speed). However, these charts include the number of observations available by 1 squares and this is sometimes illuminating. For instance, the region to the cast of the Great Barrier Reef between 10 and $20 \mathrm{~S}$ is notably deficient in observations, many squares having none at all.

Wyrtki \& Meyers (1975) prepared monthly mean surface wind stress charts for the area from $30 \mathrm{~N}$ to $30 \mathrm{~S}$ and from $125 \mathrm{E}$ to $75 \mathrm{~W}$ at 10 meridian intervals. The 145 and $155 \mathrm{E}$ sets show the stress ellect of the wind very well for the WCS. At $155 \mathrm{E}$, the northern limit of the NW directed stress (of the Sle trades) moves from about $14 \mathrm{~S}$ in Iicbruary to north of the equat or in September. The meximum stress values occur in July at $15 \mathrm{~S}$. At this time the stress has veered until at $25 \mathrm{~S}$ it is directed almost north (cl. Fig. 30C). The effect of the NW monsom is seen by the wind stress at $145 \mathrm{I}$ having a predominant easterly directed component of stress as far south as $14 \mathrm{~S}$ in January and February, but being small or north-westerly directed for the rest of the year at these latitudes. 


\section{CYCLONES}

On the average, two cyclones per year affect the WCS. They originate in the Intertropical Convergence Zone between about 8 and $18 \mathrm{~S}$ in the northern Central and Eastern Coral Sea and are most common in January to March, with less frequent occurrences in December and April. They initially move to the west; those north of $12 \mathrm{~S}$ tend to continue west while those south of that latitude tend to curve southeast.

Fig. 30 Wind roses for the Coral Sca for four quarters: (A) Dec.-Feb., (B) Mar.- May, (C; June-Aug., (D) Sep.-Nov. Bars show percentage frequency of wind direction; wind blows toward junction of frequency bars. Bottom left figure is frequency of calms; top right figure is mean speed of prevailing winds (data from Roy. Neth. Met. Inst., 1949)

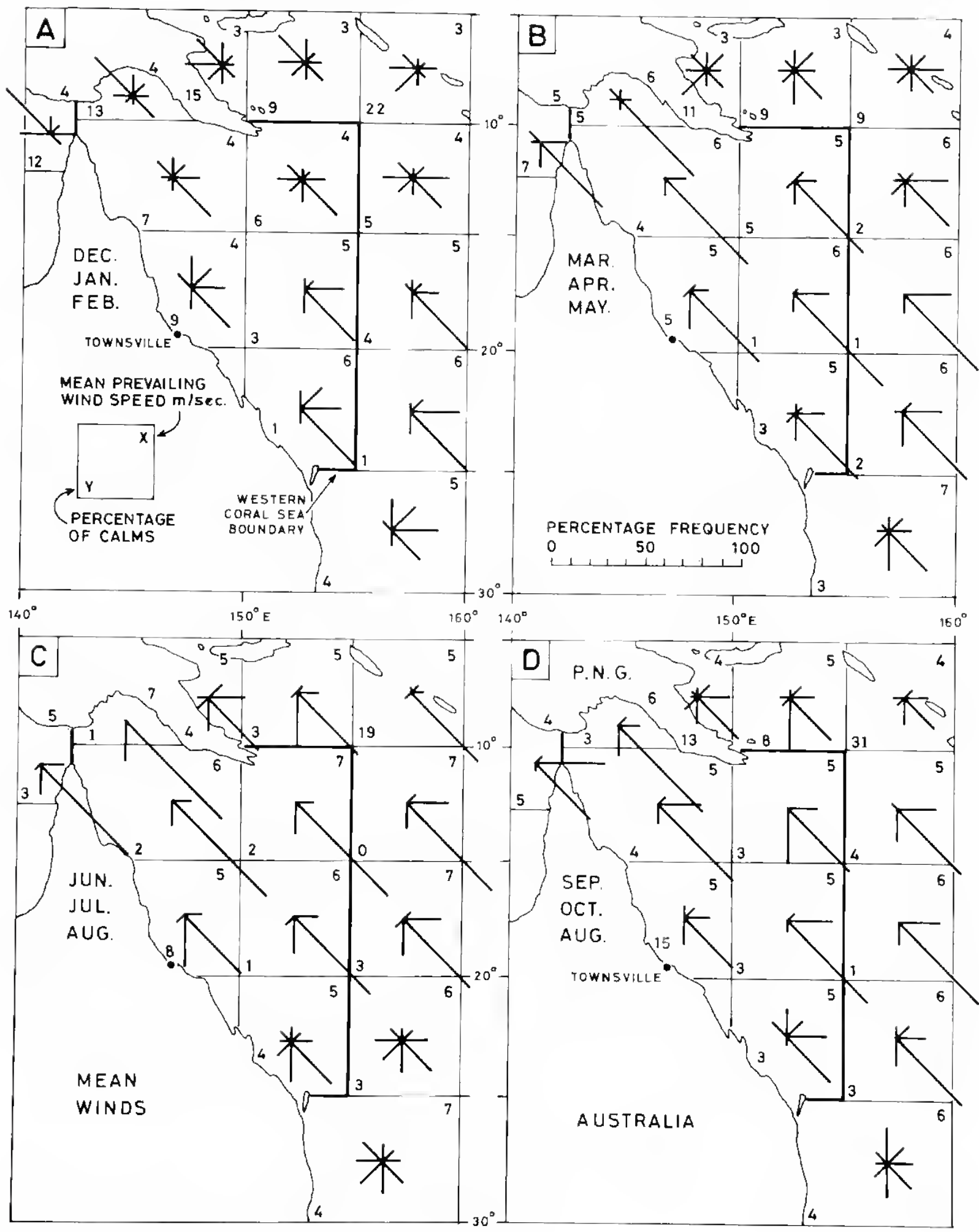


Presumably the main oceanographic effects of cyclones at sea are to cause some reduction in salinity from the associated rainfall, together with an increase in the mixed laver deptl due to the strong winds. Rougerie \& Donguy (1975) observed a significant heat loss attributable to a cyclone during the 'Gorgone 1' cruise. Cyclone Diane remained stationary from 10 to 15 1)ecember 1972 at $15 \mathrm{~S}$, $163 \mathrm{E}$. Crossing this area on 16 December the thermograph on N.O. Coriolis registered a drop in surfacc temperature from 27 to $25 \mathrm{C}$ and evidence of a decrease in temperature relative to neighbouring stations which indicated a loss of heat of $9000 \mathrm{cal} \mathrm{cm}^{2}$, There was no upwelling, simply the decrease of temperature.

\section{AIR TEMPERATURE}

Sea areas aromd Australia (Roy. Neth. Met. Inst., 1949) gives mean monthly air temperatures from ship observations, and a few isotherms are included in Fig. 34. The isotherms are roughly zonal in alignment. Temperature values in the WCS range from over $28 \mathrm{C}$ in the north to $24 \mathrm{C}$ in the south in the summer, and about $26 \mathrm{C}$ in the north to $18 \mathrm{C}$ in the south in the winter.

\section{RAINFALL}

Using ground station data, supplemented by deductions from satellite cloud-cover photographs, Taylor (1973) prepared an Atlas of Pacific Island Rainfall with monthly and annual charts. Fig. 31 shows the estimated maximum (February), minimum (September) and annual total values for the WCS from 'l aylor's Atlas. Most of the monthly charts have the same pattern of rainfall as the annual one, with increasing rainfall to the north-east to a maximum at about $10 \mathrm{~S}, 168$ E north of the New Hebrides. In the south-west Pacific, the mean monthly rainfall at this maximum off the New Hebrides is almost uniform throughout the year at about $400 \mathrm{~mm}$ per month, while the minimum rainfall area lics off the Queensland coast, migrating from about $25 \mathrm{~S}, 160 \mathrm{~F}$ in February March to $10 \mathrm{~S}$, $145 \mathrm{E}$ in August-October. According to Taylor's Atlas, the mcan rainfall over the WCS ranges from a monthly maximum of about $250 \mathrm{~mm}$ in February to a minimum of $50 \mathrm{~mm}$ in September. It should be noted that the only ground station in the Coral Sea from which Taylor had data was Willis Island.

Kilonsky \& Ramage (1975) described a technique for estimating open occan rainfall from the distribution of highly reflective clouds (HRC) from visual satellite picture mosaics of the tropical Pacific Ocean, having determined the correlation between this parameter and measured rainfall at coral island stations all less than $30 \mathrm{~m}$ high. Although there was considerable scatter about their (lincar) regression relationship between HRC and measured rainfall, the correlation was reasonahly significant and offers a method for obtaining open occan rainfall over large areas almost simultaneously.

Kilonsky \& Ramage estimated rainfull with this technique for the period May 1971 to April 1973, and compared it with earlier estimates for the $20 \mathrm{~N}$ to $20 \mathrm{~S}$ band of the Pacific. All estimates agreed in showing a peak at about $5 \mathrm{~N}$ and little variation with latitude from 0 to $20 \mathrm{~S}$. However, there were differences between the rainfall amounts, Taylor's (1973) values being among the highest. Kilonsky \& Ramagc considered Taylor's estimatcs too high, possibly because his ground truth stations included a number of 'high' islands where orographic effects are known to increase the rainfall. From HRC charts for thrce years, May 1971 to April 1974, made available to O.R.S.T.O.M., Nouméa, by C. S. Ramage, rainfall has been estimated for 5 to $20 \mathrm{~S}, 150 \mathrm{E}$ (the western limit of the charts for these latitudes) to $160 \mathrm{E}$. The mean annual rainfall for the three years is shown in Fig. $31 \mathrm{D}$ for comparison with Taylor's values (Fig. 31C). Taylor's values are higher than the 

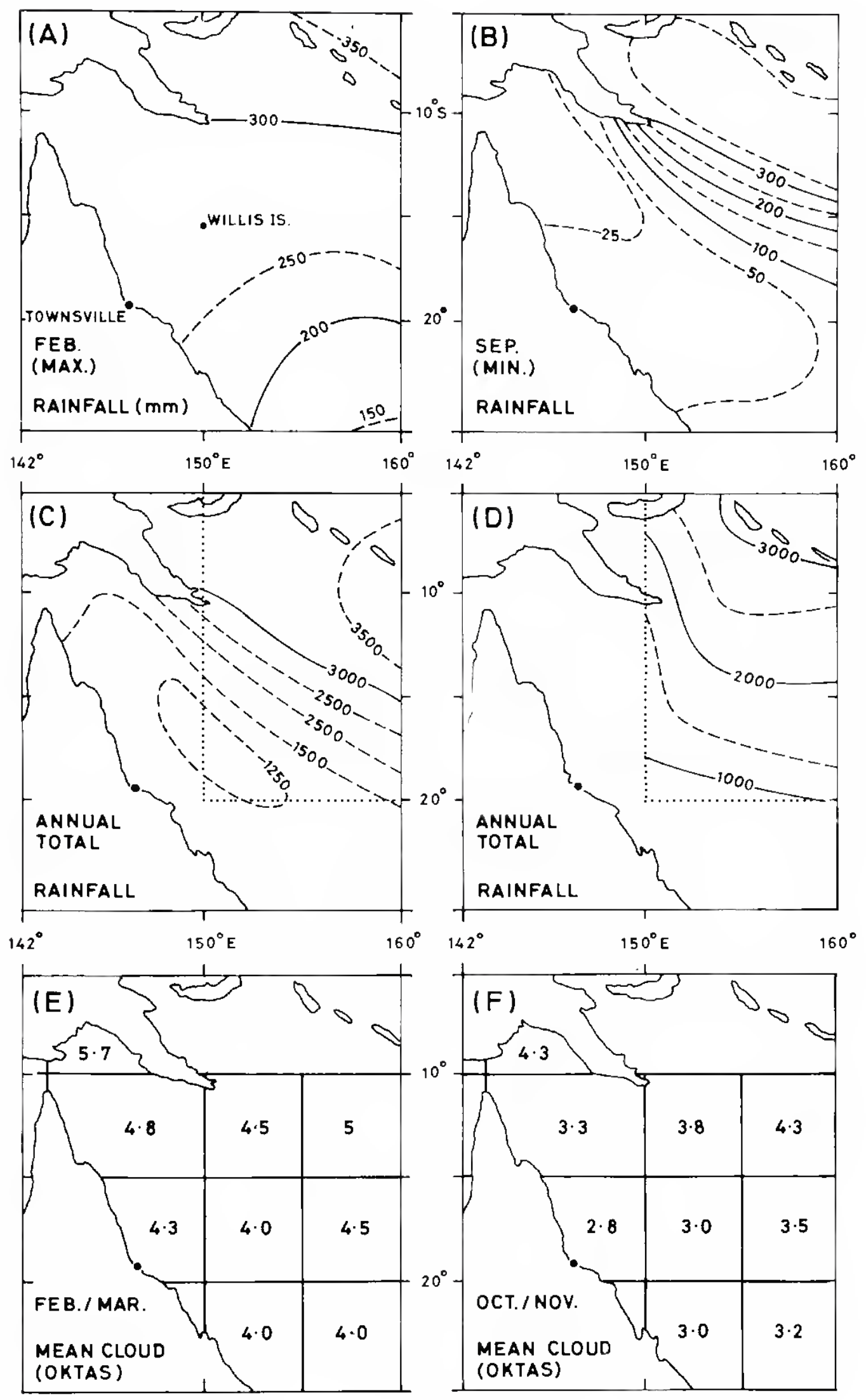

Fig. 31 Estimated rainfall (mm), Coral Sea: (A) Maximum monthly, (B) Minimum monthly, (C) Annual (A,B,C from Taylor, 1973), (D) Annual (from Kilonsky \& Ramage, 1975). Cloud amount (oktas): (E) Maximum, (F) Minimum (from Atkinson \& Sadler, 1970). 


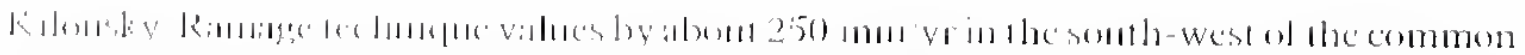

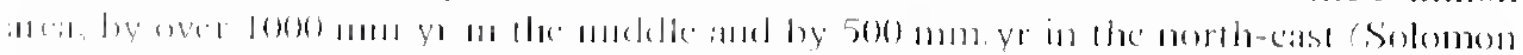
Sin:

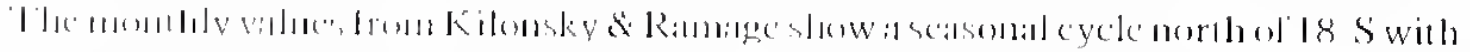

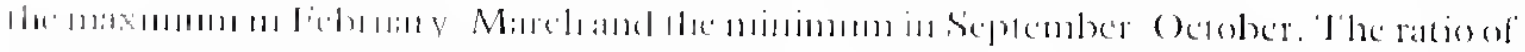

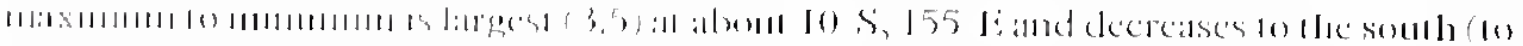
;1

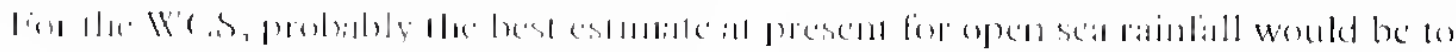

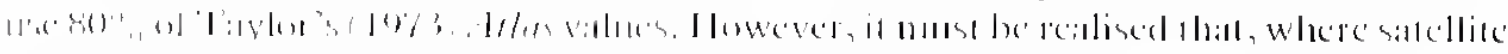

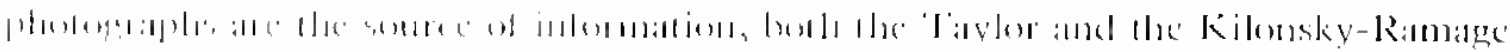

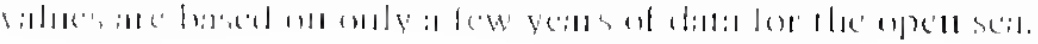

\section{$(: I,() 1)$}

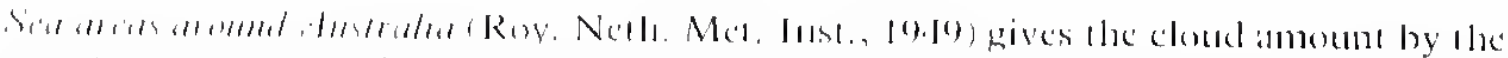

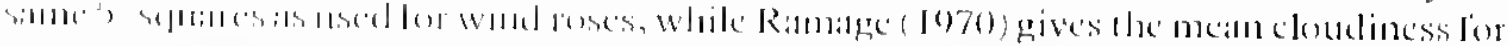

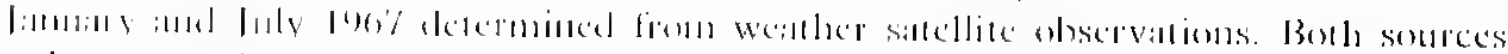

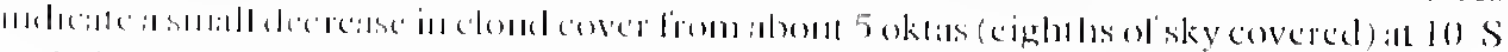

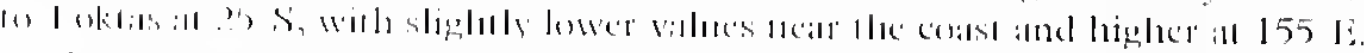

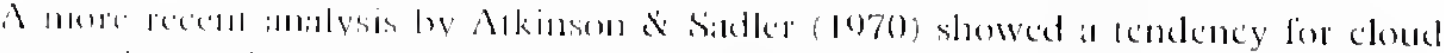

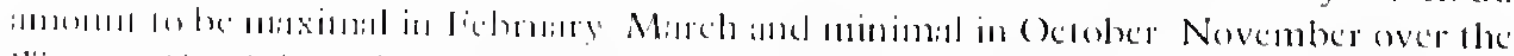

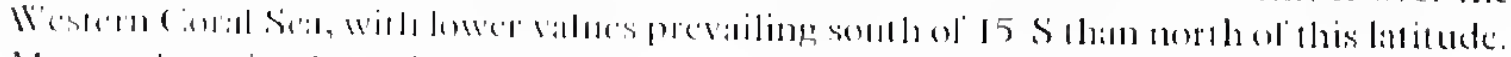

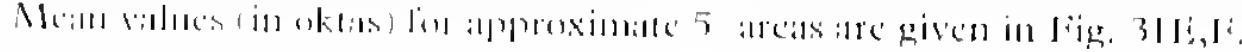

\section{INIII,IS ISI,ANI)}

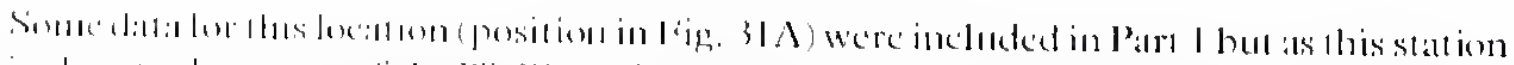

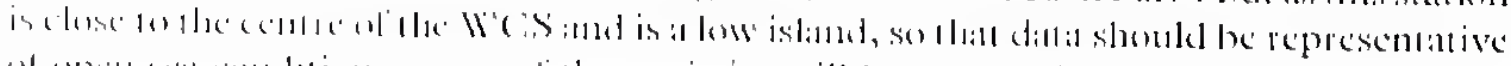

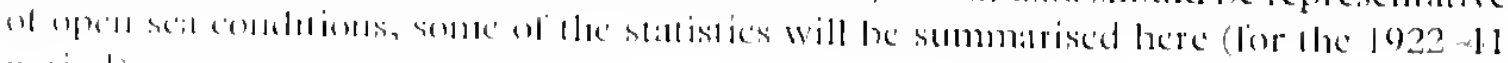
maind:

$$
\therefore 11 \text { lith Hhill }
$$

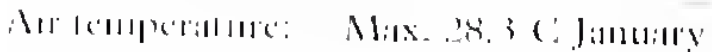
Min. 궁 July August

R:ImI:1I:

II"ind:
Max. 283 mm Jietoratay

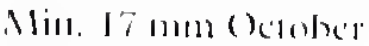

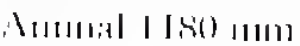

Noles

1.ong-lerm cistreme vilues were + 5.5C: relitive o lluse (cl. $\pm 12 \mathrm{C}$ at (ailims)

Rainy days $=10$ month Rainy days $=\mathrm{I}$ momuh

Mcian speced $6.7 \mathrm{~mm} s$, all directions (cl. coastal slations I $104 \mathrm{~m} / \mathrm{s}$ ).

$$
\begin{aligned}
& \text { 10" "lim } \\
& \text { s"in various }
\end{aligned}
$$

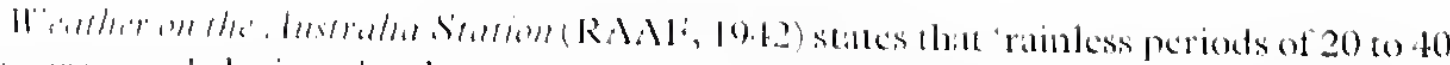

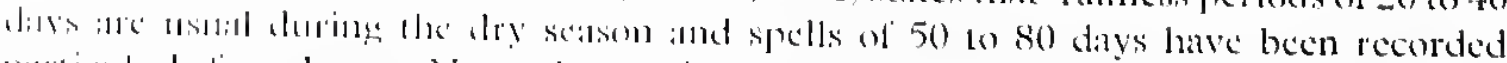

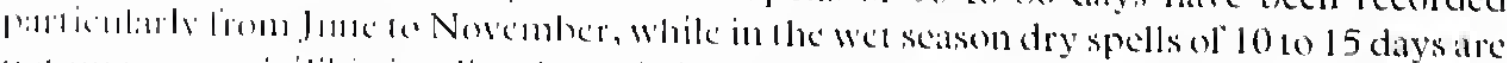

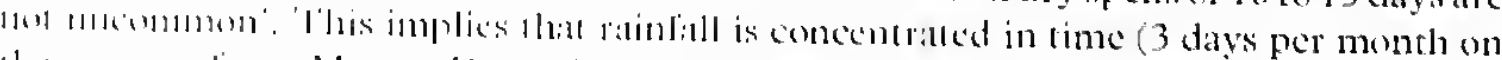

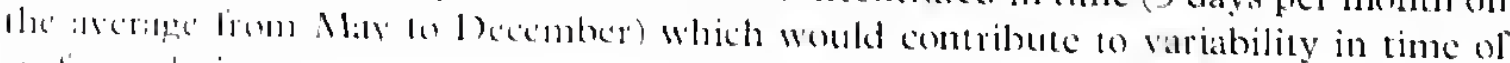

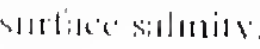


It should be noted that the meteorology and climatology of Willis Island is currently under study by the Bureau of Meteorology using all available data (personal communication, Dr J. W. Zillman, Superintendent, Physical Research). Some aspects of the SE trades of the Coral Sea have been discussed by A. B. Neal (1975) using regular and special observations at Willis Island. Neal states that 'the station is fully equipped for surface observations which are taken routinely every three hours (except midnight) and include sea temperatures at 0600 and 1800 hours measured at buoys moored in deep water beyond the western reef'. 


\title{
IV \\ Water Masses, Properties and Deduced Flow Paths
}

\author{
INTRODUCTION-SALIENT CHARACTERISTICS
}

For orientation purposes, a brief summary of the salient characteristics of the WCS water mass properties will be given before reviewing the papers upon which our present knowledge is based.

Fig. 43 shows examples of the temperature and salinity distributions at the surface during the early winter, the gross features being a decrease in temperature and an increase in salinity from north to south, and a tongue-like distribution of the isopleths near the Australian coast south of about $25 \mathrm{~S}$ (the start of the East Australian Current system). The basic change to summer conditions is an increase in temperature of $2 \mathrm{C}$ in the north and 5 or $6 \mathrm{C}$ in the south, with the disappearance of the low salinity in the Gulf of Papua by early summer and its reappearance later (January). This low salinity is attributed to Arafura Sea water driven through Torres Strait during the NW monsoon, but river runoff from Papua New Guinea may also contribute significantly.

It should be noted that the data on which Fig. 43 is based are from the only nearsimultaneous set for the WCS. They were obtained during three Royal Australian Navy Research Laboratory cruises in May-July 1968 (Scully-Power \& France, 1969a, b, c; area shown in Fig. 45A), and described by Scully-Power (1973a, b). With the exception of the description of the Central Coral Sea by Rougerie \& Donguy (1975); O.R.S.T.O.M. 'Gorgone 1' Cruise, November-December 1972, see Fig. 45A) all other descriptions or analyses of the western half of the Coral Sea have been based on more limited data distributed over several years, although there are data for other cruises ('Iule' 1965, Shoyo Maru 1973, and 'Gorgone 2' 1975) for parts of the WCS. The 'Gorgone 2' data are currently being analysed.

In the vertical, Fig. 32A shows an almost 'textbook' example of the structure in the upper $1200 \mathrm{~m}$ of the WCS, using an R.A.N.R.L. station from the 1968 cruises referred to above. The location of the station (CS $4 / 2$ Stn 14) is shown in Fig. 45A. The major features are:

\section{Temperature}

(a) an upper mixed layer of as much as $150 \mathrm{~m}$ depth from the surface;

(b) a monotonic decrease in temperature from the bottom of the mixed layer to below $1000 \mathrm{~m}$, forming a permanent thermocline with its maximum gradient between the mixed layer and about $500 \mathrm{~m}$ depth.

\section{Salinity}

(a) an upper mixed layer as for temperature;

(b) an upper salinity maximum, usually sub-surface from 50-250 $\mathrm{m}$ depth but reaching the surface in the south of the region (Subtropical Lower water);

(c) a salinity minimum at 650-1100 $\mathrm{m}$ depth (Antarctic Intermediate water).

Density

Below the mixed layer, this increases with depth, opposite to the temperature change. Density changes are determined more by changes of temperature than of salinity. 


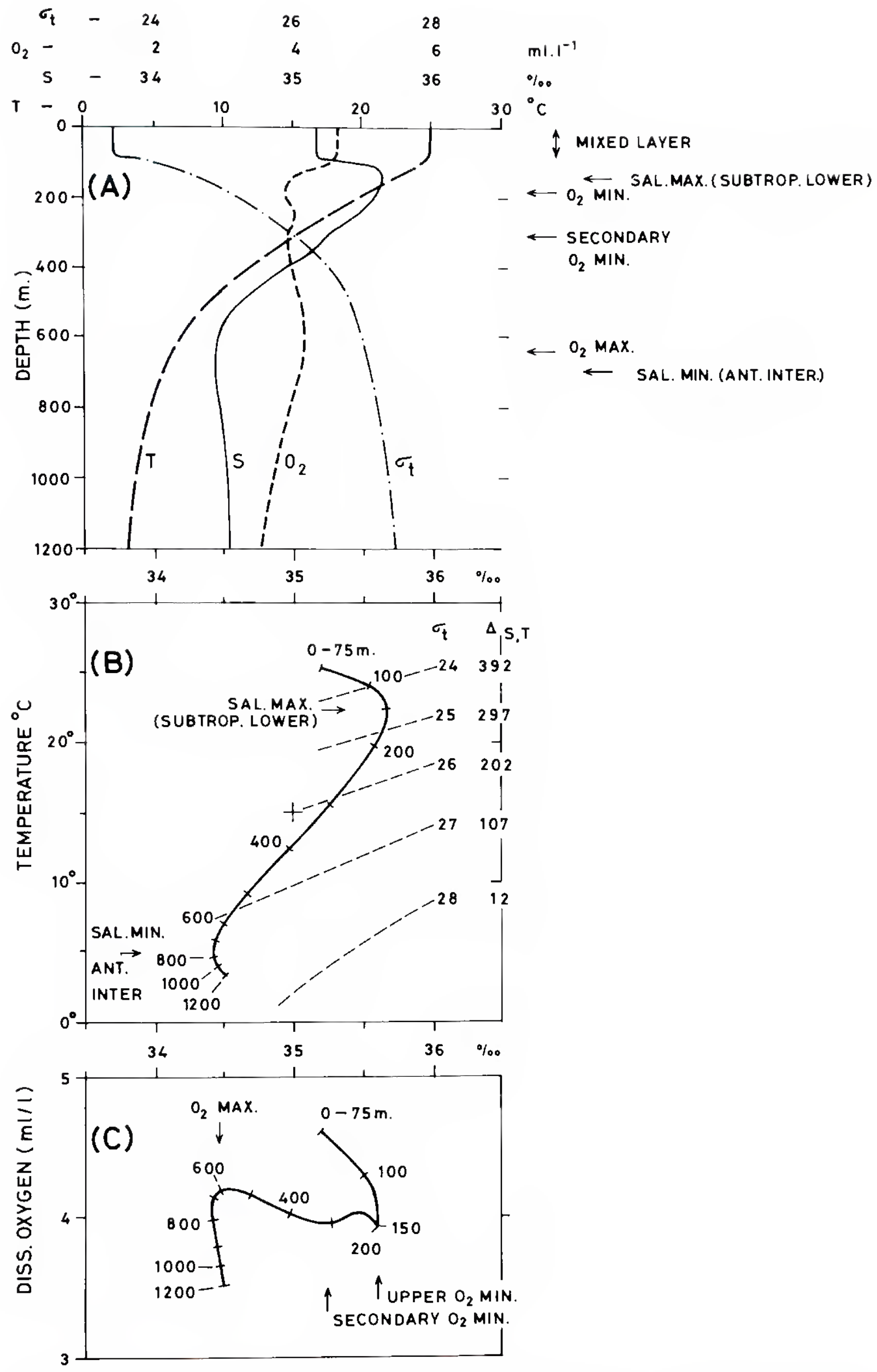

Fig. 32 (A) Typical vertical profiles of temperature (T), salinity $(\mathrm{S})$, density $\left(\sigma_{\mathrm{t}}\right)$ and dissolved oxygen $\left(\mathrm{O}_{2}\right)$ for the Western Coral Sea (R.A.N.R.L. Cruise CS42, Stn. $14(15.0$ S, $149.5 \mathrm{E})$, June 1968) (data from Scully-Power \& France, 1969b),

(B) 'T,S diagram for the same station,

(C) $\mathrm{S}, \mathrm{O}_{2}$ diagram for the same station. 


\section{Dissolvod Oxygen}

(a) an upper oxygen minimum at 150-500 $\mathrm{m}$ depth, typically a little deepcr than the upper salinity maximum (at $170 \mathrm{~m}$ in $\mathrm{Fig}$. $32 \mathrm{~A}$ );

(b) an oxygen maximum at 400-800 $\mathrm{m}$, typically shallower than the salinity minimum.

A minor feature which has been mentioned only by Scully-Power (1973a) is the occurrence of a double oxygen minimum (in Fig. 32A the second one is at $300 \mathrm{~m}$ ). ScullyPower stated that this was observed at about $25^{\prime \prime}{ }_{14}$ of the 94 stations in May-July 1968 , apparently occurring with no clcar geographic distrihution (but scc the note in the next paragraph). Scully-Power did not discuss it further but this feature also appears in the Central Coral Sca 'Gorgone 1' data (Donguy et al., 1972b). In fact, multiple maxima and minima frequently occur below the upper salinity maximum and, on a single vertical profile, it may be difficult to single out any one as the significant minimum. This feature should be studied; possibly it is rclatcd to successive inflows of Subtropical Lower water.

Fig. 33 shows the distribution of salinity and dissolved oxygen for a north-south vertical section through the WCS from ncar Port Moresby to east of Brisbane, the station positions being shown in Fig. 45A. The salinity and oxygen features described above are shown, exccpt the mixed layer which is too thin to show clearly on the depth scale used. "The boundaries of the Subtropical Lower and Antarctic Intermcdiatc w'aters have been taken as 35.5 and 34.5 respectively following Scully-Power (1973a). The subsidiary oxygen minimum mentioncd above appears in the section of Fig. 33 at seven successive stations and secms to bc a continuous and systematic feature. The oxygen maximum in the upper part of the Antarctic Intermediatc water is very conspicuous in the south, and the

Fig. 33 Vertical sections of salinity and dissolved oxygen for a north-south section of the Western Coral Sea, May-July 1968 (data from Scully-Power \& France, 1969a, b. c, station positions shown in Fig. $45 \mathrm{~A})$.
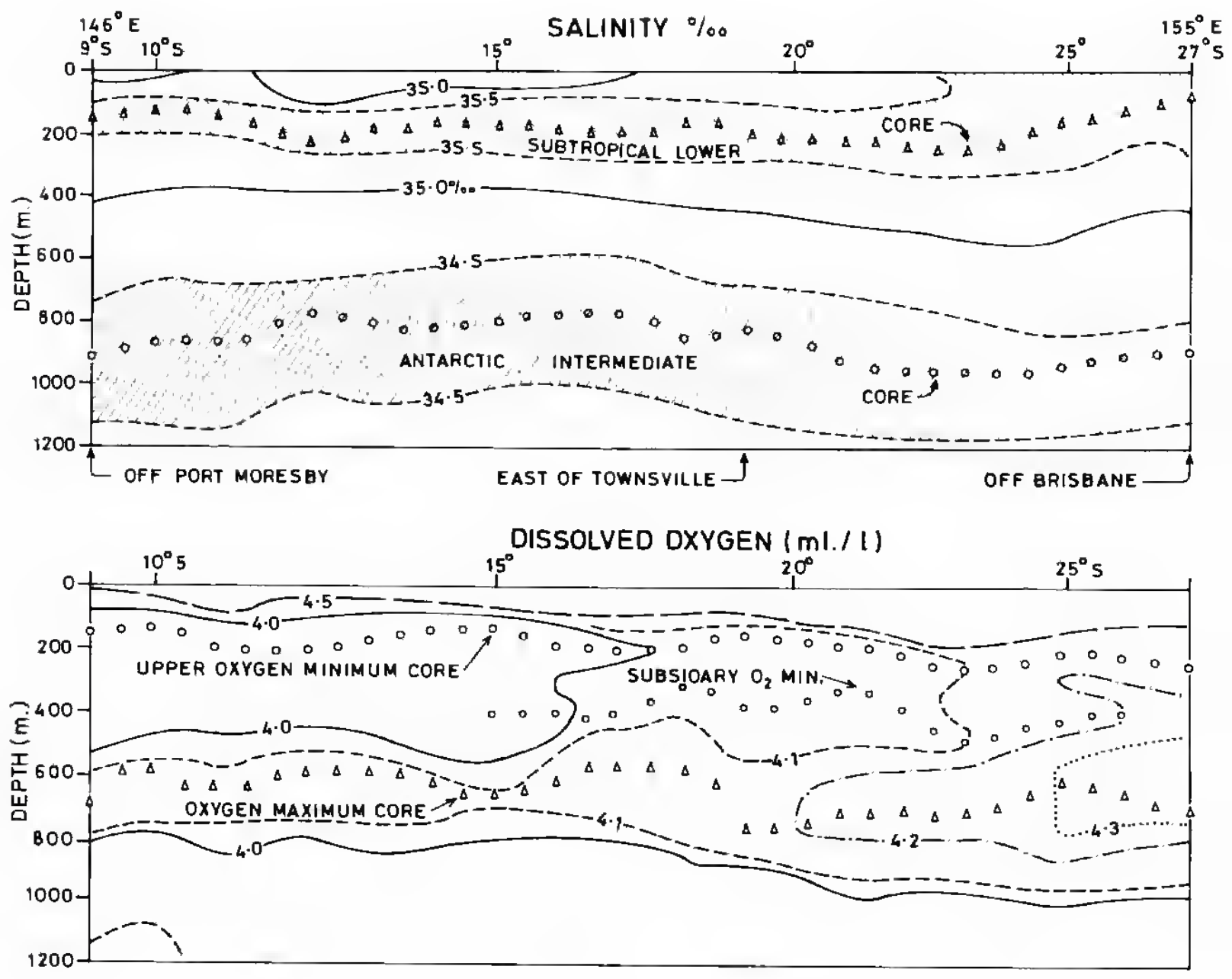
low oxygen northern component of the Subropical Lower water in the north. The Subtropical Lower water mass is seen to be at the surface in the south.

Vertical profiles, such as those in Fig. 32A, are generally used only in the first stages of checking data; most of the analysis of water masses has been carried out with characteristic diagrams, generally $\mathrm{T}, \mathrm{S}$ and $\mathrm{S}, \mathrm{O}_{2}$ diagrams, although $\mathrm{T}, \mathrm{O}_{2}$ and $\mathrm{S}$, phosphate diagrams have been used in the $S W$ Pacific. To show how such diagrams relate to the profiles, Figs. $32 \mathrm{~B}, \mathrm{C}$ present $\mathrm{T}, \mathrm{S}$ and $\mathrm{S}, \mathrm{O}_{2}$ diagrams corresponding to the vertical profiles of Fig. 32A. The linear portion of the T,S curve between 250 and $600 \mathrm{~m}$ in Fig. $32 \mathrm{~B}$ corresponds to Sverdrup's (1942) Western South Pacific Central watcr. This is not recognised as a specific water mass in the Coral Sea, while Sverdrup did not recognise the Subtropical Lower water as a specific water mass, although he did describe the subsurface ?upper) salinity maximum. It should also be noted that the curves of characteristic diagrams are notoriously non-linear in depth scale (see Fig. 32B,C) and depth interpolation should not be carricd out on such a diagram alone.

It must be realised that the area on a $T, S$ diagram representing a water mass does not indicate its volume. For instance, the Antarctic Intermediate water is represented by a very compact area in Fig. 61 compared to the Subtropical Lower water, but the former has about twice the volume of the latter in the Western Coral Sea (see Fig. 33).

Because the depth of a particular water mass may vary from place to place, it is often difficult to determine the distributions of such masses on surfaces of constant geometrical depth (apart from the water-air boundary surface) and most studies have been carried out using either the 'core method' (Wüst, 1935) or isentropic analysis (Montgomery, 1938). In the former, a 'core' is defined as the level where a property reaches an extreme value in the vertical dircetion, and a plot of the depth of this core for a region defines a surface called the 'core layer'. The location where a property has an extreme value on the core layer is called the 'origin' and flow is assumed to take place along the core layer in the direction of increase or decrease of the property (due to mixing with water having less extreme values). In isentropic analysis, flow and mixing are assumed to take place along surfaces of constant density $\left(\sigma_{t}\right)$, which approximate to isentropic surfaces, and distributions of conservative properties (c.g. T, representing heat, or salinity) and to some extent quasi-conservative ones (e.g. oxygen) indicate flow patterns. These procedures help to identify both sources of water and flow patterns to and in a region.

The flow patterns may also be studied by direct measurements of currents or indirectly by the geostrophic method.

\section{SURFACE WATER CHARACTERISTICS}

\section{Surface temperature-mean distribution}

Sea areas around Australia (Roy. Neth. Met. Inst., 1949) gives monthly charts of sea and air temperature by 1 squares, with interpolated isotherms at $1 \mathrm{C}$ intervals. Fig. 34 is based on this source. The smaller scale charts in Sverdrup et al. (1942) agree with the Dutch data. The numbers of observations in cach 1 square in the Dutch atlas vary from none at all in many squares cast of the Great Barrier Reef, to less than ten per month in most of the WCS, and to a hundred or more near major ports or in major shipping lanes. The main 'holiday' areas are listed in the legend. There is considerable scatter between neighbouring squares and the preparation of the isotherms must have required a considerable amount of personal judgment.

According to this atlas the water temperature in the WCS ranges from 26 to $29 \mathrm{C}$ in summer ( $30 \mathrm{C}$ appears in a few individual 1 squares) and from 21 to $26 \mathrm{C}$ in winter, and averages about $0.4 \mathrm{C}$ higher than the air temperaturc above it.

Away from the land, the isotherms are oriented zonally. Approaching the Barrier Reef they trend equatorward from April to September (winter, Fig. 34B), i.e. the water near the 
Recf is cooler than that further offshore at the same latitude. South of $20 \mathrm{~S}$, a southward tongue of warmer water associated with flow into the East Australian Current is evident both in winter and summer. This feature is much more conspicuous in the current itself south of the WCS area covered in Fig. 34.

The Monthly Oceanographic Charts, Tasman and Coral Seas, 1966-74 (CSIRO, 1974), referred to hereafter as the 'CSIRO Atlas', prescnt monthly accumulated temperature and salinity obscrvations for the surface waters. The individual charts present the station positions and interpolated isotherms at $1 \mathrm{C}$ intervals. The station density was quite variable and for somc months large areas wcrc blank. In these cases, some of the interpolations to prepare the isotherms became essentially extrapolations, which are always uncertain, especially in a region as complicated as the Coral Sea. In addition, therc werc somc areas, particularly east of the Barricr Reef, whcre therc were few or no station positions for any year (see below and Fig. 37 for more details).

Mean monthly surface tempcrature charts were prepared from the Atlas but, as will be cxplained shortly, their significance is limited because of the large variations with time.

The proccdurc used was to select a month and to trace the positions of a particular isotherm on one diagram for all years, then drawing a mean isotherm for that month for the whole period 1966-74. To reduce the uncertainties associated with the interpolations on the charts, only thosc portions of isothcrms lying betwcen two stations not more than $100 \mathrm{~km}$ (about 1 of latitude) apart wcrc used. Values inside the Barrier Reef were excluded. The procedure was repeated for several isotherms for the months of January, April, July and Octobcr.

This process indicated that the annual rangc of surface temperature values was about 20 to $30 \mathrm{C}$. The positions of individual isotherms extended ovcr vcry large areas when the nine years of data were combined. Fig. 35 shows the areas of occurrence of the isothcrms $24,26,28$ and $30 \mathrm{C}$, representative of the bulk of the values occurring in the WCS. It is clear that the WCS is a region of considerable variability of surface watcr temperature (and of salinity, as will appcar shortly). It is evident that attempting to

Fig. 34 Mean surface water $\left(T_{w}\right)$ and air $\left(T_{a}\right)$ temperatures, Coral Sea: (A) Summer (Jan.), (B) winter (Jul.) (data from Roy. Neth. Met. Inst, 1949). Note: There are few data for most months in areas $(10-13 \mathrm{~S}, 144-146 \mathrm{E}),(15-20 \mathrm{~S}, 148-152 \mathrm{E}),(10-20 \mathrm{~S}, 155-160 \mathrm{E})$.

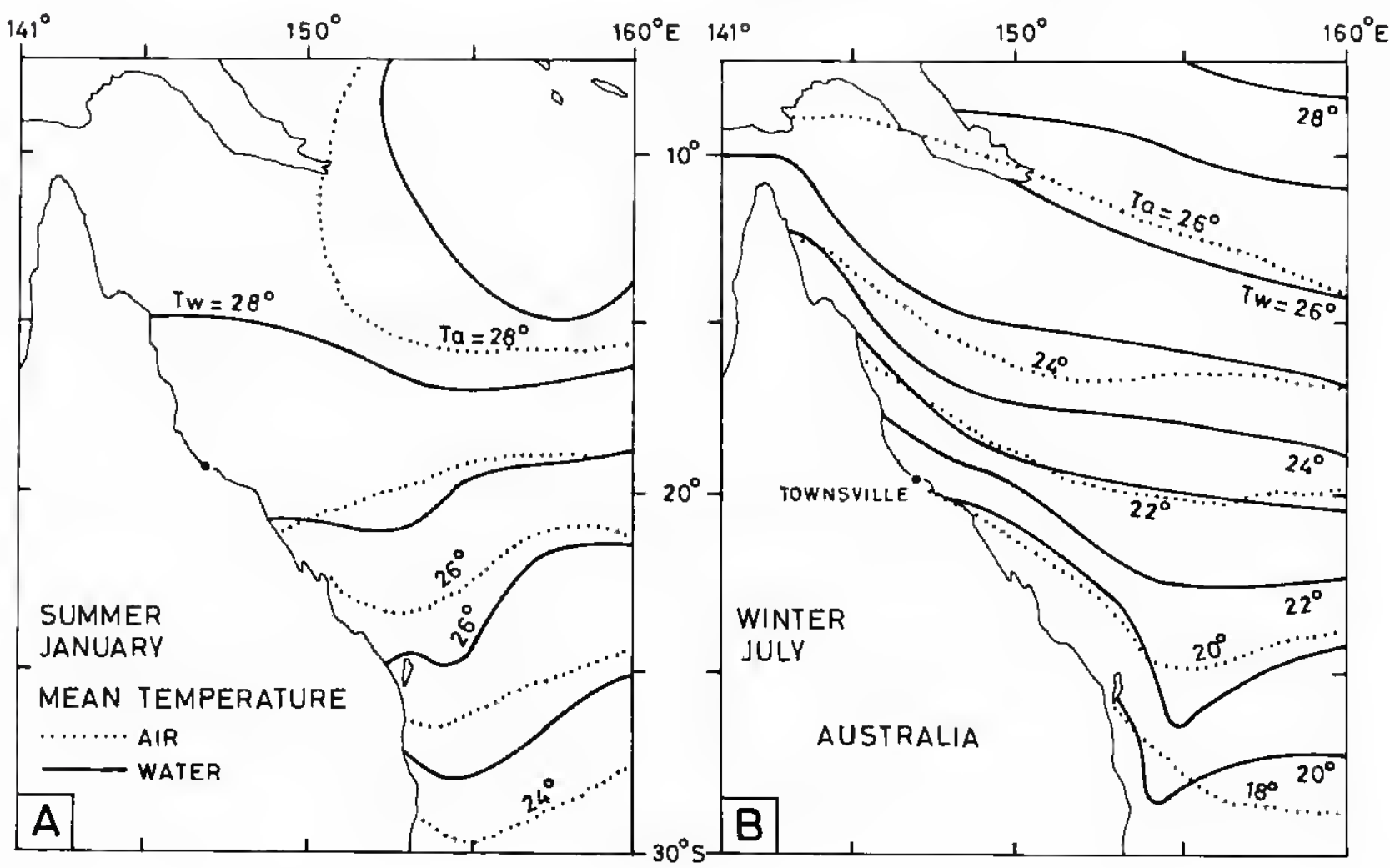


determine a mean picture of surface conditions by combining data from a number of cruises is likely to be of dubious value. Mean isotherms (Fig. 36) were drawn to show the trend of seasonal variation over the area, rather than to specify mean positions of isotherms for each month. In the main body of the WCS and within the limitations of the scatter shown in Fig. 35 there is evident:

(a) the usual trend to warmer temperatures in summer and cooler in winter at each location; and

Fig. 35 Surface temperatures, Western Coral Sea, areas of occurrence of $24,26,28$ and 30 C water fur January, April, July and October 1966-1974 (data from CSIRO, 1974). Note: For all months there are gaps in the data off the Great Barrier Reef, see Fig. 37, and some shaded areas should probably extend further west.
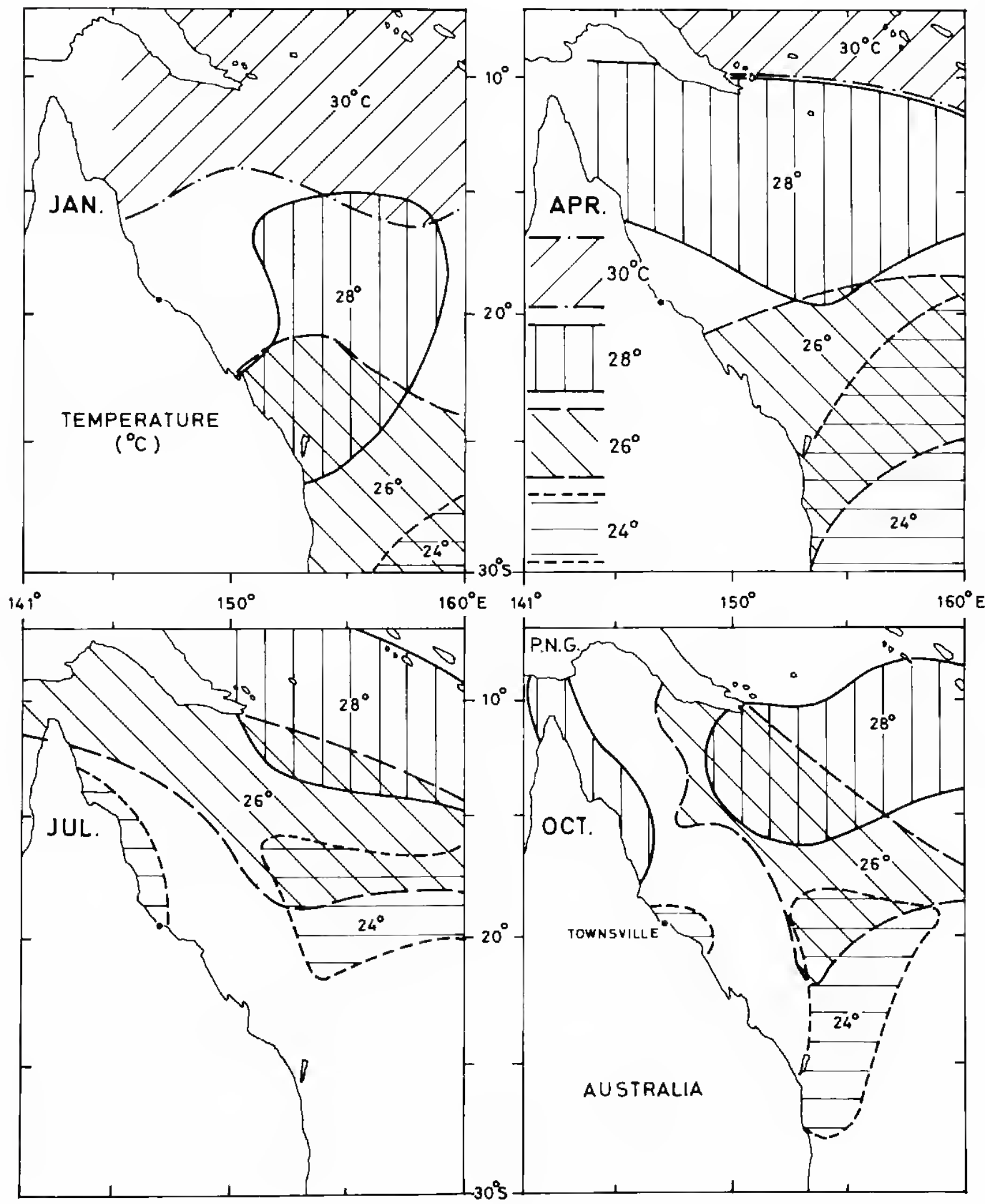
(b) the shape of the isotherms from a roughly zonal orientation in the north to a tongue shape in the south associated with the start of the East Australian Current.

A criticism is appropriate here. If one had available only the material (isotherm spot positions) from which Fig. 35 was prepared it is doubtful if the tongue form in Fig. 36 would have been drawn. It was prompted by the individual monthly charts, most of which show this feature clearly. However, the tongue is quite narrow and it shifts slightly east or west (i.e. transversely) from year to year so that the accumulated isotherm positions on the tracing spread over an area, such as the $24 \mathrm{C}$ area in Fig. 35, October, and obscure the tongue.

Fig. 36 Surface water temperatures, Western Coral Sea, mean isotherm positions for January, April, July and October, 1966-1974 (data from CSIRO, 1974). Note: The termination of some isotherms in mid-sea is probably due to gaps in data coverage.

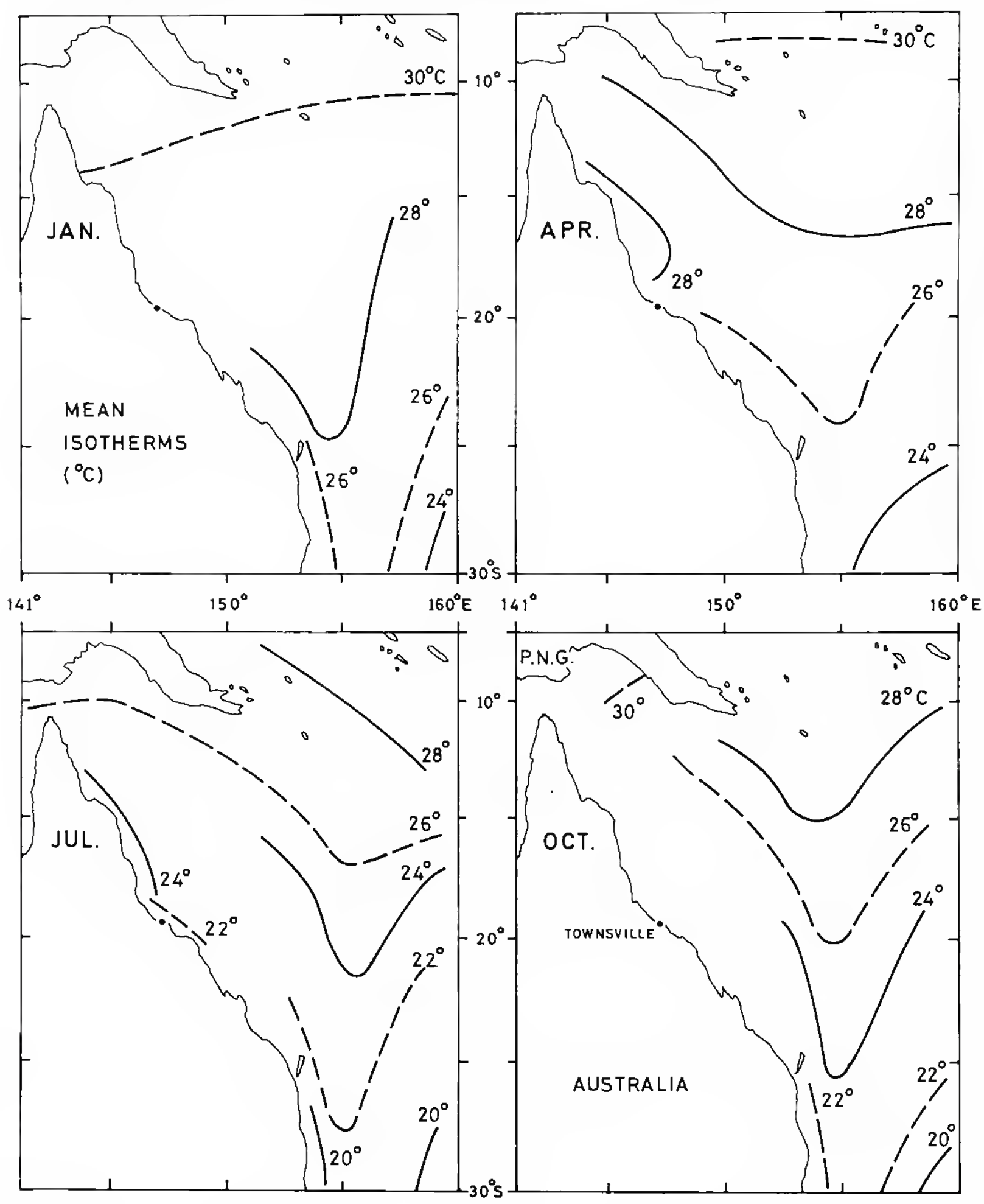


The termination of isotherms in mid-sea is usually due to gaps in data coverage rather than to the occurrence of convergences or divergences.

The isotherms in the Dutch atlas (Fig. 34) and those from the CSIRO Atlas data (Fig. 36) differ in two respects. The tongue form in the south is much more evident in the curves derived from the CSIRO Atlas than in the Dutch ones, and the CSIRO values are generally 1 to $2 \mathrm{C}$ higher than the Dutch ones for corresponding areas. With regard to the shape, it is likely that the construction of the curves of Fig. 36 in the present study was influenced by the shapes of the individual monthly isotherms in the CSIRO Atlas where the author of the Dutch atlas isotherms may have been working with the totality of his data (by 1 squares) and not had access to ready-drawn individual charts for inspiration. The reason for the difference in mean temperature values is not known.

Of the two figures, Fig. 36 indicates the character of the isotherm shapes in the area, although in a very smoothed form as the isotherms for individual months show numerous small features or irregularities. Fig. 35 is the more realistic for describing the environment on a long-term basis and probably for relating to biological observations of fixed features such as coral reefs. For comparison with biological records of a specific (past) expedition one might be able to find data in the relevant CSIRO Atlas chart for the period 1966-74 (and later years in due course), but for future projects it would be wise to plan to include physical (and chemical) measurements in parallel with any biological ones.

Finally, when using Figs. 35 or 36 one should bear in mind that the distribution of observations over the area available for preparing the CSIRO Atlas was far from uniform. Fig. 37 shows qualitatively the density of observations for a typical month. It will be seen that there are some areas for which there are no observations at all, notably and unfortunately off the Barrier Reef. As mentioned previously, this is why several isotherms terminate in this region.

An alternative treatment of the CSIRO data is offered in the next section and may be sufficient for many purposes.

Fig. 37 Density of observations of surface temperature and salinity for a typical month, Western Coral Sea, 1966-1974, in C.SIRO, 1974. (Refer to Figs. 35, 36, 39, 40.)

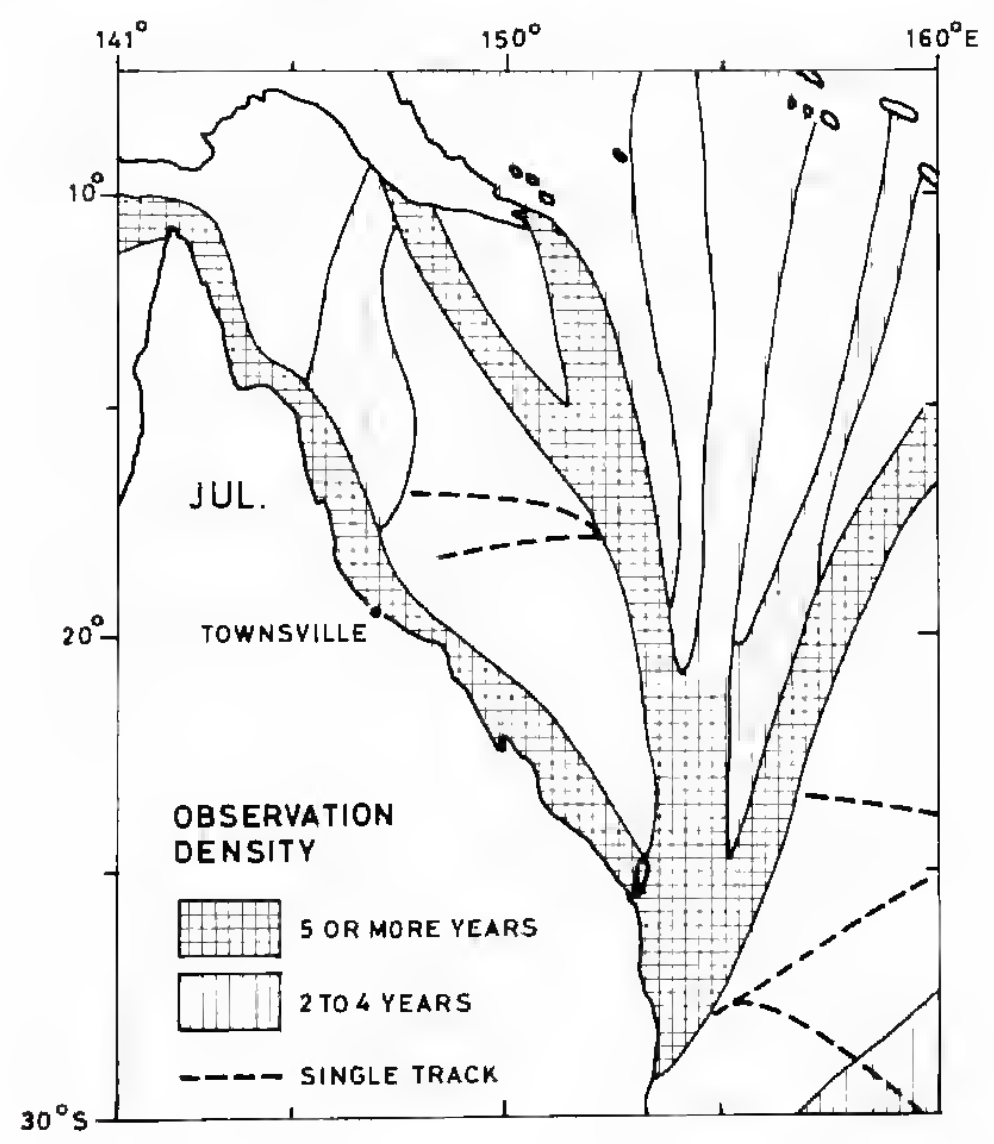


Rochford (1973) examined surface temperature and salinity values in the Tasman and Coral Seas for 1966-70 for annual and longer term variations. He determined the annual range of mean monthly temperature as shown in Fig. 38A. The range increased from $2 \mathrm{C}$ in the northeast (Solomon Is.) to about $5 \mathrm{C}$ at the Barrier Reef (and $8 \mathrm{C}$ in the south zone of the Lagoon). In a 1 square off the Swain Reefs (A in Fig. 38A) there was little or no indication of any long-term change in mean temperature.

The surface water property distributions for 1968 obtained by Scully-Power (1973a) and shown in Fig. 43 will be described later to maintain the continuity of that 1968 data set information and after the possible source areas for waters in the Coral Sea have been discussed.

The daily temperature measurements at Willis Island reported by Hogan (1925) were taken over the reef structure at various stages of the tide and were reported to be affected by solar heating. Unfortunately, therefore, they are not likely to be of much value in describing short-term changes and are not summarised here.

\section{Surfaee salinity-mean distribution}

As no chart of mean surface salinity values with any detail in the WCS was available (the chart in Sverdrup et al., 1942 has only the southern winter and that has only one isohaline for the whole of the WCS) one was prepared from the CSIRO Atlas in the same manner as for the temperature charts.

This indicated that the salinity values were mostly between 34.0 and 35.7 in the main body of the WCS with seasonal low values to less than 32 in the North-west Coral Sca. The values below 34 were usually recorded off Port Moresby in December to April. They may have been typical of the whole Gulf of Papua but there were insufficient observations in the Gulf to determine this. After April the minimum salinity in the WCS increased each month to about 34.5 in August then started to decrease again. The maximum value was usually 35.4 to 35.5 : in the south-east corner of the WCS.

Fig. 38 Mean annual ranges of temperature $(\Delta \mathrm{T})$ and salinity $(\Delta \mathrm{S})$ in upper $5 \mathrm{~m}$, Western Coral Sea (based on Rochford, 1973).

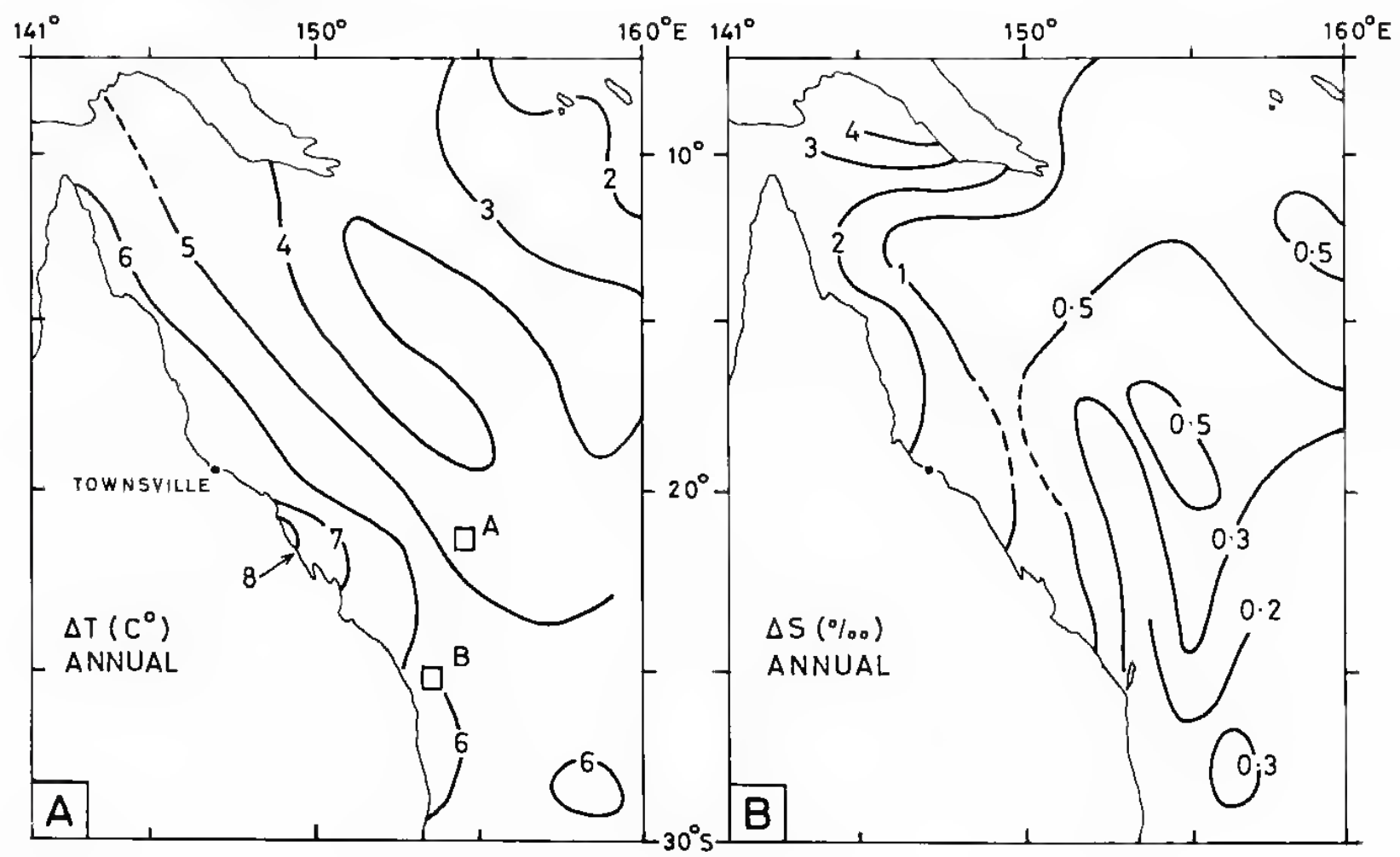


As for temperature, the positions of individual isohalines extended over very large areas during the nine-ycar period. Fig. 39 illustrates this, showing the areas of occurrence of three isohalines, 34.6, 35.0 and $35.4 \%$, representative of the bulk of the values observed. The mean positions of the isohalines are shown in Fig. 40, again to show the trend of seasonal variation rather than to specify geographic positions for mean monthly values. In the main body of the WCS and within the limitations of the scatter of the values, Fig. 39 shows that the salinity distribution for 35 and higher in the south-east half of the WCS is fairly steady, while most of the changes take place in the north-west half. One of the most obvious features is the occurrence of very low salinity water in the North-west

Fig. 39 Surface salinity, Western Coral Sea, arcas of occurrence of 34.6, 35.0 and 35.4 water for January, April, July and October, 1966-1974 data from CSIRO, 1974). See note to Fig. 35.

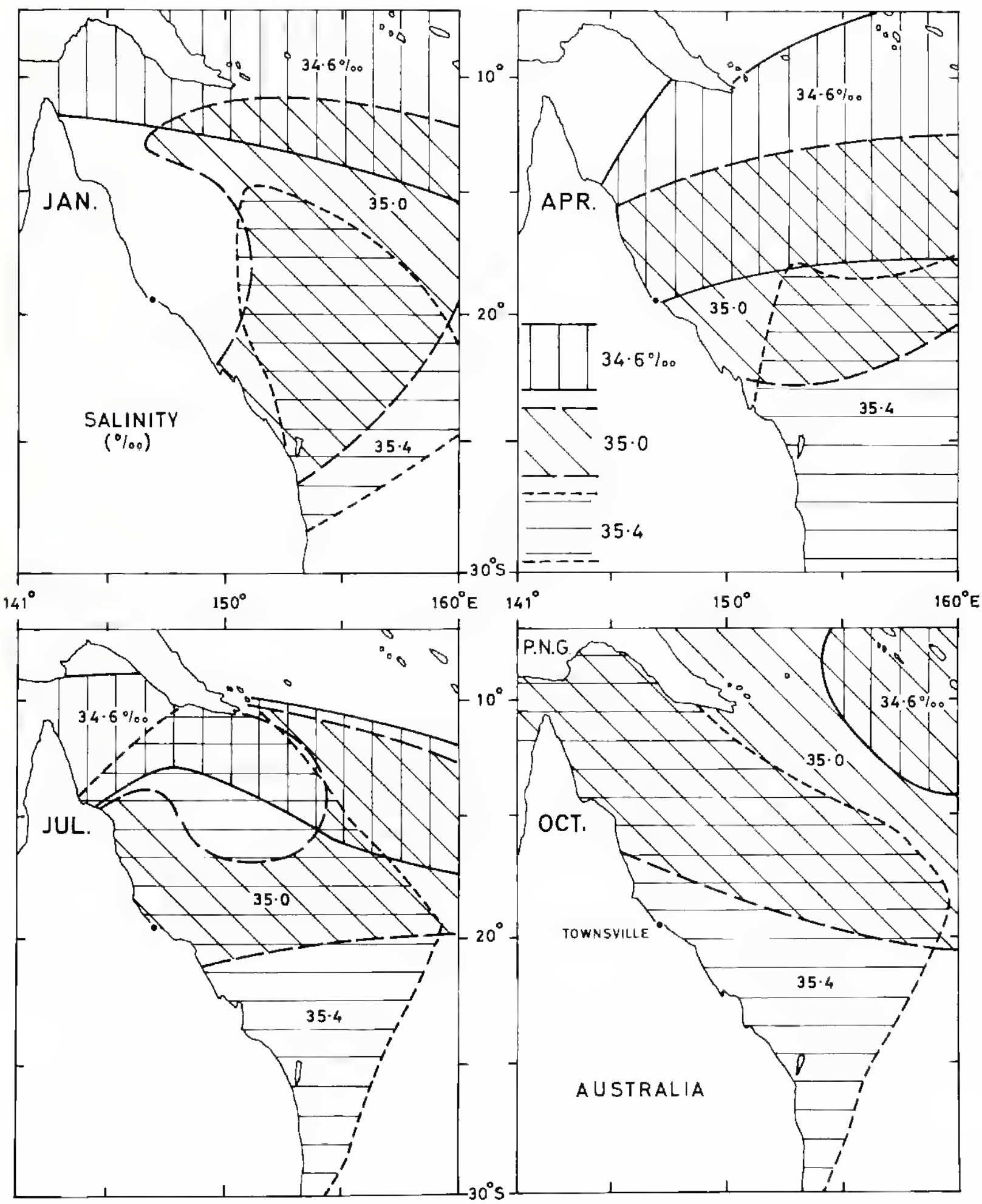


Coral Sea in the monsoon season, generally attributed to inflow from the west through Torres Strait coupled with runoff from the river system of Papua New Guinea. (The relative influence of the low salinity Arafura Sea water west of Torres Strait and of the fresh water from the rivers is not known yet, but further comments are offered in the section on Surface waters-Scully-Power.)

In the north-east sector, the lowest salinities occurred at the end of the monsoon season, c.g. April, Fig. 40. This has been confirmed in recent studies by Donguy \& Henin (1975a) who showed that, for the four-year period 1969-73, a salinity minimum

lig. 40 Surfacesalinity, Western Coral Sea, mean isohaline positions for January, April, July and October, 19661974 (data from CSIRO, 1974). See note to Fig. 36.

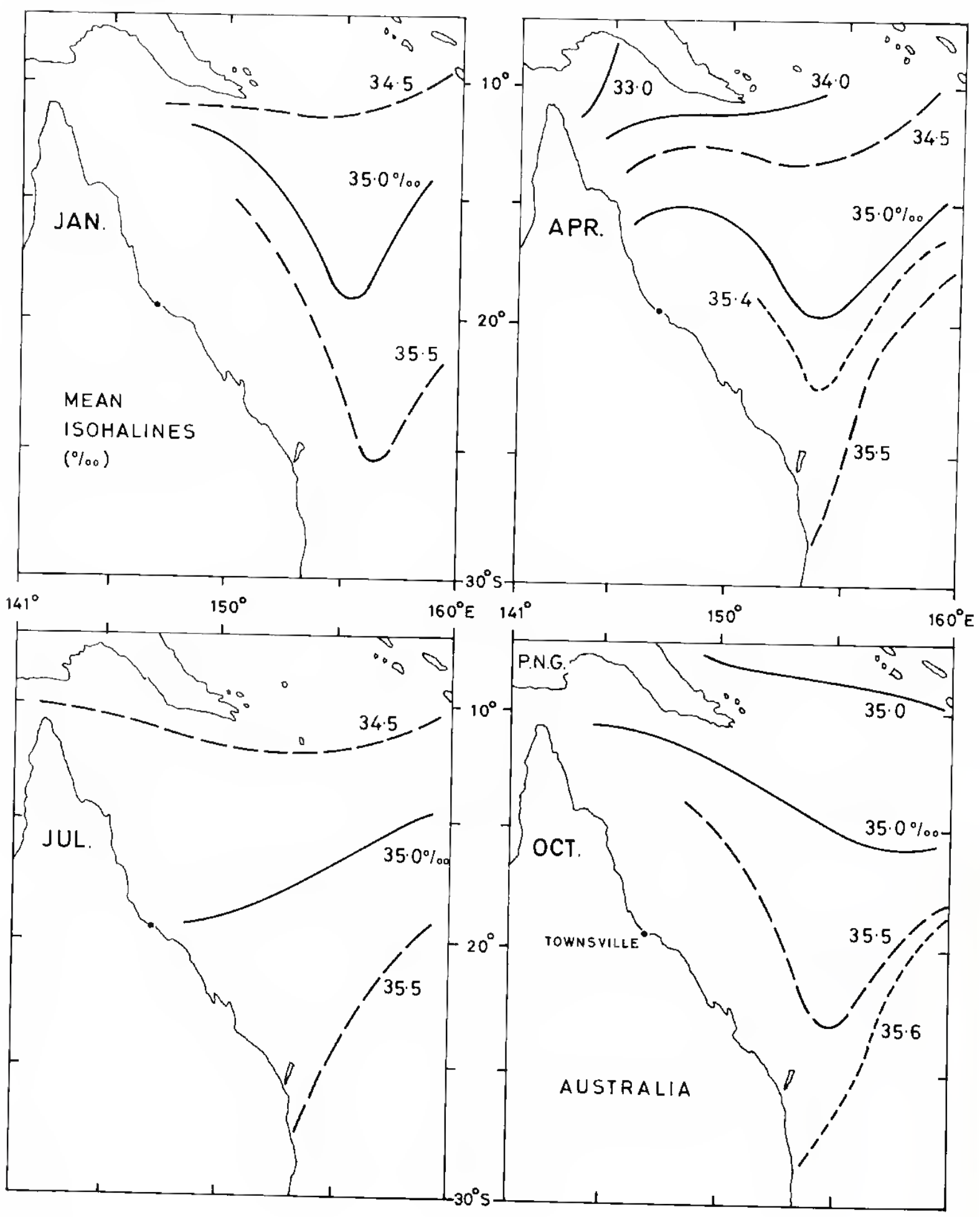


progressed south-cast across the Solomon Sea (around 10 S, 155 E in Fig. 40\%, oceurring in March at $7 \mathrm{~S}$ to May at $12+\mathrm{S}$. Donguy \& Henin demonstrated that this salinity minimum was the result of local rainfall associated with the development of the westerly (monsoon) winds in this region rather than of advection of low salinity water from the north of Papua New Guinea as had been thought previously.

The figures for mean salinity distributions derived from the CSIRO Atlas are believed to be the only ones available for the WWCS. A similar comment to that for temperature is appropriate, i.e. for a description of the long-term environment Fig. 39 is most realistic; while Fig. 40 shows the character of the temporal variations rather more clearly. In addition, the earlier comments referring to Fig. 37 on the uneven area distribution of observations should be noted.

Less confidence should be placed in the significance of the isohalines of Fig. 40 than in the isotherms of Fig. 36, particularly for the January picture (1 ig. 40 ) for which the northeastward turn at the east end of the 35.0 and 35.5 isohalines is uncertain.

Rochford (1973), in his study of annual and longer term variations, showed that the annual salinity range (Fig. 38B) varied from more than 4 in the Gulf of Papua in the North-west Coral Sea to less than 0.3 in the south-east. The long-term salinity values showed a tendency to decrease by about 0.2. in six years ofl the Swain Reefs (arca A in Fig. 38A) and a smaller decrease with time off Great Sandy Is. (area B, Fig. 38A). A conspicuous feature was a cycle with marked minima occurring at 2-year intervals at these two locations off the Qucensland coast. The reasons for these long-term changes were not known.

\section{Mean seasonal variations of surface temperature and salinity by areas}

In an endeavour to better describe the local variations of surface properties with season, the Western Coral Sea was divided into six approximately '5 areas' as shown in Fig. 41. The mean surface temperature and salinity for each area (for the sea outside the Reef) was estimated by eye from the CSIRO Atlas for each month and the long-term mean for 1966-74 then calculated. The temperature time and salinity time curves are presented in Fig. 41 A-D and the corresponding T,S, time curves are plotted in Fig. $41 \mathrm{E}, \mathrm{F}$ from the smoothed curves above. (There were insufficient data for area A, Gulf of Papua, to plot any curves.)

It is evident that clear and similar variations with time occur in all areas, with differences mainly in the magnitudes. For temperature, the mean values and annual ranges are slightly higher in the eastern areas than in the western ones, while for salinity the eastern areas have slightly smaller ranges but essentially the same mean values as the western ones. Noticeable is the small range of salinity variation in area $\mathrm{F}$.

It must be stressed that these are mean value curves. The average stanclard deviations about the monthly means were about $\pm 0.5 \mathrm{C}$ and $\pm 0.3 ;$, while cach individual monthly value was a mean of a range of values within the ' 5 ' area'. These monthly ranges were from \pm 0.5 to $\pm 2 \mathrm{C}$ and from $\pm 0.1 ;$. to \pm 2 (occasionally in arca $\mathrm{B}$ ). It should also be noted that the T,S, diagrams of Fig. 41 are not identical with those of Fig. 24 in Part 1, for which values were selected close to the Reef, not for the sea areas as a whole.

\section{Sources of surface waters in the Coral Sea-Rochford}

No water types are formed in the Coral Sea; thus the waters therein all come from external sources. In one of the first studies of the water masses in this area, Rochford (1959) analysed the surface characteristics in the Coral and Tasman Seas using T,S,f plots ( T,S diagrams with the frequency of occurrence (f) of T,S combinations included to make the display semi-quantitative; Montgomery, 1955). Mean curves were drawn through the areas of most frequent occurrence of T,S combinations. (Rochford used chlorinity $(\mathrm{Cl})$ in his paper, but for convenience this has been converted to salinity $(\mathrm{S})$ by the current relationship $\mathrm{S}=1.80655 \mathrm{Cl}$. 

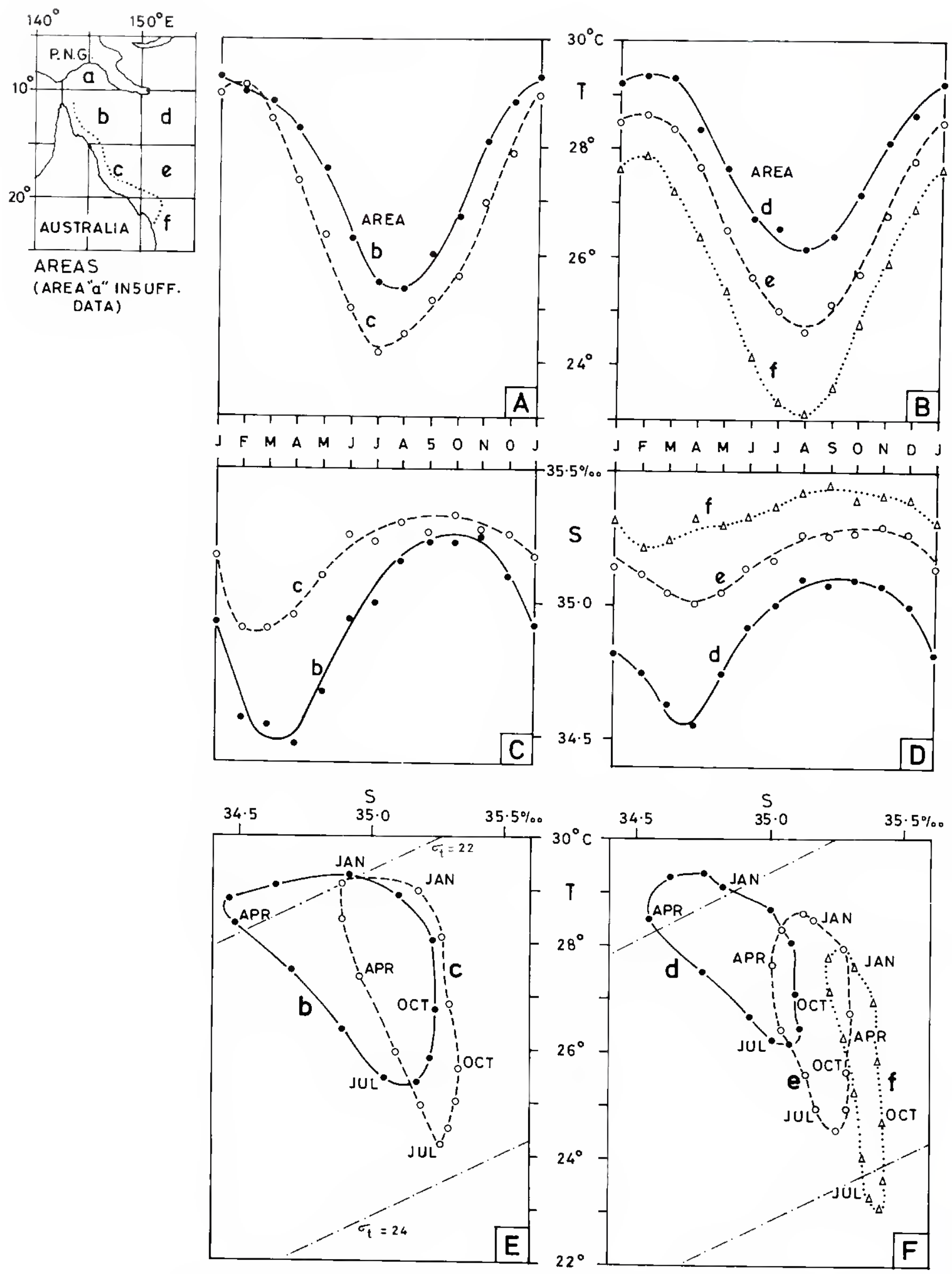

Fig. 41 Seasonal variations of surface water tempcrature and salinity, Western Corai Sea, by approximate 5 degree areas: (A,B) Temperature time, (C,D) Salinity time, (E,F) T,S, time diagrams (data from 
Rochford made the basic assumption that the effects of local evaporation and precipitation were negligible compared with those due to advection; i.c. salinity was regarded as conservative even in the surface layer. The validity of this assumption is dubious in view of Taylor's (1973) figures for rainfall in the Coral Sea showing that precipitation is significant $(1500 \mathrm{~mm}$ yr) and that the monthly amounts vary by a factor of five over the year. There is no information available on evaporation in the Coral Sea. Measurements or estimates would be very desirable.

Presumably Rochford also regarded temperature, i.e. heat content, as conservative but he made no mention of this. Most of the data available were from surface sampling from merchant ships, although these only travel along restricted lanes across the seas. For instanee, in Rochford's area 9, which corresponds closely to the defined WCS, there was only one shipping lane, from Gt Sandy Is. to the south-east tip of Papua New Guinea, and only 24 samples per month on the average.

$T$, S, f plots and mean T,S curves were prepared by Rochford for four quarters (November-January, etc.). The general character of the mean curves is indicated in Fig. $42 \mathrm{~A}$ which is an envelope of all the T,S curves with the Coral and Tasman Seas not differentiated. Rochford divided this envelope into three main zones: (1) above $28 \mathrm{C}$ where there was little annual temperature change but considerable salinity change (presumably the north Coral Sea area), (2) from 28 to $19 \mathrm{C}$ where salinity increased as temperature decreased, with greater annual changes of temperature than above $28 \mathrm{C}$, and (3) below $19 \mathrm{C}$ where salinity decreased with decrease of temperature and where there were considerable annual ranges of variation (mostly Tasman Sea samples).

Rochford compared these surface $T, S$ curves with vertical T, $S$ curves for stations in the area between Australia and $155 \mathrm{~W}$ for winter (envelope in dashed lines in Fig. 42B) and summer (envelope in dashed lines in Fig. 42C). The mean surface T,S curves for the Coral Tasman Scas are shown in full lines in these figures and the latitude scales at the left give some indication of which parts of the surface T,S curves are pertinent to the present review of the WCS.

From these T, S curves Rochford determined three major and three minor water types, mixtures of which could produce the vertical or horizontal T, S curves of Fig. 42A, B, C. These types were identified as in Table 5. The major types and the Arafura Sea water are indicated on Fig. 42B, C by number. The two remaining water types ( 5 and 6 ) have not figured significantly as such in subsequent discussions of the Coral Sea waters.

Rochford's description of the surface $T, S$ characteristics does indicate the probability of the four water types $(1,2,3,4)$ referred to above being the main contributors to the Coral Sea surface waters. (It should be noted that the word water 'type' here does not imply a large volume of completely homogeneous water as represented by a point on a T,S diagram (Sverdrup's definition) but rather the mean temperature and salinity of a water body, it being understood that the range of values about the mean is small compared to the

Table 5. T,S characteristics of Coral Tasman Sca water types (from Roehford, 1959)

\begin{tabular}{|c|c|c|c|}
\hline & & Temperature & Salinity \\
\hline & Water I ype & & \\
\hline \multirow[t]{3}{*}{ Major: } & 1. South Equatorial (from $\mathrm{N}$ of $10 \mathrm{~S}$ ) & $28.2-28.8$ & 34.7 \\
\hline & $\begin{array}{l}\text { 2. West Central South Pacific (from } \\
15-20 \mathrm{~S}, 150 \mathrm{~W} \text { ) }\end{array}$ & 26.0 & 36.5 \\
\hline & 3. Sub-Antarctic Surface (from $S$ of $45 \mathrm{~S}$ ) & $9.0-11.8$ & 34.7 \\
\hline \multirow[t]{3}{*}{ Minor: } & 4. Arafura Sea & $28-29$ & 34.1 or less \\
\hline & 5. Tropical high salinity & $29-30$ & 35.6 \\
\hline & 6. Temperate high salinity & $20-21$ & 36.5 or more \\
\hline
\end{tabular}



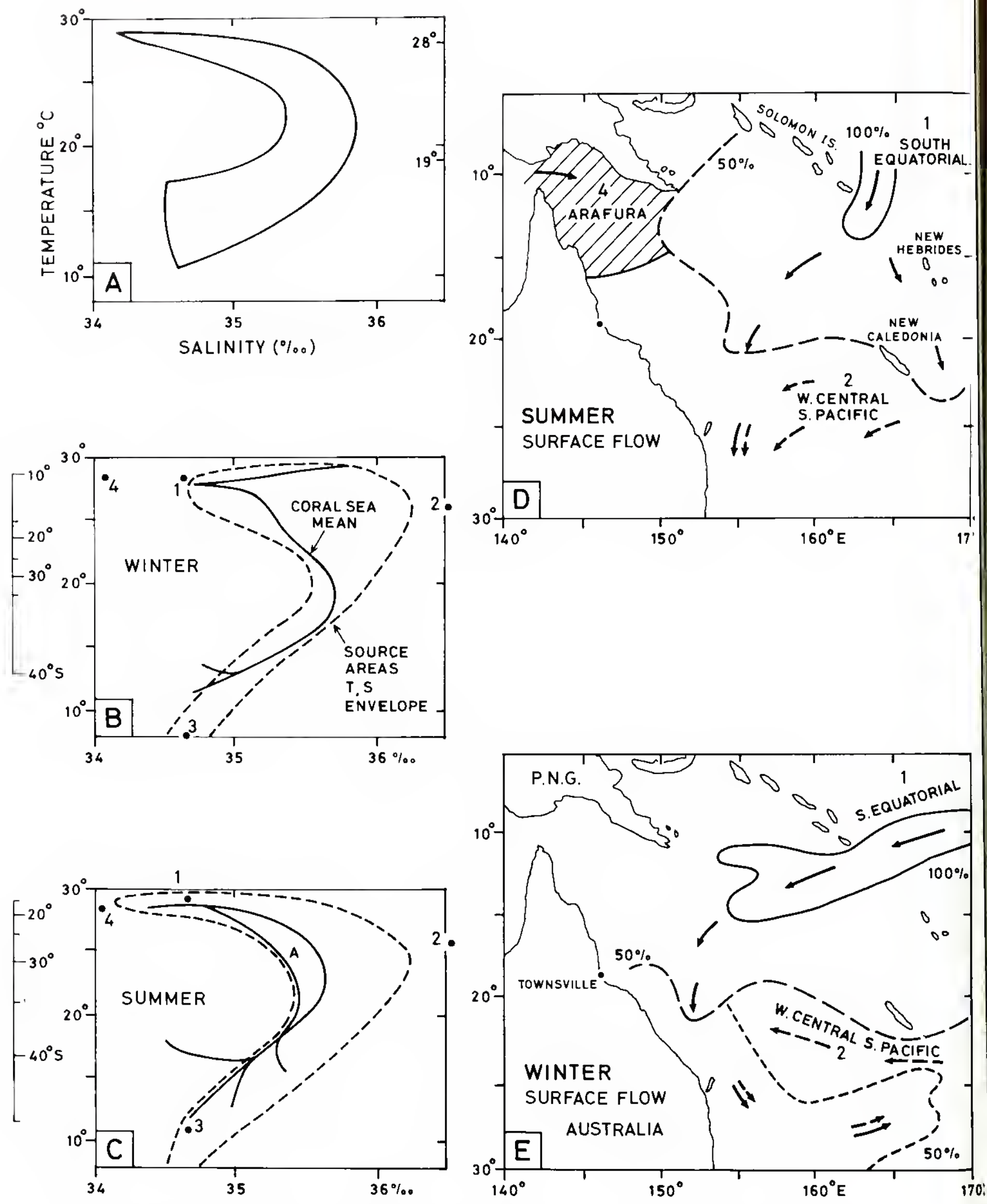

liig. 42 (A) Envelopes of surface $T, S$ values, Coral Sea,

(B) I'ull lines - mean surface T,S curves, winter, Coral Sea; dashed lines-envelope of vertical 'T,S curves for source areas; numbers-four major water types contributing; (1) South Equatorial, (2) West Central South Pacific, (3) Subantarctic Surface, (4) Arafura Sea,

(C) As for (B) but summer,

(1) Summer, and (E) Winter flow patterns, for water types of (B). (All adapted from Rochford, 1959.) 
differences between those of the water types contributing to the region.) Presumably for the WCS the two higher temperature types (1 and 2) would be the most important. This is evident in Scully-Power's data (1973a) shown in Fig. 44.)

On this basis, Rochford then used the method of the mixing triangle (ref. Appendix) on the T,S diagram to determine the percentage of each of the three major external water types contributing to the make-up of each sample in the Coral and Tasman Stas and to deduce the surface flow patterns for the four water types as shown in Fig. $42 \mathrm{D}, \mathrm{E}$. In summer (Fig. 42D) the flow was primarily meridional except for some westerly flow of West Central South Pacifie water at about 25 S. For late winter (Fig. 42E) the flow was chiefly zonal with a strong westward flow of South Equatorial water across $160 \mathrm{E}$ into the Coral Sca and inflow from the south-cast of West Central South Pacific water (and some outflow to the east at about $30 \mathrm{~S}$ of a mixture of these two waters). The mixture of South Equatorial and West Central South Pacific waters formed at about $27 \mathrm{~S}$ was called "Coral Sea' water by Rochford. He did not specify the water characteristics in his paper but from his diagrams they would appear to be about $27 \mathrm{C}$ and 35.6 . The Arafura Sea water was recognised in the North-west Coral Sea at this time and might be expected also to occur later (February to April).

Rochford also examined the total phosphorus content of the surface waters and considered that it could also be used as an identifying water property. In particular, he noted that the phosphorus content of the West Central South Pacific water was low 0.1 to $0.16 \mu \mathrm{g}$ at 1$)$ compared to that of the South Equatorial and Sub-Antarctic waters $(0.65$ to $1.0 \mu \mathrm{g}$ at $: 1)$.

\section{Surface waters-Scully-Power}

The most systematic set of observations for the WCS was made by Scully-Power (1973a, b) for the winter period, between 4 May and 20 July 1968, when three cruises comprising 94 stations were eompleted. The station positions are shown in Fig. $43 \mathrm{~A}$. Because of the coherence of this data set and its coverage of the WCS, it will be discussed in some detail.

The surface temperature and salinity distributions are presented in Fig. 43A, B to show that a reasonably simple pattern may be present when the data are comprehensive and quasi-simultancous (although the circulation did not appear to be simple: see later). These distributions resemble the very much smoothed mean distributions, Fig. 36 and 40 , constructed from the CSIRO Atlas data.

The isotherm and isohaline patterns were similar except for the feature due to a low salinity at one station in the Gulf of Papua. The surface density pattern was very similar to the surface temperature pattern, $\pi$, values increasing from 22 in the north-west to 25 at the south.

The T, S and $\mathrm{S}, \mathrm{O}_{2}$ diagrams for the surface waters showed small scatter (Fig. 44, full lines), the surface $T, S$ values being almost all within the envelope of vertical $T$, S curves for the WCS (dashed line).

Scully-Power discussed the low-salinity waters in the North-west Coral Sea (area $a b$ in Fig. 44) and suggested that continuing river runoff into the north-west Gulf of Papua was probably the major factor but that there might also be pockets ('clouds' would be a better word) of Arafura Sea water still present from the $\mathrm{NW}^{\dagger}$ monsoon inflow through Torres Strait. No figures are at hand for the runoff of the extensive river system of Papua New Guinea which cmpties into the north-west Gulf of Papua but it is noted (Brookficld \& Hart, 1966) that there are some curious features of the rainfall around the Guif. At Daru (Fig. 28) the maximum rainfall period is from January to April (57" "of the annual total) whereas from about 143.5 to $146 \mathrm{E}$, as typified by Kikori, the maximum is later (May to September), when $56^{\prime \prime}$ of the annual total falls. To the east of $146 \mathrm{E}$ the pattern reverts to a January to March maximum. The annual total at Kikori is $5760 \mathrm{~mm}$ compared to $2075 \mathrm{~mm}$ at Daru, and $995 \mathrm{~mm}$ at Port Moresby. The high rainfall area extends inland 

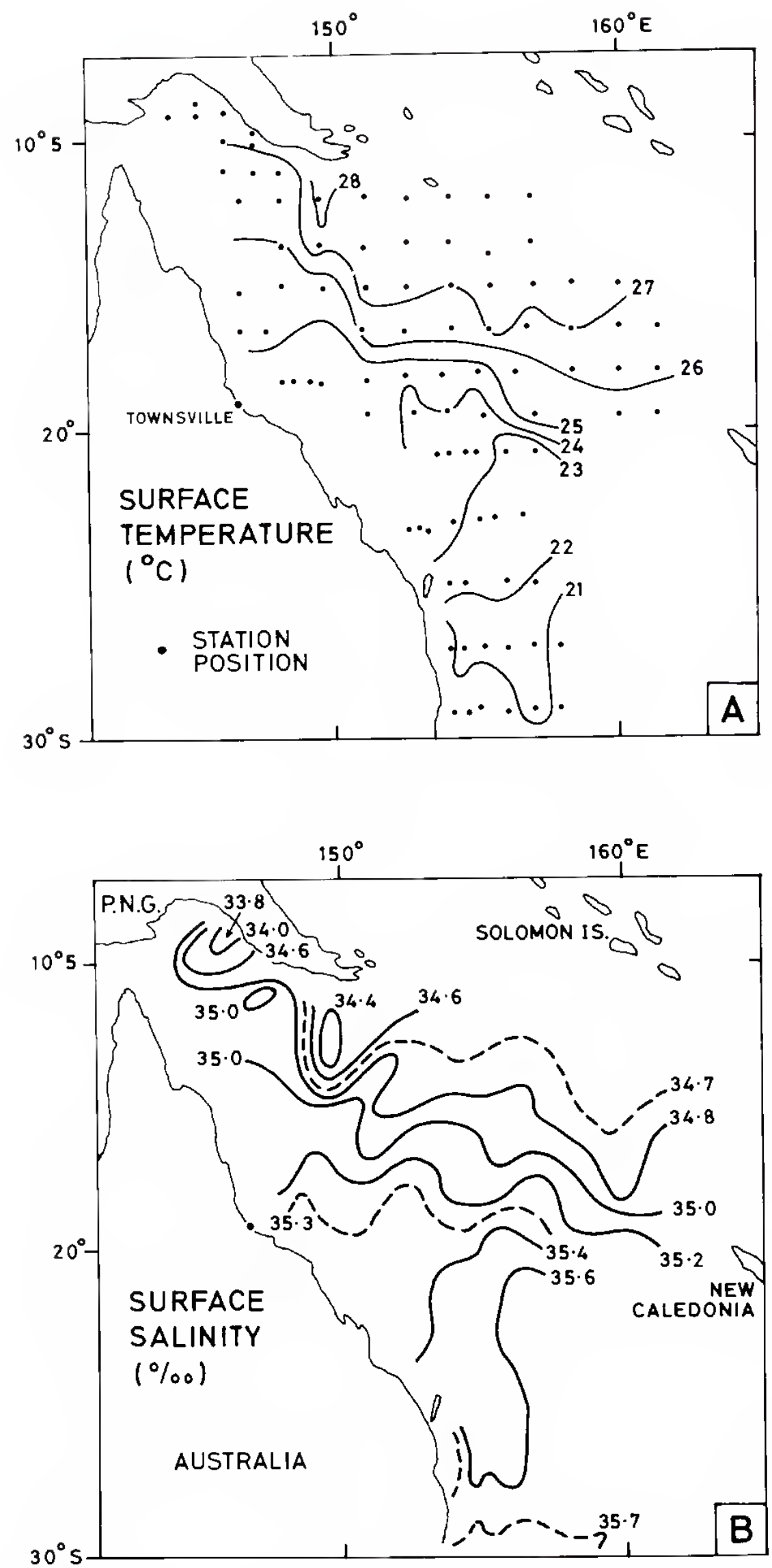

Fig. 43 (A) Surface temperature and (B) surface salinity, Western Coral Sea, May-July, 1968 (ScullyPower, 1973a). 


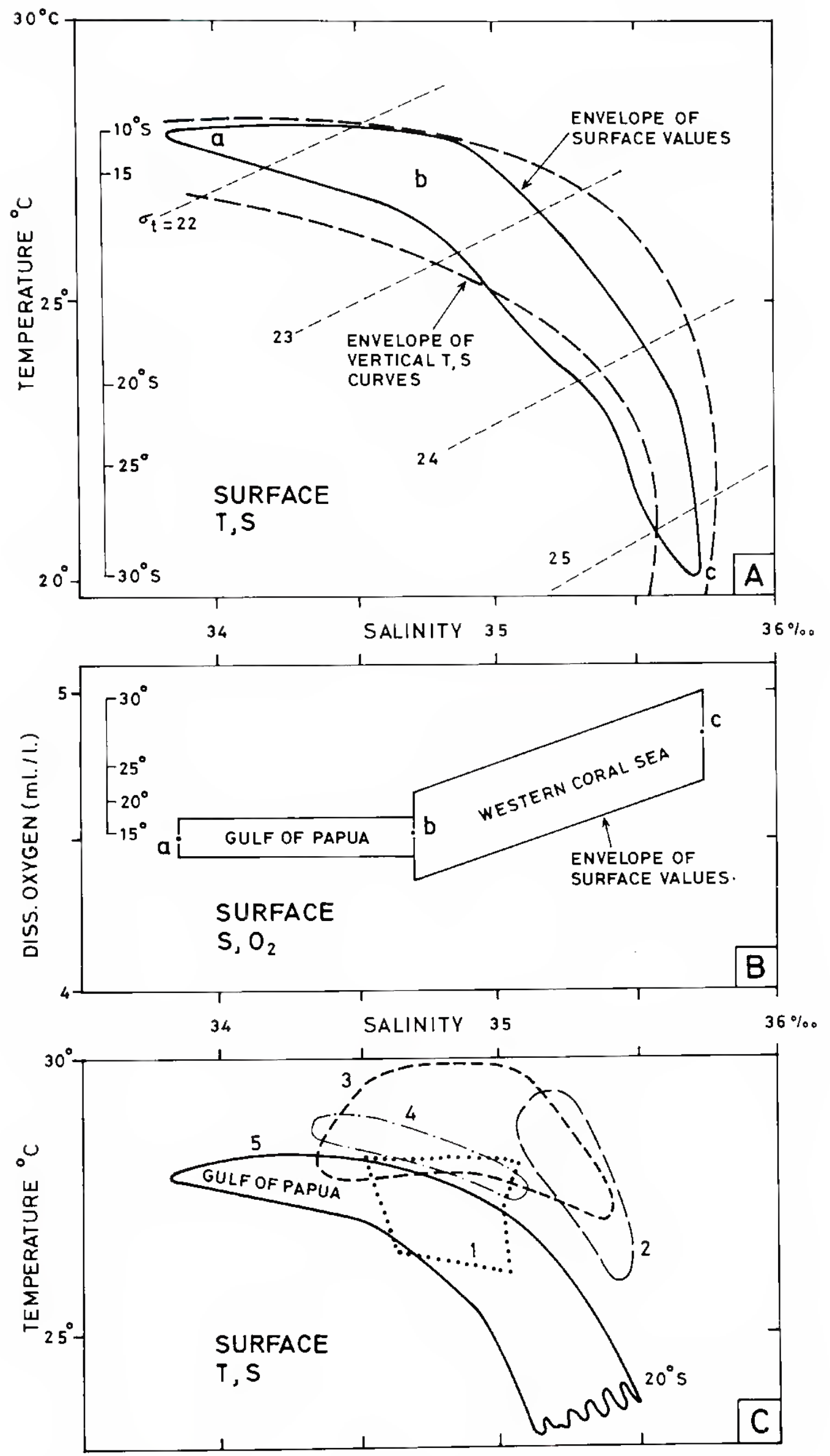

Fig. 44 (A) T,S and (B) S,O diagrams for surface waters, Western Coral Sea, May-July, 1968 (ScullyPower, 1973a),

(C) Comparison of surface T,S characteristics for several cruises in the Western Coral Sea: (1) Shoyo Maru, Oct.-Nov. 1973, (2) 'Gorgone 1', Nov,-Dec. 1972, (3) 'Iule', Jan. 1965, (4) 'Gorgone 2', May-June 1975, (5) R.A.N.R.L., May-June 1968. 
along a strip lying at about 300 true from Kikori. These differences in rainfall pattern along the north side of the Gulf of Papua are remarkable in the relatively short distances and may be responsible for some of the peculiarities of salinity patterns which have been noted in this arca (e.g. CSIRO Atlas, April 1969, May 1972, etc.).

Water of type b (Fig. 44A, B) was identificd as South Equatorial (surface) water (Rochford, 1959), while type $c$ was identified as basically the southern component of Subtropical Lower water.

The distribution of properties at the surface was consistent with a westward flow into the Coral Sea north of about $19 \mathrm{~S}$, with most of the flow turning north on approaching the Barrier Reef, the division being at about $19 \mathrm{~S}$ also. This flow pattern agreed with the geostrophic circulation discussed later.

(I)ata from a May 1972 R.A.N.R.L. cruise in the North-west Coral Sea are currently bcing studicd-personal communication, P. D. Scully-Power.)

\section{Other surface data in seasonal sequence}

Envelopes of surface T,S characteristics for five cruises which covered substantial arcas of the WCS (i.c. more than a single line of stations) have been assembled in Fig. 44C for comparison. The cruises used are listed below and the areas covered are shown in Fig. $45 \mathrm{~A}, \mathrm{~B}$ :

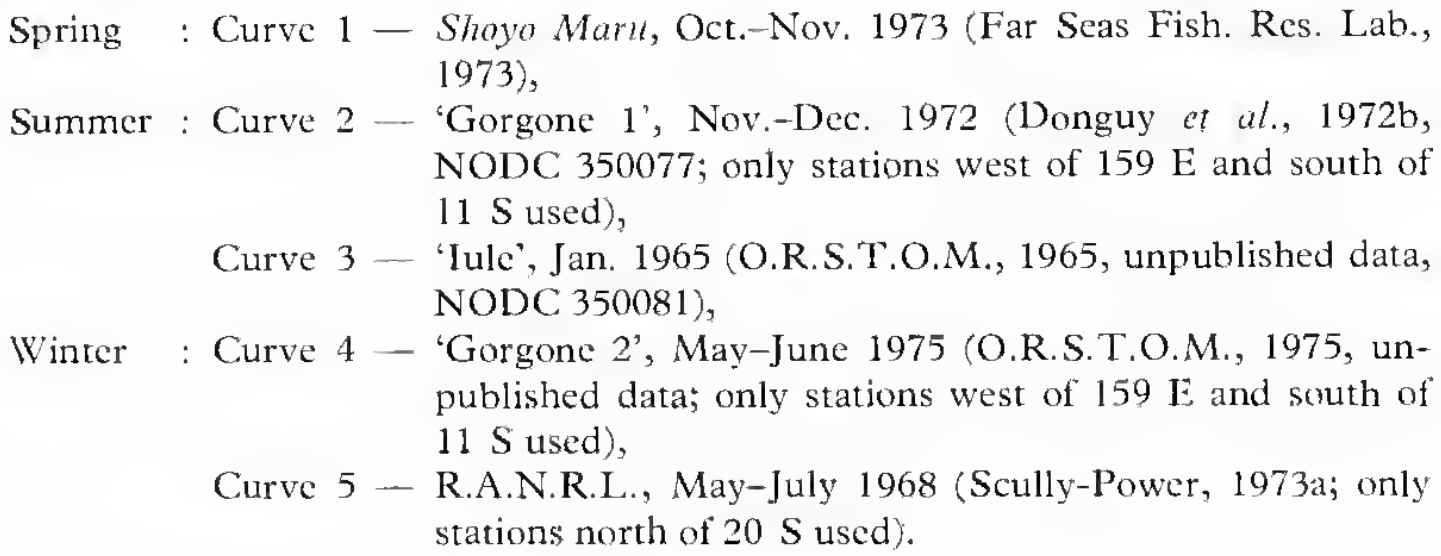

For temperature there is some indication of a seasonal change, the January cruise (curve 3) having the highest temperatures. However, it is by no means clear-cut as the 'Gorgone 2' and R.A.N.R.L. cruises (curve 4 and 5) were at about the same time of year (winter) but the former show higher temperatures by about $1.5 \mathrm{C}$.

For salinity, the shaded, low-salinity part of the R.A.N.R.L. data envelope (curve 5) was for the waters of the typically low salinity Gulf of Papua, further north-west than any of the other cruises. The difference in salinity between the two 'Gorgone' cruises may be attributed to the different seasons, 'Gorgone 1' (curve 2) being at the end of winter (high salinity period) while 'Gorgone 2' (curve 4) was after the wet season when low salinities are now known to occur systematically in the Solomon and north Coral Seas due to local rainfall (Donguy \& Henin, 1975a). In addition there may also be some effect due to possible year-to-year variations.

The larger range of salinity for the R.A.N.R.L. cruise was probably because this penetrated further into the low salinity Northwest Coral Sea, but the lower temperature for the R.A.N.R.L. cruise is probably indicative of year-to-year changes because the two envelopes are entirely separate in the temperature direction despite the fact that the two cruise areas overlap between 12 and $20 \mathrm{~S}$. This emphasises (as has been shown already) that year-to-year variations in the surface layer characteristics can be significant.

\section{Speed of movement of water masses-Rochford}

Fig. 41 shows that the lower salinity (South Equatorial) water moves south in the summer. Rochford (1973) gave two examples of estimates of the speed of southward 


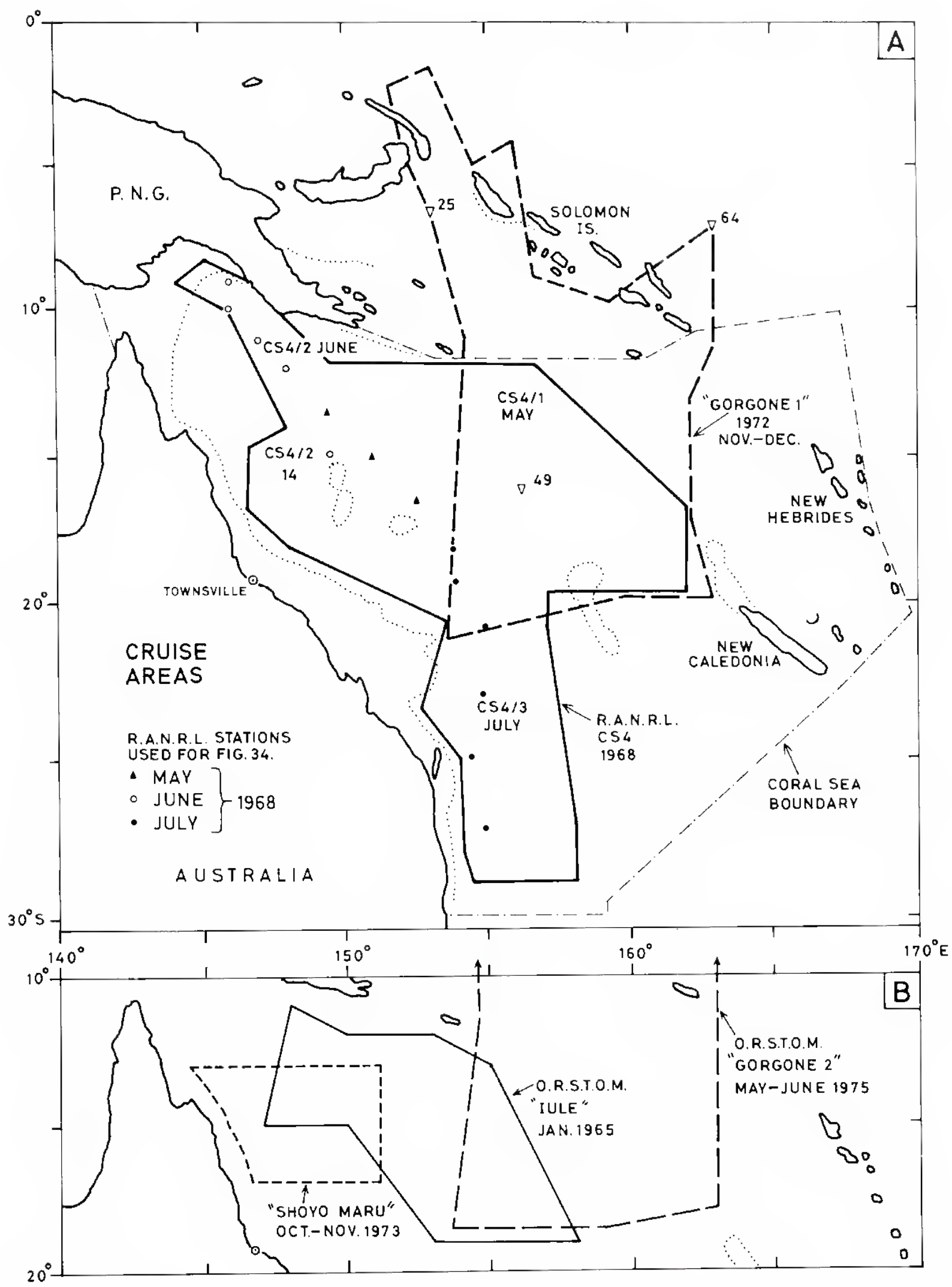

Fig. 45 Cruise areas, Coral Sca: (A) R.A.N.R.L. Cruises CS4, 1,2, 3, May-July 1968 and locations of stations for Figs. 32 and 33 (Scully-Power, 1973a), O.R.S. T.O.M. 'Gorgone l' cruise, Nov.-Dec. 1972 (Rougerie \& Donguy, 1975), (B) O.R.S.T.O.M. 'Iule' cruise, Jan. 1965; Shoyo Maru cruise, Oct.-Nov. 1973; O.R.S.T.O.M. 'Gorgone 2' cruise, May-June 1975. 
penetration of this water from the southward advance of lower salinities in successive months on the CSIRO Atlas plots. Fig. 46 shows these estimates for January to April 1966 and 1970. They yielded speeds of the order of $22-44 \mathrm{~km}$ day or 6 to 12 degrees of latitude mo along the main flow directions and about $4 \mathrm{~km}$ day perpendicular to the main flows.

\section{Mixed layer depth}

Because there is often a wind-mixed layer in the Coral Sea of depth comparable to those of the passes through the Great Barrier Reef (less than $100 \mathrm{~m}$ ), the surface water characteristics may often be sufficient to characterise the WCS waters when considering exchange between the Sea and the Lagoon. Therefore the mixed layer depth was

lig. 40 Southward progress of low salinity (South Equatorial) water in the Western Coral Soa in January-April, 1966 and 1970 (Rochford, 1973).

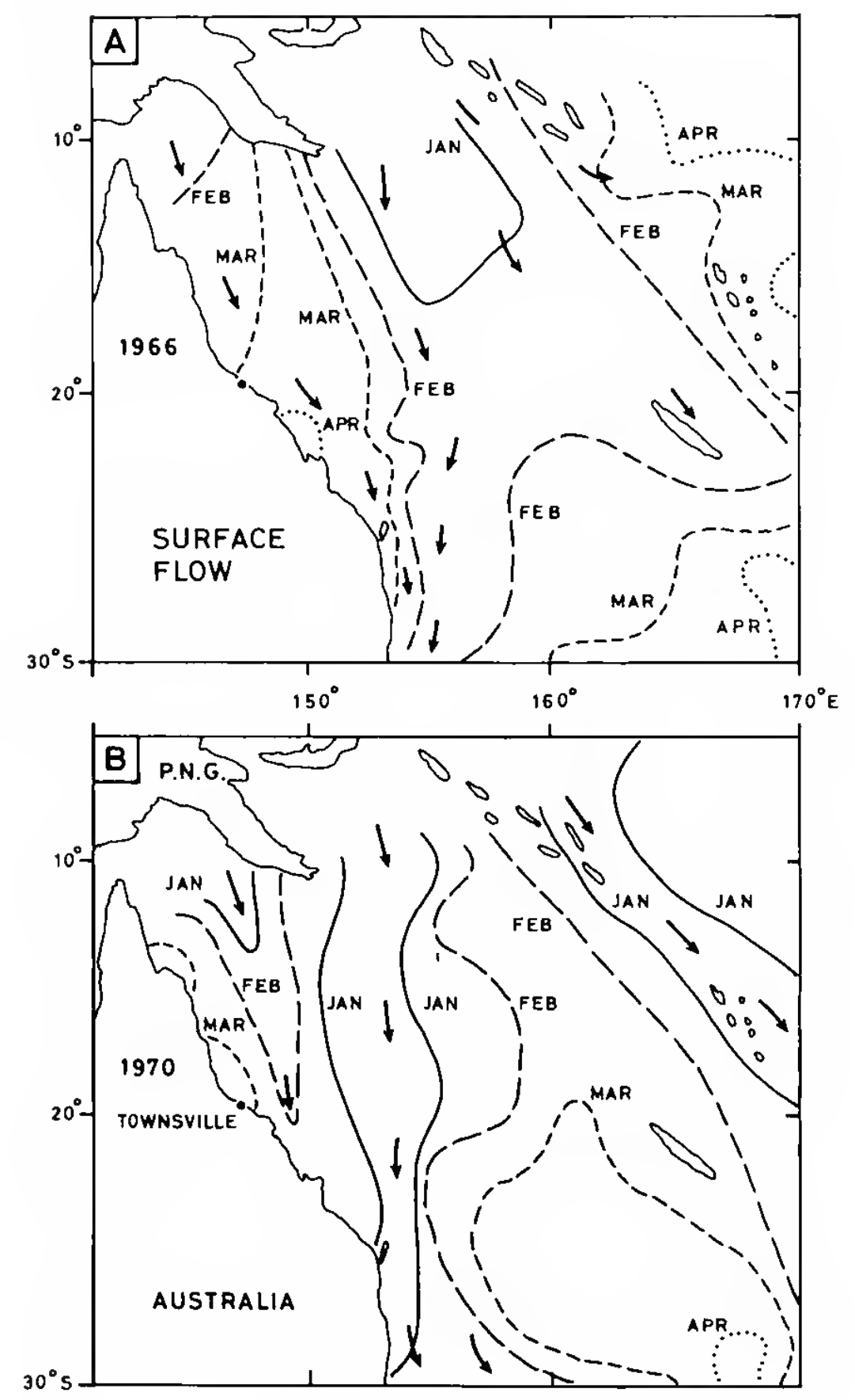


estimated from the R.A.N.R.L. 1968 cruise records (Scully-Power \& France, 1969a, b, d) and plotted on a chart; an attempt was made to contour this feature. No simple pattern was found, if the rules of contouring were followed strictly, because of the sharp changes between some pairs of stations. A broad look at the field of values resulted in Fig. 47, which indicates that the mixed layer was deepest near the Reef and shallowest along a line south-cast from the Gulf of Papua. Wind specds during the three cruises varied from 2 to $15 \mathrm{~m} / \mathrm{s}$ and averaged $6 \mathrm{~m} / \mathrm{s}$. No significant correlation between layer depth and wind specd was found.

An earlicr R.A.N.R.L. cruise in November-December 1966 (Scully-Power, 1969a) between Cairns and Papua New Guined indicated mixcd layer depths of 20 to $70 \mathrm{~m}$, which were smaller than the 1968 values on the direct line between Cairns and Port Moresby but greater to the east of this. In April-May 1967 (Scully-Power, 1969b) in the same area, values north of $12 \mathrm{~S}$ were between 0 and $25 \mathrm{~m}$ while at 13 and $14 \mathrm{~S}$ they were $20-35 \mathrm{~m}$. Winds were from 2.5 to $9 \mathrm{~m} / \mathrm{s}$ during the 1966 cruisc, and 4 to $6 \mathrm{~m} / \mathrm{s}$ at those stations where it was recorded in 1967.

For the O.R.S.T.O.M. 'Gorgone 1' cruise in the Central Coral Sca in November-December 1972 (Donguy et al., 1972b), the shallowest sample below the surface was taken at $50 \mathrm{~m}$ nominal depth and only at one or two stations was there any indication of a mixed layer reaching to this depth. 'This is consistent with Scully-Power's data in the region of overlap (see Figs. 47 and 4).

Fig. 47 Surface mixed-layer depth, Western Coral Sea, May-July 1968 (data derived from Scully-I'ower \& France, 1969a, b, c).

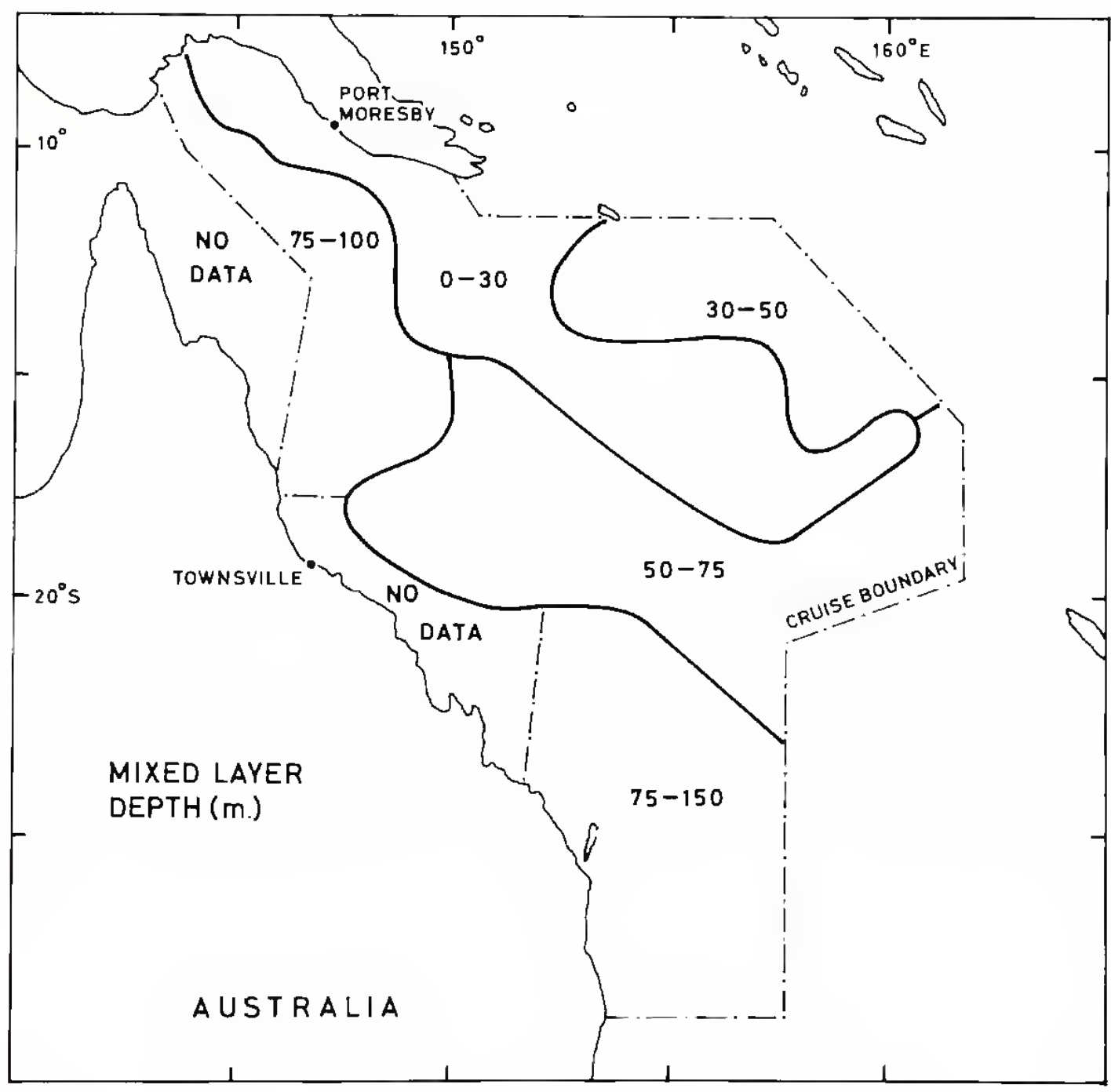


The Shovo Maru (Far Seas Fish. Res. Lab., 1973) made 75 bathythermograph casts in an area $13-17 \mathrm{~S}, 144-151 \mathrm{E}$ (north-east of Cairns) in October-November 1973, the temperature values being reported at $25 \mathrm{~m}$ intervals from the surface. From thesc it appeared that the mixed layer depth varied from 0 to $50 \mathrm{~m}$, the values along the Recf being $0-25 \mathrm{~m}$. The wind specd was mostly from 4 to $12 \mathrm{~m} \mathrm{~s}$ and there was some indication of grcater mixed layer depths being associated with greater wind speeds.

Onc concludes that, as for other characteristics, the mixed layer depth is very varjable in the WCS.

\section{SUBSURFACE WATER MASSES AND HLOW PAT'TERNS}

\section{Introduction}

The main contributors to the study of the subsurfacc water masses in the Western and Ccntral Coral Sea have been Rochford (using isentropic analysis), Wyrtki and ScullyPower (core analysis), and Rougerie \& Donguy (isentropic analysis). Papers by these authors wiil be discusscd substantially in chronological order.

\section{Isentropic analysis-Rochford}

The $27.2 \sigma_{1}$ surface. Rochford (1960a) discussed aspects of intermediate depth waters on the $27.2 \sigma_{\mathrm{t}}$ surface, which is at 700 to $900 \mathrm{~m}$ depth in the WCS and near the core of the Antarctic Intermediate water. When considering this paper it should be noted that the region north of $25 \mathrm{~S}$ and west of $162 \mathrm{E}$ (i.e. an area greater than the entire WCS) was represented by only one line of 10 stations (Umitaka Maru, 1959, unpublished, and one Planet station) at about $156 \mathrm{E}$. For these stations, on this surface, the tcmperaturc was close to $6 \mathrm{C}$, salinity was about 34.45 , dissolved oxygen increased from about $3.7 \mathrm{ml} 1$ in the north of the line of stations (mid-WCS) to $4.05 \mathrm{ml} / \mathrm{l}$ in the south, and phosphate-P increased from 1.8 to $2.05 \mu \mathrm{g}$ at $/ 1$ from north to south.

For the analysis of waters on the $27.2 \sigma_{t}$ surfacc, Rochford placed considerable emphasis on $\mathrm{S}_{9} \mathrm{PO}_{4}$ relations and identified three water types as:

\begin{tabular}{lcc}
\hline & Salinity & $\begin{array}{c}\text { Phosphate }-P \\
\text { ( g at } / \text { ) }\end{array}$ \\
\hline (7) Pacific Equatorial Intermediate & 34.60 & 3.10 \\
(8) South-west Pacific Intermediate & 34.70 & 0.50 \\
(9) Antarctic Intermcdiate & 34.02 & 1.88 \\
\hline
\end{tabular}

He contoured the percentages of each on the $27.2 \sigma_{\mathrm{t}}$ surface using the mixing triangle method. The result showed water type 7 entering the WCS from the north through the Solomon Sea, typc 8 from the north-east between the Solomon Islands and New Caledonia, and type 9 chiefly from the east by the same route (but entering the Tasman Sea from the south). The major outflow from the Coral Sea on this surface was to the south along the Australian coast (East Australian Current).

The 25.0 $\sigma_{\mathrm{t}}$ surface. Rochford (1969) averaged salinity and oxygen data by 5 squares for the south-west Pacific $\left(0^{\circ}-50^{\circ} \mathrm{S}, 140^{\circ} \mathrm{E}-160 \mathrm{~W}\right)$ to study the origin and circulation of water types on the $25.0 \sigma_{\text {, }}$ surface which is close to the core depth of the Subtropical Lower water. He identified four types (essentially subdivisions of this water) as: 


\begin{tabular}{|c|c|c|c|c|}
\hline Type & Name & Sulinity & Oxygen & ()rigin \\
\hline & & & $|m i l|$ & \\
\hline A & Tropical high salinity & 36.00 & 3.50 & Central South Pacific \\
\hline$A^{\prime}$ & Tropical low salinity & 35.25 & 3.10 & North Equatorial Pacific \\
\hline $\mathrm{B}$ & : Subtropical high salinity & 35.75 & 5.15 & Central Tasman Sea \\
\hline $\mathrm{B}^{\prime}$ & : Subtropical low salinity & 35.46 & 5.15 & West of North N.Z. \\
\hline
\end{tabular}

North of 15 S, types $A$ and $A^{\prime}$ drifted west near the equator but cast around $20 \mathrm{~S}$; south of $35 \mathrm{~S}$, types B and $\mathrm{B}^{\prime}$ drifted east and north. Types A and A' were essentially the northern component of the Subtropical Lower water, while types B and $B^{\prime}$ were southern component waters.

A comparison of winter and summer values was possible in some areas and indicated that:

(a) tropical waters $\left(\mathrm{A}, \mathrm{A}^{\prime}\right)$ drifted south along the Australian coast in the summer to winter period;

(b) subtropical waters $\left(\mathrm{B}, \mathrm{B}^{\prime}\right)$ drifted north into the Central Coral Sea in the winter to summer period.

\section{Core layer analysis-Wyrtki}

Wyrtki (1962a) carried out a core layer analysis using fairly homogeneous data from CSIRO Gascoyne cruises in 1960 and 1961 in the area between the Australian coast, New Zealand, Fiji and the Solomon Is. supplemented by the Umitaka Maru data for 1959 for the east edge of the WCS as used by Rochford (1960a, b) and also some Orsom III data south-east of New Caledonia (Rotschi, 1960c). Current nomenclature for the subsurface waters in the Coral Sea, as used in the introductory paragraph and subsequently, is based on this paper by Wyrtki.

Fig, 48 (A) T,S and (B) F, O diagrams for Western South Pacific waters (adapted from Wyrtki, 1902a),

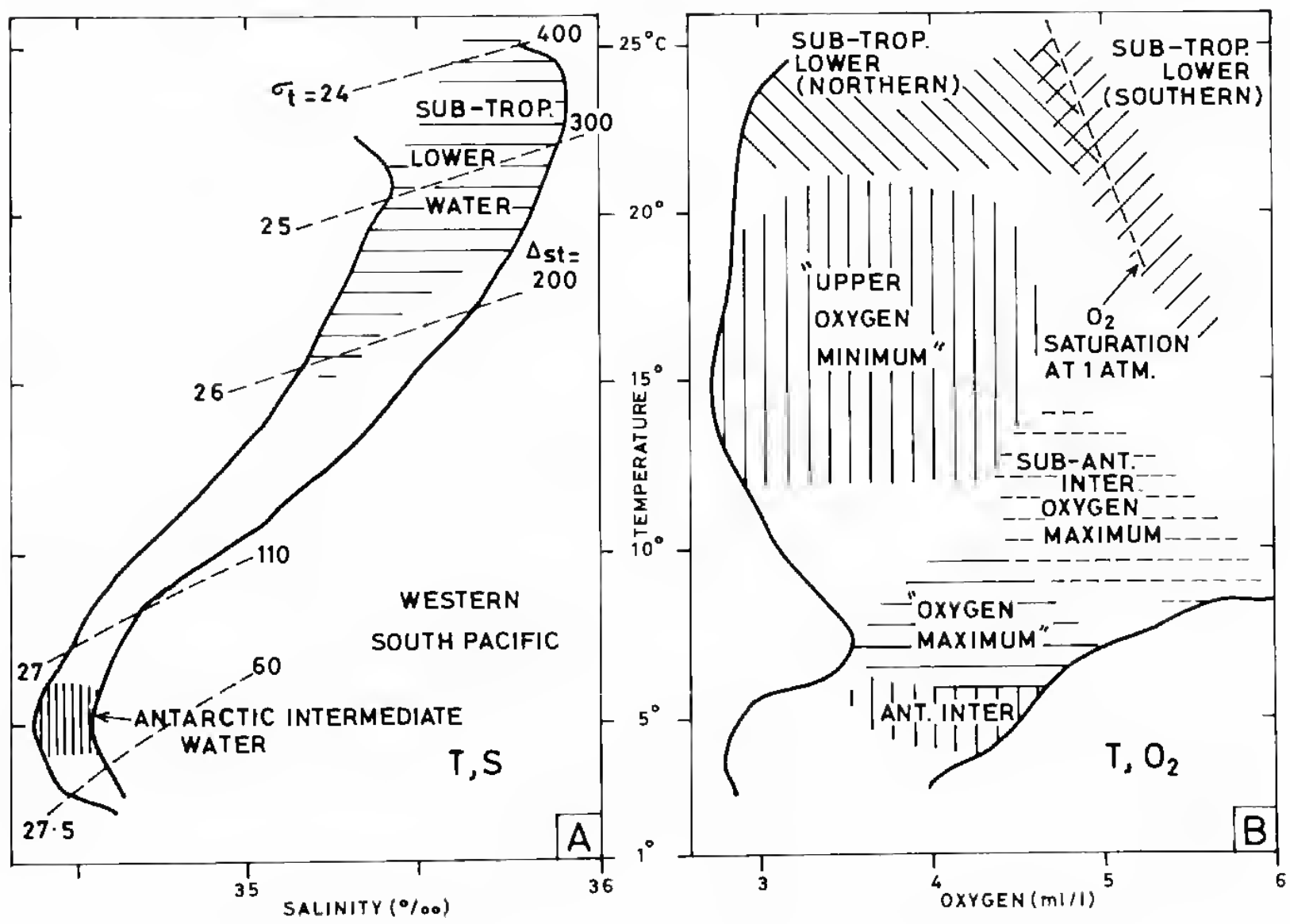


Wyrtki used $\mathrm{T}, \mathrm{S}$ and $\mathrm{T}, \mathrm{O}_{2}$ diagrams for his analysis. Fig. $48 \mathrm{~A}$ is a simplified version of his $T$, S diagram for the salinity core-layers, replacing the original station points with general shading to indicate concentrations of points, and omitting the deep and bottom water points. Fig. 4813 simplifies his $\mathrm{T}, \mathrm{O}_{2}$ diagram in a similar manner. From these and other characteristic diagrams Wyrtki distinguished three main water masses in the upper $1100 \mathrm{~m}$. Using the $\mathrm{T}$, S diagram he identified;

(10) Surface water: $\mathrm{T}>24 \mathrm{C}, \mathrm{S}$ from 34.0 to $35.6, \sigma_{1}$ from 24.0 to 25.5 (discussed by Rochford, 1957-1959, and not discussed in Wyrtki's paper or included in his T, $\mathrm{S}$ diagrams),

(11) 'Subtropical Lower' water : Salinity maximum, 'T from 18 to $25 \mathrm{C}, \mathrm{S}$ from 35.5 to 36.0 , core depth 50 to $150 \mathrm{~m}$ in the WCS,

(12) 'Antarctic Intermediate' water: Salinity minimum, T from 4.2 to $6.0 \mathrm{C}, \mathrm{S}$ from 34.37 to 34.53 , core depth 700 to $1000 \mathrm{~m}$ in the WCS.

The $T, \mathrm{O}_{2}$ diagram revealed further features of the water masses:

(a) The Subtropical Lower water clearly subdivided into a lower oxygen component ( 3 to $4 \mathrm{ml} / \mathrm{l}$ ) at stations in the northern part of the region where the salinity maximum was below the surface ('northern component' of the Subtropical Lower water), and a higher oxygen component (above $4.4 \mathrm{ml} \mathrm{l}$ ) from subsurface and surface levels and found at stations further south ('southern component' of the Subtropical Lower water),

(b) between 24 and $12 \mathrm{C}$, below the Subtropical Lower water, a layer of minimum oxygen in the vertical was found (the 'Upper Oxygen Minimum'),

(c) between 10 and $5.5 \mathrm{C}$ was a layer with maximum oxygen in the vertical ('Oxygen Maximum').

Wyrtki argued that the oxygen minimum was formed it situ by biochemical reduction, thus qualifying it as a separate water mass, but that the oxygen maximum resulted simply from vertical mixing of the lower part of the Antarctic Intermediate water with low oxygen water below it, and therefore did not qualify as a separate water mass.

Examining the distribution of properties on the core layer of the upper salinity maximum (Subtropical Lower water), Wyrtki showed that two salinity maximum $(>35.9$. ) water masses were apparent, one entering the Coral Sea from the east in the vicinity of the New Hebrides and the other via the Tasman Sea between New Caledonia and New Zealand (Fig, 49A). The oxygen content in this core showed low values $(\sim 3.2 \mathrm{ml} 1)$ associated with the northern salinity maximum and high values $(5 \mathrm{ml} 1)$ with the southern salinity maximum (Fig. 49B). The salinity and oxygen distributions suggested that the boundary between these two maxima lay approximately along $20 \mathrm{~S}$ to the north of New Caledonia and thence west-north-west toward the Gulf of Papua. The core layer of the northern component sloped upward from about $150-200 \mathrm{~m}$ in the northern Coral Sea (Fig. 49A). The southern component was at the surface at about $30 \mathrm{~S}$ in the Tasman Sea and sloped down to about $100 \mathrm{~m}$ at $20 \mathrm{~S}$. Wyrtki then identified the source of the Coral-Tasman Seas Subtropical Lower water as the Subtropical Surface Water of the South Pacific formed between 15 and $25 \mathrm{~S}, 100$ to $150 \mathrm{~W}$ whence the southern component flowed west between 23 and 33 at the surface, retaining its high oxygen content, while the northern component sank and spread to the west north of $23 \mathrm{~S}$, oxygen being consumed en route. The above remarks refer to the Subtropical Lower core layer. Wyrtki suggested using $35.0 /$ as limits to enclose, above and below, the Subtropical Lower water mass. With this definition, the southern component would extend from the surface to $400 \mathrm{~m}$ depth and the northern from 50 to $300 \mathrm{~m}$. Such relatively shallow masses would be expected to follow the surface circulation and Wyrtki considered that the general movements of the Subtropical Lower water inferred above 96 

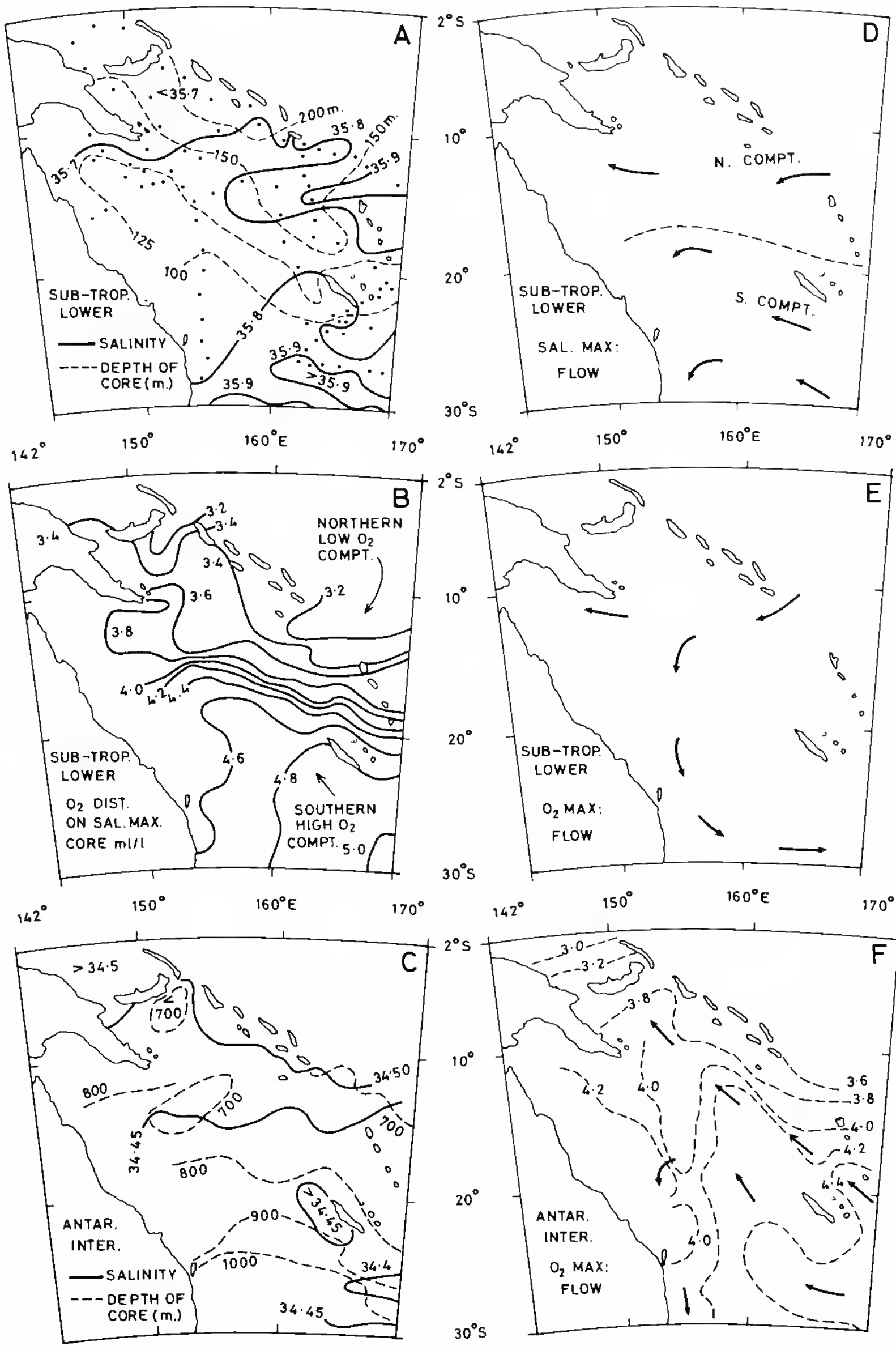

Fig. 49 Coral Sea property distributions and flows: (A) and (D) Subtropical Lower salinity maximum core layer, (B) and (E) oxygen distribution in salinity maximum core, (C) and (F) Antarctic Intermediate salinity minimum. Dots represent station positions (Wyrtki, 1962a). 
(Fig. 491) were in aceord with his description of the surface circulation (Wyrtki, 1960, and in the surface cireulation section following).

Wyrtki showed that the flow of the oxygen minimum water mass between 150 and $500 \mathrm{~m}(<3.0 \mathrm{ml} \mathrm{in}$ the north and $4.4 \mathrm{ml} \mathrm{l}$ in the south $)$, shown in Fig. $49 \mathrm{E}$, was similar to that of the salinity maximum above it. The next core, the oxygen maximum above the salinity minimum, was not regarded as a separate water mass, as explained above, and no effort was expended in tracing its movement.

Wyrtki next examined the salinity minimum layer, the Antaretic Intermediate water. An interesting feature of this water mass was that the greater part entered the Coral Sea not from the south but from the east, between the New Hebrides and New Zealand (Fig. $49 \mathrm{~F}$ ). This was evident both from the salinity distribution (Fig. 49C) and from the oxygen distribution at the level of the salinity minimum (Fig. 49F), with values of $4.4 \mathrm{ml} / \mathrm{l}$ on entry north and south of New Caledonia decreasing to $3.8 \mathrm{ml} 1$ in the Solomon Sea. The depth of the core decreased from $1000 \mathrm{~m}$ near $30 \mathrm{~S}$ to $700 \mathrm{~m}$ in the northern Coral Sea (Fig. 49C). (Rochford, 1960a, had shown a similar distribution in his discussion of properties on the $27.2 \sigma_{1}$ surlace which is close to the salinity minimum core.)

ln summary, Wyrtki listed the properties of the subsurface water masses. The values relevant to the WCS are presented in T'able 6.

Table 6. Properties of subsurface water masses in the Coral Sea

\begin{tabular}{|c|c|c|c|c|c|}
\hline Wator Muss & Feature & $T(C)$ & $S i$ & $\left.O_{2}+m / l\right)$ & Depth $/$ m \\
\hline \multicolumn{6}{|l|}{ Subtropical } \\
\hline $\begin{array}{l}\text { Lower } \\
\text { Northern }\end{array}$ & $\mathrm{S} \max$ & & & & \\
\hline $\begin{array}{l}\text { Compt. } \\
\text { Southern }\end{array}$ & (lower $\mathrm{O}_{2}$ ) & $21-24$ & $35.7-35.95$ & $3.2-4.2$ & $125-150$ \\
\hline $\begin{array}{l}\text { Compt. } \\
\text { Upper Oxygen }\end{array}$ & (higher $\left.\mathrm{O}_{2}\right)$ & $18-25$ & $35.75-35.85$ & $4.5-5.2$ & $50-125$ \\
\hline $\begin{array}{l}\text { Minimum } \\
\text { Antarctic }\end{array}$ & $\mathrm{O}_{2} \min$ & $12-21$ & $34.9-35.9$ & $2.7-4.6$ & $150-300$ \\
\hline Intermediate & $\begin{array}{l}\mathrm{O}_{2} \max \\
\mathrm{S} \text { min. }\end{array}$ & $\begin{array}{l}5.4-9.0 \\
4.2-6.0\end{array}$ & $\begin{array}{l}34.4-34.8 \\
34.42-34.47\end{array}$ & $\begin{array}{l}4.0-4.7 \\
3.9-4.4\end{array}$ & $\begin{array}{l}500-900 \\
700-1000\end{array}$ \\
\hline
\end{tabular}

Continuity of water masses along the western boundary of the Tasman and Coral Seas-Rochford

Bearing in mind the limited number of stations on which Wyrtki's (1962a) study above was based, it is interesting to review Rochford's (1968a) description of the water masses along the Australian coast, using a few more stations. The station positions (predominantly for the summer scason) are given in Fig. 50A which shows the isohalines in the core layer of the Subtropical Lower water in the WCS and the oxygen distribution by shading. The arrows show Rochford's interpretation of the flow, on the assumption that the oxygen gradients were too high to be the result of local consumption but must be maintained by flow. The 'oxygen poor' water may be identified as Wyrtki's northern component of the Subtropical Lower water and the 'oxygen rich' water as the southern component.

The depth of the salinity maximum layer increased from about $140 \mathrm{~m}$ in the Northwest Coral Sea to $200 \mathrm{~m}$ at $20-25 \mathrm{~S}$ before rising to the surface at about $30 \mathrm{~S}$. Wyrtki (1962a) showed the layer rising steadily from the North-west Coral Sea to the surface at about $30 \mathrm{~S}$ and did not show any deep patch comparable to Rochford's $200 \mathrm{~m}$ one.

Fig. $50 \mathrm{~B}$ shows the salinity values in the core of the Antarctic Intermediate salinity minimum. This layer had a depth of over $800 \mathrm{~m}$ round the margin of the North-west 


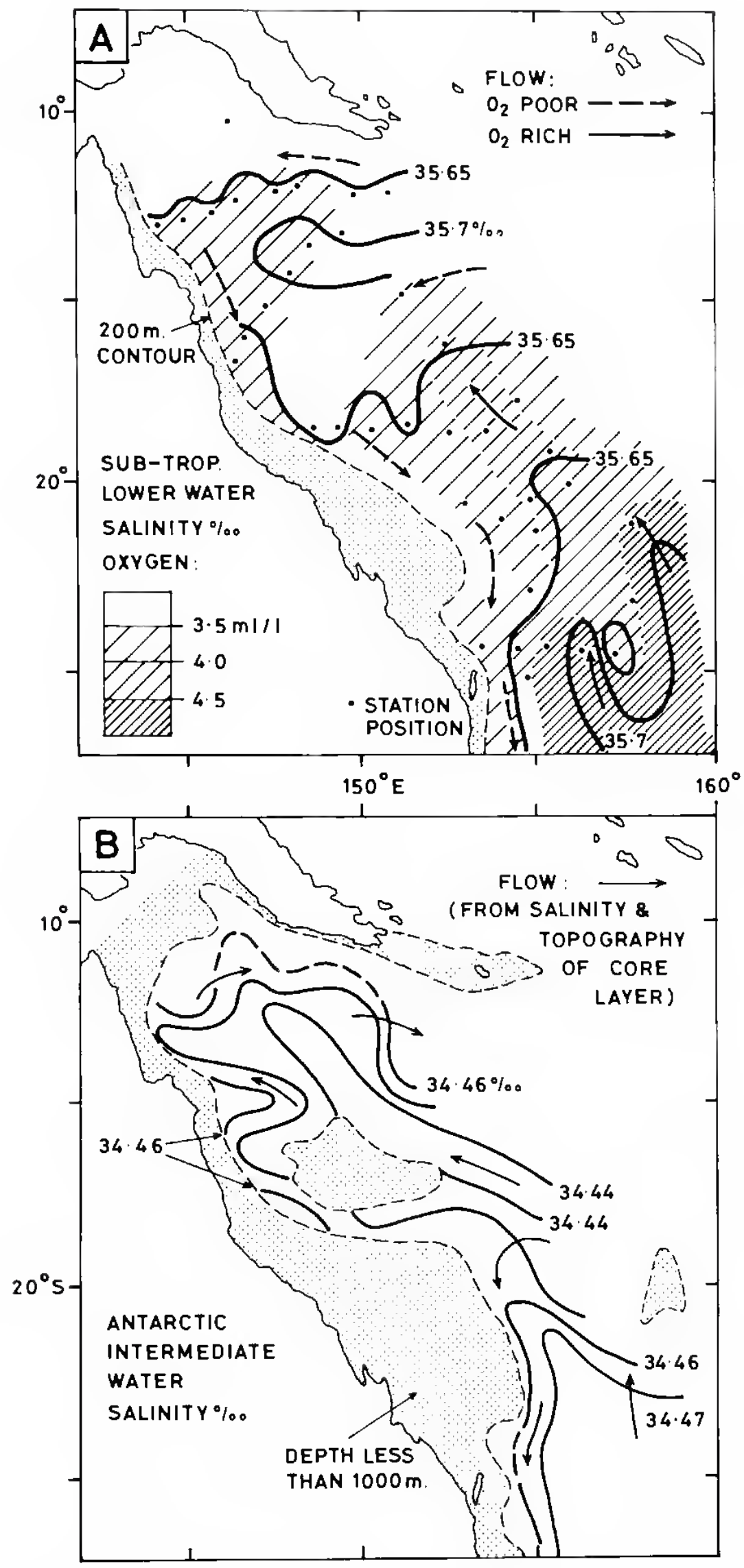

Fig. 50 Water masses and deduced flow patterns in the Western Coral Sea:

(A) Subtropical Lower water, salinity and oxygen distributions,

B) Antarctic Intermediate water, salinity distribution (Rochford, 1968a) 
Coral Sea, doming to less than $700 \mathrm{~m}$ in the centre of this area and then increasing to over $900 \mathrm{~m}$ in the south-east corner of the WCS. In suggesting flow directions (Fig. 50B), Rochford was perhaps influenced more by the topography of the corc layer than by the salinity distribution.

A comparison of Wyrtki's (1962a) and Rochford's (1968a) results is appropriate at this stage.

Rochford's salinity values for the Subtropical Lower watcr were about 0.05 to 0.1 lower than Wyrtki's, his oxygen values about $0.3 \mathrm{ml} 1$ lower, and his core layer depth greater by about $50 \mathrm{~m}$ in the north-west and $100 \mathrm{~m}$ in the south-east. For the Antarctic Intermediate Water the salinities and depths were similar in the two analyses.

The general character of the flow for the Subtropical Lower water was essentially the same in Rochford's as in Wyrtki's interpretations, but for the Antarctic Intermediate water Rochford showed a clockwise circulation in the North-west Coral Sea whilc Wyrtki did not commit himself to any direction of flow in this region. Rochford suggested that the southward flow across $20 \mathrm{~S}$ branched off from the North-west Coral Sea circulation but it could also be a southward branch of the original westward flow into the Coral Sea.

Rochford pointed out that while the Subtropical Lower water had a wide range of oxygen values in the WCS (from 3.5-6.5 ml 1 ) the Antarctic Intermediate Water had a much more restricted range ( 3.9 to $4.3 \mathrm{ml} / 1$ ), more closely related to the southern component of the Subtropical Lower water than to the northern component (although only marginally so). Hc concluded that the major flow of Antarctic Intermediatc water into the Coral Sea occurred south of Fiji and the New Hebrides (i.e. south of about $20 \mathrm{~S}$ ), which agrecd with Wyrtki's (1962a) deduction, and that little flow occurred at $800-1000 \mathrm{~m}$ from the Solomon Sca south into the Coral Sea in contrast to the inflow at shallower depths.

\section{Core analysis-Scully-Power}

The May-July 1968 data set taken and analysed by Scully-Power (1973a, b) was introduced earlier and the surface water characteristics described there. The subsurface water mass descriptions are now presented.

Subtropical Lower Water (upper salinity maximum). An example of the variation of properties with depth (Fig. 32) has already been described, using one of Scully-Power's stations in the WCS. This pattern was typical for the area, the differences being chiefly in the depth of the mixed layer and the southward increase of salinity in this layer, so that at some of the southern stations the upper salinity maximum was at the surface. Accompanying the increase in mixed-layer salinity there was a decrease in temperature so that the start of the thermocline was less sharp and the density discontinuity layer less intènse.

Fig. 51A shows the envelope of all vertical T,S curves for Scully-Power's WCS stations, showing the well-defined character of the water column over the whole WCS area. The usual main features were the upper salinity maximum and the salinity minimum below this. The depths of these features vary over significant ranges (sec Fig. 33) despite the tightness of the envelope. (This is one of the reasons for using the T, S and other diagrams as analytical tools.) The salinity maximum occurred at $\sigma_{\mathrm{t}}=24.75$ in the north, increasing to $\sigma_{\mathrm{t}}=25.20$ in the south, while the salinity minimum occurred close to $\sigma_{\mathrm{t}}=$ 27.20 everywhere in the WCS.

The upper salinity maximum (Wyrtki's 1962a Subtropical Lower water) was below the surface north of $27 \mathrm{~S}$ and at or close to the surface with the upper $200 \mathrm{~m}$ being nearly isohaline south of $27 \mathrm{~S}$. The core salinity value was 35.59 to 35.78 except for two lower values close to the Barrier Reef.

Fig. 52 shows the distribution of (A) salinity and (B) dissolved oxygen in the salinicy maximum core layer. These distributions were consistent with an inflow of a low oxygen, relatively high salinity, water from the northeast and a higher oxygen water inflow from 


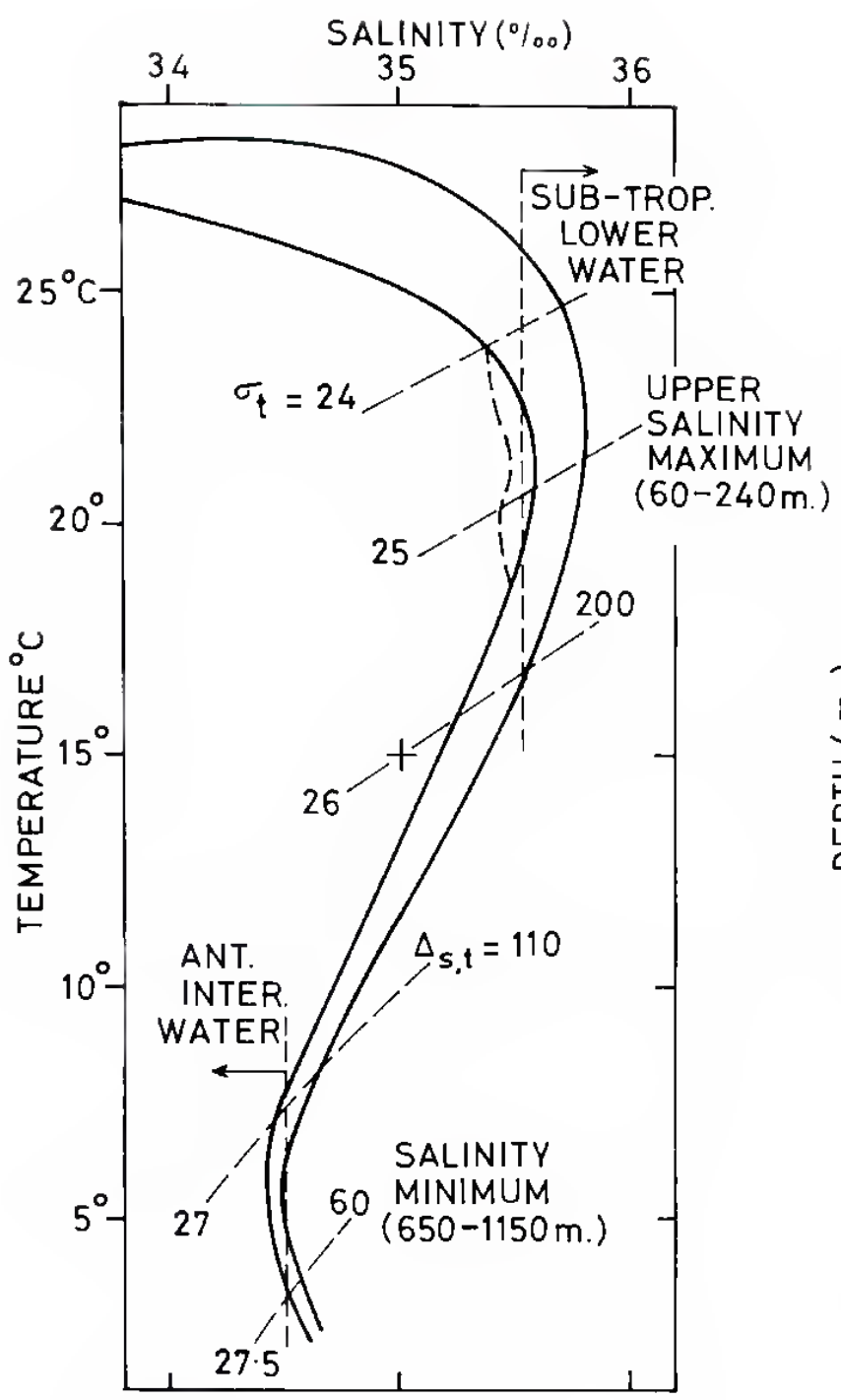

(A) $\mathrm{T}, \mathrm{S}$

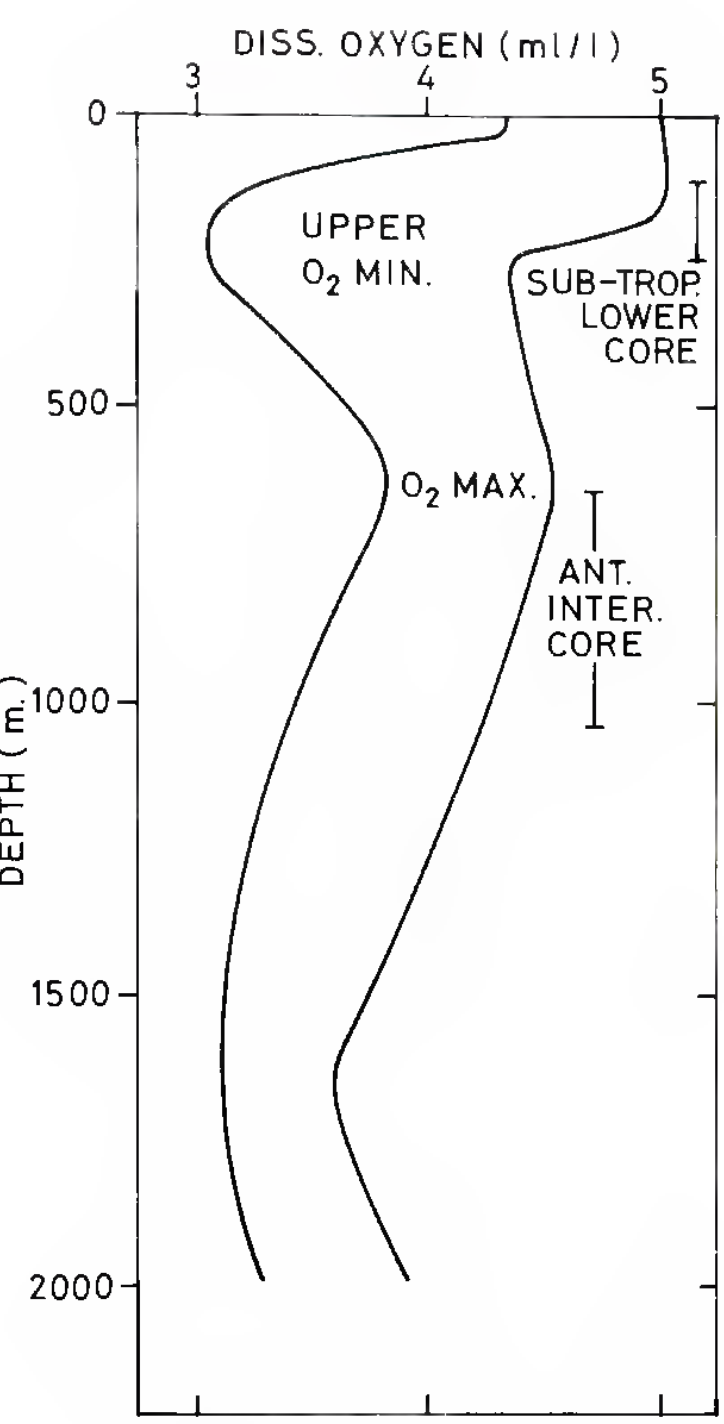

(B) $\mathrm{O}_{2}, \mathrm{z}$

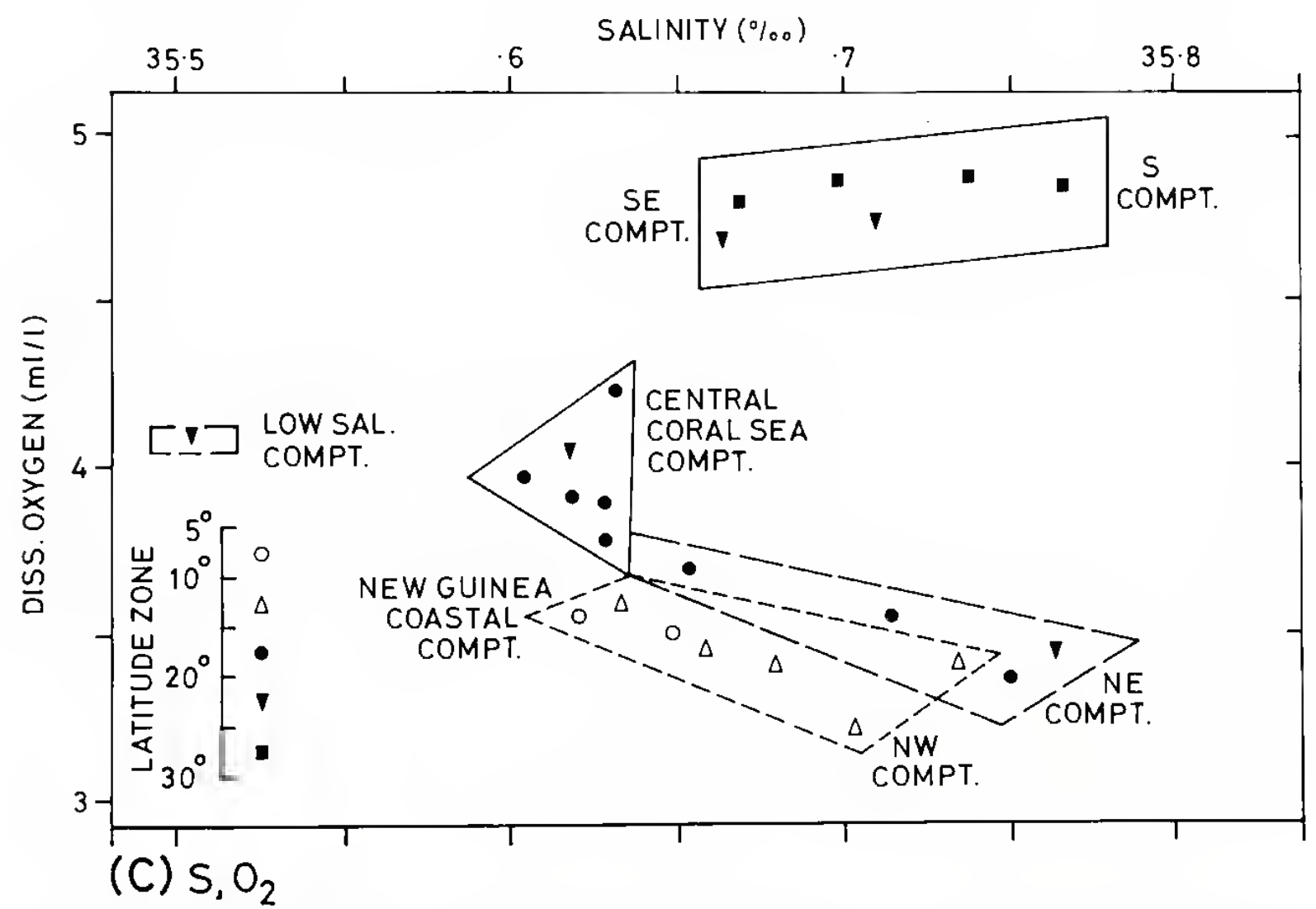

Fig. 51 Envelopes of (A) T,S and (B) $\mathrm{O}_{2}$, z curves, Western Coral Sca, May-July 1968, (C) S,O diagram for Subtropical Lower water components, Western Coral Sea, May-July 1968 (Scully-Power, 1973a). 
the south (or south-east the distribution of stations here was such as to leave this uncertain, although the salinity distribution suggested a northerly flow close to the Australian coast). Over most of the area the salinity maximum core layer depth was between 110 and $200 \mathrm{~m}$ depth and the thickness of the layer (for salinities over 35.50 ) average $180 \mathrm{~m}$. In the core, the temperature ranged from 19.3 to $23.3 \mathrm{C}$, and dissolved oxygen from 3.2 to $5.0 \mathrm{ml}$.

In discussing the water masses Scully-Power then reviewed in some detail the characteristics of the Subtropical Lower water in the WCS; as this, together with the surface water, is likely to be significant in considering exchanges with the Barrier Reef lageon, his conclusions will be summarised.

lig. 52 (A) Salinity and (B) oxygen values in the core layer of the Subtropical lower water, Western Coral Sed, May-July 1968, (C) Silinity and (1)) oxygen walues in the core of the Antarctic Intermediate water, Western Coral Sea, May July 1968 (Scully-Power, 1973a).

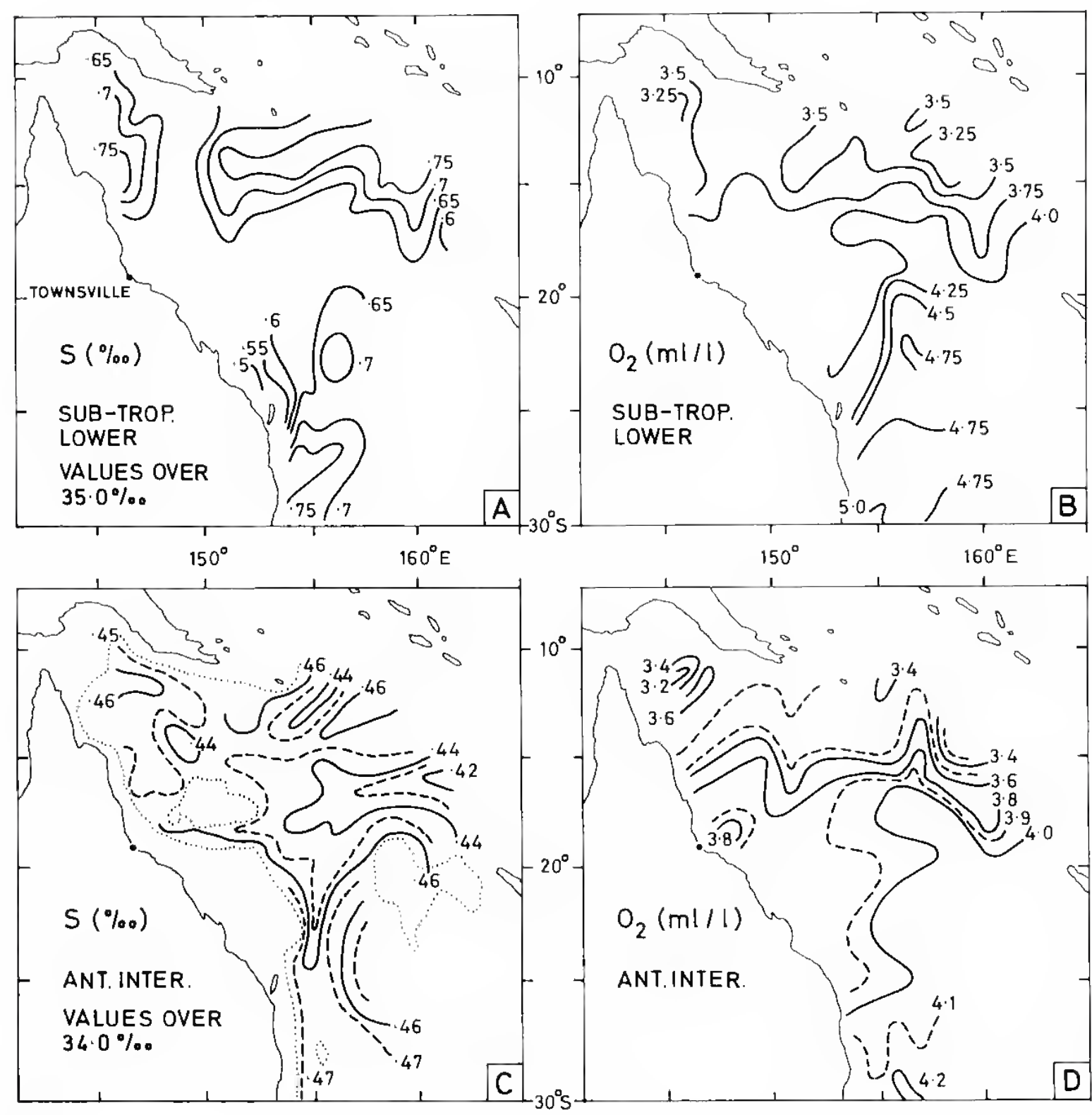


The salinity distribution in the core layer of the Suhtropical Lower water (Fig. 53A) showed three regions of high salinity values (to ahove 35.75 ireferred to from their locations as the north-east, southern and north-western components (Fig. $31 \mathrm{C}$. The other main feature was the prescnce of a uniform salinity mass (35.61 to 35.65 in the centre of the area, named by Scully-Power the 'Central Coral Sea component'.

The north-east component evidently represented an inflow into the Coral Sca of northern component Subtropical Lower water (Wyrtki, 1962a).

The southern component had its highest salinity of 35.78 close to the shore at $27 \mathrm{~S}$. Scully-Power suggested that this high salinity water might originate in the Barrier Reef lagoon and flow south, quoting CSIRO (1968a) for evidence of water over 36.00 in the Lagoon and Woodhead (1970) for southward flow. However, Scully-Power did not explain why therc was lower salinity water between the exit from the Reef lagoon (presumably by Capricorn Channel at $23 \mathrm{~S}$ ) and the location of the southern high salinity water at $27-28 \mathrm{~S}$. The T,S diagrams for Reef lagoon waters (Fig. 23, Part 1) show that in the southern zone, surface water of $\mathrm{T}=25.6 \mathrm{C}, \mathrm{S}=35.75 \quad$ and $\sigma_{1}=25.25$ occurs in July. These properties are almost identical with those in the IXCS $100-125 \mathrm{~m}$ depth salinity maximum at Scully-Power's July stations 9 and 11 at $27 \mathrm{~S}, 154.5$ and $156 \mathrm{E}$, i.e. $\mathrm{T}=20.67 \mathrm{C}, \mathrm{S}=35.78 \ldots, \sigma_{\mathrm{t}}=25.20$. The agreement is almost too good because such water offshore would require some time to gct there and would probably have its properties modified by mixing en route. The lagoon waters earlicr in the year are usually warmer and less densc, e.g. May, $\mathrm{T}=24.5 \mathrm{C}, \sigma_{t}=23.7$ and in June, $\mathrm{T}=22.0 \mathrm{C}, \sigma_{\mathrm{t}}=24 . \overline{\mathrm{T}}$. The Fig. 23 values are means and undoubtedly both more and less saline waters occur from time to time in the southern lagoon. However, a more telling point against lagoon origin of waters studied on the 1968 July cruise was that, according to the CSIRO Atlas, the lagoon salinities in April to July 1968 were all below 35.5 and densities were less than 24.5, significantly lower than the WCS Subtropical Lower values outside the Reef. It is also doubtful if the lagoon could produce sufficient quantities of ligh salinity water to supply the southern WCS.

Discussing the north-west high salinity component, Scully-Power (1973b) advanced arguments against (a) inflow through Torres Strait at any time, (b) formation in situ, and (c) flow from the Barrier Rcef lagoon. He concluded that it must have come from the north-east at an carlier time, possibly in October-Novcmber at the end of the SE trades season. Data from earlier cruises in the area (Lockerman \& Scully-Power, 1969) supported this suggestion. The Barrier Reef lagoon was dismissed as unlikely to provide sufficient high salinity $(35.70+$, ) water. The CSIRO Atlas indicatcs that water of sufficient salinity, over 35.8, was present in the lagoon in January 1968 and October-November 1967 but it is agreed that this is an unlikely source for large quantities of this water even though outflow from the lagoon does occur in the north zone see Part 1). The characteristic which chiefly tells against the lagoon as a source of the high salinity Coral Sea water is the latter's low oxygen content $(<3.5 \mathrm{ml} 1)$, although ScullyPower did not mention this point.

Scully-Power identified some minor components (Fig. 51C), a high oxygen south-east component, a New Guinea coastal component and a low salinity component occurring close to the coast at 23-25 S, possibly resulting from mixing with lower salinity surface water. The south-east component was essentially Wyrtki's Subtropical Lower water, southern (high oxygen) component. 'This entered the WCS at 21-24 S, $157 \mathrm{E}$, and temporarily divided at $23 \mathrm{~S}$ to the north-west and south-west (Figs. 52, 58B) hut rejoined to flow south along the Australian coast.

Scully-Powcr regarded the Central Coral Sea component as being derived from the low oxygen, north-east component (Subtropical Lower water, northern (low oxygen) component) after vertical mixing with the waters above and below it.

Antarctic lutermediate Water (intermediate salinity minimum). The salinity minimum was apparent on the S,z profiles (e.g. Fig. 32) but more conspicuous on the T,S diagrams (e.g. 
Fig. $32 \Lambda, 51 \Lambda$; with a very limited range of values of only 0.05 at the core layer. The salinity distribution at the core layer (lig. 52C) showed low salinity water entering the Coral Sea lrom the north-cist and turning south along 155 E. Scully-Power considered that this diagram also showed a secondary tongue of low salinity water entering from the soull-ciast at about $24 \mathrm{~S}$, and described the low salinity region in the north-west as a 'cell', presumably becalse there could be no inflow of internediate water there. The inflows were identified as Antaretic Intermediate water. The core layer of this water lay between 700 and $9(0) \mathrm{m}$ over most of the WCS, increasing to $1100 \mathrm{~m}$ in the south and for the small cell in the nerth-west. Using 34.50 ats the maximum value for this water mass, it had a mean thickness of $375 \mathrm{~m}$. In the core, the salinity varied from 34.42 to 34.47 , temperature from 4.95 to 6.20 C and dissolved oxygen from 3.8 to $4.3 \mathrm{ml}$.

Upper oxygen minimm. Some $75^{\prime \prime}$ of the stations showed a single upper oxygen minimum (Fig. 513), the remainder showing a double minimum below the salinity maximum. 'The distribution of exygen on the oxygen minimum surface was very similar to that in the core of the sallinity maximum (1)ig. 52B). Scully-Power considered that this indicated that the two water masses moved with the same flow pattern.

Oxygen maximmm. All stations showed an oxygen maximum about $200 \mathrm{~m}$ above the salinity min imum of the Antarctic intermediate water (Fig. 32). Scully-Power agreed with Rochford (1960) b) that on the basis of available information, this oxygen maximum water could not be identified as a separate water mass.

\section{Isentropic analysis-Rougerie \& Donguy}

'Gorgone I' 1972, late winter. 'The most recently published account of waters in the Coral Sea is that by Rougerie \& 1)onguy (1975) for the Central Coral and Solomon Seas between 2 and $20 \mathrm{~S}, 153$ to $163 \mathrm{E}$, with 72 stations completed between 14 November and 20 Decumber 1972 (O.R.S.T.O.M. 'Gorgone I' 1972 cruise), i.e. at the end of the SE trades season (see Fig. 31). This cruisc overlapped the area of the R.A.N.R.L. May-July 1968 cruises by Scully-Power in the region 12 to $20 \mathrm{~S}, 153$ to $163 \mathrm{E}$ (Fig. $45 \mathrm{~A}$ ).

During this cruise, the general characteristics of the water structure for the part of the WCS covered were similar to those described in previous accounts. The Subtropical Lower water had a core layer salinity of over 36.0 north of the Solomon Is., 35.9 to 35.8 in the Solomon Sea and decreased to 35.65 in the centre and south of the Coral Sca, T, S and $S, O$, diagrams are shown in Fig. 53 for typical stations representative of these three regions, the station positions being shown in Fig. 45A. "l'he northern salinity maximum occurred at a thermosteric anomaly of about $340 \mathrm{cl} / \mathrm{t}$ (corresponding to $\sigma_{\mathrm{t}}=24.5$-see Appendix), while the southern maximum was at about $3(0) \mathrm{cl} \mathrm{t}\left(\sigma_{1}=25.0\right)$. "lhese two waters correspond to Wyrtki's northern and southern components of the Subtropical Lower water and were also clearly distinguished by their oxygen content. Rougerie \& Donguy located the boundary between these two components at about $14 \mathrm{~S}$ with a region ol overlap at about 15 to $18 \mathrm{~S}, 153$ to $156 \mathrm{E}$.

At thermosteric anomalies of 230 to $90 \mathrm{cl} / \mathrm{t}\left(\sigma_{1}=25.7\right.$ to 27.2$)$ the linear part of the $T, S$ diagram showed a mixture of Subtropical Lower and Antaretic Intermediate waters (Fig. $53 \mathrm{~A}$ and cf. Fig. 51A) common to all the 'Gorgone $l^{\prime}$ stations and similar to the R.A.N.R.L. ones. The $\mathrm{S}, \mathrm{O}_{2}$ structure was, however, nuch more complex as is evident in Fig. 53B. The strong oxygen minimum around Stn. 65 north of the Solomons can be traced back to the low oxygen layer in the eastern Pacific near Peru ('Tuchiya, 1968). The upper part of this oxygen minimum layer passed through the gaps in the Solomon Is. chain and thence to the north part of the Coral Sea.

The oxygen maximum of the Antaretic Intermediate water was also evident in the $\mathrm{S}, \mathrm{O}_{2}$ diagram (Fig. 53B), occurring at 500 to $700 \mathrm{~m}$ with values as high as $4.5 \mathrm{ml} 1 \mathrm{in}$ the Coral Sea. Rougeric \& Donguy (1975) referred to this as 'Coral Sea Water' (34.6 to 34.8 ' 4.0 to $4.4 \mathrm{ml} / \mathrm{l})$, not to be confused with Scully-Power's 'Coral Sea Component' of the Subtropical Lower water (about $35.6,4.0 \mathrm{ml} / \mathrm{l}$ ). 


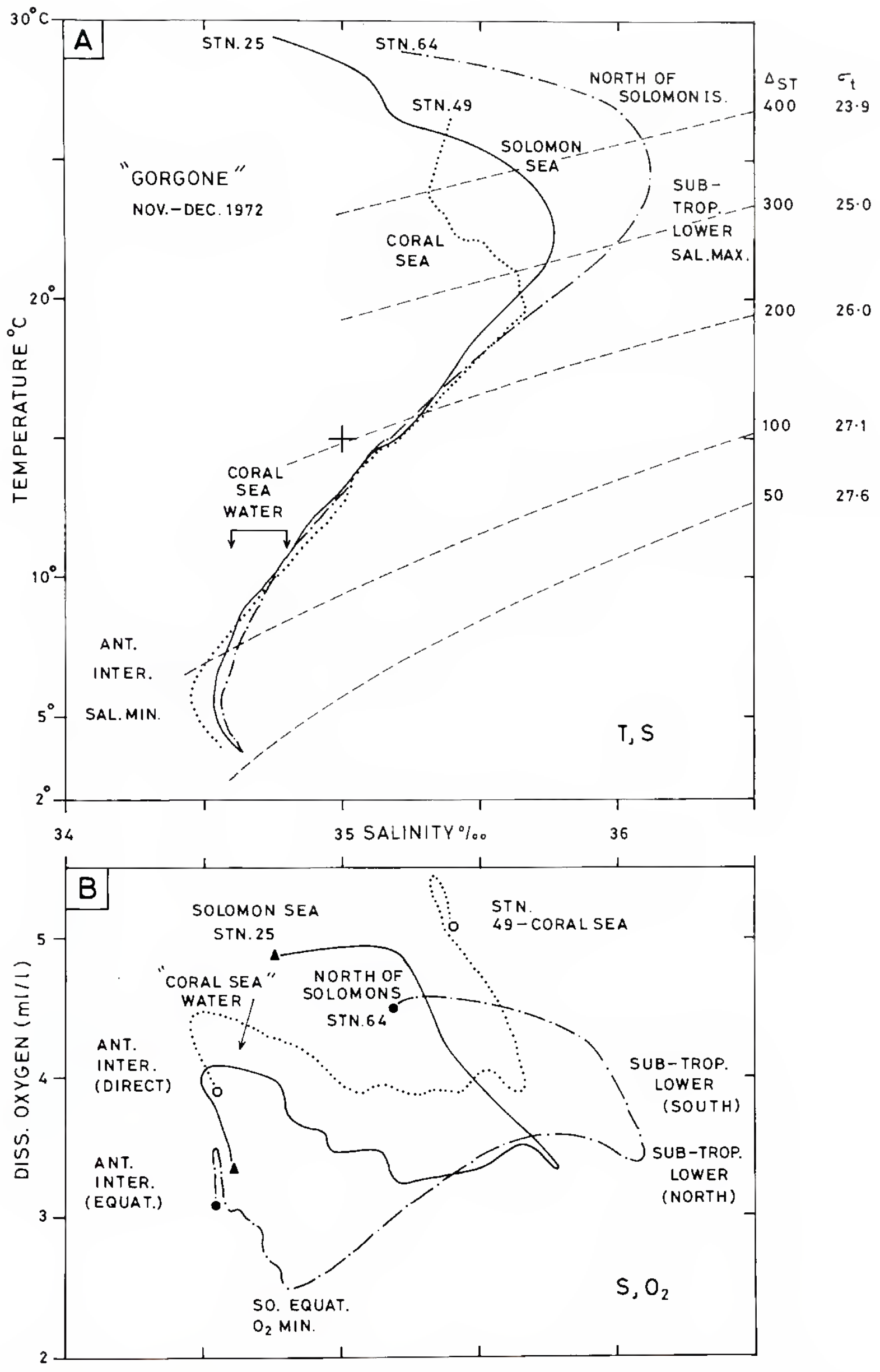

Fig. 53 (A) T,S and (B) S,O curves for selected stations, Solomon and Coral Seas, 'Gorgone l' cruise, Nov.-Dec. 1972 (Rougerie \& Donguy, 1975). Station positions in Fig. 45. 
I'he salinity minimum of the Antaretic lntermediate water was found to have a salinity between 39.15 and 34.55 and nxygen content of about $4.2 \mathrm{ml} / \mathrm{l}$ in the Coral Sea whereas that in the Solomon Sea was about $4.0 \mathrm{ml} 1$ and north of the Solomon Is. about $3.5 \mathrm{ml} 1 \mathrm{l}$. It Wals concluded that as Reid (1965) and Johnson (1973) had suggested, the Antarctic Intermedale water could enter the Coral Sea both from the south-east and also from the Itorth-ealst passing south of the Solomon ls, after making a wide circuit through the épuatorial regions.

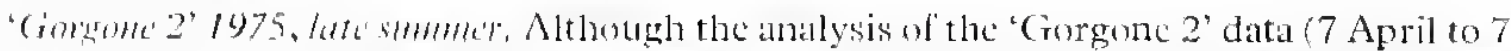
Maly 1975 is nor complete, some comparisons with the 'Gorgone l' late winter cruise can be made.

Along the 150 li meridian during 'Gorgone 2' the upper layer of salinity less than 35. extended to $16 \mathrm{~S}$ in the Coral Sea and was 1 wice as deep $(60) \mathrm{m}$ average) as during "Cougene 1', 'l'his southward spreading of the luw salinity South Iyultorial water may be attributed to lle NI" monsion wind stress, in conseguence of which the New Guinea (obstal Current attains its miximum strength at this time (Wyrtki, 1901) and brings into the Solomon Sea water from the western equatorial Pacific whose salinity is further decreilised by heavy raintall in the Solomon Si:al.

Below the surface, the 35.5, isohaline in the transition zone with the Subtropical Lower water (southern component) was at $160 \mathrm{~m}$ depth in the Solomen Sea but rose sharply to the south unt in the (coral Sea it was $501060 \mathrm{~m}$ shallower than during 'Gorgone 1'. At the core of the Subropical I swer water, the salinity was not over 35.8 and the vertical salinity gradient was much less than during 'Gorgone L'. In these tropical waters where the salinity has a significant effect on the density field, a result was that during 'Gorgone 2', in April-May, the vertical stability was relatively small so that vertical advective movements were ahle to produce 'doming' at 12 to $13 \mathrm{~S}$ and 17 to 18 S. In November - I)ecemher 1972 ("Gorgone 1") the doming was slight and contrihuted little to increasing the typically low nutrient values of the upper waters.

The dissolved oxygen distributions were generally similar for the two cruises. However, the oxygen maximum of the subequatorial water which was present at $300 \mathrm{~m}$ deptls to the north of the Solomon Is. and between 10 and $12 \mathrm{~S}$ during "Gorgone I had almost disappeared at this southerly position during 'Gorgone 2', In the summer, therefore, it appears that the extension to the south-east of the upper waters has an effect as deep as $300 \mathrm{~m}$ and partially prevents the movements into the Solomon Seal of low oxygen water from the eastern Pacific, 'This depth of $300 \mathrm{~m}$ is that at which the T,S curves for the two cruises come together, perhaps indicating the limit to the depth of penetration of climatic effects.

\section{Consistency of subsurface water characteristics}

In order to estimate the consistency with time of subsurface water characteristics in the WCS, envelopes of ' $T, S$ data from 50 to $1200 \mathrm{~m}$ depth were prepared for each of nine cruises within the area 10 to $19 \mathrm{~S}, 14 \%$ to $159 \mathrm{E}$ (although not all cruises covered the whole area). The cruises used were from the five sets listed in 'Other surface data in seasonil sequence' from 1965 to 1975 together with two other R.A.N.R. L. cruises for the Norlh-west Cural Sea, i.e. cruise CS1 for Nuv.-Dee. 1966 and CS2 for Apr.-May 1967 (Scully-Power 1969a, b). The 1968 R.A.N.R.L. data set was divided into its three constituent cruises to make nine envelopes in all. The $T, S$ envelopes were very similar in position and width on the diagram, the main differences occurring above $20 \mathrm{C}$, i.e. above the salinity minimum ot ahove about $200 \mathrm{~m}$.

Seven of the envelopes are shown in Fig. 54, the other two duplicating the November and May periods (envelopes 2 and 5), Table 7 below shows the mean position of the centre lines of the envelopes and the scatter in position about the mean.

The variation in mean $T, S$ characteristics was about $\pm 1 \mathrm{C}$ or \pm 0 . I ahove $20 \mathrm{C}$. i.e. above the salinity maximum, and only $\pm 0.2 \mathrm{C}$ or \pm 0.02 below $20 \mathrm{C}$. 


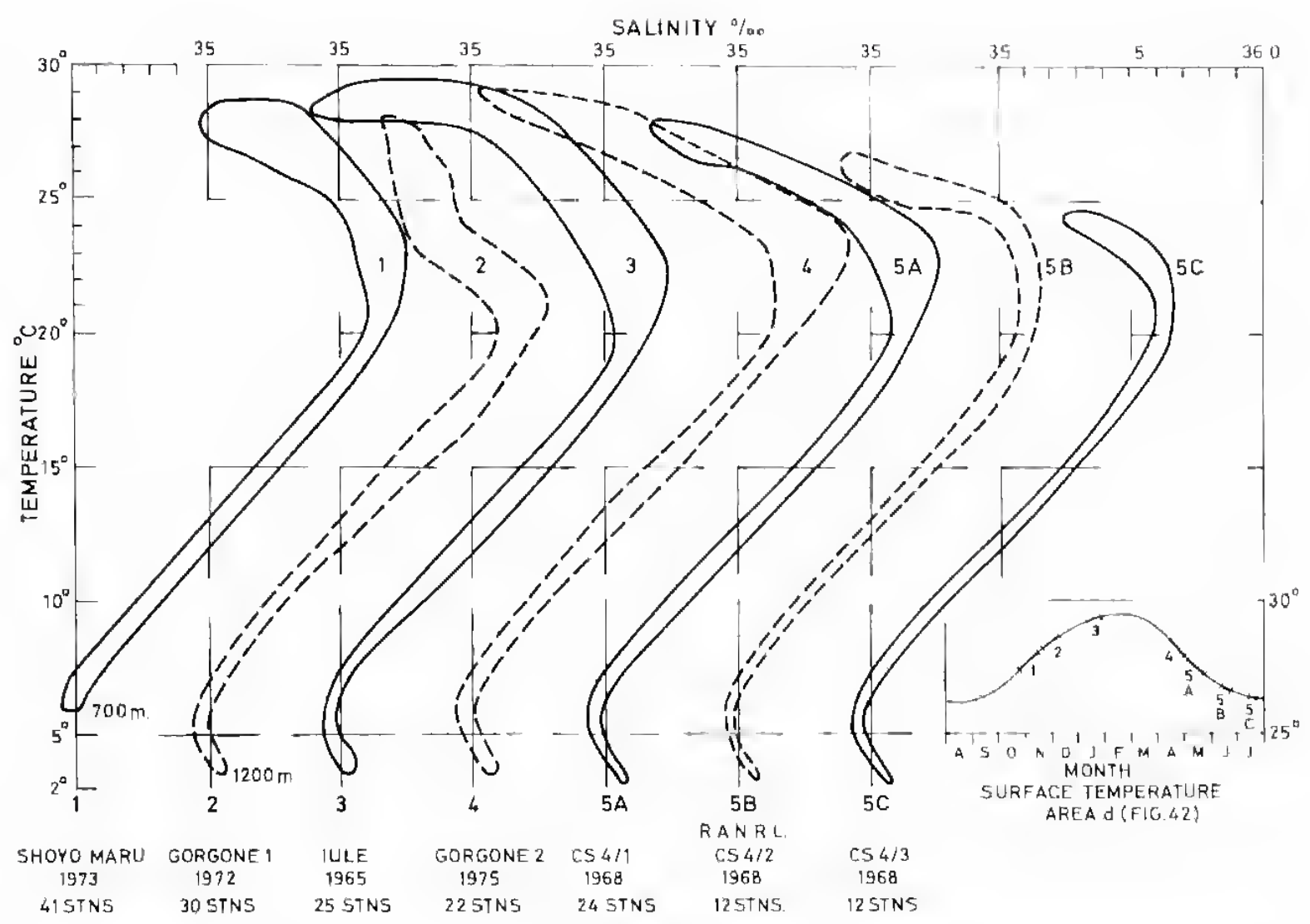

Fig. $54 \mathrm{~T}, \mathrm{~S}$ envelopes for data from 50 to $1200 \mathrm{~m}$ depths $700 \mathrm{~m}$ unly for curve $1 \mathrm{in}$ the nor thern part of the Western Coral Sea 11 w 19 S). 'T"ime of year shown on inset with surfice temperature curve for ared d sec Fig. 41 ).

The widths of the envelopes were much the same lor all the data sets, the average width perpendicular to their centre-lines being equivalent, above the salinity maximum (i.e. above about $22 \mathrm{C}$ or $150 \mathrm{~m}$ ), to $1.5 \mathrm{C}$ or 0.15 on the 'l', $\mathrm{S}$ diagram and below $20 \mathrm{C}$ or $200 \mathrm{~m}$ to less than $\mathrm{IC}$ or 0.1 (i.e. less than $0.2 \sigma_{1}$ ).

The envelope width in Fig. 61 is wider than these values because it covers data from all three constituent R.A.N.R.L. cruises together and from a more extensive area, both north, west and south, than do the data from the diagrams in Fig. 54.

Bearing in mind that the cruises took place in different seasons and were distributed over a ten-year period, the above analyses indicate that below the surface layer, the '1',S characteristics of the major part of the WCS show only small changes with time.

$\mathrm{T}, \mathrm{O}_{2}$ and $\mathrm{S}, \mathrm{O}_{2}$ envelopes were prepared but these were generally not as well defined as the T,S envelopes and it was not possible to compare the cruises meaningfully for these combinations. On the $\mathrm{T}, \mathrm{O}_{2}$ envelopes the upper minimum and lower maximum of oxygen were present but not clearly defined as there was much more scatter than for the ' $l$ ', $S$ plots. (The envelopes had a width in the oxygen dimension of 50 to $75^{\prime \prime}$ " of the total range of oxygen values below the surface ( 1 to $1.5 \mathrm{ml} / \mathrm{l}$ width compared to a total range of about 2 $\mathrm{ml} / 1)$ ). The envelopes became narrow $(0.2$ to $0.4 \mathrm{ml}$ ) only below the Antarctic Intermediate water. For the $\mathrm{S}, \mathrm{O}_{2}$ diagrams, when all the data from a cruise were plotted no characteristic envelope was evident in most cases. This is to be expected in view of the convoluted nature of even individual $\mathrm{S}, \mathrm{O}_{2}$ curves (c.g. Fig. 32C, 53B). The exception was for the Shoyo Maru cruise for which both the $\mathrm{T}, \mathrm{O}_{2}$ and the $\mathrm{S}, \mathrm{O}_{2}$ envelopes were narrow in the oxygen dimension (only 0.2 to $0.4 \mathrm{ml} / 1$ ). For this cruise the Subtropical Lower water was entirely northern (low oxygen) component, whereas some southern (high oxygen) component was present for the other cruises. The probable reason was that the Shoyo Mart cruise covered a smaller area than the other cruises and was restrieted to the northwestern part of the WCS (west of $151 \mathrm{E}$ ) whereas the others extended as far as 7 further east and 2 further south. 
Wyrtki (1962a) noted that the oxygen content of many of the southern component Subtropical Lower water samples in the Coral and Tasman Seas was above the (one atmosphere) saturation value for their temperature (Fig. 48). In the northern part of the WCS this was rarely the case in the Subtropical Lower water which was chiefly the northern component whose oxygen content was well below saturation. However, many of the samples in the upper waters above the salinity maximum in the nine cruises discussed above did have an oxygen content above saturation.

These results indicate that most variation occurs above the salinity maximum whose depth in the WCS is generally $200 \mathrm{~m}$ or less. Because the variations in the upper layer are presumably due chicfly to climatic changes, this suggests that the limit to downward penetration due to such effects may be less than the $300 \mathrm{~m}$ estimated from the analysis of the 'Gorgone 1 \& 2' results described earlier. The reason for this depth limitation is probably because the layer immediately above the salinity maximum generally has a maximum of gravitational stability and this acts as a discontinuity layer restricting downward turbulent transfer of water properties.

Table 7. Mean of centre lines of T,S data envelopes below $50 \mathrm{~m}$ depth for nine cruises from 1965-75 for Western Coral Sea, and range of positions about the mean

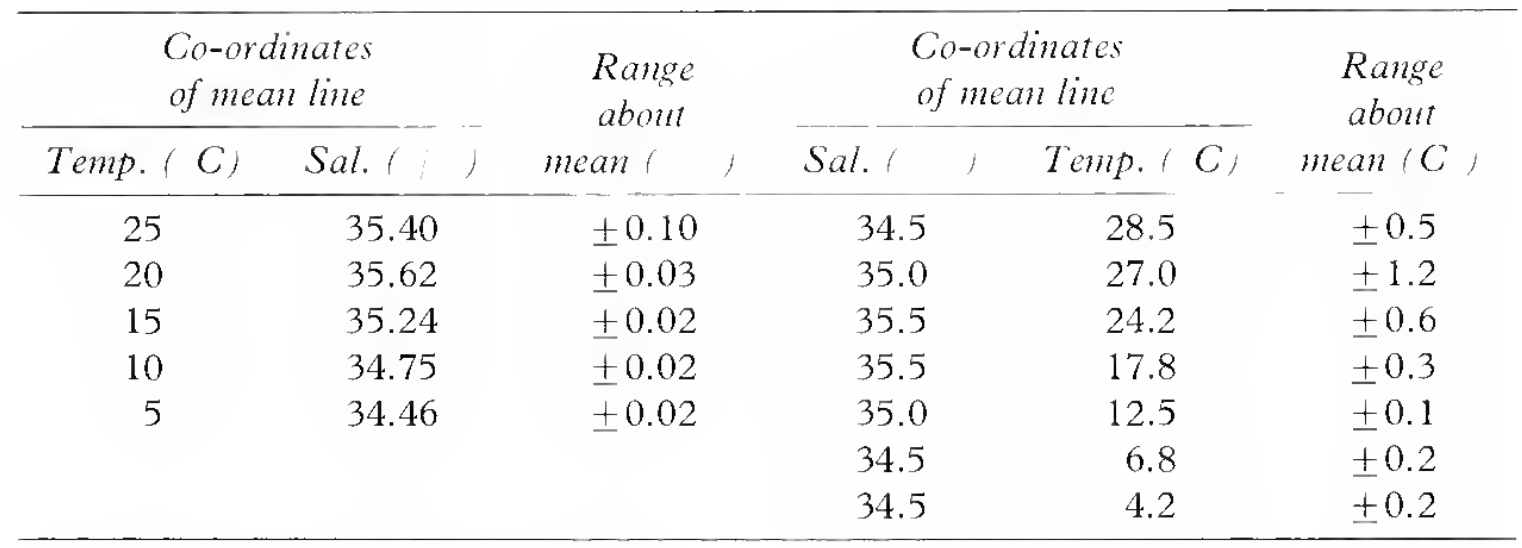




\section{$\mathrm{V}$ \\ Circulation}

\section{INTRODUCTION}

In Chapter IV, the distributions of water properties were described together with inferences on the flow paths of the various water masses but with few estimates of the speed of travel being available from this source. 'This chapter will revicw the available information on the velocity of water motion, i.e. the path followed together with some estimate of the speed - either directly in distance per unit time or as volume transport per unit time across a vertical section (units discussed in the Appendix). The sources of this information have been:

(a) ship's navigation logs in which the difference between the course and speed through the water and the track and speed made good over the ground was attributed to water motion (for the surface layer only), or

(b) dynamic considerations related to the distribution of density of the water (geostrophic method) for the surface and sub-surface waters.

As far as is known, no direct measurements of currents are available for the IVCS (although there are some for the East Australian Current further south).

\section{SLRFACE CIRCULATION}

\section{Wyrtki, 1960, I962b-Current atlas and geostrophic circulation}

The most ambitious surface current description for the Coral and Tasman Scas was by Wyrtki (1960), based on the Allas of surface currents, sonth-zestern Pacific Ocean (U.S.N.H.O., 1944) with reference also to Sea areas around Australia (Roy. Neth. Met. Inst, 1949) and other atlases. Wyrtki presented the surface currents for an area from 5 to $48 \mathrm{~S}, 142$ to $180 \mathrm{E}$ in two sets of twelve monthly charts, one showing current arrows with speed indicated and the other in the form of streamlines. The latter show the direction of the current at each point along their length but do not indicate the speed as directly as the coded current arrows. (It should be noted that streamlines show an instantaneous pattern of flow and are not the same as trajectories, the path followed by particles over a period of time, except in the steady state when the circulation does not change with time. If the thickness of the moving surface layer remains constant, then crowding of streamlines implies increase of speed and vice versa, but if the layer thickness varies, this indication of speed will be obscured.)

Although Wyrtki's current charts look very complete (and are frequently used as references), later studies have revealed differences in many aspects. This is not surprising, because the material on which the charts were based was inhomogeneous (many sources) and had numerous gaps in coverage of the area, so that considerable interpolation must have been neeessary to produce the apparent complete cover of Wyrtki's charts. Therefore, only parts of three charts will be reprodueed here, selected as samples to show the character of the eurrent patterns deduced by Wyrtki. These are in Fig. 55A,B,C, for the months of January, April and August. A selection of specd values, in $\mathrm{km}$ day has been 
added from the current arrow chart. The major features of the WCS surface flow patterns according to Wyrtki's charts were:

(a) westward or south-westward flow (into the WCS) across $160 \mathrm{E}$ from 10 to $25 \mathrm{~S}$ all year (Wyrtki's 'Trade Drift'),

(b) at $155 \mathrm{E}$, from 15 to $25 \mathrm{~S}$, a south-west or south flow all year (the start of the East Australian Current); at $155 \mathrm{E}$, from 10 to $15 \mathrm{~S}$, flow to the west or south-west from May to December, to the north in January, to the south in February, and west or north-west in March and April,

Fig. 55 Surface flow patterns for (A) January, (B) April, (C) August, and (D) regions of convergence and divergence, Coral Sea (Wyrtki, 1960). Numbers represent speeds in km day.
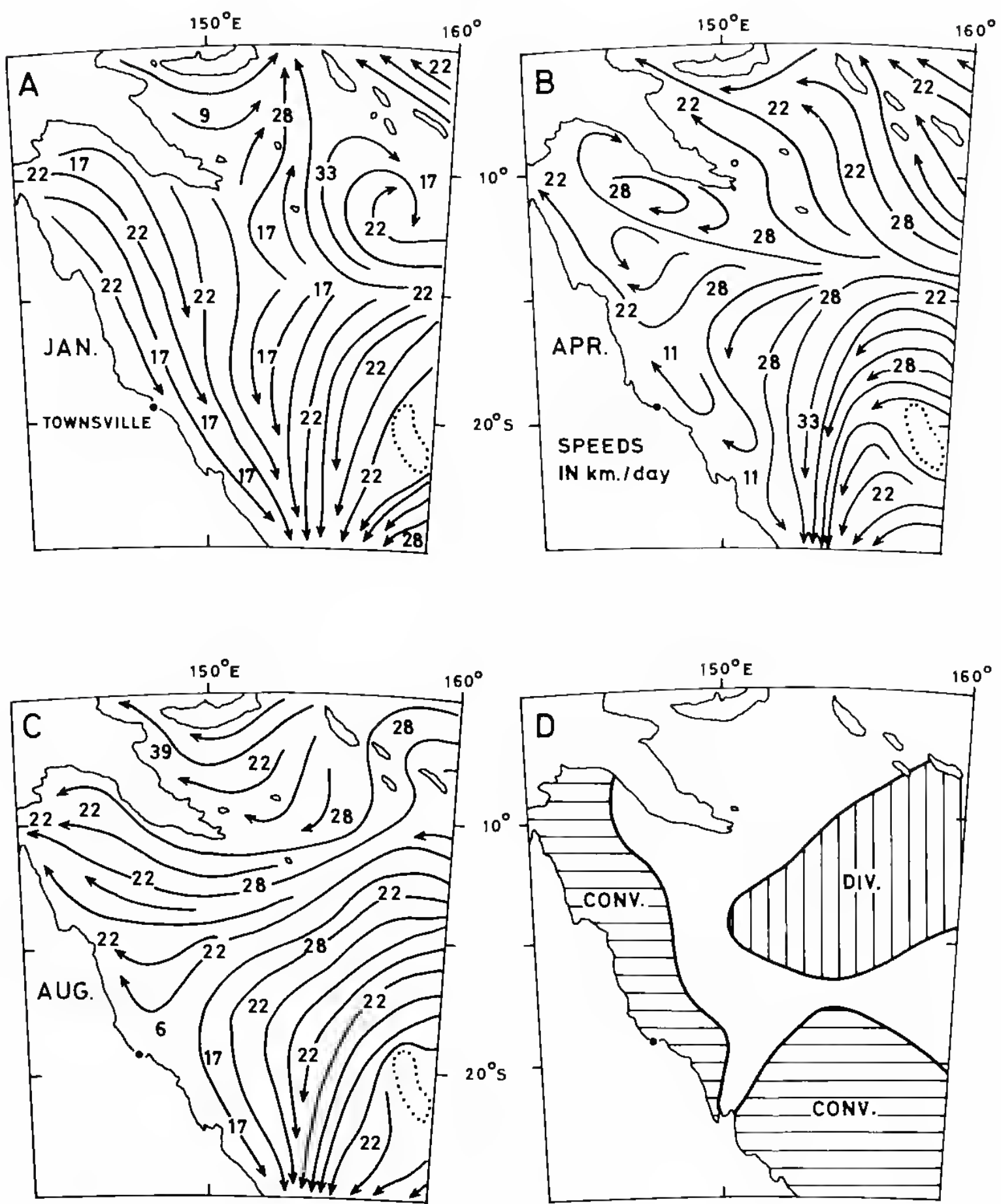
(c) outside the Barrier Reef (an area notably lacking in information in the original Atlases) the current was shown as:

(i) at 9 to $11 \mathrm{~S}$ (Torres Strait), west from April to November, and east from December to March (NW monsoon;

(ii) from 11 to $19 \mathrm{~S}$, north or north-cast from March to November, and south or south-east from December to February,

(iii) between 20 and $25 \mathrm{~S}$, south-east all year, except for a weak northerly flow at $20 \mathrm{~S}$ in June.

In Fig. 55 the January chart is reasonably representative of II'yrtk's December to March charts, the April chart for April to June and the August chart for July to November, "Typically, the original January and August charts and their respective periods showed relatively simple circulations, while the April to June ones were more complex. Wyrtki deduced regions of convergence and divergence from the starting and termination of streamlines (although this seems to be a somewhat uncertain procedure in view of the subjective manner in which the streamline charts were prepared). In general, as Fig. 55D shows, there appeared to be areas of divergence in the north-east and areas of convergence in the west against the Barrier Reef and in the south at the start of the East Australian Current. This might imply sinking at the Reef but probably not much because the water column is very stable below the mixed layer. Most of the convergence here resulted in a division of flow north-west and south-east parallel to the Reef as shown for August (Fig. 55C). The position of this division was at about $15 \mathrm{~S}$ in February, 18 to $20 \mathrm{~S}$ in March to September, and then moved north again to about $14 \mathrm{~S}$ in December. There was no division in January when Wyrtki had a strong south-east streamline pattern emanating from Torres Strait and continuing down the coast. (Note that this did not imply that Torres Strait water reached as far south as the East Australian Curtent because the speeds were not sufficient - only about 17 to $22 \mathrm{~km}$ day or 5 to 6 degrees of latitude per month.) 'The castwond flow through Torres Strait was attributed to NW' monsonn wind stress, and Wyrtki also showed a strong flow into the north of the Coral Sea from the Solomon Sea in February and March.

For most months, Wyrtki showed a significant flow over or through the Barrier Reef between 19 and $23 \mathrm{~S}$ into the lagoon and then out again north of Gt Sandy Is. (24 S) to join the East Australian Current. He did not comment on this, nor has anyone else. It implies a considerable flushing of lagoon waters by WCS waters and could be a significant feature in the exchange of thesc waters if it is true. This feature warrants investigation in connection with Barrier Reef lagoon oceanography.

It may be noted in passing that the Atstratia Pilot, Vol. IV (1962) used four of Wyrtki's charts but had the July and October charts reversed.

In a later paper on the geopotential topography (see Appendix) and circulation in the Western South Pacific, Wyrtki (1962b) combined data from January to April from three vears and showed the topography of various pressurc surfaces relative to the $1750 \mathrm{db}$ surface ( $\mathrm{db}=$ decibar, see Appendix). Unfortunately, during this period of the year considerable changes take place between months in the surface circulation according to Wyrtki's (1960) charts (cf. Fig. 55A,B). The surface circulation from his 1962 calculation showed the convergence to the East Australian Current as in all months, a southeast flow in the Solomon Sea as for the February chart (and possibly March), and an eastward flow to the south of Papua New Guinea as for January and March to April in his monthly charts. Essentially, he had a clock-wise circulation occupying the WCS, and an anticlockwise one in the Central Coral Sea (13 to $30 \mathrm{~S}, 155$ to $165 \mathrm{E}$ ) with little net westward flow across $160 \mathrm{E}$ into the Coral Sca, which was surprising. Wyrtki commented that the westward surface flow across $160 \mathrm{E}$ in his monthly charts ('Tradc Drift') was due to the wind stress and would not appear on the distribution of geostrophic currents, citing a 
similar situation in the Indian Ocean. He maintained that the wind stress flow should be added to the geostrophic flow (see $A$ ppendix) giving a general westward flow into the Coral Sea across $160 \mathrm{E}$ between about 10 and $20 \mathrm{~S}$, although this might be less regular than the subsurface flow. (This argument is of doubtful validity.)

In summary, the January to April (3 years) compilation agreed with the monthly charts in the southeast corner of the WCS (south of $15 \mathrm{~S}$, east of $155 \mathrm{E}$ ) all the time and with the March chart over the whole area, but disagreed with the January and February charts in the WCS (and with the January and April charts in the Solomon Sea). This was probably as good agreement as could be expected for a variable period of the year for the surface circulation.

In a recent calculation of the dynamic topography for the whole Pacific, Wyrtki (1974) presented mean topographies for the sea surface relative to $1000 \mathrm{db}$ for two-month periods. The contours in the diagrams were at $10 \mathrm{dyn} \mathrm{cm}$ intervals which is rather coarse. for this small region but there was a general tendency for inflow to the Coral Sea across $160 \mathrm{E}$ from 10 to $15 \mathrm{~S}$, and outflow from 15 to $20 \mathrm{~S}$ at the surface.

\section{Rotschi, 1958-6I-Earlier O.R.S.T.O.M. cruises}

Five cruises by the Institut Français d'Océanie (now O.R.S.T.O.M., Centre de Nouméa, Section d'Occanngraphic) (Rotschi, 1958a,b, 1959c, 1960d, 1961b) were referred to by Wyrtki (1962b) and these have been reviewed together with a sixth cruise (Rotschi, 1961c) for the area between the Solomon Is., the New Hebrides and New Calcdonia, a little to the east of the present area under review. All but one of these cruises (May 1960) showed a westward flow at the surface approaching $160 \mathrm{E}$ between the Solomons (11 S) and about $14 \mathrm{~S}$. Between $14 \mathrm{~S}$ and New Caledonia (20 S) the surface flow was sometimes to the west, sometimes to the east. The net transport to the west above $1000 \mathrm{~m}$ varied from 16 to $37 \mathrm{sv}$. (See Appendix for definition of $1 \mathrm{sv}$.)

These earlier cruises, together with later ones, for the arca between 10 to $19 \mathrm{~S}, 155$ to $165 \mathrm{E}$ have been re-examined by Donguy \& Henin (1975b) and their deductions will be reviewed later.

\section{Takahashi, 1959, 1960-Eddy in Coral Sea}

Takahashi $(1959,1960)$ showed a cyclonic (clockwisc) eddy in the eastern Coral Sea which does not seem compatible with Wyrtki's or O.R.S.T.O.M. results. The southward flow (Takahashi) at $162 \mathrm{C}$ might well be associated with Wyrtki's flow into the Coral Sea but his northward flow at $15 \mathrm{~S}, 150 \mathrm{E}$ was opposite to the most persistent feature of all twelve of Wyrtki's (I960) charts and his 1962 results. Actually, it is doubtful if Takahashi had sufficient stations to delineate his eddy fully. (Note that this eddy is incorrectly referred to as a 'counterclockwise' eddy by Rotschi \& Lcmasson, 1967, possibly a misinterpretation of 'Takahashi's use of the phrase contra solem, ref. Sverdrup et al., 1942, p. 437.)

\section{Donguy, Oudot \& Rougerie, 1970-Review of 1956-68 northern Coral Sea data}

Donguy et al. (1970) reviewed the surface and subsurface circulations of the Solomon and Coral Seas, using data from 32 cruises between 1956 and 1968, and assembled current schemes for the summer and winter scasons.

For the summer (Fig. 56A) they identified from north to south (modified in the light of Donguy \& Henin's 1975 b findings), the following currents and related water masses:

(a) Equatorial Current to the west-Subtropical water, northern component (Sverdrup et al., 1942, called this the 'South' Equatorial Current),

(b) New Guinea Current to the east-Equatorial water, continuing as 
(c) South Equatorial Counter Current to the east,

(d) South Equatorial Current to the west-Subtropical water, southern component,

(e) South Tropical Counter Current to the east (from the Coral Sea, ref. Donguy \& Henin, 1975b),

(f) East Australian Current to the south-cast.

Fig. 56 Currents, Coral and Solomon seas, (A) surface, summer, (B) surface, winter, (C) $150 \mathrm{~m}$, summer, (D) $200 \mathrm{~m}$, winter (Donguy ot al., 1970). Abbreviations for current names: E.C. = Lquatorial Current, N.G.C. $=$ New Guined Current, S.L.C.C. $=$ South Equatorial Counter Current, S.E.C. = South Equatorial Current, S.I'.C.C. = South Tropical Counter Current, E.A.C. = last Australia Current.
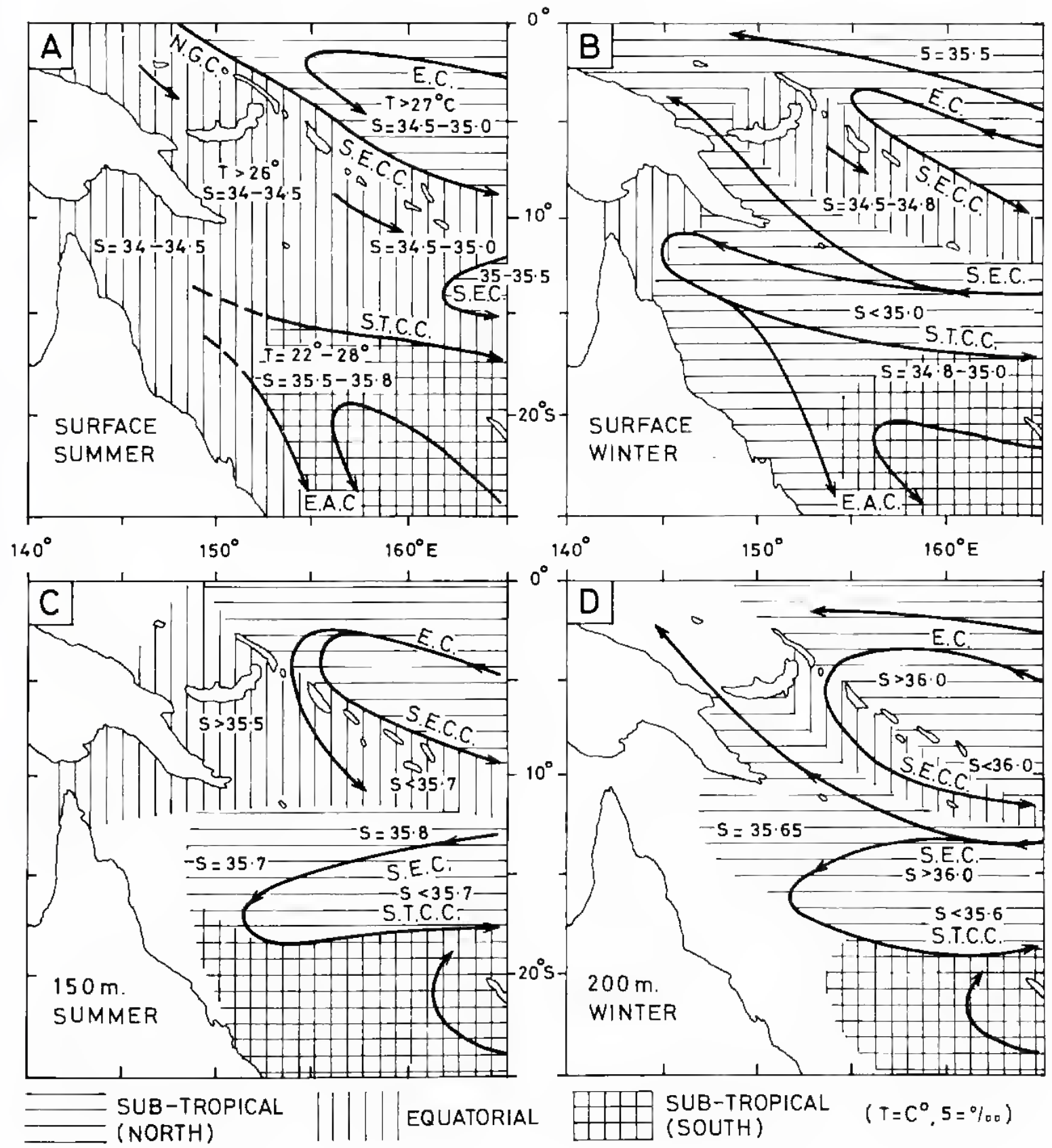
I'he surface water of the Coral Sea in the summer was identified as mainly the low salinity cquaturtal surface water firm the north, together with a component of Arafura Sea waler coning through l'orres Strait.

In the winter ( $1 \cdot i g .5013)$ ahe main feature was a considerable extension to the west of the Suth Liquatorial Current due to the Sti lades. Part ol this South Equatorial Current flowed nortbwest through the Solomon Sea to join the liquatorial Current and part contributed to the List Austalian Current. I'he Subtropical Counter Current was slightly lurther south and more siline $(34.8$ to $35.0 ;)$ ) than in summer. "1"he contribution of the Bepuatorial (Jurent to the South liquatorial Current was also more saline $(34.5$ to 3.4.8 than in summer. '1 he speeds in these currents were generally smalt, 1 to $5 \mathrm{~cm}$; s.

Most of the surfiec walcr in the Coral Sea in the winter was the Subtropical Surface water of the South Pacilie diluted by some Equatorial water.

It must be borne in mind that the ahove description was of broad features and that signilicant differences in detail between years may be expected, lot example as mentioned in the next section.

\section{Rougerie \& Donguy, 1975-'Gorgone 1' 1972 cruise, northern Coral Sea}

In November-1)ecember 1972 during the 'Gorgone I' cruise (Rougerie \& Donguy, 1975), regarded as a winter circulation period because it was still in the SE trades regine, the South Equatorial Counter Current was evident only north of the Solomon Is. (not south as well) and the South Tropical Counter Current which was conspicuous in 1956 betwec11 15 and $18 \mathrm{~S}$ was, in 1972, only eviclent just north of New Calcdonia (see also the nexl section). '1'he strong westward flow across 160 E was elcar in 1972 from 10 to $18 \mathrm{~S}$. (A curious feature which often occurs in the surface dynamic topography about 16 to $17 \mathrm{~S}, 156 \mathrm{l}$ is a cyclonic gyre of diamcter about $300 \mathrm{~km}$.)

\section{Donguy \& Honin, 1975 b-Review of flow at 158 and 163 lE}

Donguy \& Henin (1975b) assembled the available data to 1972 ( 13 cruises) for the area between New Caledonia and the Solomon Is., forming two lincs of stations close to $158 \mathrm{E}$ and $163 \mathrm{E}$ respectively. They decermined mean dynamic heights relative to $1000 \mathrm{db}$ for the two sections, omitting two cruises which were notably different lrom the others. Fig. 57 shows the currents identificd across the two sections from the mean dynamic heights. The presently unnamed current (U in Fig. 57) north of the Chesterfield Is. was possibly identified with the northerly tow to the west of New Caledonia described by Scully-Power (1973b) and the next section. At the right in Fig. 57 are given the maximum mean speeds at the surface relative $101000 \mathrm{db}$, the maximum mean speeds in the upper $100 \mathrm{~m}$, the maximum observed speeds and estimates of the volume transports for two of the currents. (As the northern limit of the South Equatorial Counter Current was not determined, its volume transport was not calculated.) One of the cruises omitted from the mean dynamic height calculation was the 1972 'Gorgone l' cruise which showed westward flow across the whole section at 158 E and westward over most of the section at $163 \mathrm{E}$.

\section{Scully-Power et al, 1969, 1973a, b-Western Coral Seat}

Lockerman \& Scully-Power (1969) calculated geostrophic currents lor a limited area in the North-west Coral Sea for the end of November 1966 and the end of April 1967. At the surlace in November there was a clockwise circulation with casterly flow at 25 to $40 \mathrm{~cm} / \mathrm{s}$ between 10 and $12.5 \mathrm{~S}$ and a westerly flow of 20 to $30 \mathrm{~cm} / \mathrm{s}$ between 14 and $15 \mathrm{~S}$. In April a similar circulation was observed with speeds of 20 to $60 \mathrm{~cm} / \mathrm{s}$. The November circulation was opposite to Wyrtki's (1960) surlace current chart which showed anti-clockwise circulation in November with a flow west through Torres Strait, and a weak clockwise circulation in December. Lockerman \& Scully-l'ower's April circulation was basically in agreement witb Wyrtki's April and May charts, and with Wyrtki's (1962b) geostrophic estimate from January to April data which showed a clearly 
developed clockwise circulation at the surface centered at I $3 \mathrm{~S}, 148 \mathrm{E}$ to the SSL of Port Moresby.

The most complete coverage of the Western and Central Coral Sea, albeit only for the winter season, was that described by Scully-Power (1973a, b, c) based on the three cruises in May, June and July 1968 (Fig.45A) and on data for May, June 1971 (R.A.N.R.L. Cruise CS7, unpublished data). In Fig. 58A, which also indicates the station positions, the surface dynamic topography relative to $1500 \mathrm{db}$ is presented to show the circulation. Scully-Power noted that the surface circulation was rather complex but drew attention to two features:

(1) although there was considerable westerly flow into the Coral Sea across 160 li, most of this water flowed out to the north into the Solomon Sea rat her than turning south across $20 \mathrm{~S}$ to feed the East Australian Current. This was not in keeping with usual ideas of flow in this region, c.g. Wyrtki $(1960,1962 b)$,

(2) an anticlockwise eddy was present between 20 and $26 \mathrm{~S}$, off the Capricorn Channel area of the Reef.

In addition, attention is drawn to:

(3) the very strong flow south at about $24 \mathrm{~S}$ close to Gt Sandy Is.

It is noted that, although not mentioned by Scully-Power, the U.S.N.O.O. Pilot Charts for the South Pacific (1955) show a similar feature to item (1) lor winter. For September to May (summer), the main surface flow shown is west or south-west across $160 \mathrm{E}$ with much of this flow proceeding south across $20 \mathrm{~S}$ to feed the East Australian Current system, but for June-August (winter) the westward flow across $160 \mathrm{E}$ divides at about $25 \mathrm{~S}$, part going south and part north across $20 \mathrm{~S}$. The pattern resemhles ScullyPower's surface and $150 \mathrm{~m}$ winter flow patterns with the division at $25 \mathrm{~S}$ rather than at

liig. 57 Currents and transports in the Central Coral Sea (1)onguy \& Henin, 1975). Abbreviations fon current names: S.E.C.C. $=$ South Equatorial Counter Current, S.E.C. - South Hquatorial Current, S.T.C.C. = South 'l ropical Counter Current, U-Unnamed current.

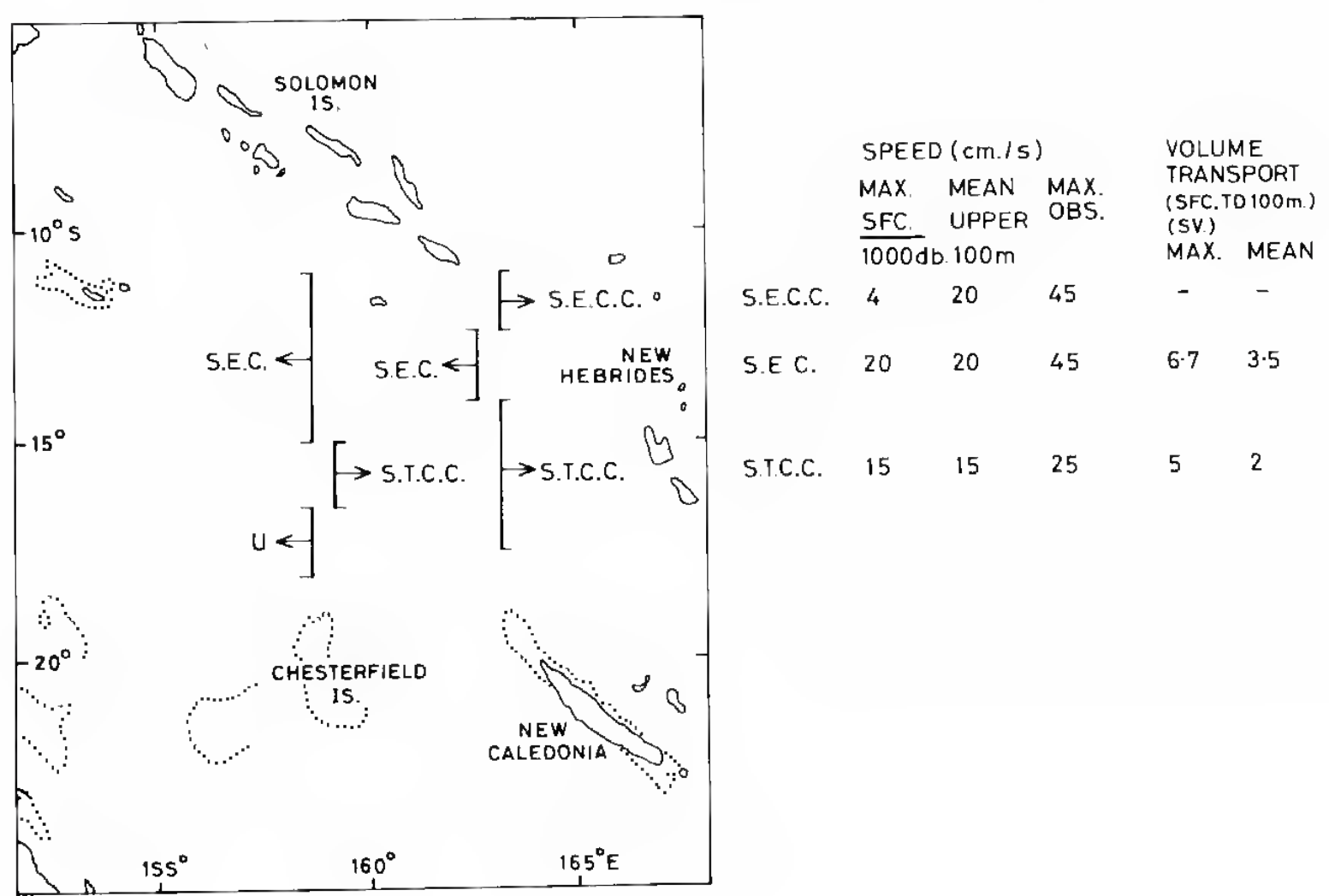




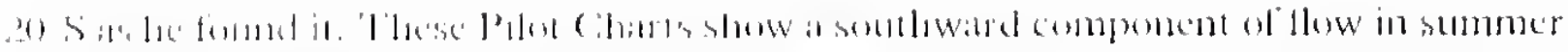

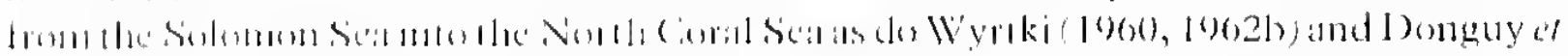

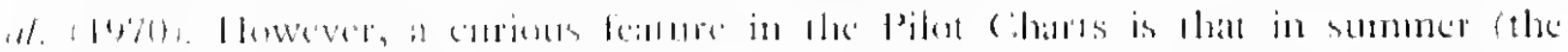

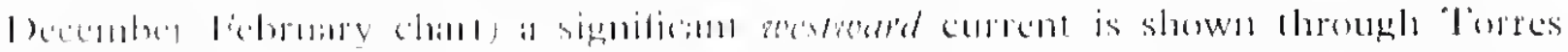

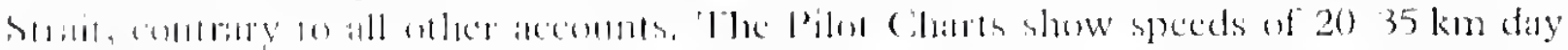

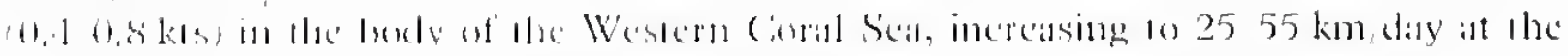

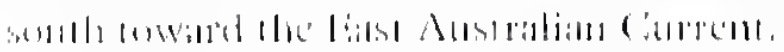

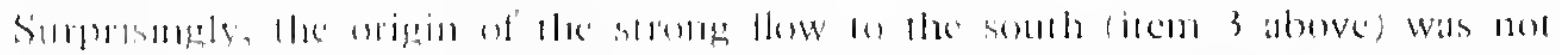

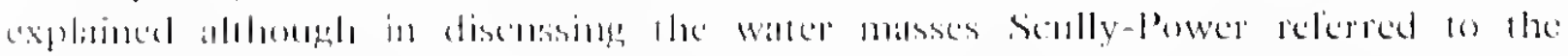

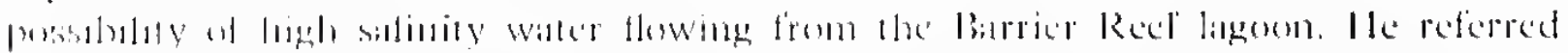

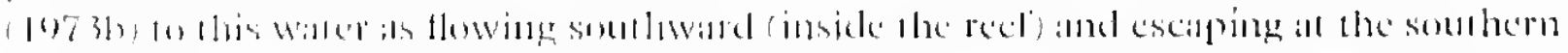

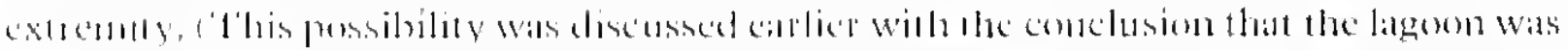

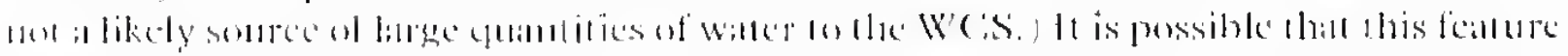

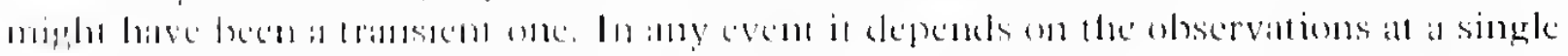

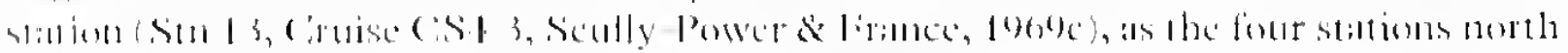

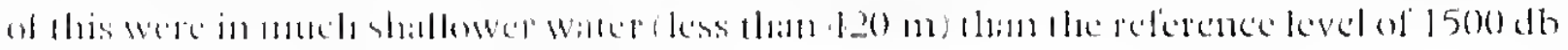

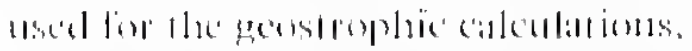

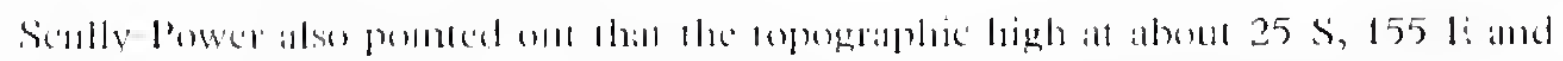

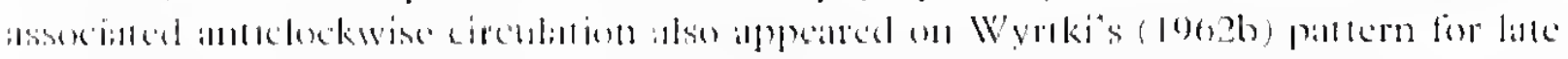

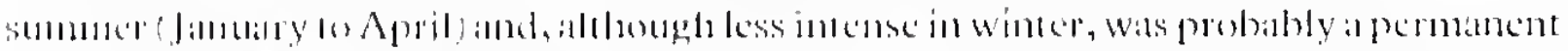

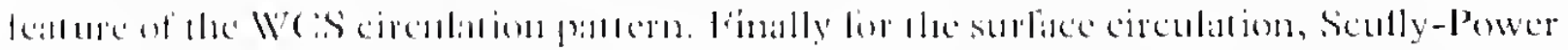

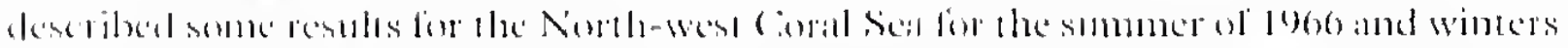

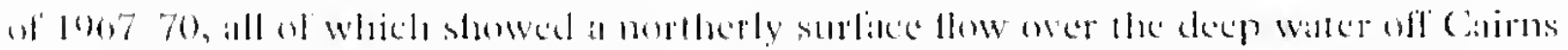

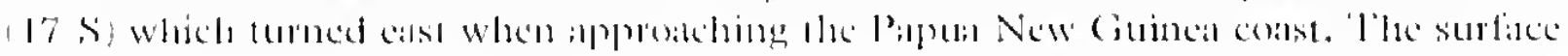

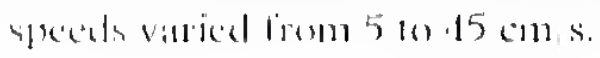

\section{SULSURIACI: (IRC:UIAIION}

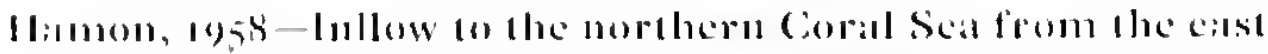

1 lammon(c)

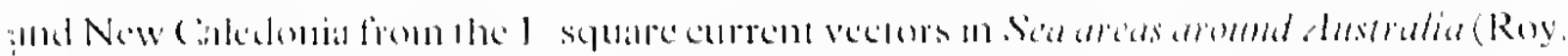

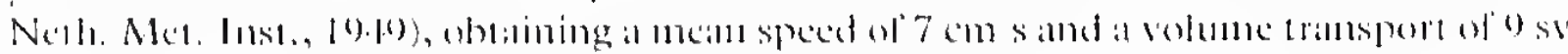

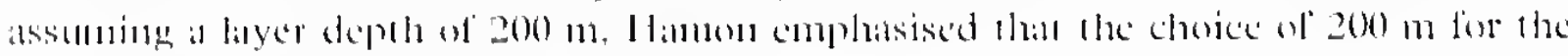
uppert biver llow wis only an estimate and that the solume transport should only be

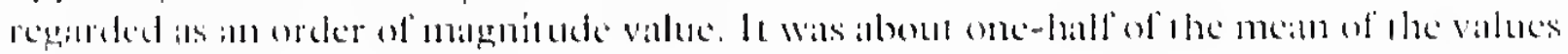
bolow cakculated by Wyrtki.

\section{Wretki, ro62h-Cieostrophic circulaton in the Coral Scal}

II"yrki (19021) also determined the geopentential topographies of the 100, 200, 400,

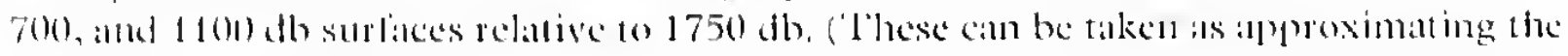
silne deptlis in melres.)

A $10(x)$ and $290 \mathrm{~m}$, the westward llow into he Corat Sea was better developed than at Ihe surlice, being stronger at $200 \mathrm{~m}$ than al $100 \mathrm{~m}$. The circulation at these depths

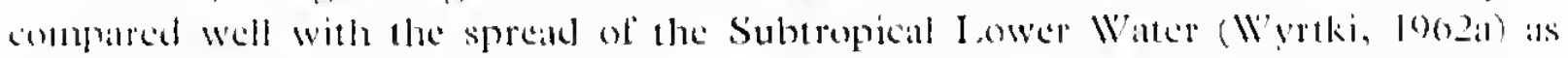
described previonsly. The westerly llow across 100 E was still evident at 400 m, and all 700 m where il eomsisted ol Antaretic Lntermediate water. Al 1100 m there was little refied

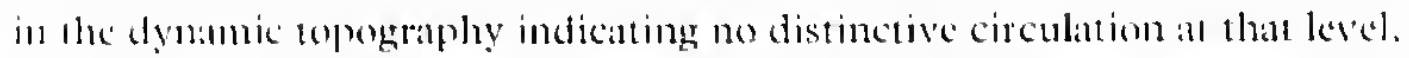

\section{Rotsehi, 1958-61-0.R.S.T.(O.M. earlier cruises, volume transports}

listween 100 and $500 \mathrm{~m}$ all six cruises (sec above) showed a westward flom into the Coril Sea, lar these cruises, Wyrki (1962b) showed the $300 \mathrm{~m}$ low's which were characteristic of the 100 to $500 \mathrm{~m}$ layer. He regarded the $100 \mathrm{~m}$ and decper dynamic 
topographies and associated geostrophic eirculations as indicative of the total flow below $100 \mathrm{~m}$ but for the surface the wind stress flow had to be added. in his opinion.

From the O.R.S.T.O.M. data Wyrtki (1962b) calculated the volume transport !at about $163 \mathrm{E}$ ) into the Coral Sea between the Solomon Is $(11 \mathrm{~S})$ and about $18 \mathrm{~S}$ where the reef system extending northwest from New Caledonia ends, and obtained, from the surface to $1000 \mathrm{~m}$ :

$\begin{array}{lrrr}\text { Nor. 1956 } & 23 \mathrm{sy} & \text { leb. } 1960 & 25 \mathrm{sv} \\ \text { Junt } 1958 & 26 \mathrm{sv} & \text { May } 1900 & 12 \mathrm{sv} \\ \text { Nov. } 1958 & 6 \mathrm{sv} & \text { Aug. } 1960 & 15 \mathrm{st} \\ & & \text { Mean 18 sr }\end{array}$

The transport maximum occurred at 100-300 m deptin and on two occusions there was a small net transport to the east between the surface and $100 \mathrm{~m}$. The speed of this flow was small, only 3 to $5 \mathrm{~cm}_{\mathrm{s}} \mathrm{s}$ at its maximum.

Donguy, Oudot \& Rougeric, 1970-Reriew of 1956-68 northern Coral Sea data

In their review of the Coral Sea circulation, Donguy al. (1970) found that below the surface, at 150-200 $\mathrm{m}$ (Fig. 56C, D), the same currents were present as at the surface but the South Equatorial Current penetrated well into or across the Coral Sea in hoth seasons, and the salinities were higher than at the surface. "The speeds in the vicinity of $160 \mathrm{E}$. averaged about $3 \mathrm{~cm} \mathrm{~s}$.

\section{Rougerie \& Donguy, I975-'Gorgone I'1972, late winter}

During the 'Gorgone I' cruise (Rougerie \& Donguy, 1975), the flow below the surface was generally similar to the flow at the surface except that the (eastward) counter currents were weaker and shallower than the westward currents. At about $150 \mathrm{~m}$ (salinity maximum) and at 300 to $500 \mathrm{~m}$ (oxygen minimum) the westward flow predominated. The South Equatorial Counter Current was present north of $10 \mathrm{~S}$ but the South Tropical Counter Current had practically disappeared. At 500 to $700 \mathrm{~m}$ (oxygen maximum) the flow was zonal in the eastern and southern parts of the Coral Sea but the part north of $15 \mathrm{~S}$ turned to the north into the Solomon Sea at about $155 \mathrm{E}$.

The westward transport of the South Equatorial Current was 37 sv across $153 \mathrm{E}$. The South Tropical Counter Current carried $3 \mathrm{sv}$ at $153 \mathrm{E}$.

\section{Rougerie \& Donguy (unpubl.)-'Gorgone 2' 1975, late summer}

Although the analysis is not complete, some preliminary comparisons between this 'Gorgone 2' late summer and the 'Gorgone 1' late winter results can be offered.

The end of the summer is characterised by the marked development of eastward Hows. Between 10 and $12 \mathrm{~S}$ the South Equatorial Counter Current reaches $50 \mathrm{~cm}$ s at the surface and still has a speed of $20 \mathrm{~cm} / \mathrm{s}$ at $200 \mathrm{~m}$. Its depth decreases eastward and on leaving the Solomon Sea the $20 \mathrm{~cm} \cdot \mathrm{s}$ isotach is at only $100 \mathrm{~m} \mathrm{depth}$. Between 15 and $17 \mathrm{~S}$ at the end of the summer the South Tropical Counter Current is slower and shallower than the South Equatorial Counter Current but shows the same decrease in speed and depth as it progresses eastward. Its southern boundary coincides with a thermohaline front where the salinity exceeds 35.0 ; and the temperature falls below $28 \mathrm{C}$.

Dynamic height calculations relative to $1000 \mathrm{db}$ indicated the presence in this zone during 'Gorgone 2 ' of a trough identical to that observed during 'Gorgone 1' and at the same position, $16.5 \mathrm{~S}, 156 \mathrm{E}$. This continuing dynamic structure is associated with the presence here of an isohaline, nutrient-poor layer which is about $100 \mathrm{~m}$ deep and was of considerable horizontal extent during 'Gorgone 1'. This trough is at the centre of a cyclonic gyre with which the eastward flow appeared to be closely related. The continuance of the gyre may be associated with the flow but it is possihle that it is only when the SE trades weaken (in the summer) that the waters start moving to the east and develop the South Tropical Counter Current. 'This was inconspicuous during 'Gorgone 1' (at the end of the SE trades season) but reached a speed of 15 to $35 \mathrm{~cm}$ s at the surface 


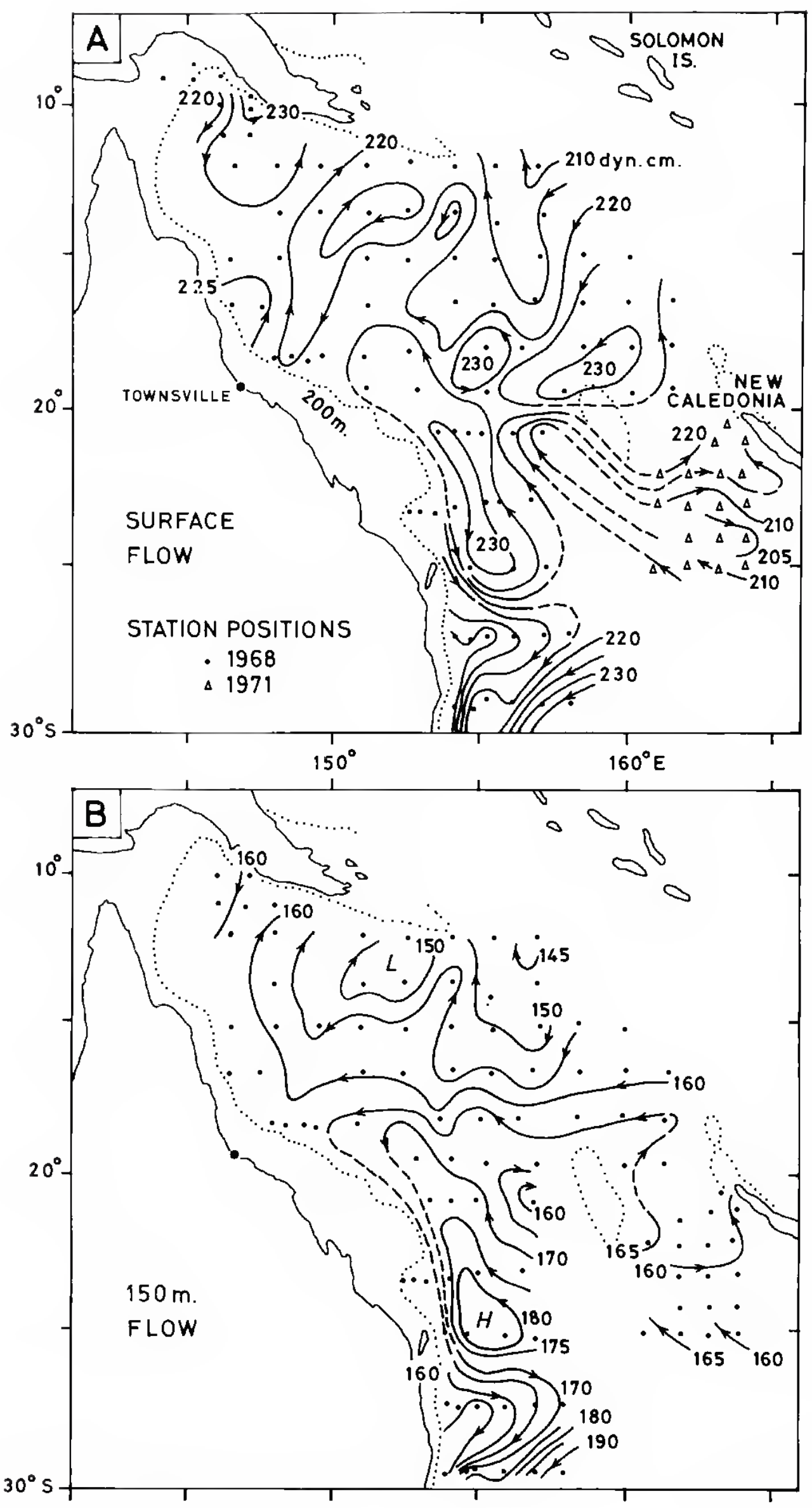

Fig. 58 Geopotential topography and flow patterns relative to $1500 \mathrm{db}$, Western Coral Sea, May-July 1968, (A) surface, (B) $150 \mathrm{db}$ level (Scully-Power, 1973a). 
during 'Gorgone 2'. During this cruise, the South Equatorial Current, squeced between the two counter currents and opposed by the NW winds, had a surface speed of lest than $20 \mathrm{~cm}$ s. In the north-wcst of the Solomon Sea the westward flow had a similar speed but below the surface had a core of about $100 \mathrm{~m}$ thickness with a speed of $30 \mathrm{~cm}$.

Scully-Power et al., 1969, I973 a,b,c-Geostrophic circulation May-July 1968 and volume transport budgets, Western Coral Sea

Lockerman \& Scully-Power (1969) found clockwise circulation in the North-west Coral Sea at the $900 \mathrm{db}$ level (about $900 \mathrm{~m}$ ) in November 1966 with speeds of 5 to $8 \mathrm{~cm}$ s, and in April 1967 they found what appeared to be the northern half of a clockwise circulation with speeds of 15 to $20 \mathrm{~cm} / \mathrm{s}$. This meant that the wholc column from the surface to $900 \mathrm{~m}$ had a clockwise circulation. Wyrtki's (1962b) calculations for this region showed little movement below $400 \mathrm{db}$.

Fig. $58 \mathrm{~B}$ shows the circulation at about $150 \mathrm{~m}$, the level of the core of the Subtropical Lower (salinity maximum) water in the WCS, from Scully-Power's (1973a,b) study of the winter regime. The circulation at this level was simpler than at the surface (Fig. 58A) but had the same main features. The division of the main westward flow at $18.5 \mathrm{~S}$ when it reached the Barrier Reef was clearer than at the surface where it occurred at about $19 \mathrm{~S}$, close to the average for May to July in Wyrtki's (1960) charts.

Scully-Power pointed out that the dynamic topography slopes at $150 \mathrm{~m}$ were not very different from those at the surface, and he considered that the flow pattern at this level was probably representative of the mean flow of the whole upper layer, the irregularities in the surface pattern probably being duc to local wind stress variations. The circulation at 900 $\mathrm{db}$ (Antarctic Intermediate water) relative to $1500 \mathrm{db}$ was basically the same as at $150 \mathrm{~m}$ although much reduced in intensity (speeds about one-fifth of those at $150 \mathrm{~m}$ ), and the strong flow to the south off Gt Sandy Is. was absent.

Scully-Power (1973c) went on to calculate volume transport budgets for the Coral Sea by selecting quasi-synoptic (i.c. near simultaneous) sections and calculating the flow across each of these from the surface to $250 \mathrm{~m}$ and surface to $1500 \mathrm{~m}$ depth (Fig. 59A). This showed a westward flow of $37 \mathrm{sv}$ across $157 \mathrm{E}$ (CD) into the WCS. Of this $28 \mathrm{sv}$

Fig. 59 Volume transports in sverdrups $\left(10^{\prime \prime} \mathrm{m}^{3} \mathrm{~s}\right.$, A) Western Coral Sca, May-July 1968, (B) Northwestern Coral Sia (Scul]y-Power, I973c).

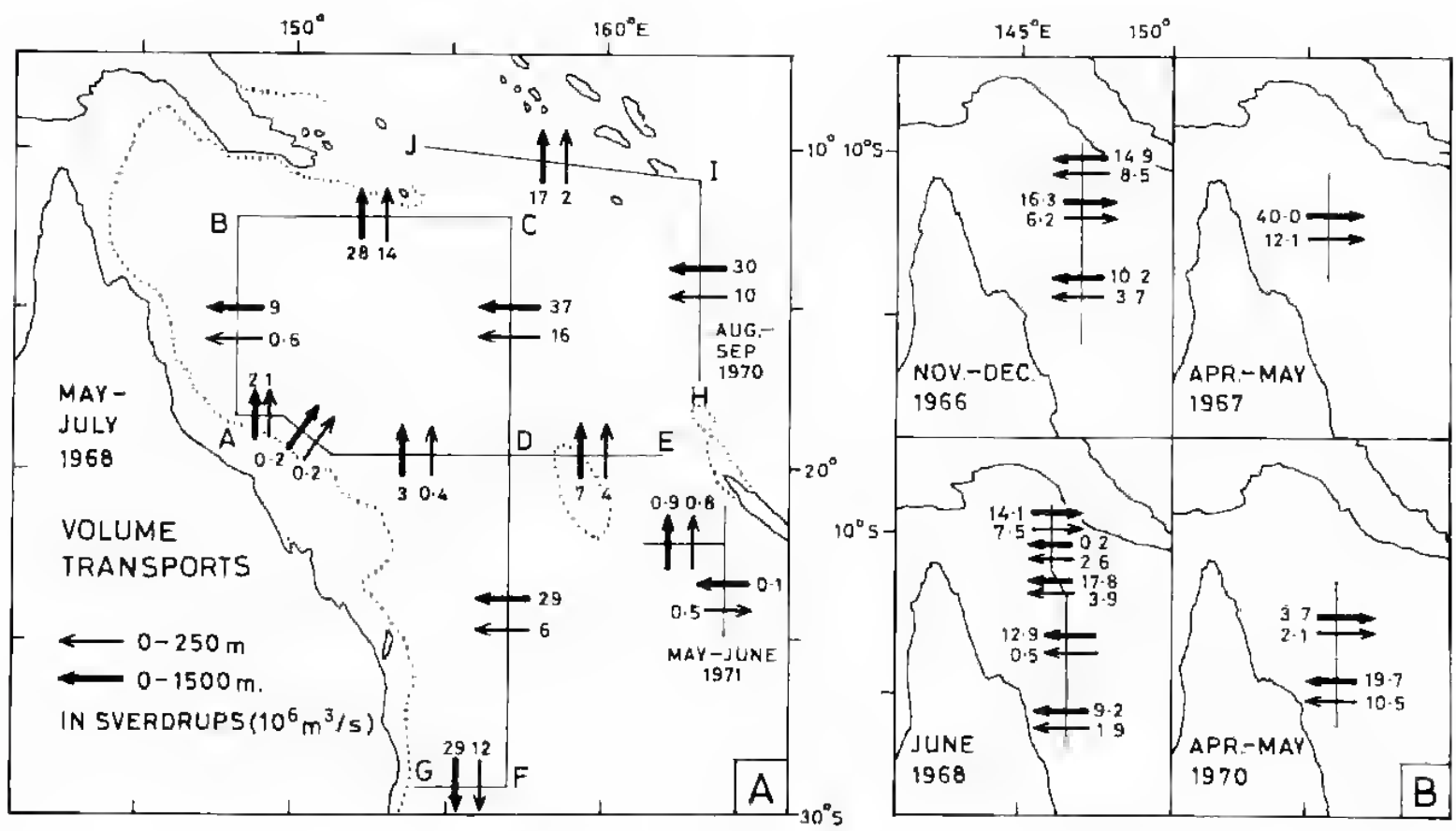




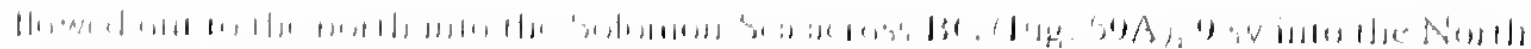

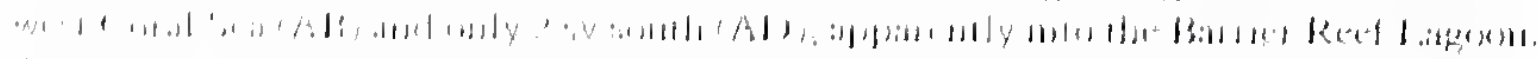

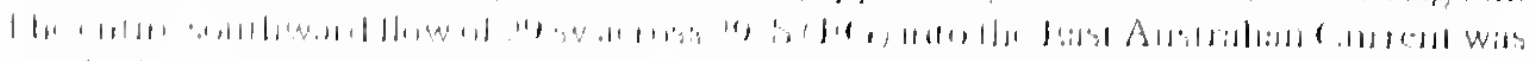

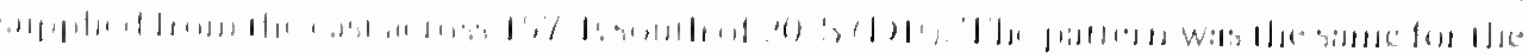

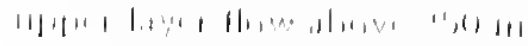

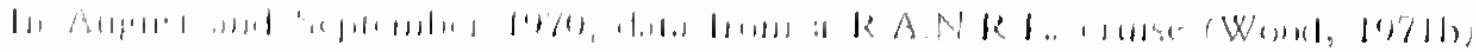

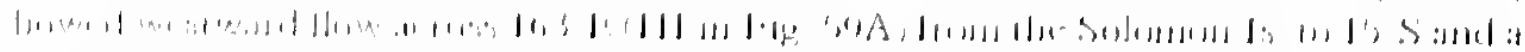

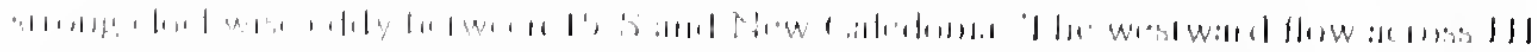

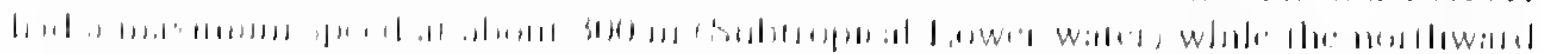

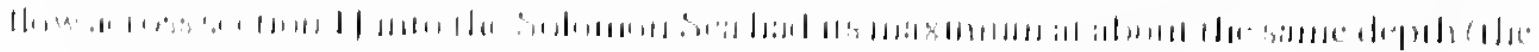

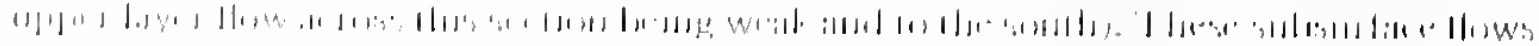

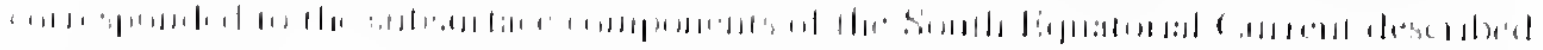

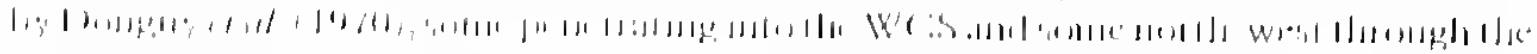

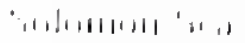

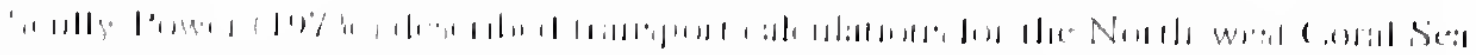

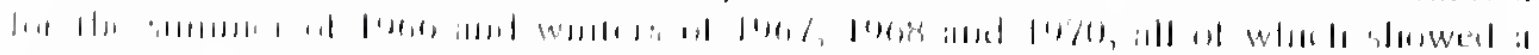

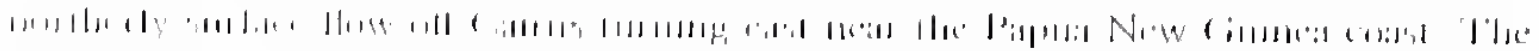

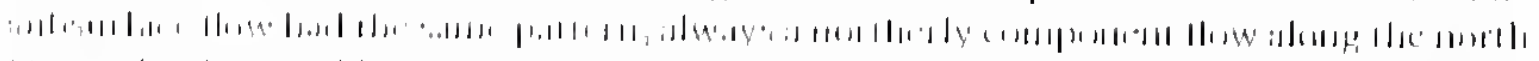

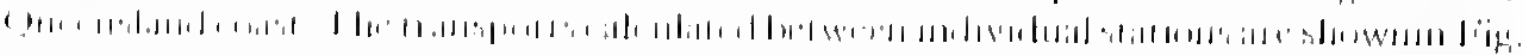

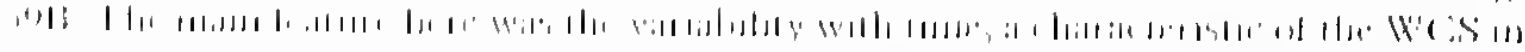

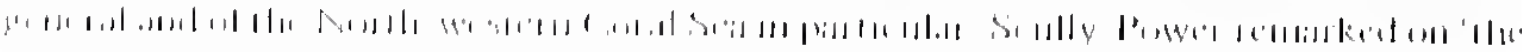

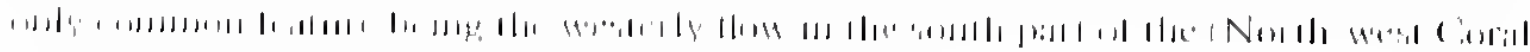

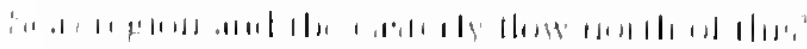

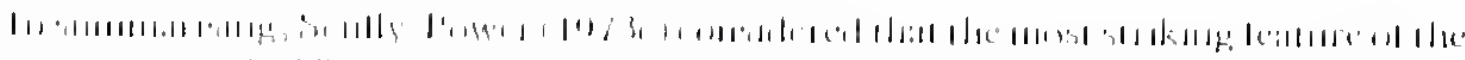

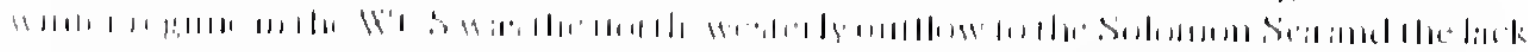

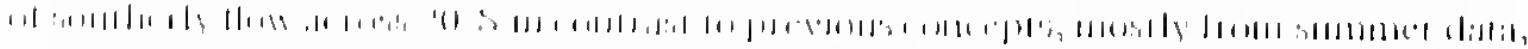

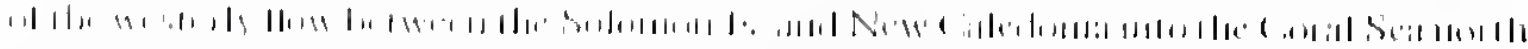

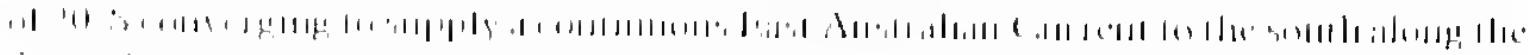

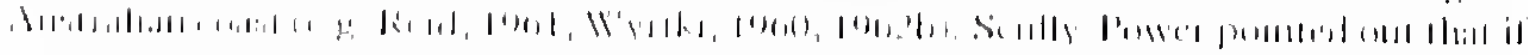

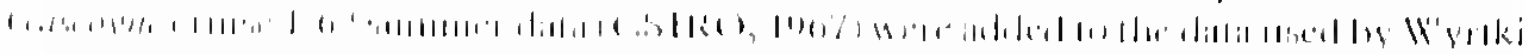
I I f

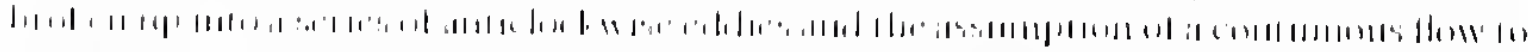
l|

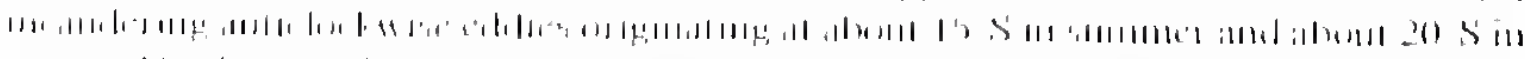

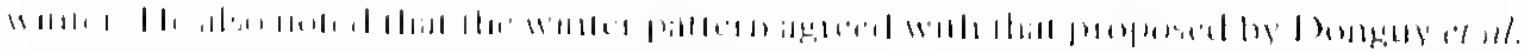

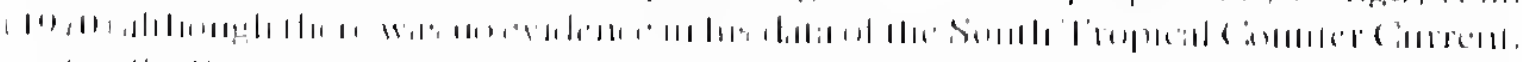

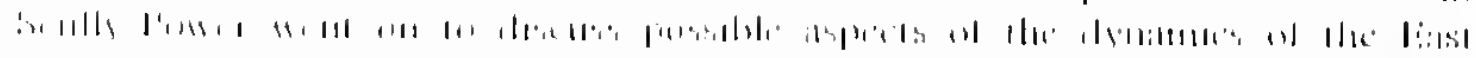

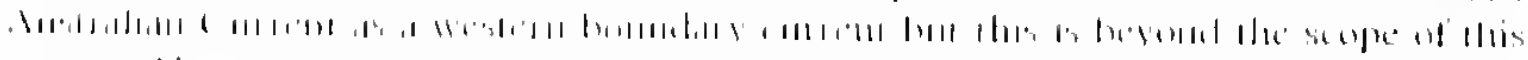

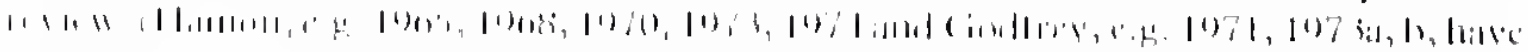
1, d.

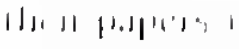

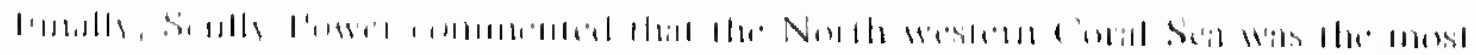

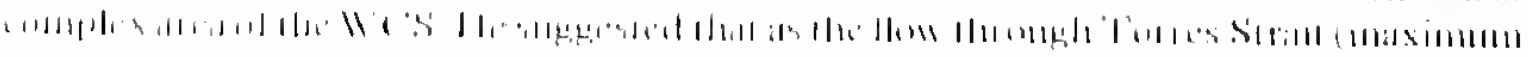

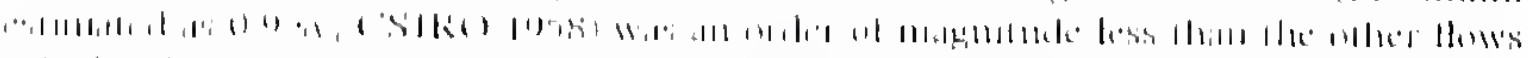

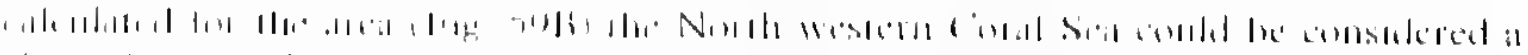

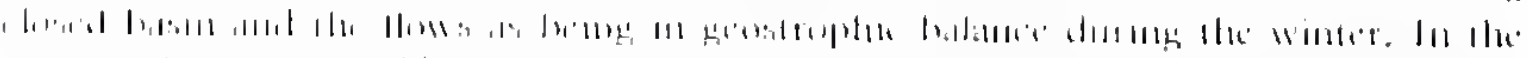

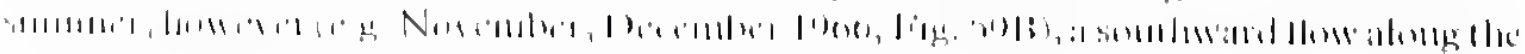

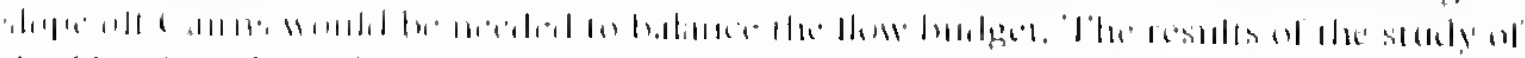

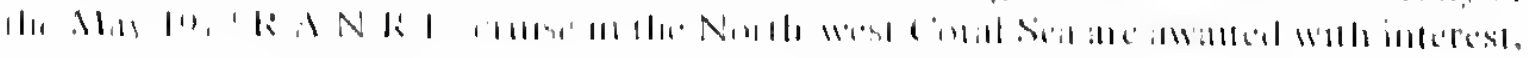

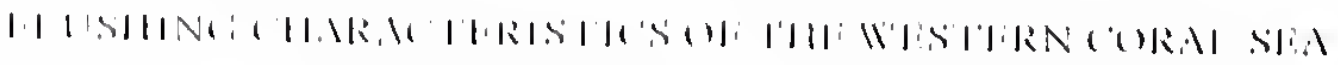

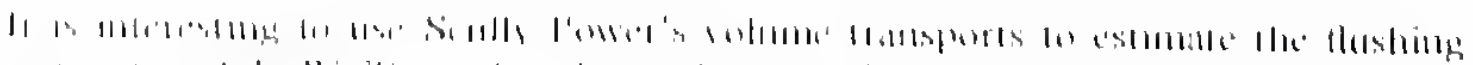

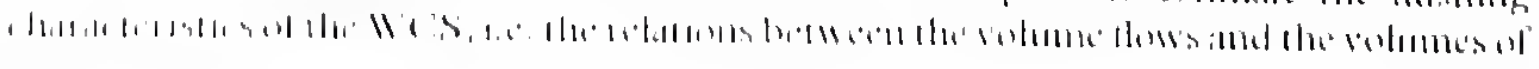


water in the basins. This has been done for three areas of the WVS, the North-west Coral Sea, the main body between about $12 \mathrm{~S}$ and $20 \mathrm{~S}$, and the southern part between aboul $20 \mathrm{~S}$ and $29 \mathrm{~S}$. These areas were chosen to enable Scully-Power's (1973c) rolume transports to be used. It has been assumed that the transport in the upper $1000 \mathrm{~m}$ would be $90^{\prime \prime}$ "of Scully-Power's values calculated to $1500 \mathrm{~m}$, and the Reef areas have heen assumed to be $100 \mathrm{~m}$ deep. The figures ohtained are shown in Table 8 .

For areas 2 and 3 the annual inflow is greater than the basin volume of the upper layers, which implies, to a first approximation, that the water will be replaced in less than one year ('replacement time'). In estaurine oceanographic jargon these basins are 'well flushed' for such large areas. The valuc of 5 years replacement time for the $0-250 \mathrm{~m}$ layer in area 1 follows from the net transport of only $0.6 \mathrm{sv}$ into the area (across scction $\mathrm{AB}, \mathrm{Hig}, 59 \mathrm{~A}$ ) which appears unreasonably low by comparison with the larger values (by a factor of ten) across this section for other cruises (Fig. 59B). A more likely replacement time would be about 0.5 to 1 year, similar to the values for the othcr areas.

It will be appreciated that these estimatcs, which extrapolate values from one threemonth period to annual values, must be regarded as only approximate; but as there is no indication that the circulation changes drastically during the year, they arc believed to bc realistic. Naturally, year-to-year variations are to be expccted.

\section{UPWELLING OFF THE EAST AUSTRALIAN COAST}

Godfrey (1973) made somc calculations of transport relative to $1300 \mathrm{db}$ off the east Australian coast between positions approximately as follows: (A) $18 \mathrm{~S}, 147 \mathrm{E}$; (B) $19 \mathrm{~S}$, $157 \mathrm{E}$; (C) $28 \mathrm{~S}, 158 \mathrm{E}$; (D) $39 \mathrm{~S}, 155 \mathrm{E}$; (E) $38 \mathrm{~S}, 150 \mathrm{E}$, using such data as were available near to those points. Across ABC there was a very small nct outflow abovc $100 \mathrm{~m}$ and an inflow from $100-1300 \mathrm{~m}$ of about $18 \mathrm{sv}$, with its maximum at $300 \mathrm{~m}$. There was an indication that most of this inflow was across the north-south section BC. Across CD there was a strong outflow (to the east) with its maximum at the surlace and most of the flow above $300 \mathrm{~m}$; across DE thcrc was a less strong outflow with its maximum ncar the surface. The sub-surface inflow and strong surfacc outflow implicd upwelling between the coast and the line ABCDE, probably within $50 \mathrm{~km}$ of the coast. The vertical flow was calculated to have its maximum at $250 \mathrm{~m}$ depth with a value of $7.5 \mathrm{sv}$, corresponding to a vertical speed of about $10 \mathrm{~m} /$ day which is a high value for upwelling. It should be noted that the upwelled water was not high in nutrient content. Typical values for $\mathrm{P}-\mathrm{PO}_{4}$ werc:

\begin{tabular}{ccccc}
\hline Depth: & Sfc & $100 \mathrm{~m}$ & $200 \mathrm{~m}$ & $400 \mathrm{~m}$ \\
P-PO $_{-1}$ & 0.1 & 0.15 & 0.3 & $1.0 \mu \mathrm{g} \mathrm{at} / 1$. \\
\hline
\end{tabular}

Table 8. Basin volumes and volume flows in to the Western Coral Sea

\begin{tabular}{|c|c|c|c|c|c|}
\hline Area & & $\begin{array}{l}\text { Sfc. to } 250 \mathrm{~m} \\
\text { (incl. reefs } \\
\text { ass. to be } \\
100 \mathrm{~m} \text { deep. } \\
\left(\times 10^{1+} \mathrm{m}^{3}\right)\end{array}$ & $\begin{array}{l}250 \text { to } 1000 \mathrm{~m} \\
(\text { excl. reefs }) \\
\left(x 10^{\left.\mathrm{t}+\mathrm{m}^{3}\right)}\right.\end{array}$ & \multicolumn{2}{|c|}{$\begin{array}{l}\text { Replacement time }= \\
\text { basin volume inflow } \\
\text { per } y \text { r }\end{array}$} \\
\hline NW Coral Sea & Vol & 1.0 & 2.3 & 5 & 1 \\
\hline (west of $148 \mathrm{E}$ ) & Inflow $\mathrm{yr}$ & 0.2 & 2.4 & & \\
\hline $\begin{array}{l}\text { Main WCS } \\
\text { (148 E to } 157 \mathrm{E} .\end{array}$ & Vol & 2.0 & 5.9 & 0.4 & 0.9 \\
\hline 12 to $19.5 \mathrm{~S}$ ) & Inflow/yr & 5.3 & 6.9 & & \\
\hline $\begin{array}{l}\text { South WCS } \\
\text { (west of } 157 \mathrm{E} \text {, }\end{array}$ & Vol & 1.2 & 2.8 & 0.5 & 0.4 \\
\hline 19.5 to $\left.29^{\circ} \mathrm{S}\right)$ & Inflow $/ \mathrm{yr}$ & 2.2 & 6.9 & & \\
\hline
\end{tabular}




\section{VI \\ Simuls}

WAIII:MAIBIIS

$1 \ldots 1, \ldots+1,1+\ldots+1$

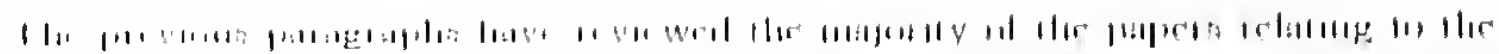

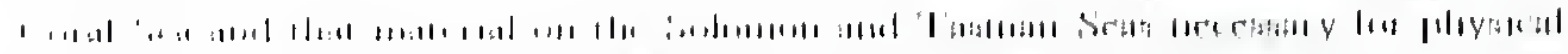

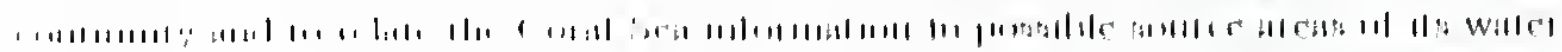

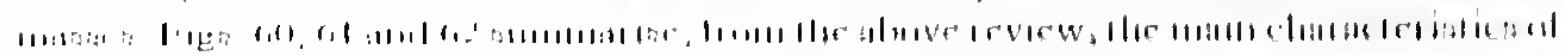

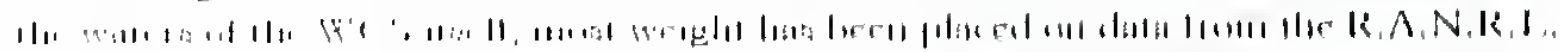

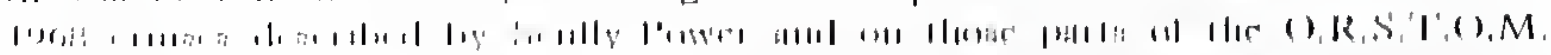

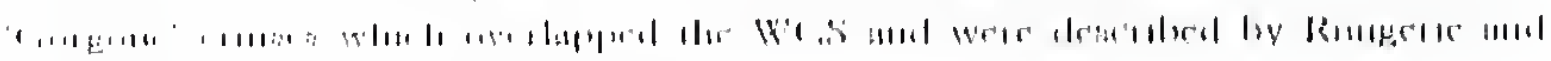
$11,11,119$

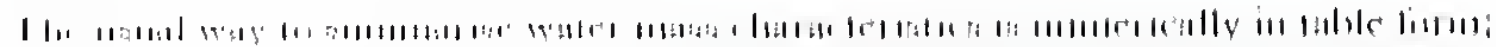

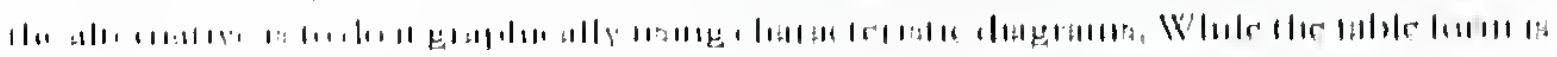

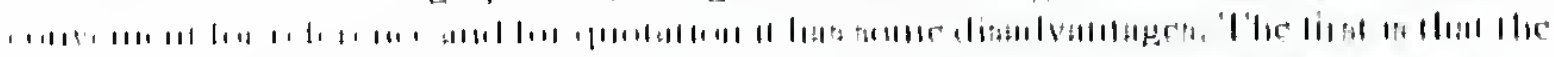

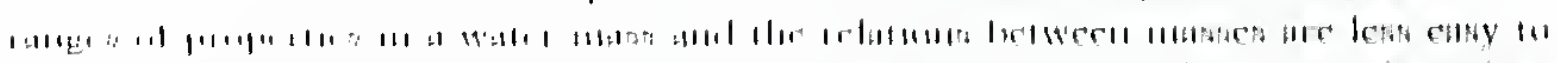

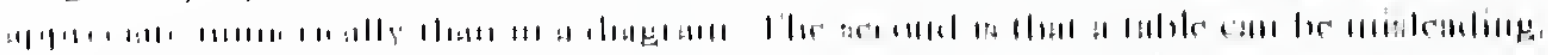

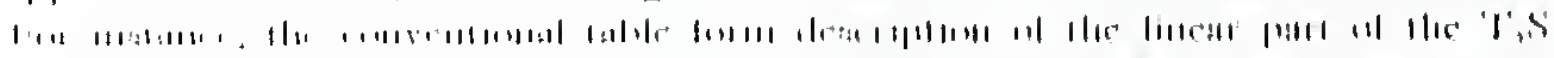

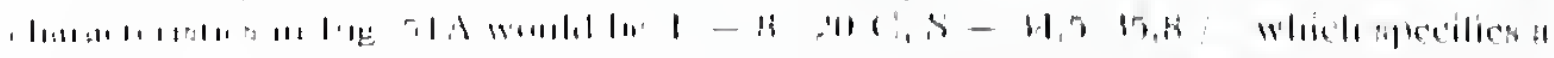

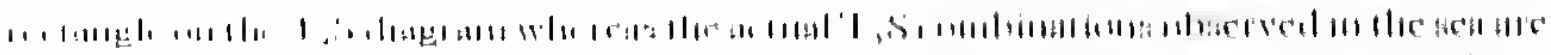

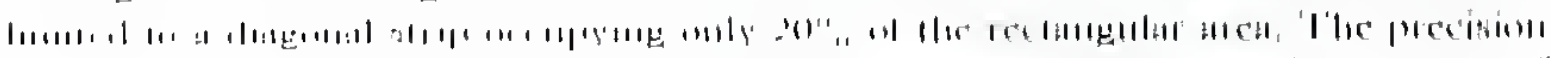

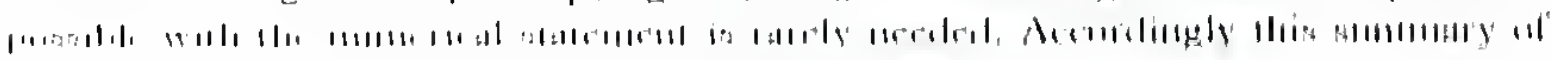

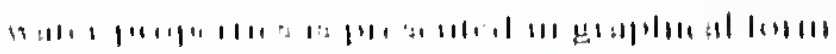

$\because 11,11,11: 11,1: 3$

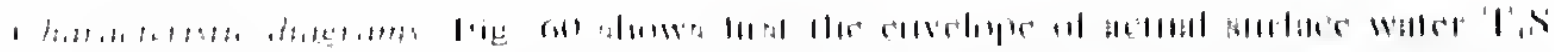

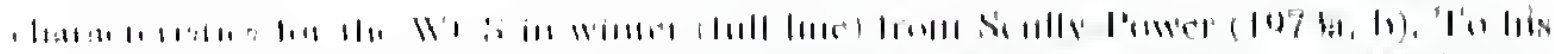

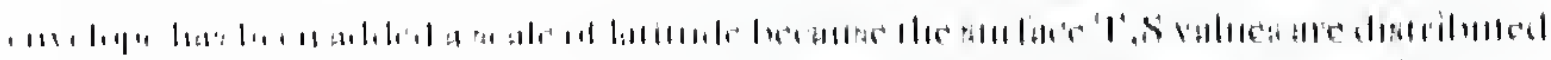

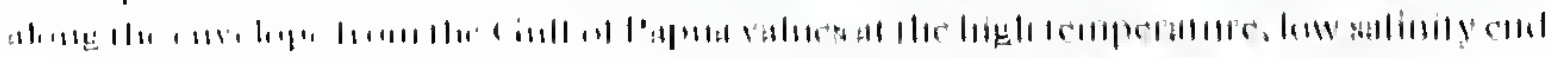

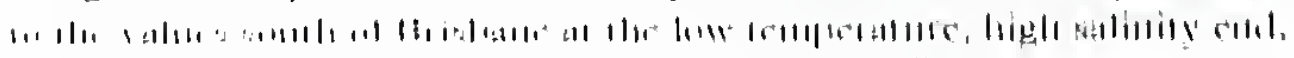

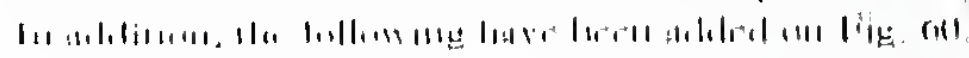

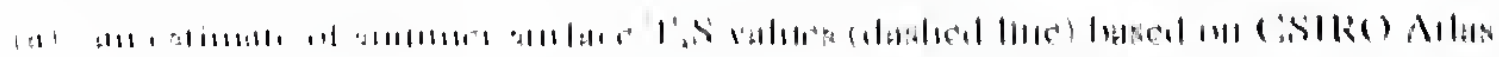
(1) $11,1: 11: 1$.

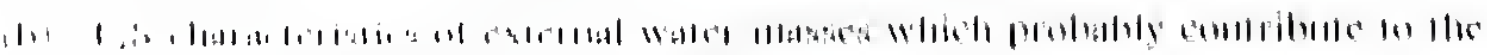

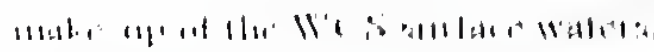

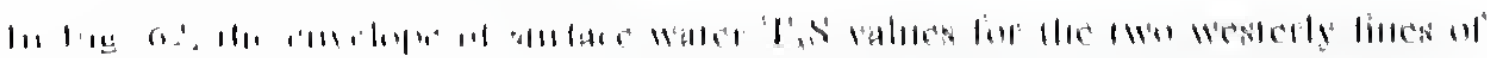

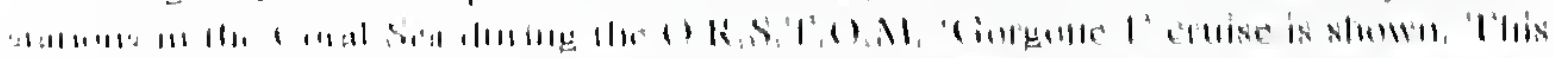

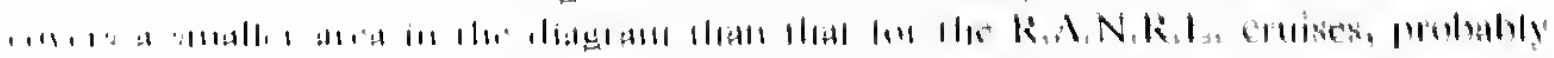

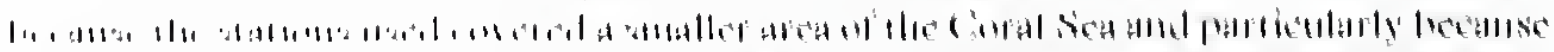

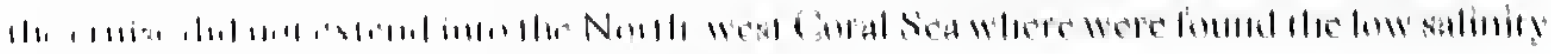

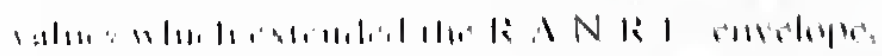

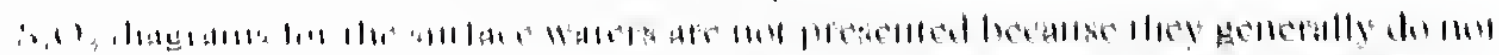

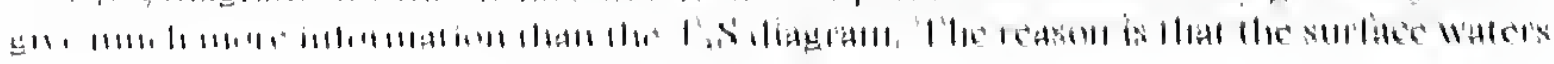
$1:$ 


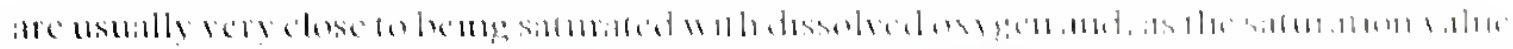

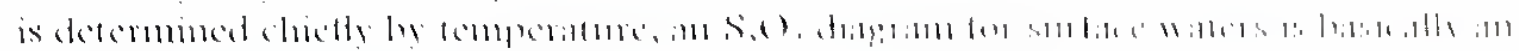

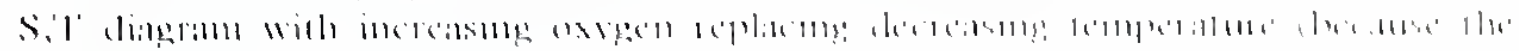

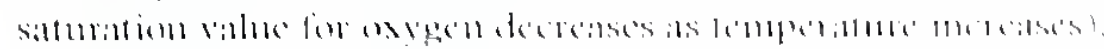

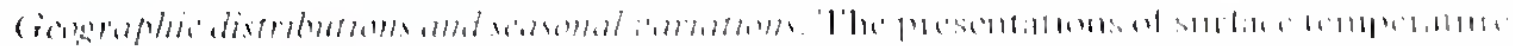

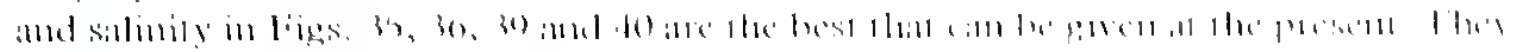

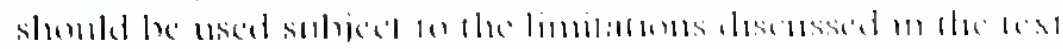

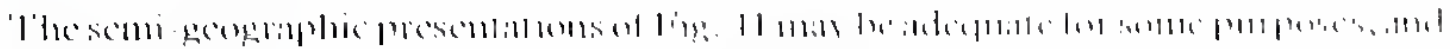

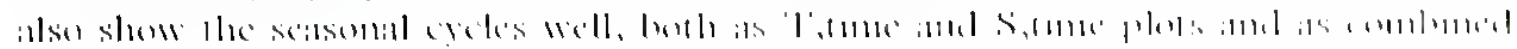
'I’,s,

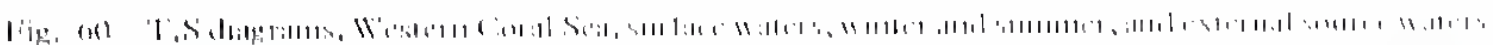

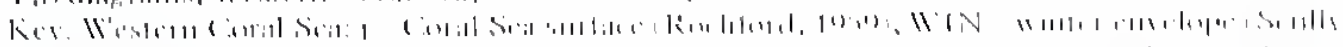

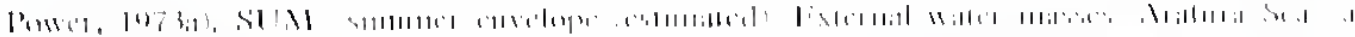

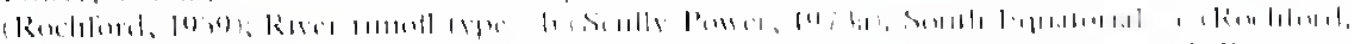

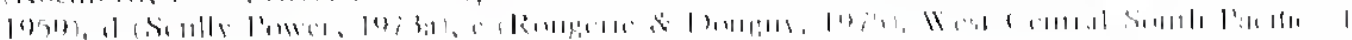

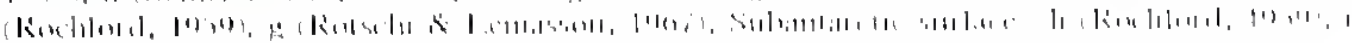

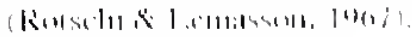

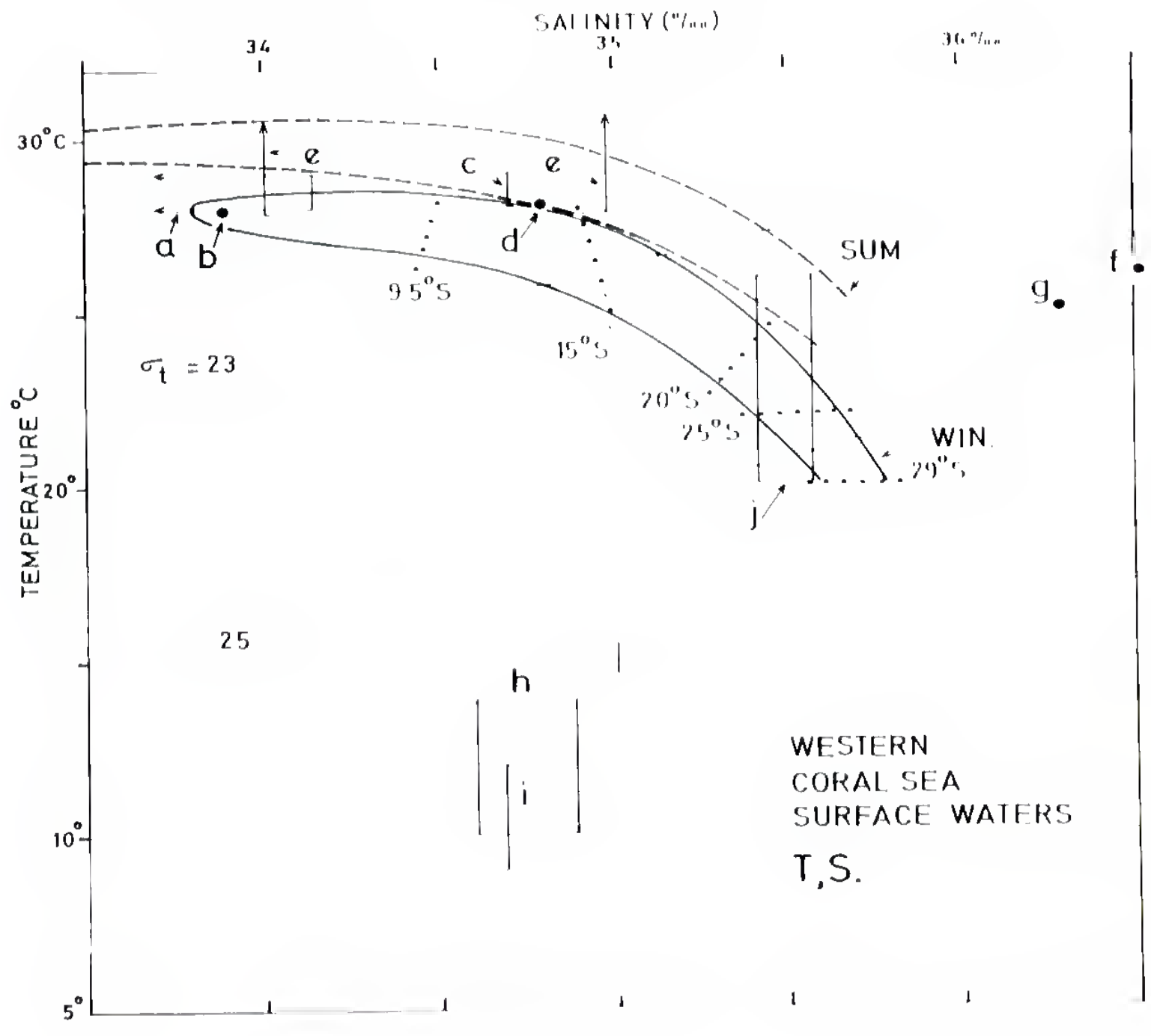


Sulsordiace waters

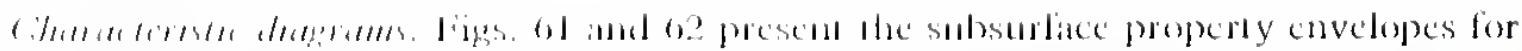

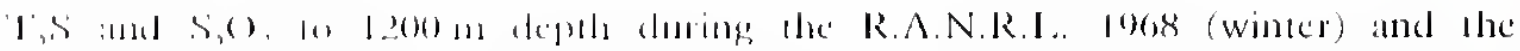

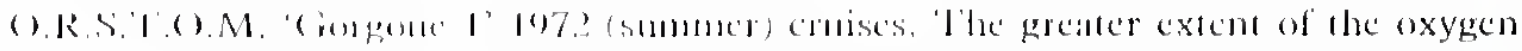

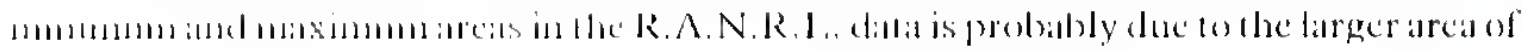

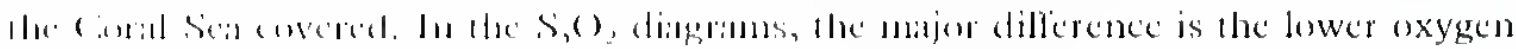

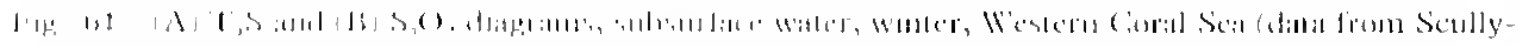

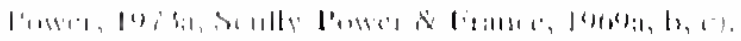

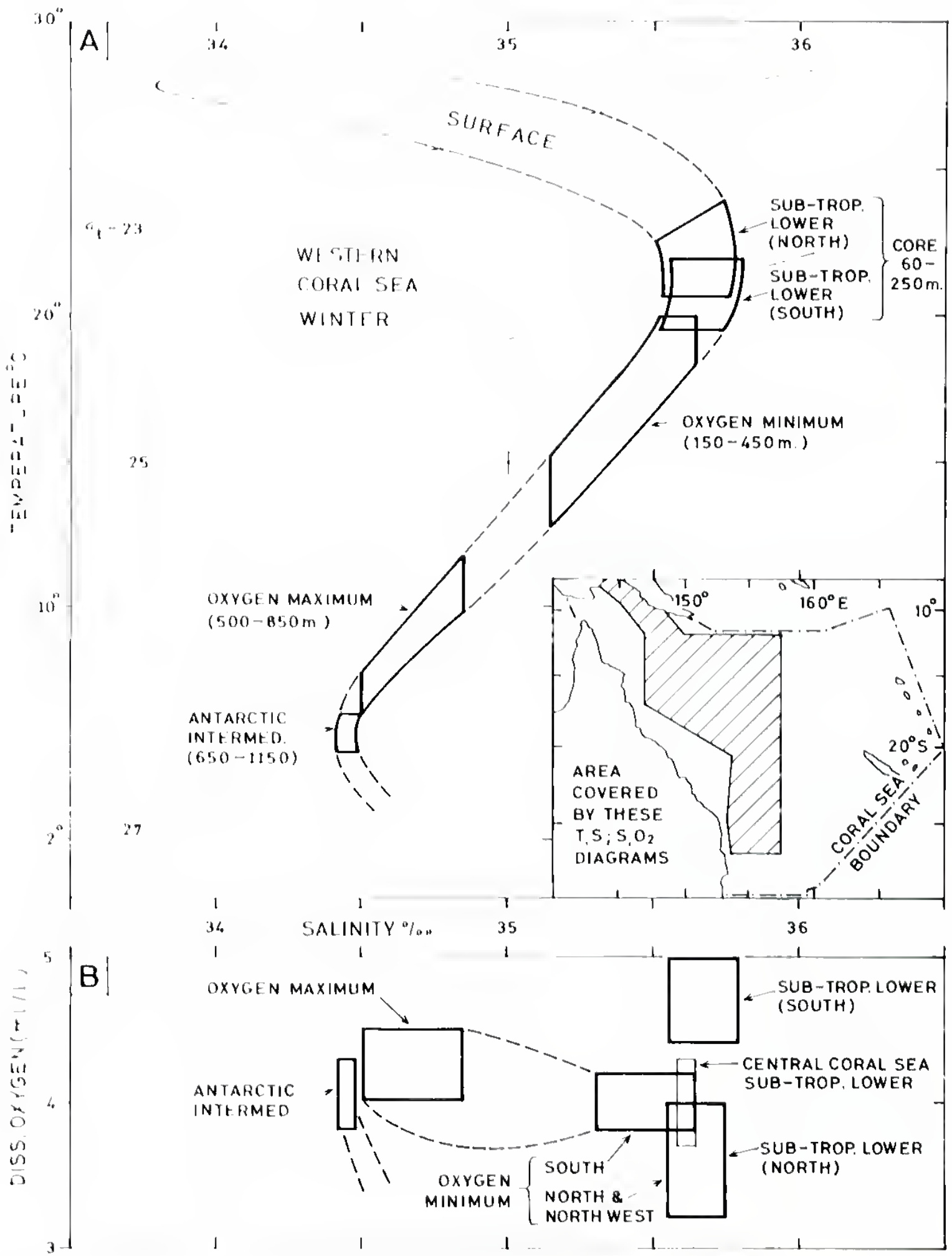


content of the Subtropical Lower water, southern component, in the 'Gorgone I' data. This is probably because the cruise area did not extend as far south as the R.A.N.R.I. one, and therefore did not pick up as much of the higher oxygen southern component. (Much of the Subtropical Lower water in the R.A.N.R.L. cruise area south of the 'Gorgone 1 ' area had oxygen values of 4.5 to $5.0 \mathrm{ml}$. .)

Fig. 62 (A) T,S and (B) S,O, diagrams, subsurface water, summer, Wuest Cantral Conal Seal data from Rougeric \& Donguy, 1975, and 'Gorgone l' data record, 1)onguy d al., $1972 \mathrm{~b}$ '.

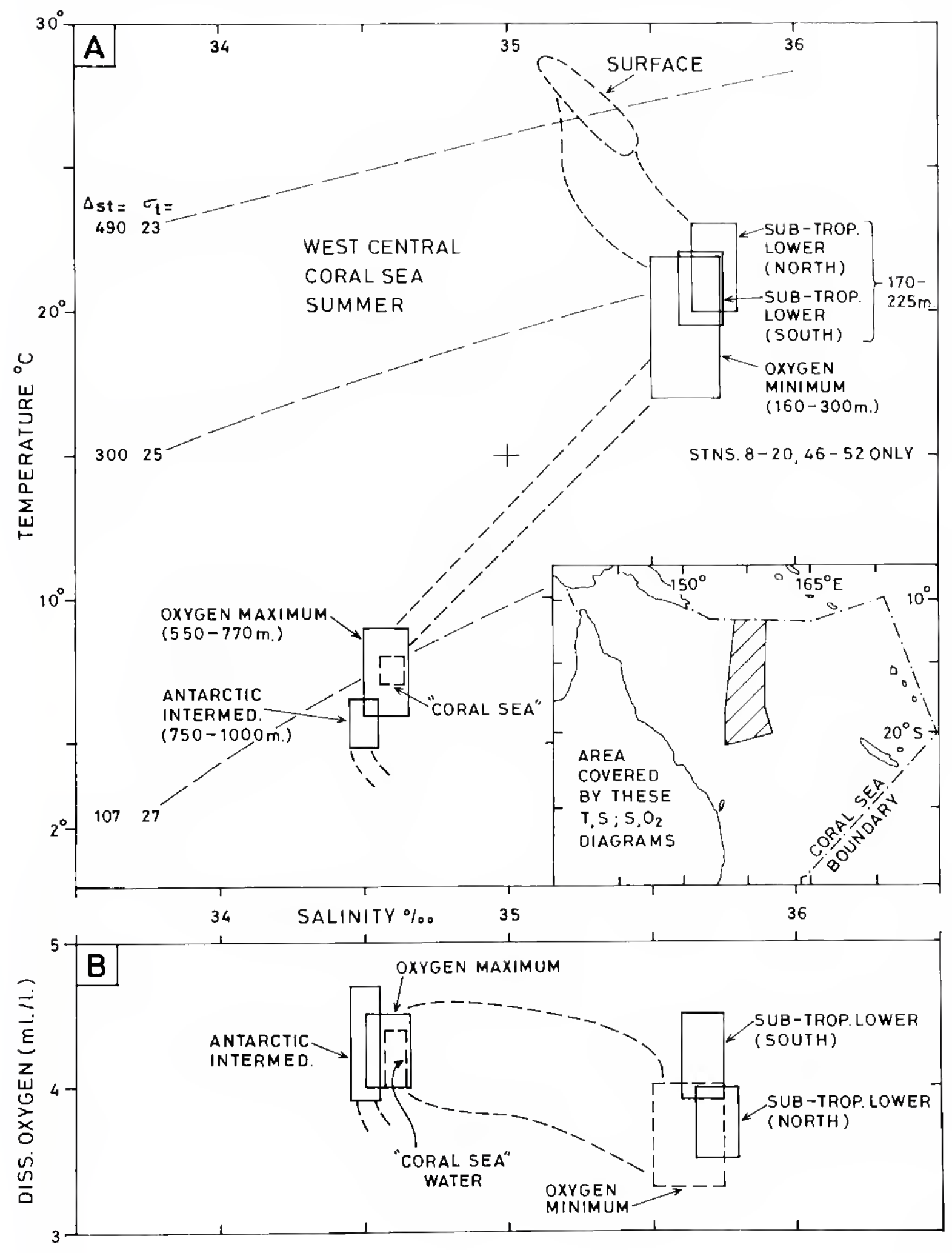




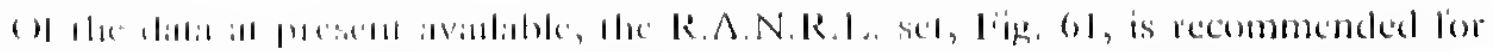

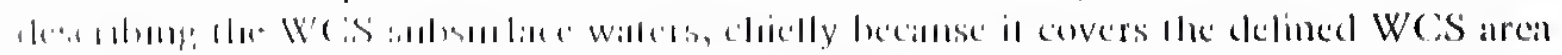

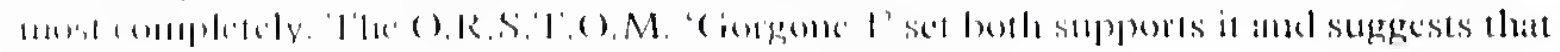

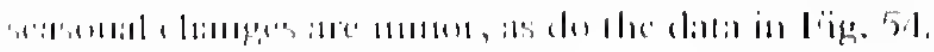

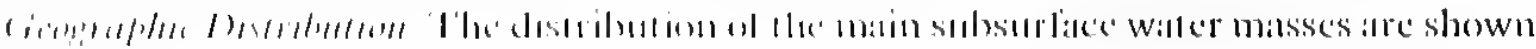
al. fullow,

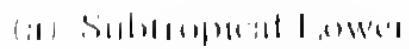
hy salinily
liips. 14 A, 1), 50A, 52A,

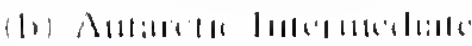
hy usyfich
hy axygen
: Iv sillinity
liks. . 1913, 1:, 5213,
lifis. $140(5,5)$
lifis. 1.1) 1i, 521).

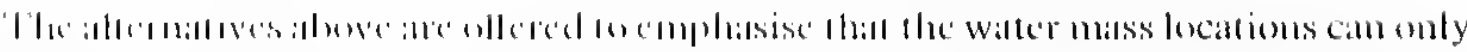

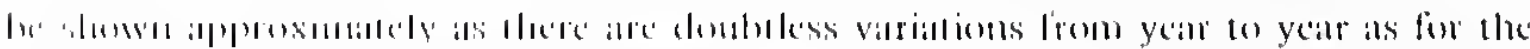

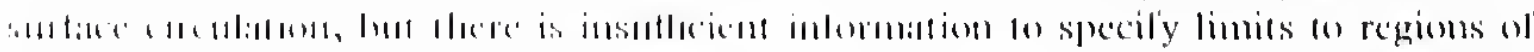

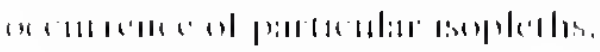

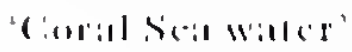

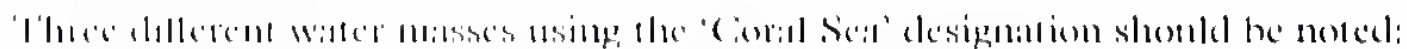

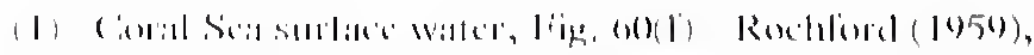

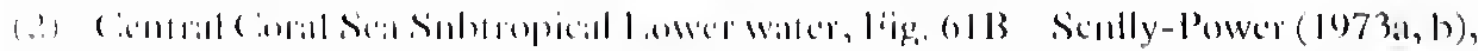

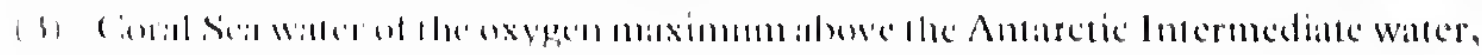

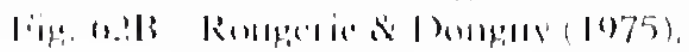

\section{(:IR: $: 11 . \pi 110 \mathrm{~N}$}

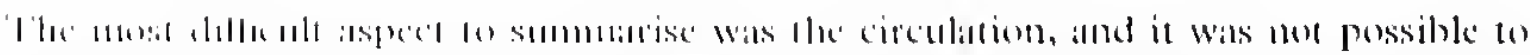

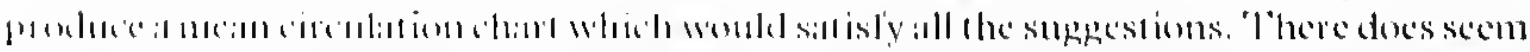

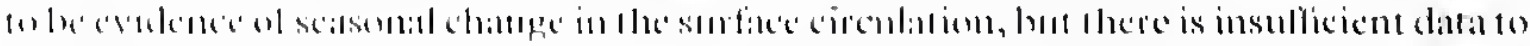

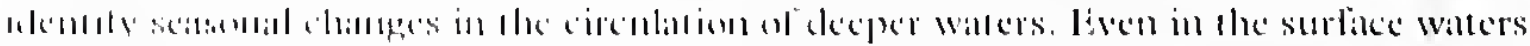

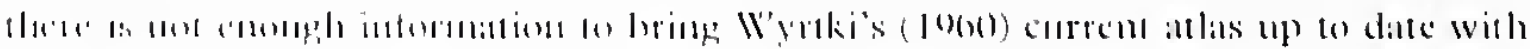

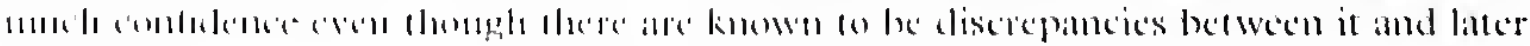
(1:16.1.

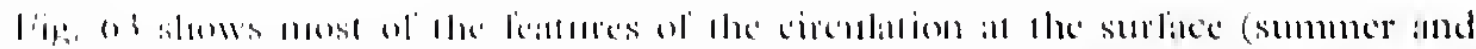

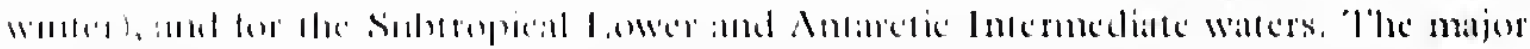

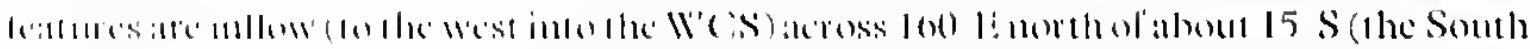

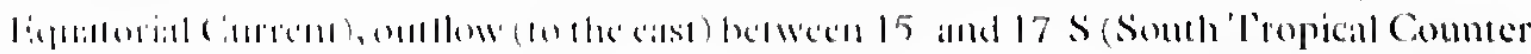

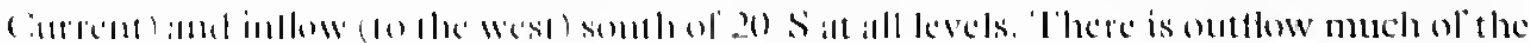

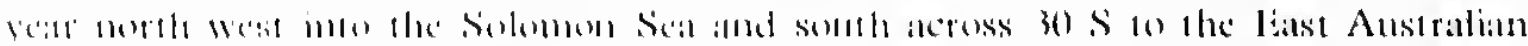

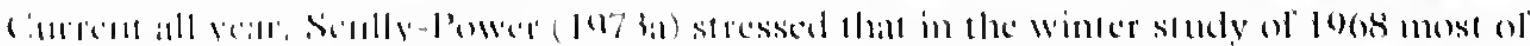

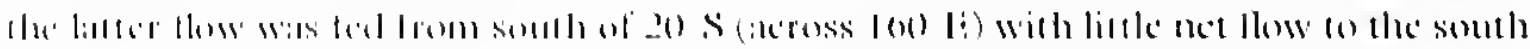

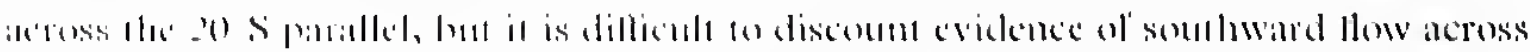

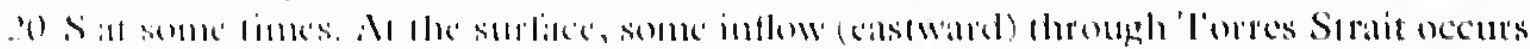

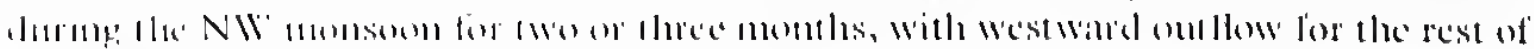

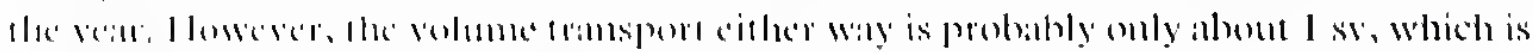

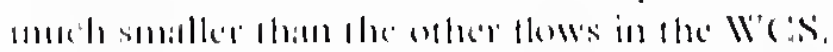

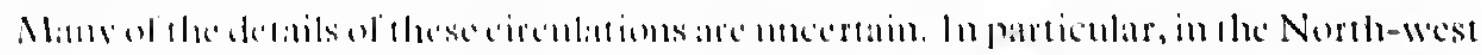

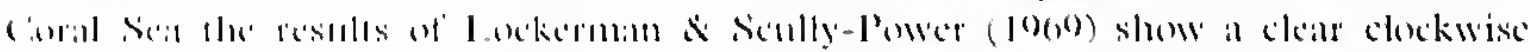

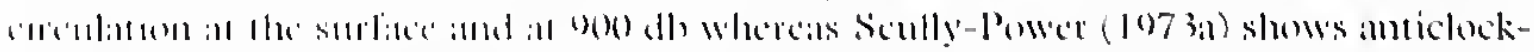

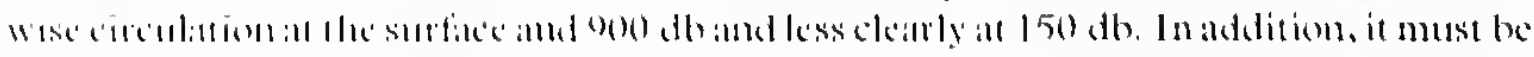

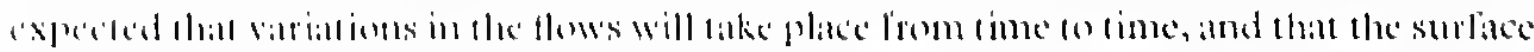

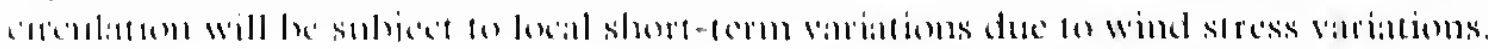

$1 \therefore 1$ 
From the flow budgets calculated by Scully-Power an analysis suggests that the waters of the upper $1000 \mathrm{~m}$ of the Western Coral Sea are replaced in one-half to one year, i.e. the region is well flushed.

Fig. 63 Mean circulations, Western Coral Sea, surface: (A) summer, (B) winter; subsurfiace: (C.) Subtropical Lower water, core depth $50-250 \mathrm{~m}$, layer thickness $200 \mathrm{~m}(>35.5 \quad$ ), (1) ) Antarctic Intermediate water, core depth $650-1150 \mathrm{~m}$, layer thickness $400 \mathrm{~m}(<3.4 .5 \quad$ ). Abhrevian ions lior current names as for Fig. 56.

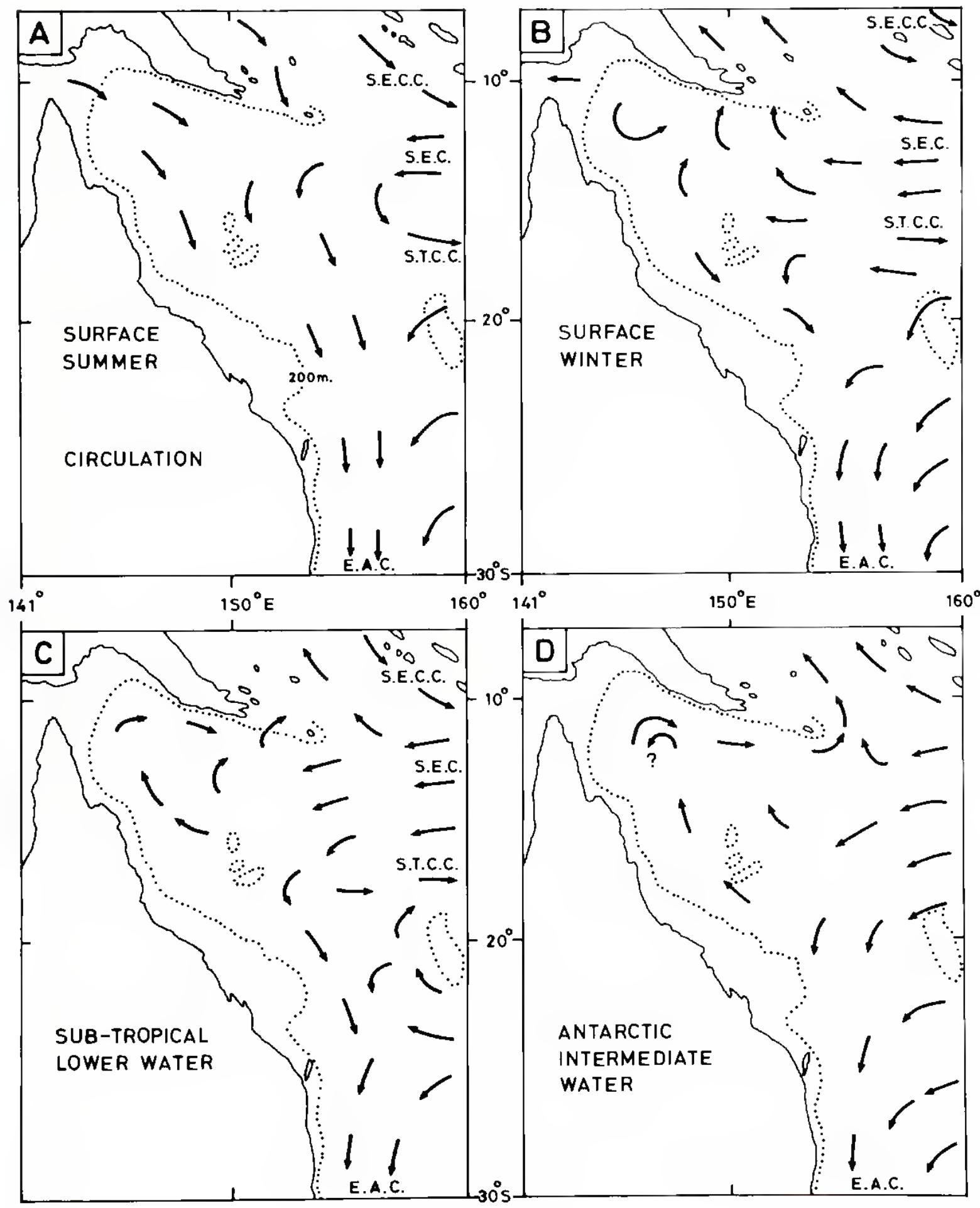




\section{Appendix}

\section{Units, conversion factors and glossary}

1. 1.'llshli:

\begin{tabular}{|c|c|c|c|c|c|}
\hline \multicolumn{2}{|l|}{ I 11:11116:al mile } & & 1111 & 00180 & $1.85 \mathrm{~km}$ \\
\hline \multicolumn{2}{|l|}{ 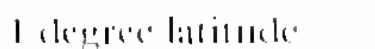 } & \multicolumn{2}{|c|}{59.801111} & & $110.7 \mathrm{~km}$ \\
\hline & & & & & \\
\hline MI l:11ilukk & 10 & 15 & 20 & 25 & $30 \mathrm{~s}$ \\
\hline \multirow[t]{2}{*}{ I lesplomp } & 50 & יו & 57 & 55 & 5211 \\
\hline & 110 & 108 & 105 & 101 & 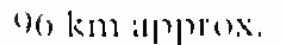 \\
\hline
\end{tabular}

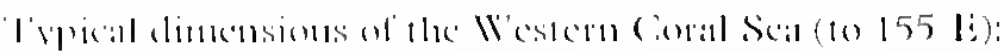

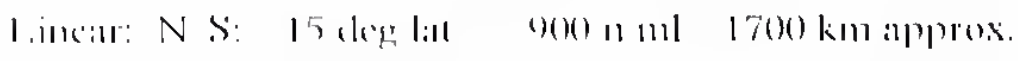

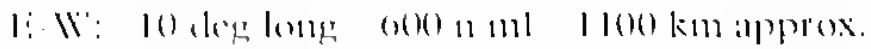

\begin{tabular}{|c|c|c|c|}
\hline \multirow{3}{*}{ Are:a } & Rul :1rc:1 & 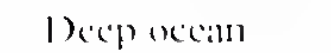 & Totil \\
\hline & $3.3 \times 10^{5} \mathrm{~km}$ & $11.5 \times 10^{4} \mathrm{~km}^{2}$ & $15 \times 10^{5} \mathrm{~km}$ \\
\hline & $3.3 \times 10^{+1} \mathrm{m1}^{\circ}$ & $11.5 \times 10^{11} \mathrm{m1}$ & $15 \times 10^{11} \mathrm{~m}^{2}$ \\
\hline Vollumk & 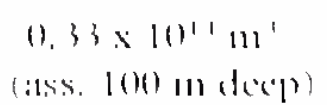 & $\begin{array}{l}11.5 \times 10^{11} \mathrm{~m}^{3} \\
(1010000 \mathrm{~m} \mathrm{depth})\end{array}$ & $12 \times 10^{1+4} \mathrm{~m}^{3}$ \\
\hline
\end{tabular}

2. Sincel:

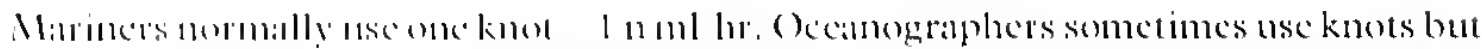
ustlilly use 1 a

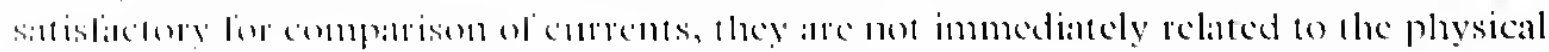

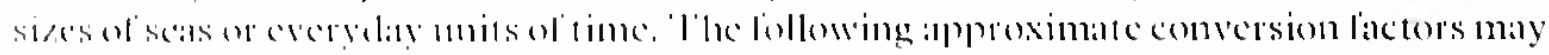

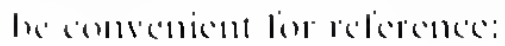

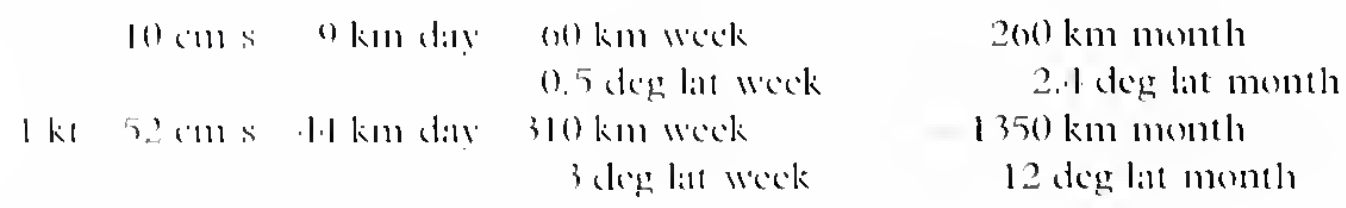

3. Vinume tratsport or How:

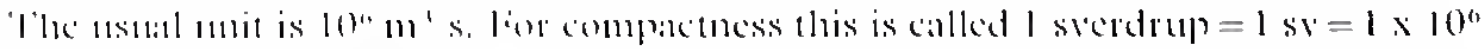
111's. (kof. l'ickind, 1975).

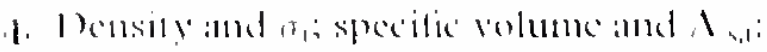

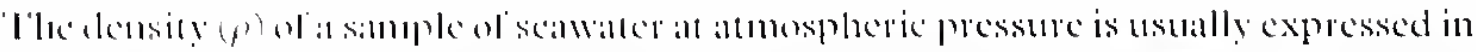

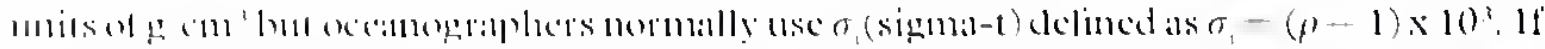

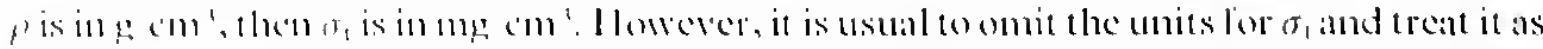
a pure mumber. (Strickly speaking this is correct heciuse operationally the quantity

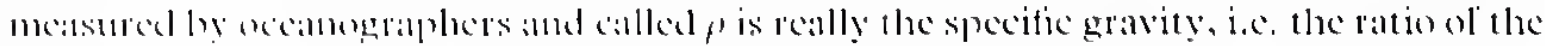

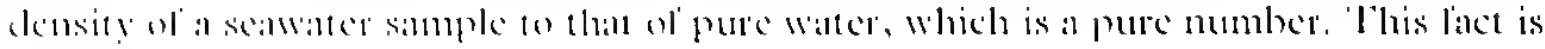
often lingutem.) 
An alternative quantity, specific volume $\%=1 \rho$, is used for dynamic oceanography calculations and related to this is the thermosteric anomaly, $\Lambda_{x, L}$ which is often used in place of $\sigma_{\mathrm{t}}$. The two are directly related as:

\begin{tabular}{|c|c|c|c|c|c|c|}
\hline$\sigma_{\mathrm{t}}=$ & 23 & 24 & 25 & 26 & 27 & 27.2 \\
\hline$\Delta_{\mathrm{s}, \mathrm{t}}=$ & 488 & 392 & 297 & 202 & 107 & 88 \\
\hline
\end{tabular}

Thermosteric anomaly is usually stated with units of centilitres tonne (cl t) although it also is really non-dimensional.

5. Glossary:

Cyclonic

- clockwise (in the southern hemisphere)

Isopleth

Decibar (db) - unit of pressure, I bar $=10 \mathrm{db}=1000 \mathrm{mb}=750 \mathrm{~mm} \mathrm{Hg}$. (In the sea, a pressure of $1 \mathrm{db}$ is close to that exerted by a column of $1 \mathrm{~m}$ of sea water, so that the $100 \mathrm{db}$ level is close to the $100 \mathrm{~m}$ depth etc.)

Dynamic height

- really a unit of work, despite its name. If data from a number of oceanographic stations are available, the dynamic height of a given pressure surface may be plotted on a chart and contoured. Then (if friction is ignored) flow on that surface will be parallel to the contours of dynamic height and, in the southern hemisphere, the direction will be such that the greater dynamic height will be on the left when facing in the direction of flow.

The statement 'dynamic height (or topography) of the $150 \mathrm{db}$ etc. surface relative to $1500 \mathrm{db}$ ' (for example) implies that it is assumed that the water at the $1500 \mathrm{db}$ pressure level is stationary so that the speed may be calculated at the $150 \mathrm{db}$ etc. levels. For more detail, refer to a text on dynamic oceanography, e.g. Sverdrup et al. (1942), Neumann \& Pierson (1966).

Geostrophic flow

- literally 'carth turned'; steady flow compatible with a balance between pressure forces due to the mass distribution and the (virtual) Coriolis force due to the rotation of the earth (and ignoring friction forces).

Mixing triangle method

- See, for example, Rochford (1959, I960a). 


\section{References}

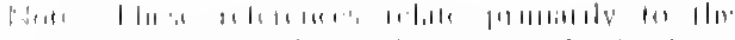
| | |

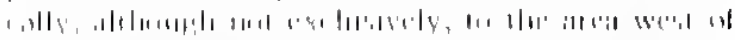

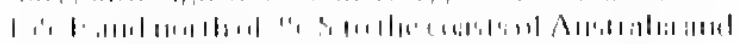

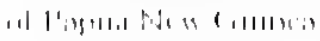

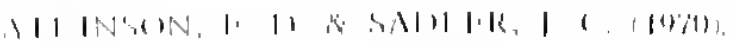

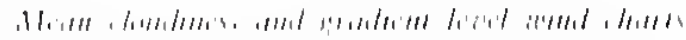

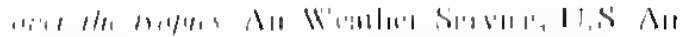

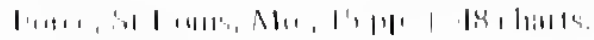

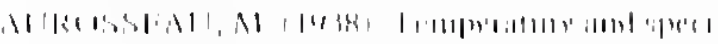

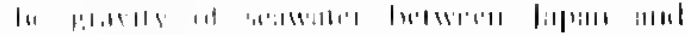

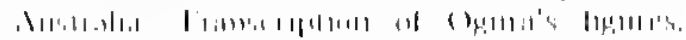

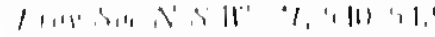

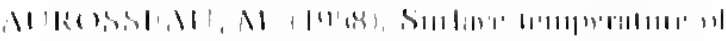

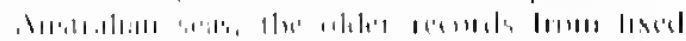

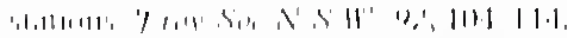

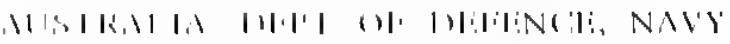

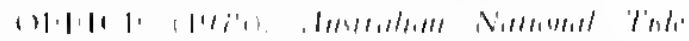

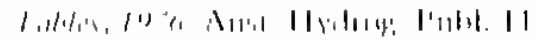

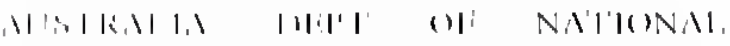

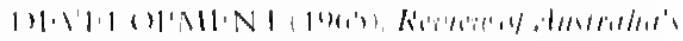

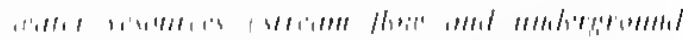
B.

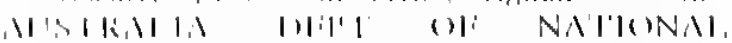

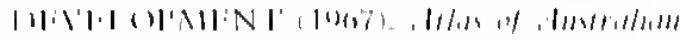

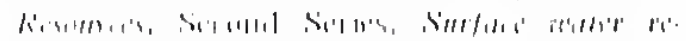

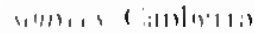

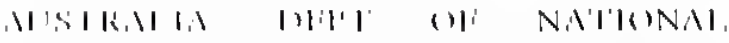
I I. III

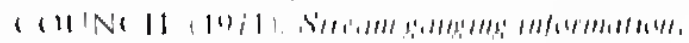

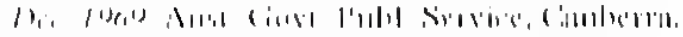

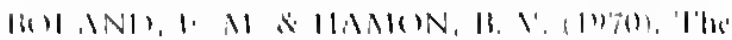

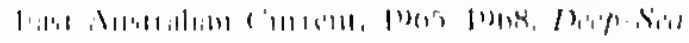
li, 1 , i i itr.

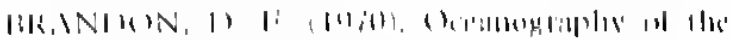

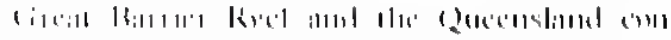

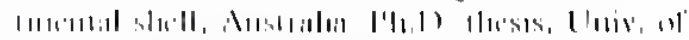

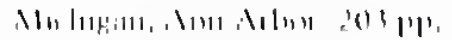

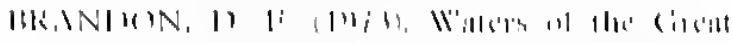

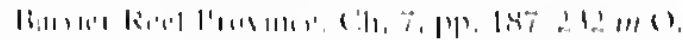

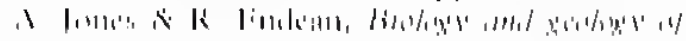

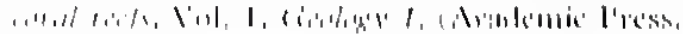
$\mathrm{Ni}$

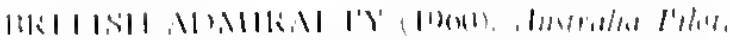

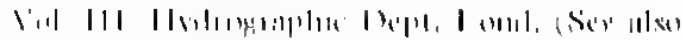

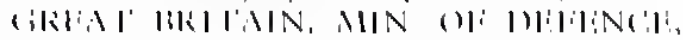
III)

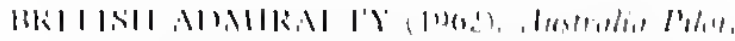

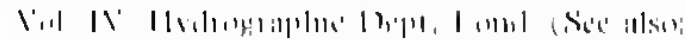

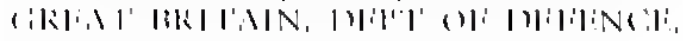

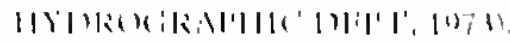

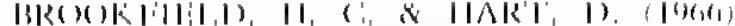

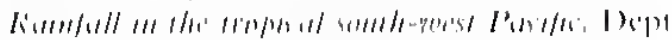

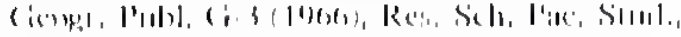

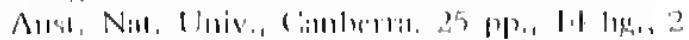
liblis,

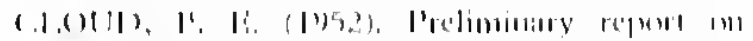

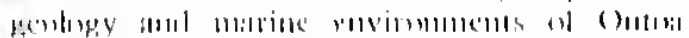

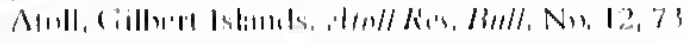
Iי.

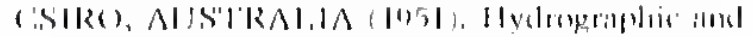

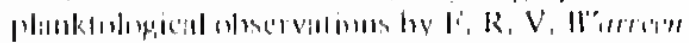

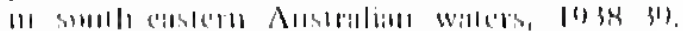

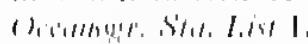

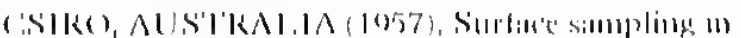

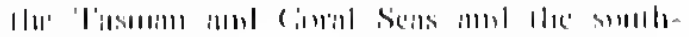
(4) 11.

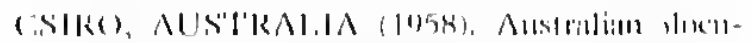

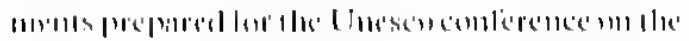

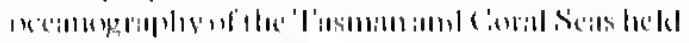

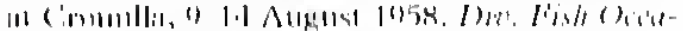
IIn, KI, IK.

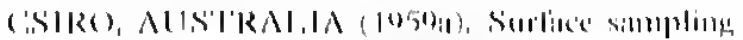

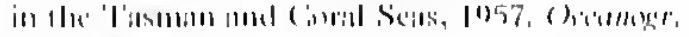
S1, I.M 30.

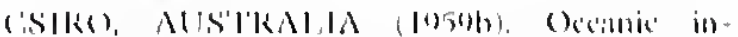

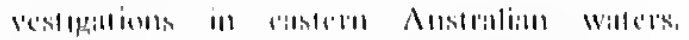

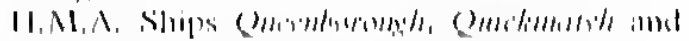

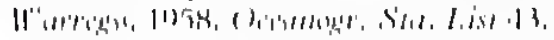

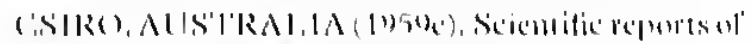

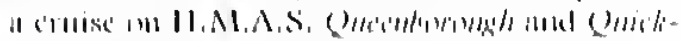

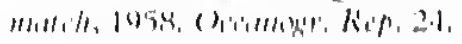

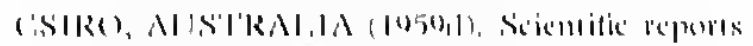

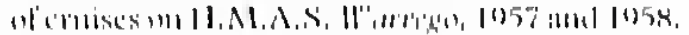

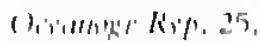

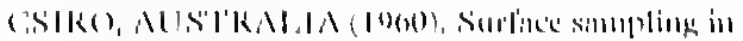
110 (') (1) lil i).

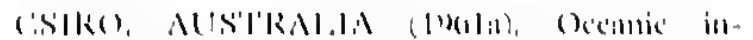

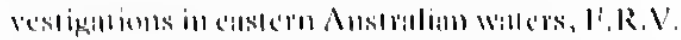

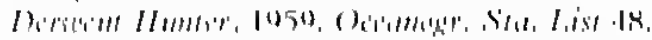

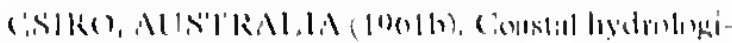

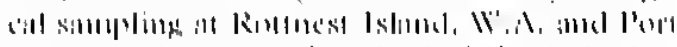

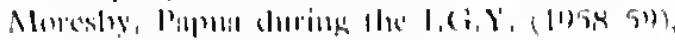

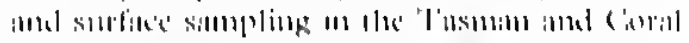

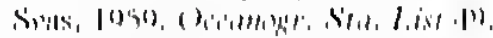

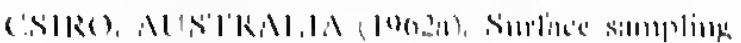

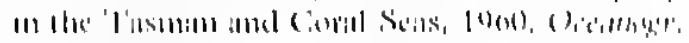
Sifl, IN 5 ( )

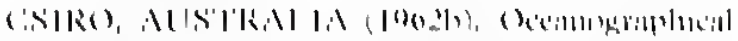

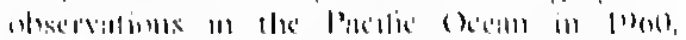

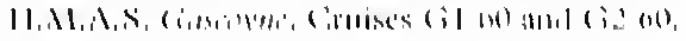

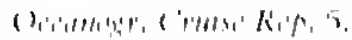




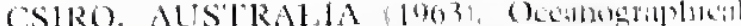

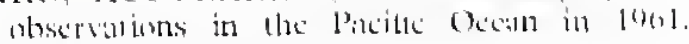

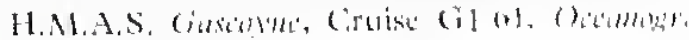
Gimise Rip. \&.

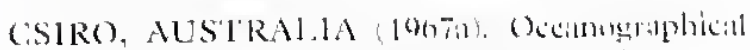

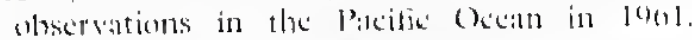

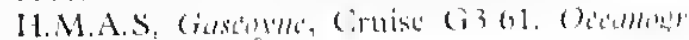
Cimisi Rip. 12.

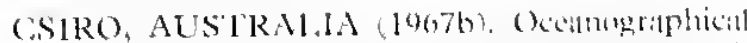
whscrvations in the Pikifie Oedm. H.M.A.S

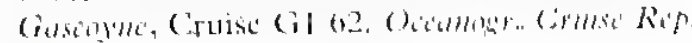
13.

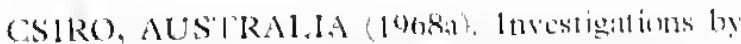

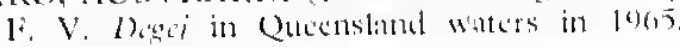

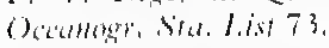

CSIRO, AUSTRAl.1A (19)8b). ()eanngraplucal observations in the lacilic ()ean in 1963.

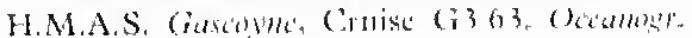
Crmisic Rop. 20.

CSIRO, AUSTRALIA GOORE. Ocianngraphlicill

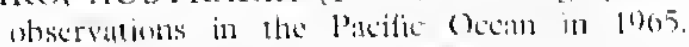

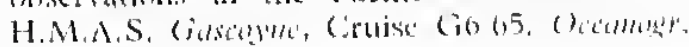
Grmit Rtp. As.

CSIRO, AUSIRALIA (197.1). Monthly ncemongraphic charts, Tasman and Coral Sous from

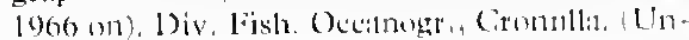
publ.)

1)ONGUY, J. R. \& HENIN, C, 1975:1). Surlike waters in the north af the Corill Sial dast. 7. Mar, finshas. Ras. 26, 2932001.

DONGUY, J. R. \& HININ, (., (1075h) lividene of the South l'ropical counter Courene in the

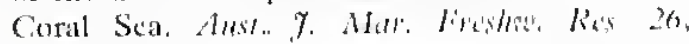
$105-409$.

DONGUY, J. R., HENIN, C. \& ROUGIIRIL, I". (1974a). Surface water in the northern (ivral Sciil. (Abst.) p. 7 in B. R. Stanton (Kd.), P'rke, Rag. Workshop on 'Circulation Sindics in the SumbWest Pacific.' W'allington, 197.4.

DONGUY, J, R., HENIN, C. \& ROUCiliRli, li (1974b). Surface water exchanges between the Coral Sea and the Pacific Ocean. (Abst.) pp. 8,0 in B. R. Stanton (Ed.), Prox. Rece. W"urkslunp on 'Circulation Studies in the South-ll'cst P'acific:. Wellingtun, 1974.

DONGUY, J. R., HENIN, C, ROULILRIL, Ii, \& LE CORVAISIliR, A. (1972a). Surtiace cunditions in the South Tropical P'acific from Australia to Polynestit. p. 71 in R. liritset (Comp.), Occamegraphy of the Simth Pacthic 1972, N.Z. Nat. Comm. for Unesco, Wellingtun, $524 \mathrm{pp}$.

DONGUY, J, R., IIENIN, C., ROUGiliRIli, li,

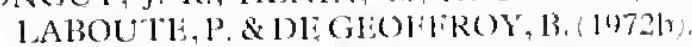
Resultats des observations physica-chimiyate de

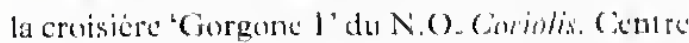
O.R.S.T.O.M. de Noumin, Sir. occianngir. (Unpublished data report.) (U.S.N.O.D.C. 350077).

1)ONGUY, J. R., OUDOT, (. \& ROUCIIR!li, li. (1970). Circulation superficielle «t subsuperficielle en Mer da Cormil a is 170 li. Ciah, O.R.S.T.O.N. S"r. aciunsur. $8,320$.

IEASION, A. K. (1970). The rides "f the cumincm of Australia. Res. pap. 37. Horace Lamb Contre occiangr. Ress, p. 326.

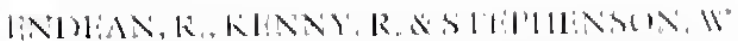

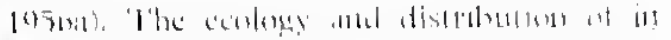

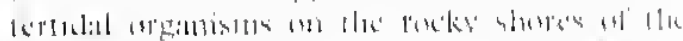

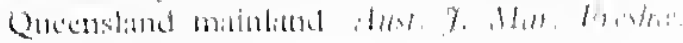
Res.

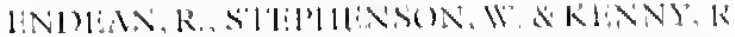

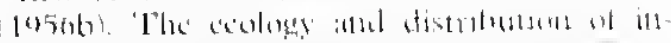

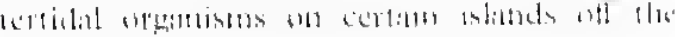

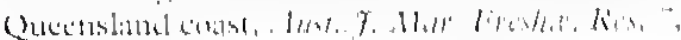
$317 \quad 312$

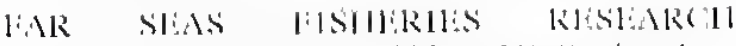

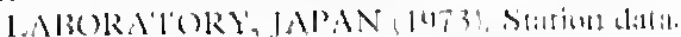

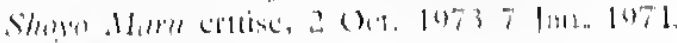
fisti. Agency at laprial.

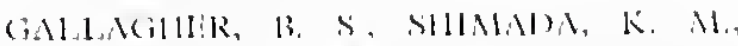

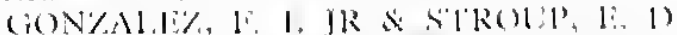
(1971), lides and cotrenes in liatuming stoll

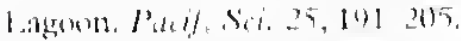

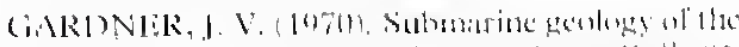

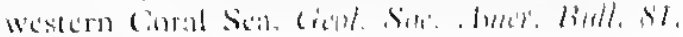
25002201.1

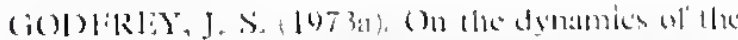

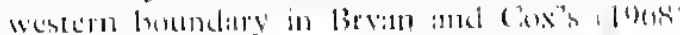

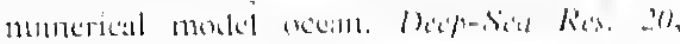
10.131058 .

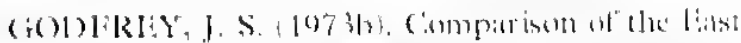
Austrilian? Gutrent with the western bumblary

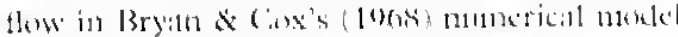

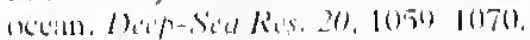

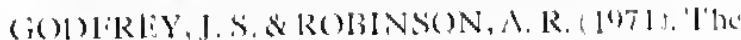

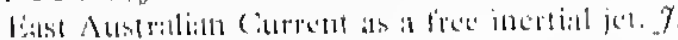
Mell. Res. 2\%, 256280

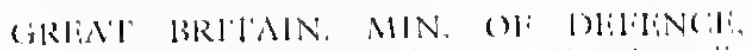

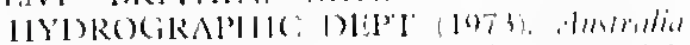

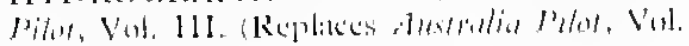
III, 1960) and Vol. IV, I962).

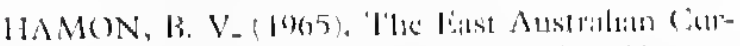

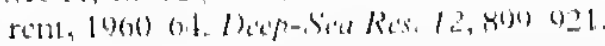

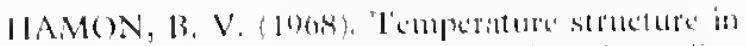

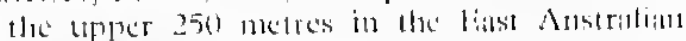

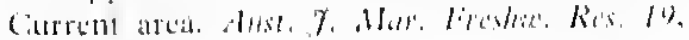
1) 14.

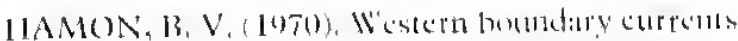

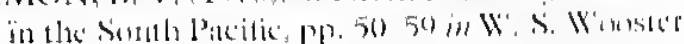

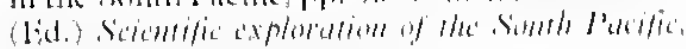

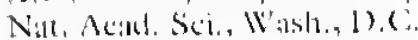

HAMON, 13. V. (1973). "line lias Australiath Cur-

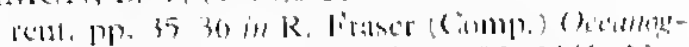
ruphe of the Sirmh Pactic, 1972, N.\%. Nitt. Comm, lint Unescer, W'cllingtom, $52.1 \mathrm{l}$.

II MMON, B. V. (J97f). Recent work in physical

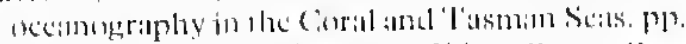

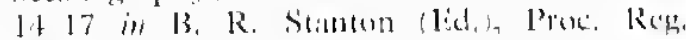
Workshop on 'Circulation studies in the SonthWist l'acitic', W'llingtum, 197.t.

HAMON, B. V. \& (iRILG, M. A. (1972), Meisnscil-

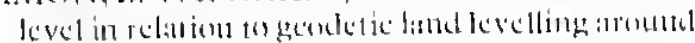
Alstritias. \%.

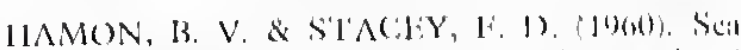

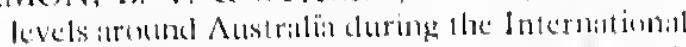

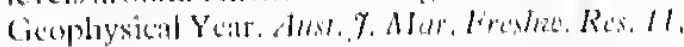
209281.

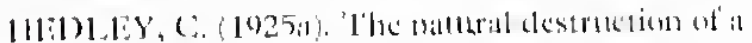

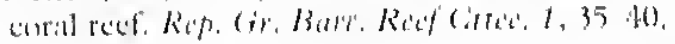




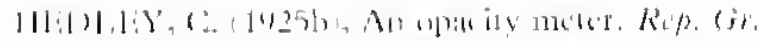

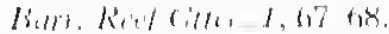

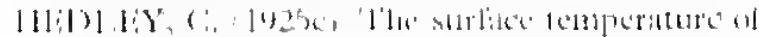

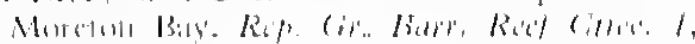
1 (1) 150).

IIJ

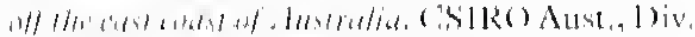

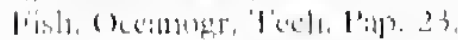

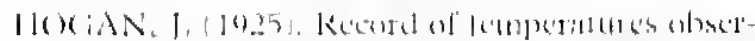

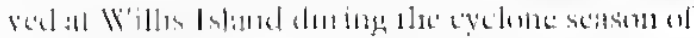

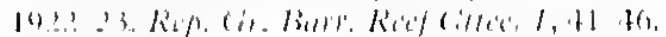

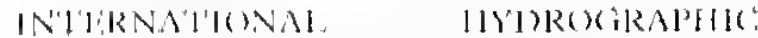

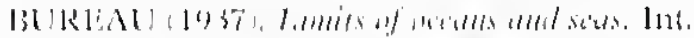

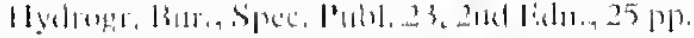

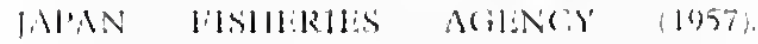

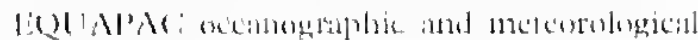

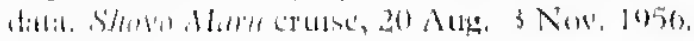

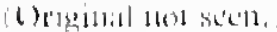

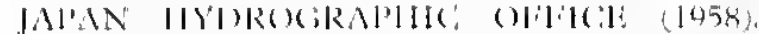

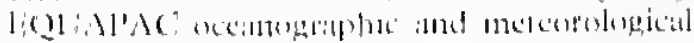

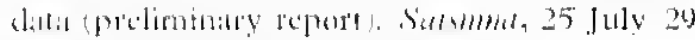

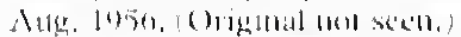

JARRIGIi, li, RAI)K, R, KRAUSil, (i, \&

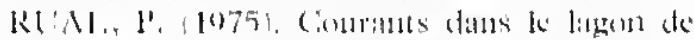

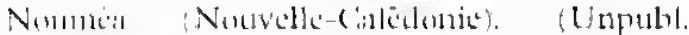

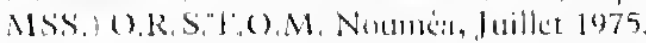

f()INSON, R, li. (1973), Antaretic Intermediate

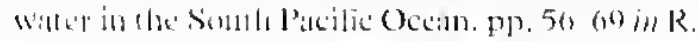

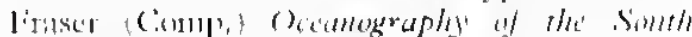
I'arla' 1973. N.\%. Nat Comm. fir Unescos, Nellinglom, 5.2! pp.

KliNNY, R. (197t) Inshore seat surlide sompers-

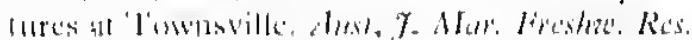
$3,15$.

KII.ONSKY, B, I, \& RAMACIL, ( S. (1975), A

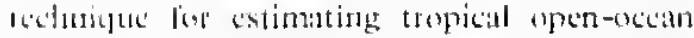

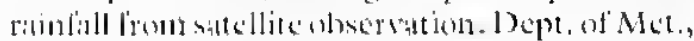
Univ. Ilawati, Contr, 75-1.t (Unjubl. MSS.)

KIM1BAL1,11,11, (1928), Antount of solat ladiation 1hat deathes the surfice of the carth on land and als lle seat, and motloxds by which it is measured.

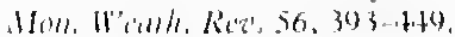

KINSI:Y, 1), IN" \& KINSI:Y, B, L. (1967), 1)iurnal changes in oxyeten coment of the water over the

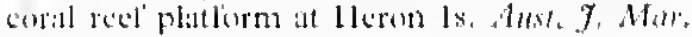
Hrishen. Res. 18, 23-3.t.

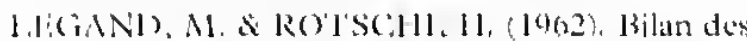
welerelus actanugraplatques liançatses en

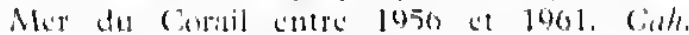

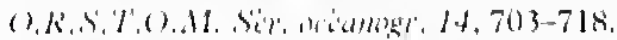

L.OCKI:RMAN, R, C.\& SCULLY.POWFR, P. 1).

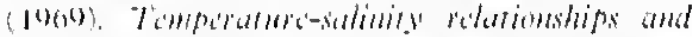

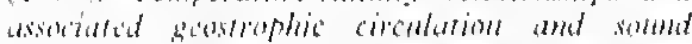

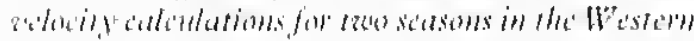
Coral Sin. Roy. Anst. nav. res. lab. l'ceh. Note $10 \mathrm{~s}$.

MAGNII:R, Y, \& I'I'ION, B. (1972), La circulation en Baic d'Ampiasindava (Madagascar) et sos implisanions biochimiques. Ciuh, ().R.S.T, O.M. Si'r. aciumogr. $. X, 75-97$.

MAMMARICKX, J, CHASE, 'l', L', SMITH, S. M. \& 'IAYI.OR, I. 1. (1974). Bathwhetry of the

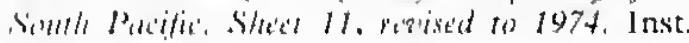
mur. Rescurr, wech, Rep, 44A, Scripps Inst. (xe:mugr., Calif:

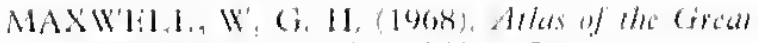
Buritr Roy libavier, N.Y., 258 pl?.

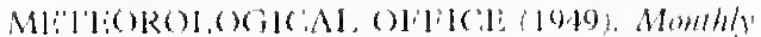

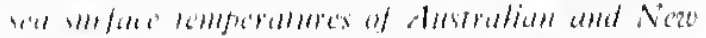

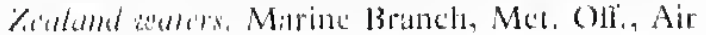
Min, l.onut.

MICIIII, A., COH.IN, C., IMLSROSHIRS, R. \& oubol', (i. 1971: Ohervations sur

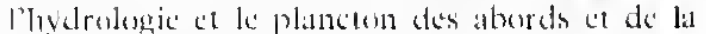

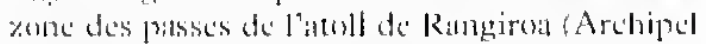

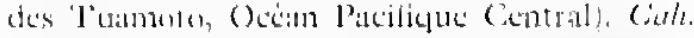
().R.S.\%.().M., S'r octanogr, IX, $375+402$.

MON'l'(iOMliRY, R, B, 1938), Circulition in the upper lityess ol the southern North Atlantic deduced with the usc al isentropic analysis. I'up.

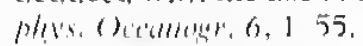

MON'l' ;OMliRY, R, B, la55), Charicteristics (1)

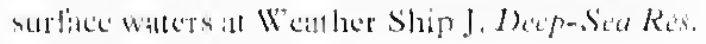
Suppl. 1'ul. 3. 331331.

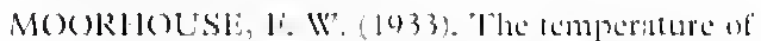
the waters in the andeherage, low lskes. Si. Rep.

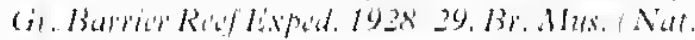
Iliv. 1, $1114,98101$.

NHAl., A. 13. 1975). Some aspects of the south-e:1st rades of the Coral Soa MSS of presentation to loth Amer. Mat. Sirs, l'uch. Cont, (m) llurricanes and 'l'ropical Mecomology, liborida, May, 1975). Res. \& 1)ev. Branch, Bur. uf Mct., Melbourne.

NLUMANN, G. \& PIIRSON, IN, 1, 1906,

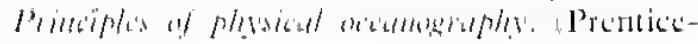
IIIII, N.J.!.

NESWE1.1., 13. S, (1971). The hidrotogical

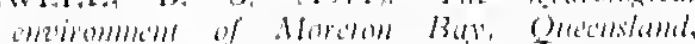
1967 68. CSSIRO Aust. Dix. I'ish, Ocenogr. 'l'ch, Pap, 30 ).

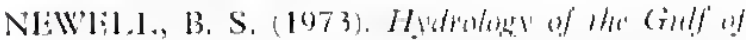
(itrfouraria, 1970 71, CSIRO Aust... Div. lish. Oceinugr. 'Foch. Pap. 35.

ORR, A. P. (1933a). P'hysical and chemical conditions in the sea in the neighbourheod of the Great Barrier Reef. Sit. Rep. Gr.. Barritr Rey lixped. 1928-29. Br. Mus. Nal, Ilist, , II 31 . 3786.

ORR, A, P, (1933b). Variations in some physical and chemical conditions on and near Low lsles Redt. Sci. Repo (ir. Barricr Ricf Lixpal. 1928-29. Br. Mis. Nut. Hist., /1141,87-98.

PICKARL, G, I. (1961). Oceanongraphic features of inlets in the British Columbia mainland coast. F. lish. Res. Bid. Can. 18,907.999.

PICKARD, G. L. (1975), Descriptize' plowicul occanographer, Second Ldn. (1'crgamon, Oxlord.) $21.4 \mathrm{pp}$.

PI'ION, B. \& MAGNIlik, Y. (1971). l.es regimes hydrologiques de la Baic d'Ambaro (nord-ouest de Madagastar). Cah. O.R.S.T.O.AL, Str. oceanogr. IX, 149-166.

RAMAGE, C. S. (1970). Meteorology of the South Pacific tropical and middle latitudes, pp. 10-29 in W. S. Wooster (Ed.) Scicntific exploration of the South Pacific. Nat. Acad. Sci, Wash., D,C.

RHII), J. L. (1961). On the geostrophic flow at the surface of the Pacific Ocean with respect to the 1000 decibar surface. Tellus 13, 489-502. 


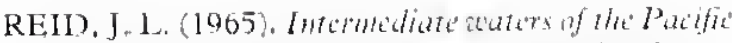
Ocean. Johns Hopk. oceanogr. Stuk. No. 2, $85 \mathrm{pp}$.

ROCHFORD, D. J. (1957), The identitication and nomenclature of the surlice water masses in the "Tasman Sca (datis to the end of 1954 Alust. F. Mur. Freshas. Res. 8, 369-113.

ROCHFORD, D. J.(1958a). 'Total phosphorus as a means of identifying cast Australian water masses. Deep-Sea Res. 5.89-110.

ROCHFORD, D.J.(1958b). The Masmal cirthlation of the strface evater masses of the Tasmant ant Coral Seas. CSIRO Aust, Div. Fish. Oelaningr. Rep. 16.

ROCHFORD, D. J. (1959), The primary atomal waler masses of the Tasman and foral bias CSIRO Aust., Div. Fish. Oesmongr. 'lech. 1'ap. 7.

ROCHIORD, D. J. (1960a). The intermediate depth waters of the lasmin and Coral Seas. I. The $27.20 \sigma_{\mathrm{r}}$ surtace, dust. . Nar. Froshes, Res. II, $127-\mathrm{I} 47$.

ROCHFORD, D. J. (1960t). The intermediate depth waters of the Tasman and Coral Scas. II The $20.80 \sigma_{1}$ surface. Anst. F. Mat. Freshe. Res $11,148-165$.

ROCHFORD, D. J. (1960c). Some aspects of the deep circulation of the Tasman and Coral Seas. Alst. F. Mar. Frewh. Res. 11,166-181.

ROCHFORD, D. J. (1962). 'The intermediate depth waters of the Tasman and Coral Seas. III. Succession of water types cast of Port Hacking in 1957-59. Alust. F. Har. Frekw. Res, 13, 61-88.

ROCHFORD, D. J. (1966). Some hydrolengical features of the castern Arafura Sea and the Gulf of Carpentaria in August 1964. All:3. F. Mat. Fireshe. Res. 17, 31-60.

ROCHFORD, 1), J, $1968 \mathrm{a}$, The continuity of water masses along the western boundary of the Tasman and Coral Seas. Aust. 7. Mar. Fitehes. Res. 19, 77-90.

ROCHFORD, D. J. (1968b). Origin and circulation of water types on the 26,00 sigma-t surface of the southwest Pacific. Anst. F. Mar. Freshat. Res. 19 , $107-127$.

ROCHFORD, D. J. (1969). Origin and circulation of water types on the 25.00 sigma-1 surface of the southwest Pacific. Awt. F. Afar. Freshat. Rox. 20, $105-114$.

ROCHFORD, D. J. (1973), Patterns of change in surface salinity and temperature of the Tasman and Coral Scas, 1966-71, pp. 105-112 in R Fraser (Comp.) Occanography of the Sumh Pacific 1972, N.Z. Nat, Comm. fur Unesco, Wellington, $524 \mathrm{pp}$.

ROCHFORD, D. J. (1974), Some preliminary results of the Tasman and Coral Seas ships of opportunity sampling program of the CSIRO Division of Fisheries and Occanography, $\mathrm{pr}$. 12-13 in B. R. Stanton (1d.) Proc. Rug. Wurkshop on "Circulation studics in the South-W"est Pacific'. Wellington, 1974.

ROTSCHI, H. (1958a). Orsom 111. Rapport technique de la croisiere $56-5$. Occanographic physique, O.R.S.T.O.M., l.l.O. Rapp. Sii. 5.

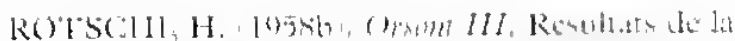

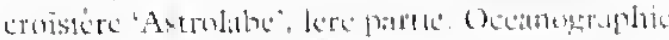
physigue ().R.S.l'().M.. I.l.(), Rurp sir.h.

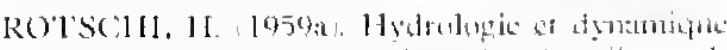

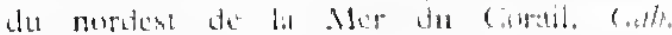

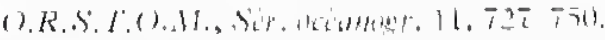

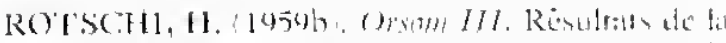

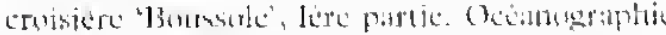

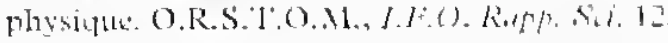

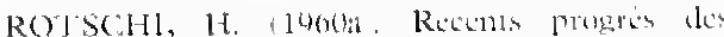

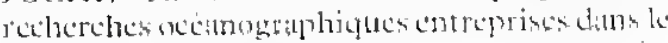

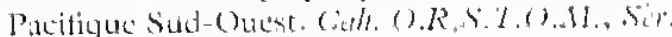
wiullug. . $811,219267$.

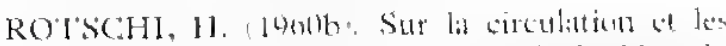

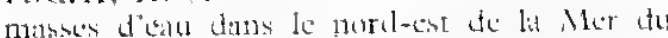

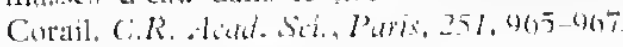

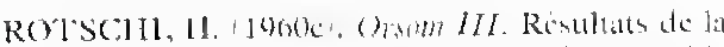

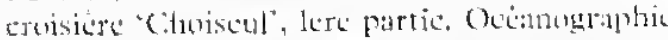

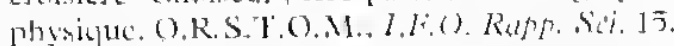

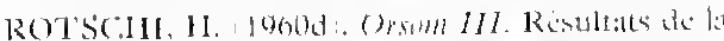

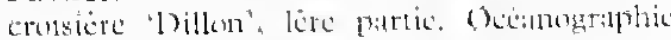

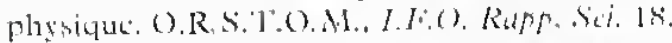

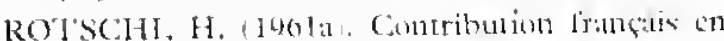
1900 a la connatssane de la Mer du Gratil Occanographic physigute. ("uh. ().R.S.T.()..K. Sir, octumgr. X111 +3-1-455.

ROTSCH1, H. 1961b: Risultals des obscronions

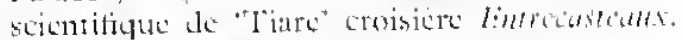
O.R.S.T.O.A., l.l.(). Rapp . ici. 21.

ROCSCHI, H. (19610), (2),om///. Restlats de lit

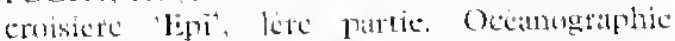
physique. O.R.S.T.O.M. I.I. O. Raph. Sit.22.

ROTSC:H1, H. 196ld). Intluence de la divergence des sillomon sur la repartition de cerfaines proprietes des caux. (i.R. Acud. fici., Pemis. 25, $2559-2561$.

ROl'SCH1, H. (1962:1). Sur la disergence des

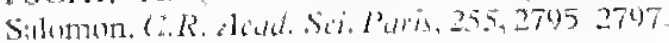

ROISCHI, H, 1902b). Oxyghe, phesphilte be gat carbonique tolal en Mer du contail. Decp-bia Res, $8,181185$.

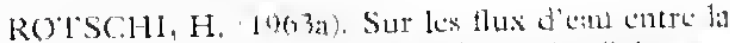
Nouvellu-Calcdonie et l'archipel des Salonum. C.R. Acud. Sit. Puris, 256, 2609-2012.

ROTSCHI, H. \& LLMASSON, 1, (1967), Oceanugraphy of the Coral and Titsman Scats. Anm. Rä. Otianugr. mat. Biol. 3. 19-97.

ROUGI:RIE, I: \& 1)ONGUY, J. R. 1475 La mer du Cortil en rigime dalize de sud-cot, coull. O.R.S.T.(O.M. Sir. octumer. XII1, th 67.

ROYAL AUSIRAI.1AN AIR FORC:E (19.22). Wrather on the Alsirulia stutime, locat information. P'ubl. 252, Vu1. 11, Melbultat.

ROYAL NITHERIAANAS METHORO-

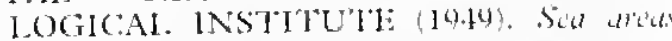

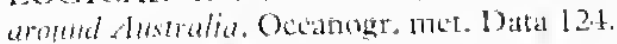

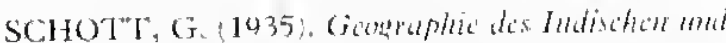
Stillu ()akans, (C. Bussen. Hamburg.

SCLLIY-POWER, P. 1). (1969a). Ocedengruphit

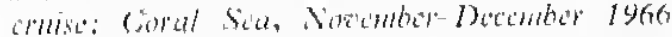
Ruy. Aust nave res. Iab. Tich Memo. 1.4 69.

SCULLY-POWER, P. D). (1969b). Occammeraplic cruise: Coral Sara, Aprit-May 1967. Roy. Aust. nav. res. Lab. "Tech. Memu. 1569. 


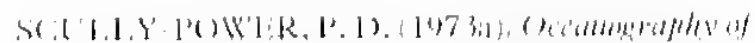

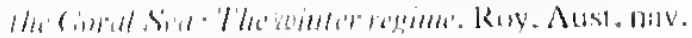

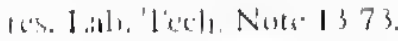

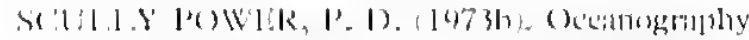

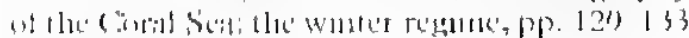

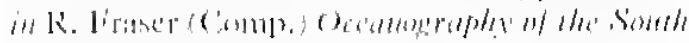

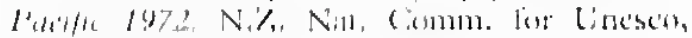

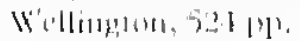

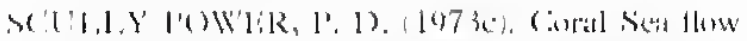

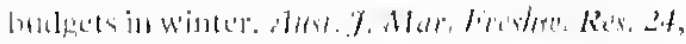
3) 315 ,

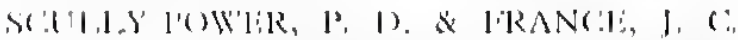

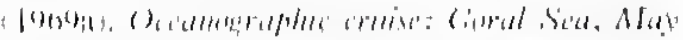

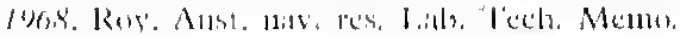
(lixl. $2(n)$.

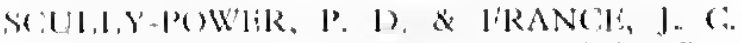

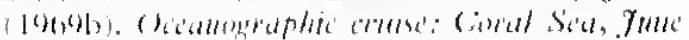

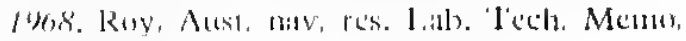
(lixe) 3, (6) .

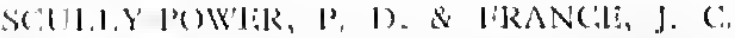

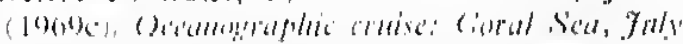

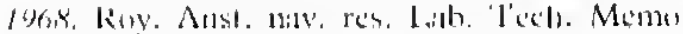
(lixi.) 160 (i)

S"1AN'(O), B R, 1975). Hiblinglaphy of the

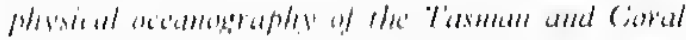

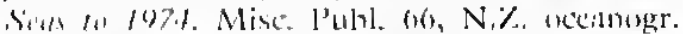

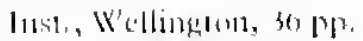

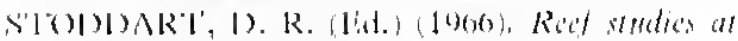

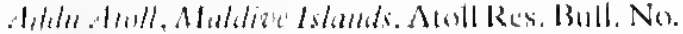
$116,122 \mathrm{P}^{3}$.

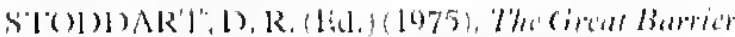

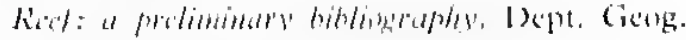

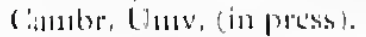

SVIRI)RUI", II, JUIINSON, M, W, \&

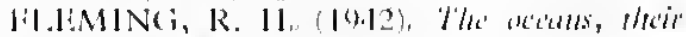

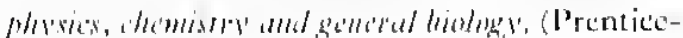

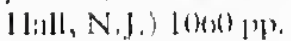

'I'NKAIIASIII, 'I', (1059). Hydrograplacal re-

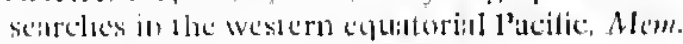
lik. Hish. Kuglshima, 7, 141147.

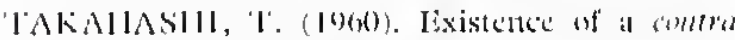
salem vorlecil motion in the Coral Scis, Rec.

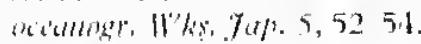

I'AY'I, OR, R. (. . 1973). An atlas of l'acilic islinds latulall. 1lawiri losi. (icoplays, 111G-73-9, (unpulpl, MSSis.

'lRAN'l'liR, 1). J. (1058). Reproduction in Auslabian puist oysters (Lamellibranchia). Ams. Z. Nor, lines. Kis, 9, 509574.

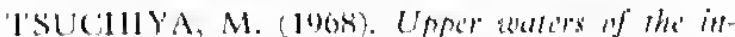

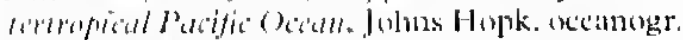
siud. No, 1, 50 pp.

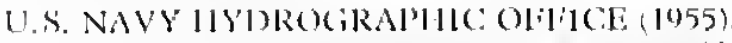

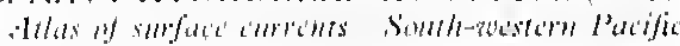
()'all, 11,(), 1'ub), 506, II'ish. 1).C. (reprinted 1)(is),

13.S. NAVAI, OCI:ANOCIRAPHIC: OHF1CE (1955). Allas al Lilat (iharts, somb Pacific and ladiun (l'tuls. U.S.N.(), (), Publ, 107, Wish., 1). $(i$.

U.S.S.R. (1650), Morstivi IIlas, I, Navigatiamm-

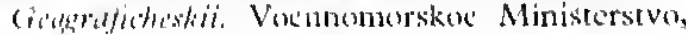
bisticets.
VAUX, 1). (1970). Sirfince temperatule and salinity fill Australian walers, 1961 65. CSIRO Aust., l)iv, lisin. Oceanogr. Allas No, 1.

V(IN ARX, W. S. (1948). '1'he circulation systems of Bikini and Rongclap Tagoons. Trams. Amer, ktolshys, Un, 29,861-870).

W1:1313, 1). J, (1973a). 'lidal resonance in the Coral Sici. Nature $243,511$.

WIII313, 1). J. (1973b), On the age of the semi-diurnal Iidc. I)ci-Sea Res. 20, 847-852.

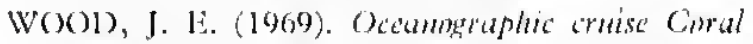
Sea, Arajura Sia and Gava Trench, Aprit-Mav, 1969, Roy, Aust, nav, res, Lab. Tech. Memo. (lixt.) 12 (6).

WOO1), J, E. (1971a), Oceangraphic survey: Coral Sua, April-Muy 1970. Roy, Aust, nav. ies. I ab. 'l'cils. Mermo, 21/71.

W() ()1), J, li, (1971b), Oceanographic survey; Coral Sea, August-September 1970. Roy. Aust, nav, res. Lab. 'lech. Memo, 22/71.

WOODHLAD, P. M. J. (1968). Sea surface drift between central Queensland and New /caland. Aust.7. Sici. 31, 195-196.

WOOLHEAI), P. M. J. (1970), Sea-surface circulation in the southern region of the Great Barricr Rect, Spring 1966. Aust.F. Mur. Freshow. Rcr. 21, 89) 102 .

WUS'1, G, (1935), Dic stralasphäre, Wiss, Ergebn. disch. atlant. Hixped. Metcor., Bd. 6, 1 Tiel, 2 Listi, $288 \mathrm{pP}$.

WW YR']K1, R, (1960). Sirface circulatian in the Carul and Iasman Sas. CS1RO Aust. Div. lish. Occanongr. 'l"ech. Pap, 8.

WYRTK1, K. (1901a). The flow of water into the decp sea basins of the western South Pacific Ocean. Aus\%, J. Mar, Jiresho. Res. 12, 1-16.

WYR'IKI, K, (196lb), Physical oceanography of somth-cast Asian waters, Scientific results of marinc investigations of the south China Sca and the Gulf of Thailand 1959-61. NAGA Rcp. 2 (Univ, Calif, Burkıluy) 195 pp.

WYRTK1, K, (1962a). 'The subsurface water masses in the western South Pacific Ocean. Aust. F. Mar, Lirsha'. Res. 13, 18-47.

WYR'TK1, K. (1962b). Gcopotential topographies and associated circulation in the western South Pacific Occan, Aast, F, Mar. Freshow. Res, 13, $80-105$,

IVYR'l'K1, K. (1962c). The oxygen minima in relation to occan circulation. Deep-Sea Res, 9, 11-23.

WYRTKl, K. (1967), Circulation and water masses in the castern equatorial Pacific Ocean. Int. $\%$. Octanol, limmol, 1, 117-147.

WYRTK1, K. (197.7), The dynamic topography of the Pacific Ocwan and its fluctuations. Hawaii Inst, Geophys. H1G-74-5 (unpubl. MSS).

WYR'Kl, K, \& MEYERS, G, (1975). The trade wind ficld over the Pacific Occan, Part 1. The mein fisld and the mean annual variation. Hawaii Inst. Geophys. HIG-75-1, (unpubl. MSS). 
Some sources of aerial photographs of the Great Barrier Reef region (Dr J. Veron, personal communication):

1. Central Mapping Authority, Brisbane \& Sydncy

2. Commonwealth Department of Services \& Property, Brisbane

3. Commonwealth Acrial Photography, Division of National Mapping, Department of National Resources, Canberra

4. RAAF Base, Laverton, Victoria 




